The Collections, Museums and Gardens of Göttingen University

This work is licensed under the Creative Commons License 4.0 "BY-NC-ND" 


\section{Words of Welcome}

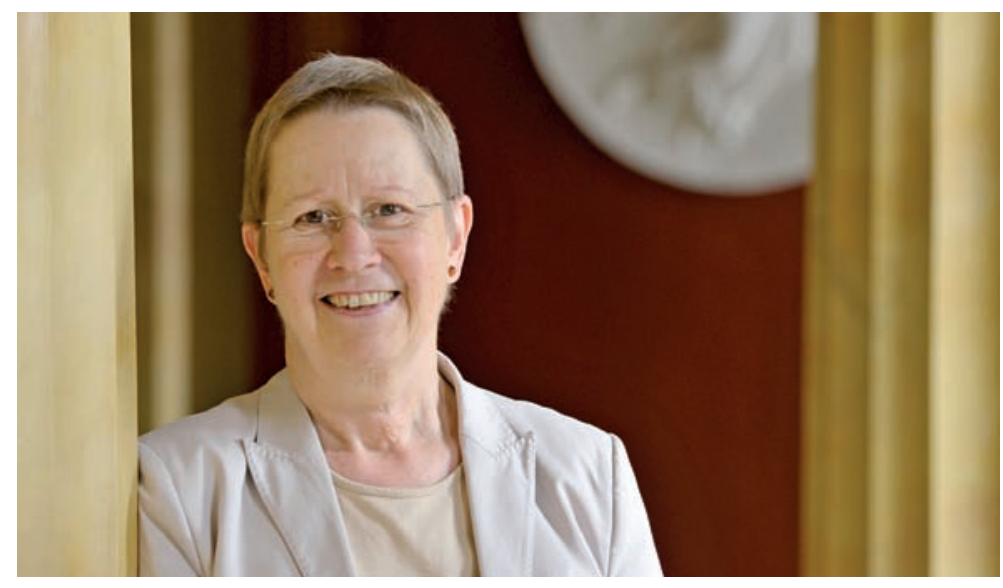

Dear readers and prospective guests,

This book comes to you as an invitation to get to know the Collections, Museums and Gardens of Göttingen University. For more than 275 years, researchers, students and friends of our university have been collecting fossils, instruments, plants, manuscripts and a great deal more. Collections were created that offer astonishing insights into the world of science and scholarship. On the basis of these objects, we can learn how knowledge was generated and communicated, and how the collections - many of which are of unique quality - have developed. The objects continue to play an important role in research and teaching. Modern investigative methods and interdisciplinary approaches are yielding quite unexpected results.

Not all the university's treasures are on view to the public. This book offers, for the first time, a comprehensive overview of its collections. Above all, I would like to thank the curators who not only maintain and preserve our collections but are also setting new accents in Göttingen. The team at the Centre for Collection Development is supporting them in the process. I wish them all great success in their valuable endeavours.

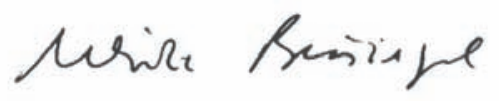

Prof. Dr. Ulrike Beisiegel

President of Göttingen University 

THE COLLECTIONS, MUSEUMS AND GARDENS OF GÖTTINGEN UNIVERSITY 


\section{Contents}

- Centre for Collection Development 6

\section{Of representations and relics - Cultural Studies}

A 01 Collection of Paintings 8

$\begin{array}{ll}\text { Collection of Prints and Drawings } & 10\end{array}$

$\begin{array}{ll}\text { Collection of Sculptures } & 12\end{array}$

$\begin{array}{ll}\text { A } 02 \text { Cast Collection of Antique Sculptures } & 14\end{array}$

$\begin{array}{ll}\text { Antiquities Collection } & 16\end{array}$

Wallmoden Sculpture Collection $\quad 18$

Numismatic Collection 20

A 03 Teaching Collection for Pre- and Protohistory 22

A 04 Apparatus Diplomaticus 24

A 05 Ethnographic Collection 26

$\begin{array}{ll}\text { Asia } & 28\end{array}$

Oceania (South Seas) 30

$\begin{array}{ll}\text { America } & 32\end{array}$

Africa 34

A 06 Collection of Musical Instruments 36

A 07 Collection of Historical Books for Children and Young Adults 38

A 08 The Heinz Kirchhoff Collection - Symbols of Femininity 40

\section{Of body and mind - Medicine}

B 09 Collection on the History of Obstetrics 42

B 10 Collection of Medical Moulages 44

B 11 Legal Medicine Collection 46

B 12 Human Embryology Documentation Collection 48 (Blechschmidt Collection)

B 13 Blumenbach Collection of Skulls 50

From algae to zinc - Natural Sciences and Mathematics

C 14 The Old Botanic Garden: Plant Diversity from Throughout the World 52 The Historical Fern House and Fern Collection 54 
C 14 Special Collection of Bromeliads 56

C 15 Herbarium of Göttingen University 58

$\begin{array}{ll}\text { Pharmacognostic Collection } & 60\end{array}$

$\begin{array}{ll}\text { C } 16 \text { Culture Collection of Algae } & 62\end{array}$

C 17 Palaeobotanical Collection 64

C 18 Museum of Zoology 66

$\begin{array}{ll}\text { Bird Collection } & 68\end{array}$

$\begin{array}{ll}\text { C } 19 \text { Anthropological Collection } & 70\end{array}$

C 20 Forest Zoology and Wildlife Biology Collections 72

$\begin{array}{ll}\text { C } 17 \text { Palaeozoological Collections } & 74\end{array}$

$\begin{array}{ll}\text { Geological Collections } & 76\end{array}$

C 21 Forest Botanical Garden and Phytogeographical Arboretum 78

C 17 Geopark 80

C 22 The Experimental Botanic Garden 82

C 17 Amber Collections 84

Geological Collection of the Adolfinum Bückeberg 86

$\begin{array}{lr}\text { Mineralogical Collections } & 88\end{array}$

Collection of Precious Stones 90

Collection of Meteorites $\quad 92$

Historical Geosciences $\quad 94$

C 23 Göttingen Museum of Chemistry 96

C 24 Collection of Historic Physical Apparatus 98

'Physicalisches Cabinet'

C 25 Collection of Historical Instruments at the Institute of Geophysics 102

C 26 Collection of Historical Items at the Institute of Astrophysics 104

C 27 Collection of Mathematical Models and Instruments 106

$\begin{array}{ll}\text { C } 28 \text { Computing Museum of the GWDG } & 108\end{array}$

\section{Of manuscripts, monographs, maps}

D 29 Collections of Göttingen State and University Library 110

Map Collection 112

$\begin{array}{ll}\text { Scholarly and Literary Papers } & 114\end{array}$

Collection of 18th Century German Printed Books 116

$\begin{array}{ll}\text { Asch Collection } & 118\end{array}$

$\begin{array}{ll}\text { D } 30 \text { Göttingen University Archives } & 120\end{array}$ 
Georg Christoph Lichtenberg's Göttinger Taschen Calender (Göttingen Pocket Calendar) for 1779 informs its readers: "Göttingen is the first university in Germany, perhaps in Europe, to have been furnished with a genuinely academic museum". Serving both research and teaching purposes, the Royal Academic Museum referred to here was not only frequented by members of the university, but also attracted the interested and the curious from Göttingen and, indeed, from throughout the world.

Many of the holdings present at that time have remained in our university's collections to this day. However, since the closure of the Royal Academic Museum in the mid-19th century, these and countless other items have been visible - if at all - only to a very limited extent. All but forgotten, they were stored out of view, their existence often scarcely known even within the faculties and institutes with which they were associated. But in the framework of the so-called Sunday Walks, since 2006 the public has been able to visit five collections: the Ethnographic Collection, the Art Collection, the Cast Collection, and the Museums of Geoscience and Zoology. All the others remained largely concealed from public view.

This situation has now changed in a very positive way. Since 2013, the Collection of Musical Instruments has also formed part of the Sunday Walks agenda. Further collections present selected objects in exhibition areas accessible to the public. In the exhibition 'Dinge des Wissens' held on the occasion of the university's 275-year anniversary (summer 2012), items and treasures from all the university's collections were on display over a period of four months. At a new museum now in planning, the Göttingen University will be inviting the interested public to take a look 'behind the scenes'. This museum will at the same time create a space for crossdisciplinary exchange among students and academics. The institution will take up its activities where the 18th century Royal Academic Museum left off.

We are delighted to be able to present to you in this small volume - before the new museum opens - insights into the many richly diverse collections, museums and gardens of Göttingen University. 


\section{Introduction}

The University of Göttingen possesses within its research and teaching collections, exhibitions and diverse range of gardens, unique museum holdings in an exceptionally wide range of knowledge domains.

Among these are many objects and convolutes of outstanding significance worldwide. These notable holdings have always played an important role in student life and the academic work pursued at Göttingen University, as well as in university members' training and research activities.

The beginnings of the collections date back to a time well before the founding of the university itself in 1737. Initially existing in isolation as the Naturalien Cammer (Cabinet of Natural Curiosities), botanical collection, numismatic collection or model collection, in 1773 several of them were brought together in terms of space and content as the Königliches Academisches Museum (Royal Academic Museum) and extended considerably. Some of the collections continued to exist into the early 20th century as the Naturhistorisches Museum (Natural History Museum), but ultimately, in the late 1920s and early '30s at the latest, they were transferred to separate institutes and have since been maintained separately.

Many of the collections play an important role in the university's research and teaching, as for a large number of subject areas material objects are indispensable for didactical, investigative and learning processes. The relevance of other collections, however, lies above all in their contribution to the history of science and knowledge, vividly bringing to life and illustrating archive and book holdings also held by the university.

This rich heritage gives the University of Göttingen special opportunities, but it also brings obligations. The collections and gardens should be accessible for use in the research context, preserved for future generations, and also remain available for university teaching. This necessarily involves the responsible supervision and care of holdings by curators or, in the case of smaller collections, by members of the university taking on responsibility for them in a part-time capacity.

In presenting this Collections Guide, the University of Göttingen would like to inform its staff, students and the general public from near and far about its rich and diverse museums holdings from the areas of art, cultural history, archaeology, ethnography and ethnology, cultural anthropology, medicine, the natural sciences and mathematics, and warmly invites guests to visit them. 


\section{Centre for Collection Development}

Auditorium • Weender Landstraße 2 • 37073 Göttingen • www.uni-goettingen.de/collection-development

The Centre for Collection Development: pivotal point of the university's work on objects; photograph: Stefanie Rüther
Established: 2013

\section{Contact:}

Dr. Marie Luisa Allemeyer Director, Centre for Collection Development Tel.: +49551 39-20739 kustodie@uni-goettingen.de
30 collections, 30 curators, several million objects with infinite potential for research - and also, since summer 2013, a Centre for Collection Development.

This new central institution of Göttingen University has the task of enhancing the use of the academic collections in research and teaching and presenting the university to the public. It also supports the university's collections so that their potential in these areas can be exploited to the full.

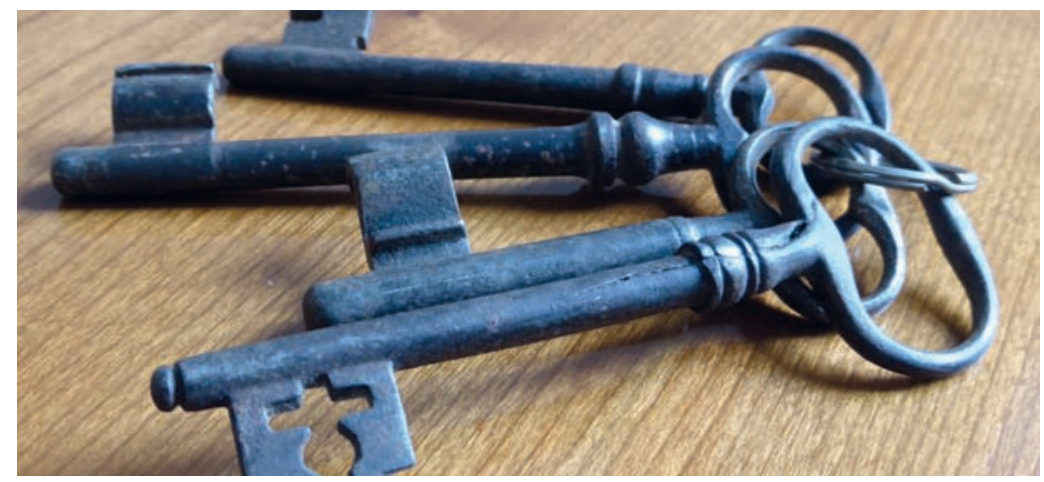

The institution carries out activities lying within the three domains of 'Collection Management', 'Research on the Development of Knowledge' and 'Communication of Science and Scholarship', interconnecting them in programmatic manner.

The task with highest priority in the area of collection management is to ensure that the objects in each collection will be safeguarded and preserved, and loss or damage prevented. It is likewise essential that the collections are documented and recorded digitally, thereby improving their usability, regardless of subject area and user location. A significant step in this process is to develop tailored database structures that contain and enable retrieval of the relevant information for answering current and future research questions. The individual databases will be interlinked via a Göttingen portal, enabling searches to be carried out across the entire spectrum of collections.

A further role of the Centre for Collection Development lies in advancing research into the research process itself. In close collaboration with the newly established Professorship in the Cultures and Materiality of Knowledge, the Centre for Collection Development will thus support the setting up of the doctoral programme 'Material Cultures of Knowledge' and coordinate the close linkage between the academic teaching in this domain and the collections. The Centre for Collection Development also 


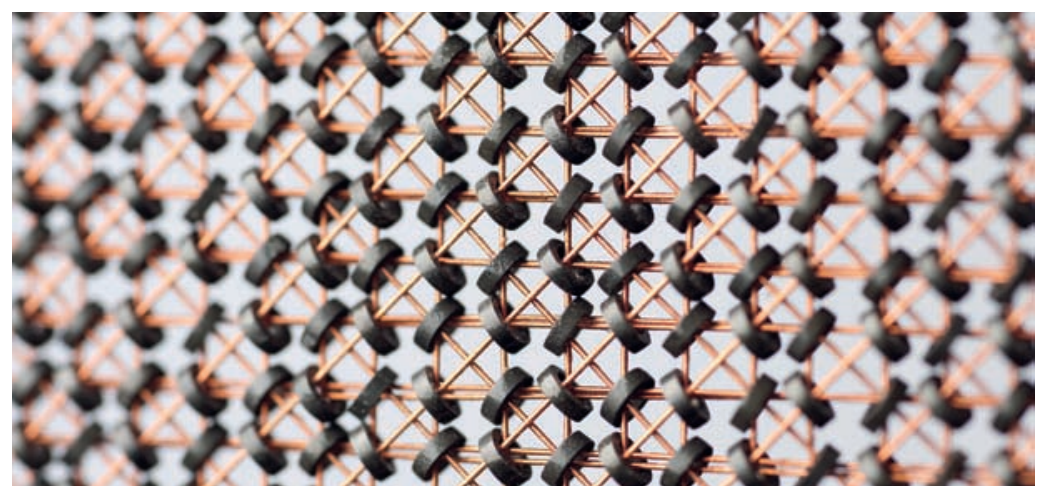

fosters networks among Göttingen researchers working on knowledge production and those active in this field elsewhere.

The third task of the Centre for Collection Development is the communication of science and scholarship, with a view to raising the visibility of what is going on behind the walls of the university. This task is closely connected with the planned new museum, for which the Centre for Collection Development provides the institutional framework. Visitors will be able to learn more about how knowledge is generated and what impact it has on society in an exhibition presented in a dynamic process of change over time. There is no institution better placed than the university itself to open up public perception of the dramatically swift developments taking place in science and scholarship. And to this end, there could scarcely be material better suited to illustrating these developments than the very objects with, on, and through which scientific discoveries were made and knowledge generated - at this university in particular, where the advancement of research has always been closely linked with the object.

By establishing the Centre for Collection Development, the university is manifesting its intention to preserve for the long term its academic collections, museums and gardens and expand their accessibility, in order to tap for posterity their potential for use in research, teaching and the communication of science and scholarship.

Marie Luisa Allemeyer

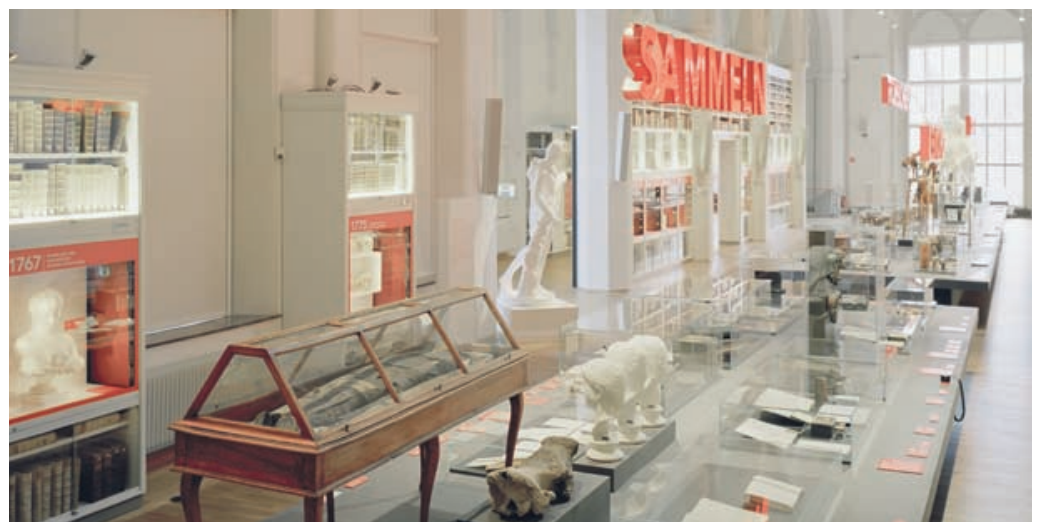

Part of computing device Computing Museum of the GWDG; photograph: Stephan Eckardt
View of the exhibition Dinge des Wissens; photograph: Brigida González 


\section{Collection of Paintings}

Art Collection of Göttingen University • Gallery of Paintings and Sculptures in the Altes Auditorium

Weender Landstraße 2 • 37073 Göttingen • www.uni-goettingen.de/art-collection

Francesco Botticini (1446-1497), Mary and St. John Praying to the Child, second half of the 15th century, $89.5 \times 60.5 \mathrm{~cm}$, wood, came into the possession of the university in 1882; photograph: Katharina Anna Haase

View into the Gallery of Paintings; photograph: Frank Stefan Kimmel

Established: 1796

Number of items: c. 300

Public exhibition: yes

Admission: $€ 3$, red. $€ 1.50$

Open: Sun. 10:00 - 16:00

Tours: First Sunday of every month at 11:30 presenting the 'artwork of the month', or by appointment

\section{Contact:}

Dr. Anne-Katrin Sors

Tel.: +49 551 39-5093, -5092, -5098 kunsts@gwdg.de
Göttingen University's Collection of Paintings dates back to the year 1795: in his last will, Johann Wilhelm Zschorn (1714-1795), Higher Appeal Court Secretary in Celle, bequeathed the university more than 270 paintings, which were transported to Göttingen in 1796 on three horse-drawn carriages. A condition of the legacy was that the works must be carefully preserved, publicly exhibited and put to use in support of academic education - although at that time, Art History had not

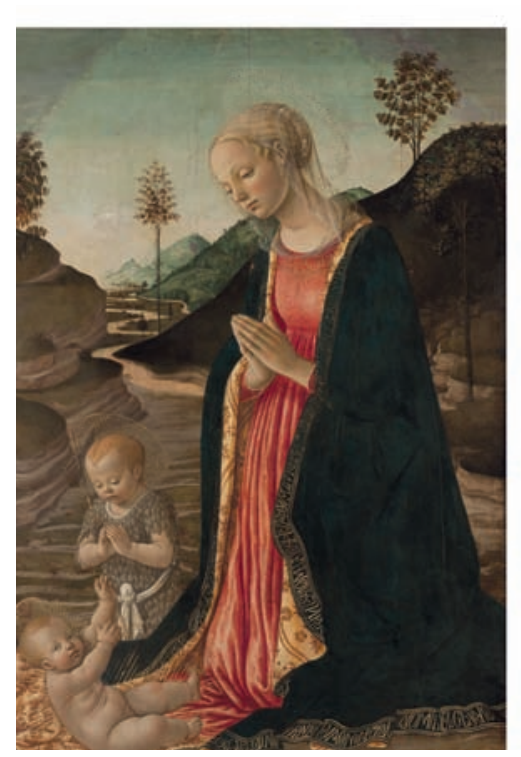
yet come into existence as an academic subject. The collection of artworks was intended "for the development of taste, accustoming the eye and the senses to that which is good and beautiful (...) Our age demands besides bread-and-butter degree studies also some culture" (Göttingische Anzeigen, 1796).

As early as 1805, Johann Dominik Fiorillo (1748-1821), the collection's first curator, published a printed catalogue, but it was not until 1926 that the collection was first documented for academic purposes by Wolfgang Stechow

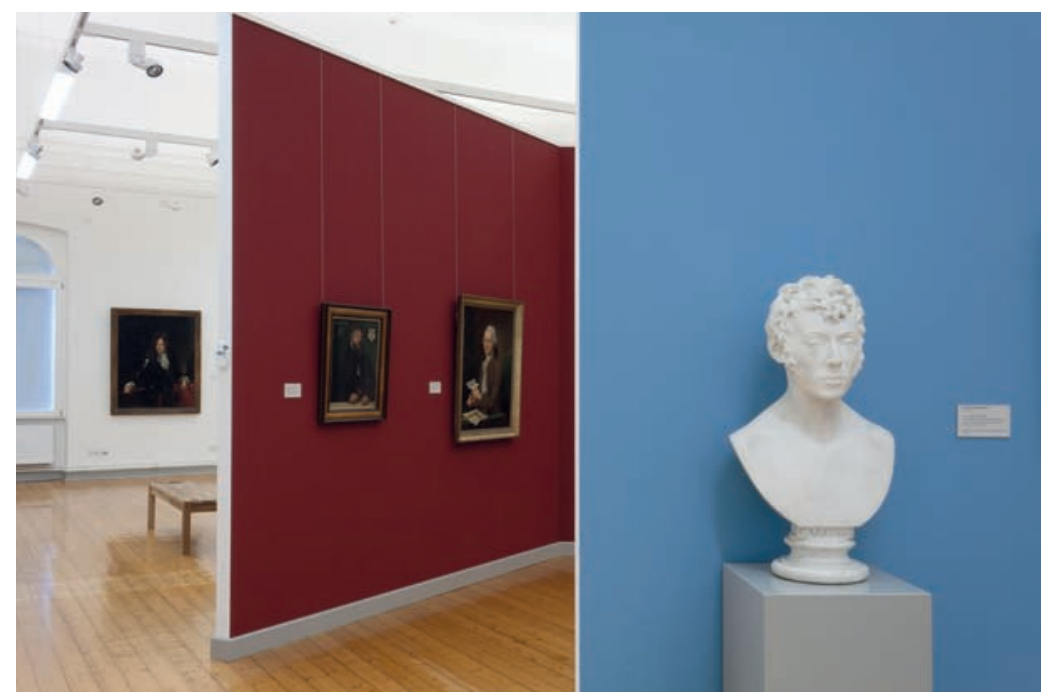




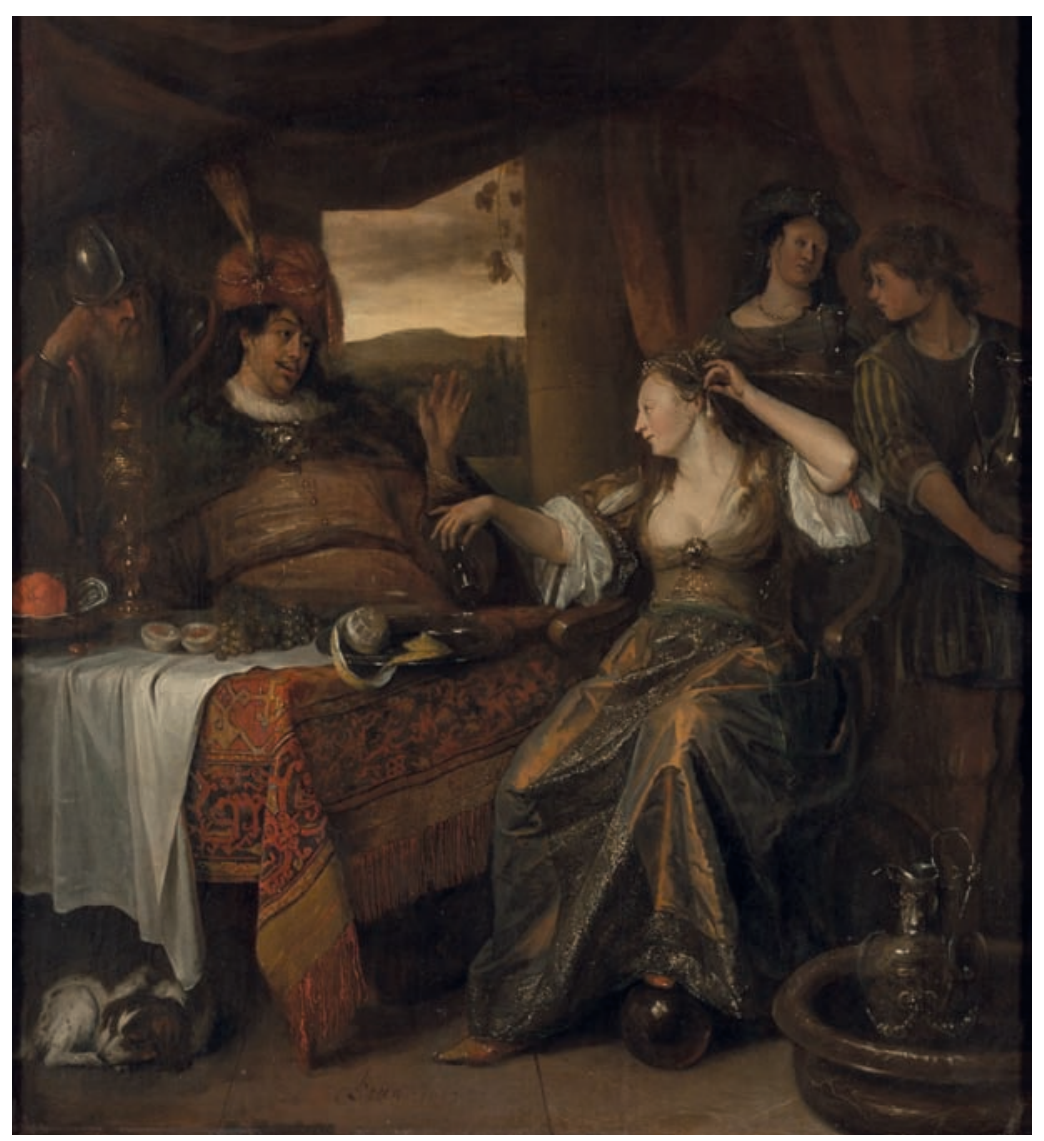

Jan Steen (1626-1679), The Banquet of Antonius and Cleopatra, $1667,67.9 \times 56 \mathrm{~cm}$, wood and canvas, bequest of Johann Wilhelm Zschorn, 1796; photograph: Katharina Anna Haase

(1896-1974). Donations by Professors Julius Baum (1882), Karl Ewald Hasse (1902) and Wilhelm Dilthey (1907) enlarged the collection considerably, particularly in the area of Italian painting.

The Collection of Paintings is rich in works by masters such as Lippo Vanni (c. 1315-after 1375), Francesco Botticini (c. 1446-1497), David Teniers the Elder (1582-1649), Jan Steen (c. 1626-1679), Jan van Goyen (1596-1656), Jan Victors (1619-1679), Salomon van Ruysdael (1602-1670), and Joos de Momper (1564-1635). But Göttingen University also possesses modern period works, among them paintings by Paula Modersohn-Becker (1876-1907) and Max Pechstein (1881-1955). After several changes of location - from the apartment that housed the first curator, via the Royal Academic Museum, to the Accouchierhaus, and then to Theaterplatz - in 1987 the Collection of Paintings was eventually accommodated in the Altes Auditorium. Following a major refurbishment, it has been on view, also to the public, in modernised exhibition rooms since 2011. 


\section{Collection of Prints and Drawings}

Art Collection of Göttingen University • Prints and Drawings Collection

Nikolausberger Weg $15 \bullet 37073$ Göttingen • www.uni-goettingen.de/art-collection

Pablo Picasso (1881-1973), Female Torso (Torse de Femme), 1953, 834 x $473 \mathrm{~mm}$, paper, aquatint, donated 1954; photographs: Katharina Anna Haase

Hans Süss von Kulmbach (c. 1480-1522), Portrait of a Boy (Bildnis eines Jünglings), c. 1511, $233 \times 173 \mathrm{~mm}$, paper, chalk, ink, watercolour, opaque white
As early as 1736, Johann Friedrich Armand von Uffenbach (1687-1769), a wealthy patrician from Frankfurt, had already bequeathed a large part of his art collection to Göttingen University, which was officially founded the following year. His bequests included 10,000 prints as well as 1,000 drawings. In 1770, shortly after Uffenbach's death, the collection arrived at Göttingen, where it now forms the backbone of the Prints and Drawings Collection as well as the historic, quantitative and qualitative heart of the Art Collection. Through various acquisitions and bequests the collection has grown to its present size of around 15,000 prints and 2,500 drawings. Especially notable among the benefactors is Wolfgang Stechow (1896-1974), an associate professor of Art History, who, despite having been forced to emigrate to the USA in 1936 due to his Jewish heritage, showed remarkable generosity and left his entire collection to Göttingen University.

Uffenbach himself drew up an inventory of the prints that he donated to the collection; then, around 1800, Johann Dominik Fiorillo (1748-1821) compiled both an inventory of drawings and one of prints. Notable pieces in the collection include works by Sandro Botticelli (1445-1510), Hans Holbein the Elder (1465-1524), Hans Burgkmair (1473-1531), Rosso Fiorentino (1494 - 1540), Hans von Aachen (1552 - 1615), Frans Francken II (1581 - 1642) and Gerrit van Honthorst (1592-1656). The collection also contains many items from the 19th and 20th centuries, including works

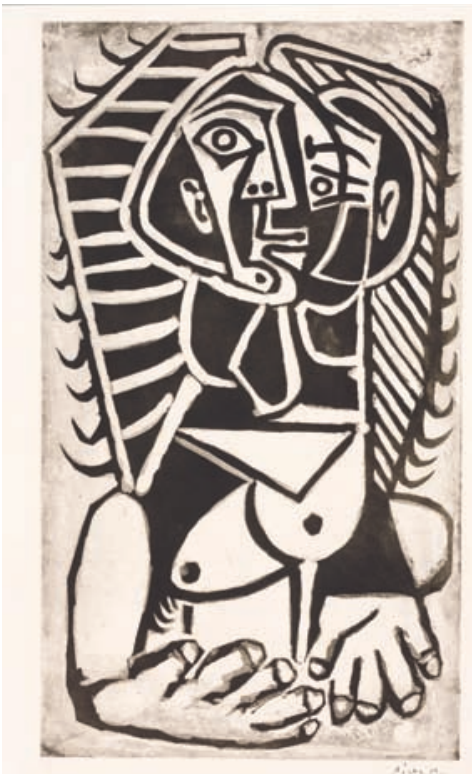

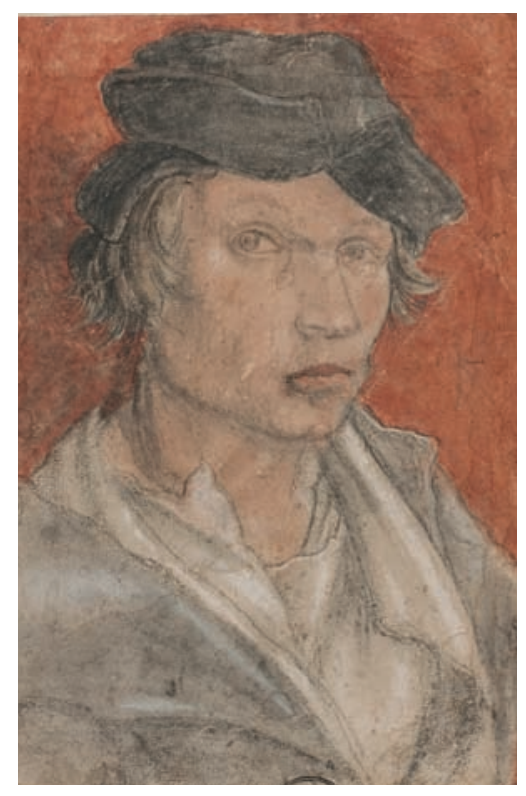

Established: 1736

Number of items: c. 17,500

Public exhibition: no

Open: by appointment

Tours: First Sunday of every month at 11:30 presenting the 'artwork of the month', or by appointment

\section{Contact:}

Dr. Anne-Katrin Sors

Tel.: +49 551 39-5093, -5092, -5098 kunsts@gwdg.de 


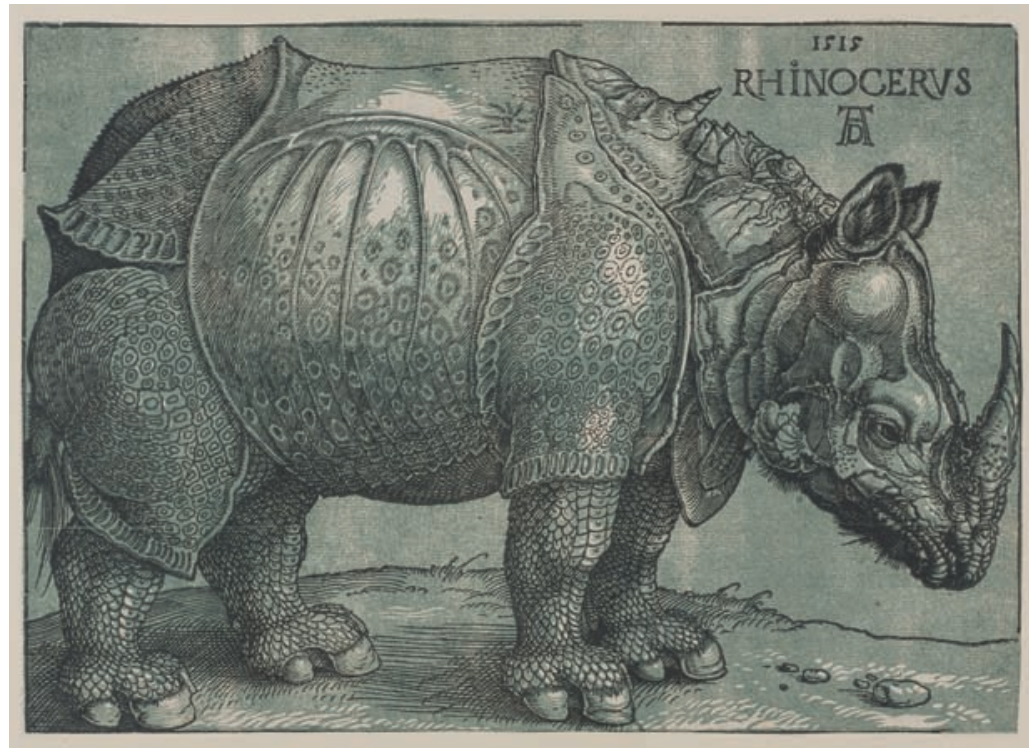

by Wilhelm Schadow (1788-1862), Andreas Achenbach (1815-1910), Eduard Bendemann (1811-1889), Erich Heckel (1883-1970), Emil Nolde (1867-1956) and Franz Marc (1880-1916), among others. The print holdings at Göttingen are of particular significance for academic teaching and research in art history due to the large quantity of prints by Albrecht Dürer (1471-1528) and his contemporaries. Among the holdings are an astonishing number of prints by Rembrandt and even one of his original printing plates is extant. The collection also contains a representative cross-section of prints by Dutch artists across various styles and important works by significant pre-modern and modern artists, such as Piranesi, Francisco de Goya (1746-1828) and Pablo Picasso (1881-1973).

Anne-Katrin Sors

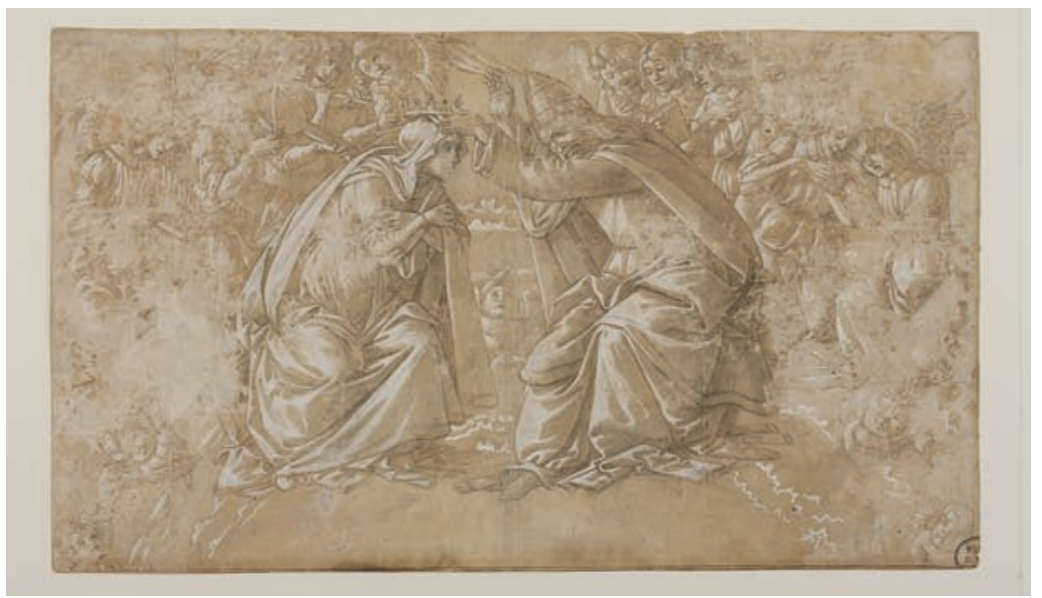

Albrecht Dürer (1471-1528),

Das Rhinozeros (The Rhinoceros), woodcut with green tone plate, c. 1515
Sandro Botticelli (1445-1510), The Coronation of Mary, c. 1488, 225 x 383 mm, paper, brown pen-and-ink drawing over black chalk, brown wash, heightened with white, inscription: [S]andro Botticello (on reverse) 


\section{Collection of Sculptures}

Art Collection of Göttingen University • Gallery of Paintings and Sculptures in the Altes Auditorium Weender Landstraße 2 • 37073 Göttingen • www.uni-goettingen.de/art-collection

Friedrich Wilhelm Doell (17501816), Bust of mathematician and physicist Abraham Gotthelf Kaestner (1719-1800), sculpted: 1800-1803, marble, height $57 \mathrm{~cm}$, plinth height $15.5 \mathrm{~cm}$; photographs: Katharina Anna Haase

Otto Herbert Hajek (19272005), articulation of space, Farbwege mit Zeichen - Wandlungen, height $65 \mathrm{~cm}$, 1984, wood
Established: c. 1780

Number of items: c. 100

Public exhibition: yes

Admission: $€ 3$, red. $€ 1.50$

Open: Sun. 10:00 - 16:00

Tours: First Sunday of every month at 11:30 presenting the 'artwork of the month', or by appointment

\section{Contact:}

Dr. Anne-Katrin Sors

Tel.: +49 551 39-5093, -5092, -5098 kunsts@gwdg.de
The University of Göttingen's Collection of Sculptures can be subdivided into three differing sections. The first contains marble and plaster busts depicting significant characters in the institution's history, as is typical for a university collection. Among these sculptures, the bust of legal historian Christian August Gottlieb Goede (1774-1812) completed in 1813 by Johann Gottfried Schadow (1764-1850), is of particular interest; students and colleagues of the scholar commissioned this work in his memory. Also noteworthy, not least for its close-to-reality but less-than-flattering depiction of the subject, is Friedrich Wilhelm Doell's (1750-1816) bust of mathematician and physicist Abraham Gotthelf Kaestner (1719-1800), sculpted in 1800 .

In addition to these sculptural portraits in stone or plaster of personages representing the university's history, the collection also contains a small number of wooden sculptures from the 14th-18th centuries. These originate from a variety of regions and contexts. It is believed that the university received the first of them - depicting three sleeping boys on the Mount of Olives and crafted in 1500 - in 1902 as a bequest from Privy Councillor Professor Karl Ewald Hasse. Then, in 1907, a Swabian School Madonna with Child, which had belonged to Professor Wilhelm Dilthey, came into the Göttingen collection. On this basis, several items were purchased during the 1920s and 1930s with the support of the Universitätsbund, including the oldest sculpture in the collection, which dates back to the early 14th century. Further sculptures came to
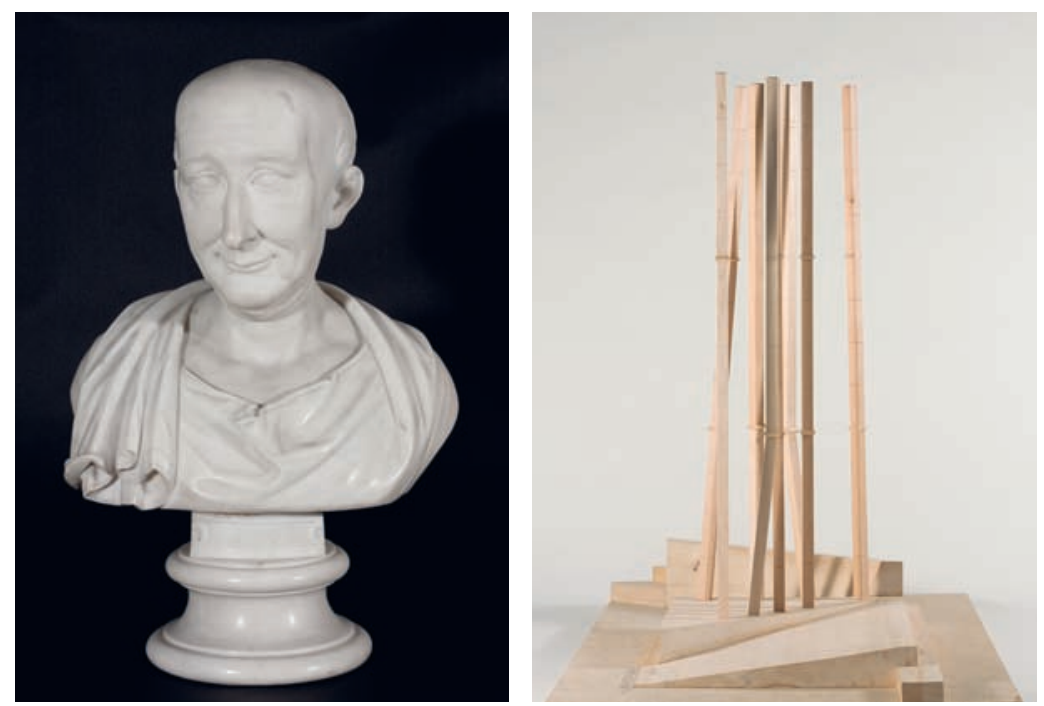


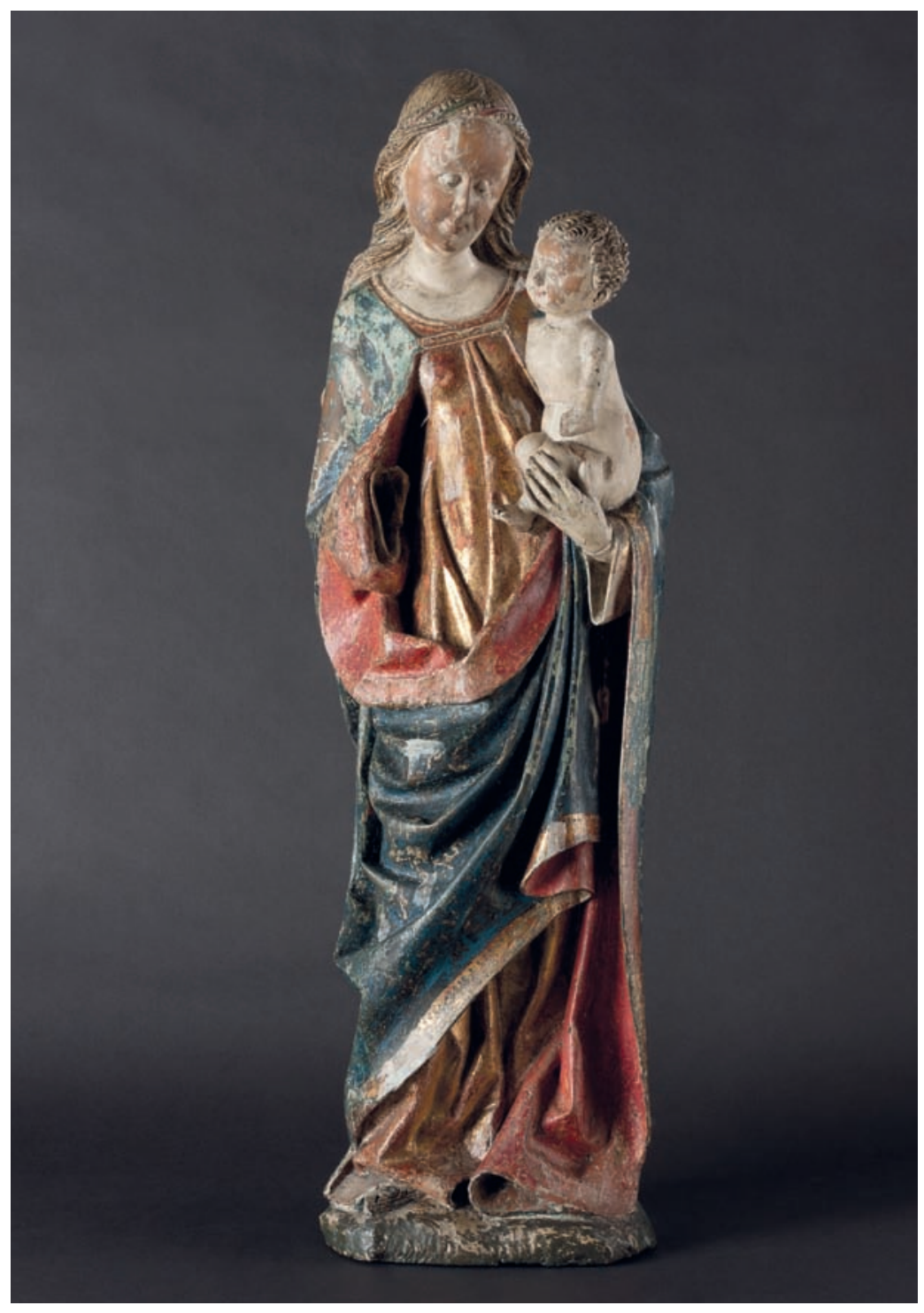

From the Rhineland, Madonna with Child, c. 1470, limewood, height $88.5 \mathrm{~cm}$, three-dimensional, hollowed out, with thin board attached to the back

the university from the private collection of Justus Theodor Valentiner (1869-1952), who had worked in the service of the university as curator.

The third and final section of this collection consists of sculptures by well-known modern artists purchased over the course of the university's history. Among them are six preliminary designs for an 'Art in Architecture' competition that date from the 1980s, including pieces by Horst Antes (b. 1936) and Otto Herbert Hajek (1927-2005). In its entirety, the Collection of Sculptures provides an unusually comprehensive cross-section of sculptural art history from the Middle Ages until the present day. 


\section{Cast Collection of Antique Sculptures}

Institute of Archaeology, University of Göttingen

Nikolausberger Weg 15 • 37073 Göttingen • www.uni-goettingen.de/archaeology-collection

Colour reconstruction of the east frieze of the Siphnian Treasury at Delphi, c. 530 BC. The reconstruction, prepared on the basis of latest research findings, was carried out under the direction of Dr. Ulrike KochBrinkmann, for the exhibition Bunte Götter (Gods in Colour), shown in the collection rooms in 2011. Photographs: Stephan Eckardt

So-called Ludovisi Gauls, Roman copy after a Hellenistic original, c. 230 BC

Early Greek figure of a youth (kouros) from Sounion, C. 600 BC

Statue of Nike, Greek goddess of victory, from the island of Samothrace, c. 190 BC

\section{Established: 1767}

Number of items: c. 2,000

Public exhibition: yes

Open: Sun. 10:00 - 16:00

Admission: $€ 2$, red. $€ 1$

Tours: by appointment

\section{Contact:}

Dr. Daniel Graepler Tel.: +49 551 39-7502, -7497 sekretariat.archinst@phil.unigoettingen.de
Göttingen University's Institute of Archaeology is home to the oldest university collection of plaster casts in the world. Consisting of more than 2,000 original-sized reproductions of antique sculptures from over 150 museums, the collection is also amongst the largest of its kind in international comparison. The originals from which the casts are taken are mainly from Ancient Greece and Rome, while a small number come from Egypt, the Ancient Orient and Byzantium.

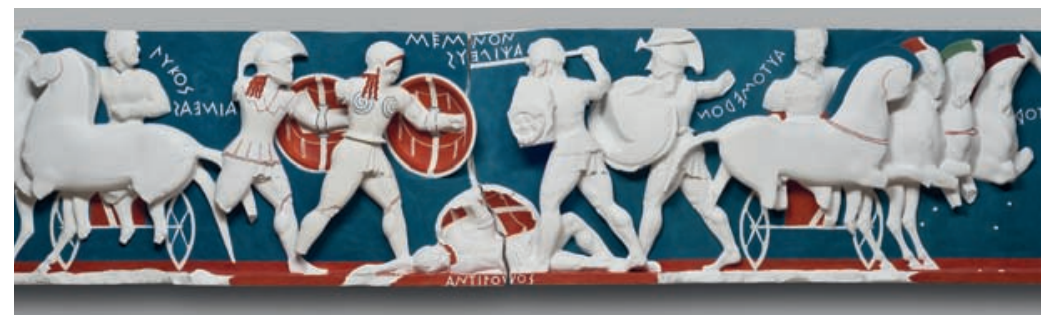

The initial foundations of the collection were laid by Christian Gottlob Heyne (1729-1812), who brought archaeology into being as an academic subject with the series of lectures on 'Studies of the Antique' that he held regularly from 1767 . The plaster casts then standing in the University Library served him as visual material for this innovative lecture series. Heyne's collection, which ultimately numbered approximately 70 items, was considerably expanded by Karl Otfried Müller (1797-1840), who among other achievements succeeded in acquiring from the British Museum numerous casts of the Parthenon sculptures in Athens. When the collection was moved into a new wing of the departmental building in
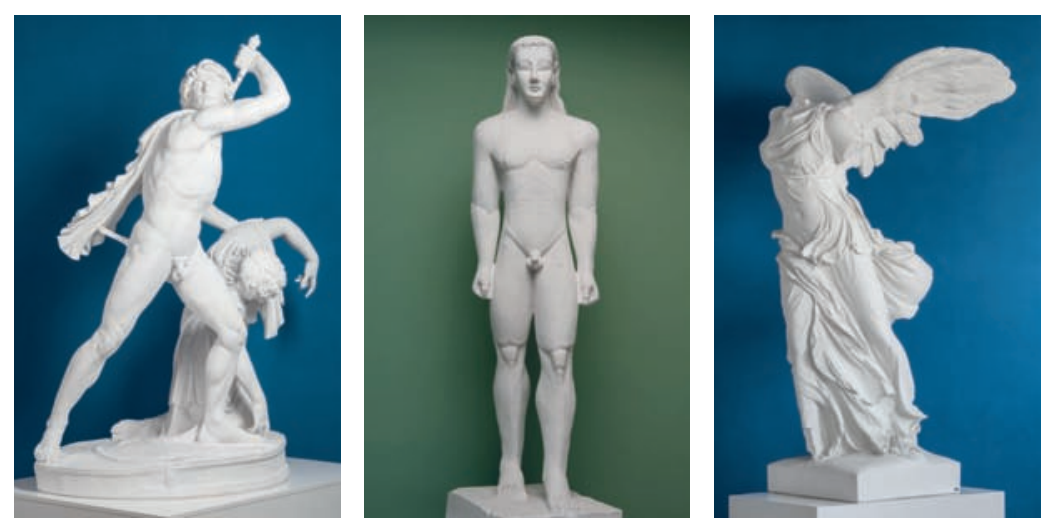


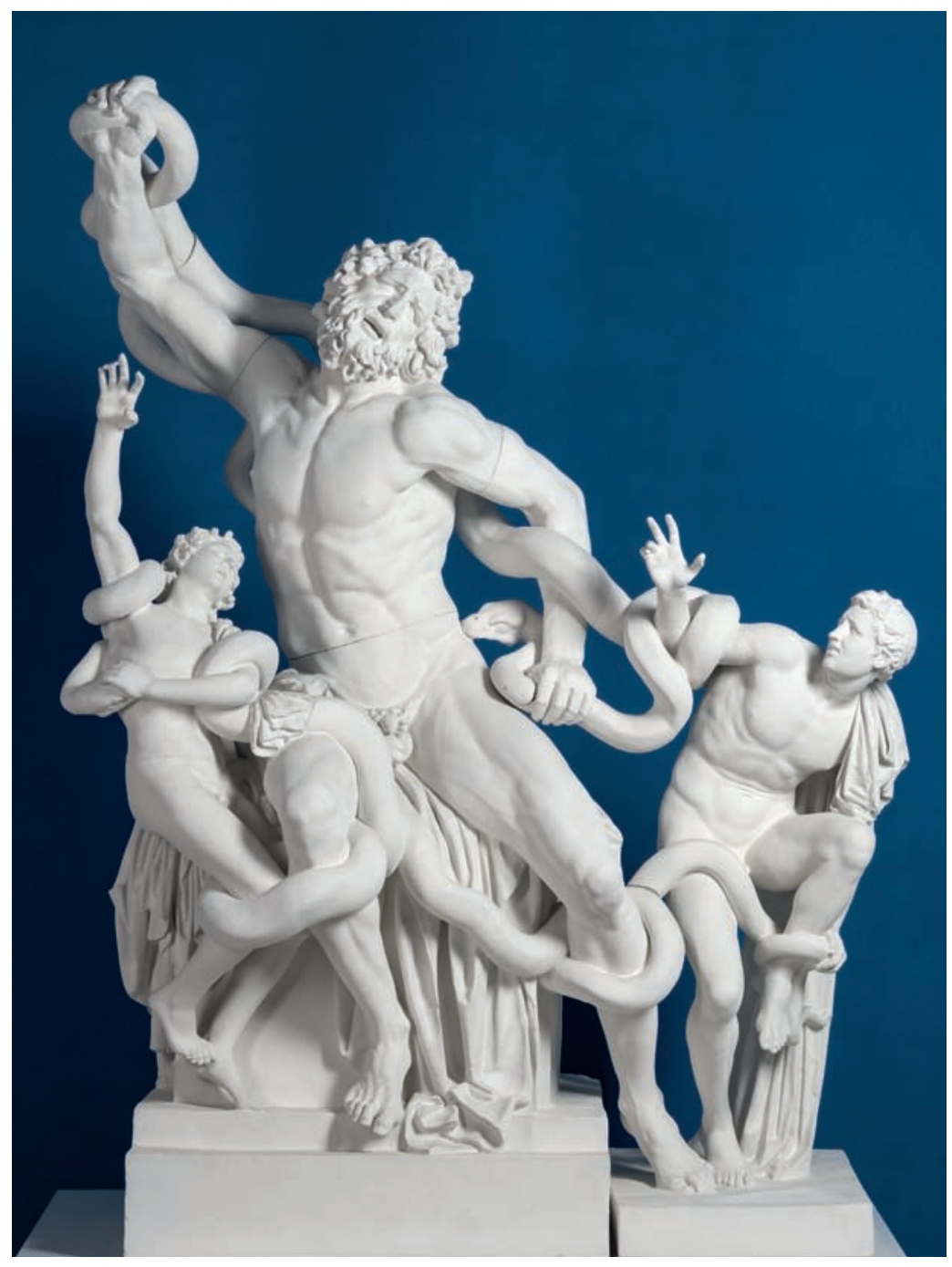

Laocoon group, 1 st century $\mathrm{BC}$. A partial cast of the famous marble group in the Vatican Belvedere stood in Göttingen University Library from 1774 . It was replaced by the cast of the whole group in 1906.

Nikolausberger Weg where it remains to this day - the extension was built specifically for this purpose - it had grown to more than 1,000 items.

Since the 1970s, the holdings maintained for research and teaching purposes have further increased, and to a significant extent. They have also been made accessible to the public. Arranged according to their era, the casts stand in eleven rooms. All statues are mounted on movable plinths with castors, for optimal use in teaching. Storage rooms in the basement house several hundred further casts - heads, busts and small sculptures. The collection continues to expand, the focus being on the history of the Greek and Roman portrait. The entire holdings of the collection of plaster casts are accessible for viewing online at www.viamus.de, in the form of a 'virtual museum of antiquity'. 


\section{Antiquities Collection}

Institute of Archaeology, University of Göttingen

Nikolausberger Weg 15 • 37073 Göttingen • www.uni-goettingen.de/archaeology-collection

This view into the exhibition room of the Antiquities Collection provides a glimpse into the diverse holdings, which were acquired primarily during the 19th century: Greek vases, Roman sculptures, Etruscan clay urns and bronze statuettes. Photographs: Stephan Eckardt
The Antiquities Collection in Göttingen University's Institute of Archaeology first came into being in 1839, when the famous Göttingen classical scholar Karl Otfried Müller (1797-1840) acquired the first vases, clay figures and marble sculptures for Göttingen University during the course of a research visit to Italy and Greece. Under the direction of the first holder of the Chair for Archaeology, Friedrich Wieseler (1811-1892) and his successor Karl Dilthey (1839-1907), the collection of ancient vases, in particular, grew considerably through regular purchases and thanks to permanent loans from the Berlin Royal Museums. In addition to complete vessels, extensive holdings of ceramic fragments were acquired for the collection, these being particularly instructive for purposes of archaeological education. The collection's Etruscan section was enhanced in particular by Gustav Körte (1852-1917), Director of the Institute of Archaeology from 1907, who acquired significant additions especially in the area of small bronzes.

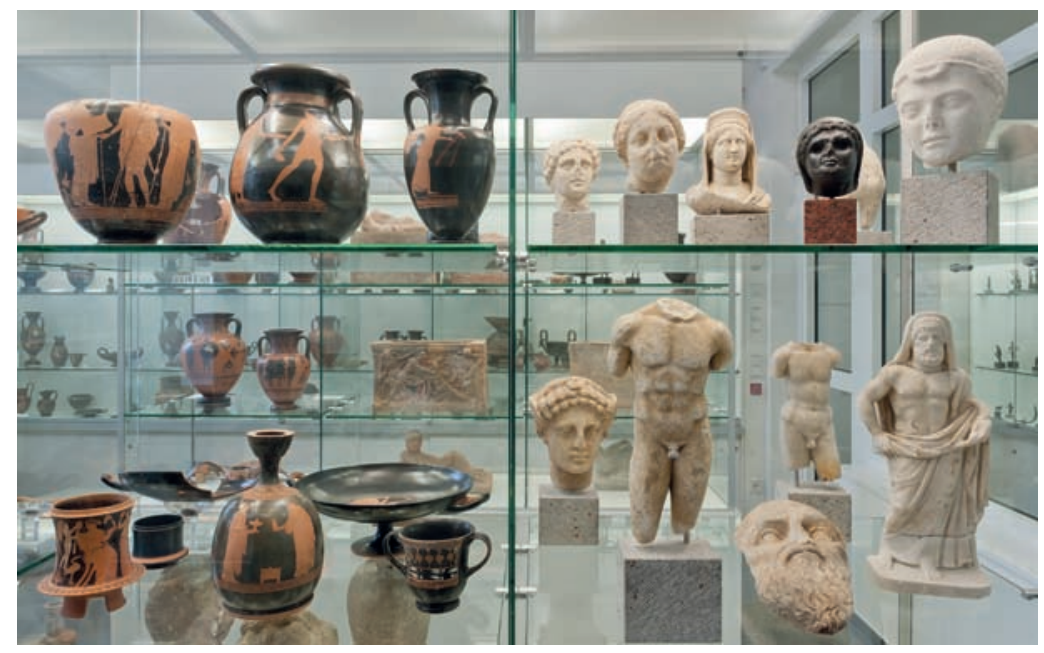

Since archaeological objects offered for sale on the art market frequently originate from illicit excavations, no further purchases of objects have been made for the Göttingen Antiquities Collection over recent decades. But the collection has for many years contained extensive assemblages of items found in official excavations. In 1902, for example, the Institute received from Berlin some of the material discovered by Heinrich Schliemann in Troy. Equally significant are the findings from excavations carried out by the archaeologist Johannes Boehlau (1861-1941). Items he discovered at Larisa on the Hermos (western Turkey) and at Pyrrha on the Greek island of Lesbos, together with the accompanying documentation, 


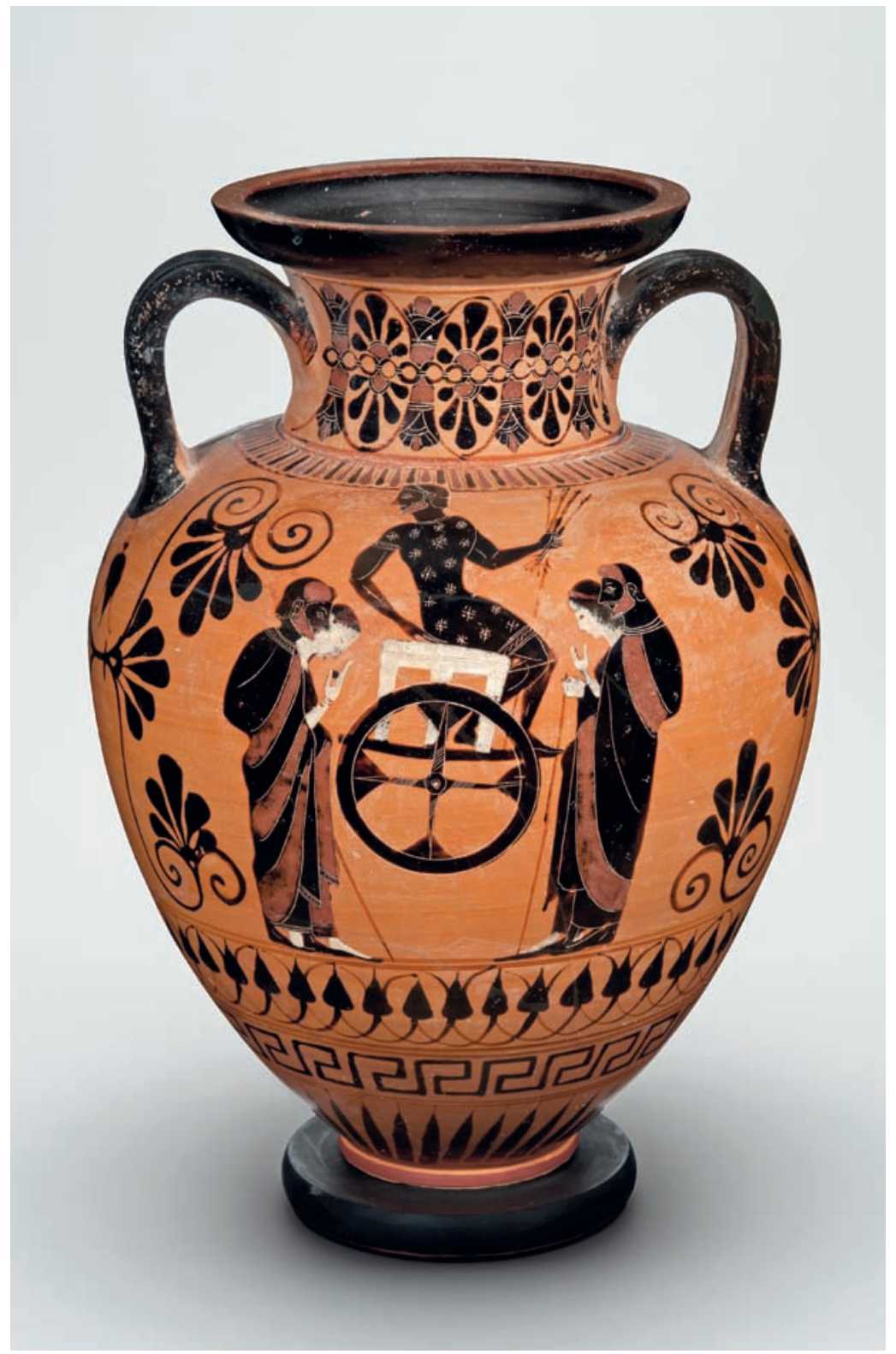

are held at the Archaeological Institute in Göttingen and are frequently consulted by international researchers.

The diversity of the materials, genres and cultures represented - in addition to Greek, Etruscan and Roman artefacts the holdings include items from Egypt and the Middle East - not only grants the Göttingen Antiquities Collection special significance in the research context but also renders it a particularly valuable resource for archaeological training.
Amphora by the so-called Swing Painter, Athens, c. 540 BC. The depiction on the vase shows the Attic hero Triptolemos, who was sent out by Demeter, goddess of fertility, in a serpent-drawn chariot to teach crop cultivation to humankind. This is the oldest known illustration of the frequently represented myth. 


\section{Wallmoden Sculpture Collection}

Institute of Archaeology, University of Göttingen

Nikolausberger Weg 15 • 37073 Göttingen • www.uni-goettingen.de/archaeology-collection

Bust of an unknown Roman in a toga, marble, 2nd century $A D$; photographs: Stephan Eckardt

Perseus frees Andromeda, marble, 2nd century AD. During Wallmoden's lifetime this group was the most famous work in his collection.

\section{Established: 1765}

Number of items: 56

Public exhibition: yes

Open: Sun. 10:00 - 16:00

Admission: $€ 2$, red. $€ 1$

\section{Contact:}

Dr. Daniel Graepler

Tel.: +49 551 39-7502, -7497 sekretariat.archinst@phil.unigoettingen.de
The Wallmoden Collection is a long-term loan by H.R.H. Prince Ernst August of Hanover to Göttingen University's Institute of Archaeology, where it has been on display since 1979. The collection consists in large part of ancient Roman marble works that were acquired in 1765 by General Johann Ludwig von Wallmoden (1736-1811), later Reichsgraf (Imperial Count) von Wallmoden-Gimborn, an illegitimate son of George II August of Great Britain and Hanover. Modelled on an English concept, this collection of antiquities is the oldest of its kind in Germany to have remained complete almost in its entirety. This makes it an outstanding documentation of the 18th century reception of ancient art. Following Wallmoden's death in 1811, the collection was sold to the House of Hanover, in whose ownership it remains to this day.

The collection encompasses 56 statues and busts as well as marble urns with relief decoration, dating mainly from the 1 st to 3 rd centuries AD. During the 18th century, all these works were subject to restorations and modifications by leading Italian sculptors, in particular Bartolomeo Cavaceppi (1716-1799), in line with the aesthetics of the day. It is these additions and restorative work that render the objects particularly valuable for archaeological training, since unlike plaster casts, these items allow students to learn the complex process of differentiation between ancient and modern elements, an indispensable skill for professional analysis of Greek and Roman sculptures from old collections.
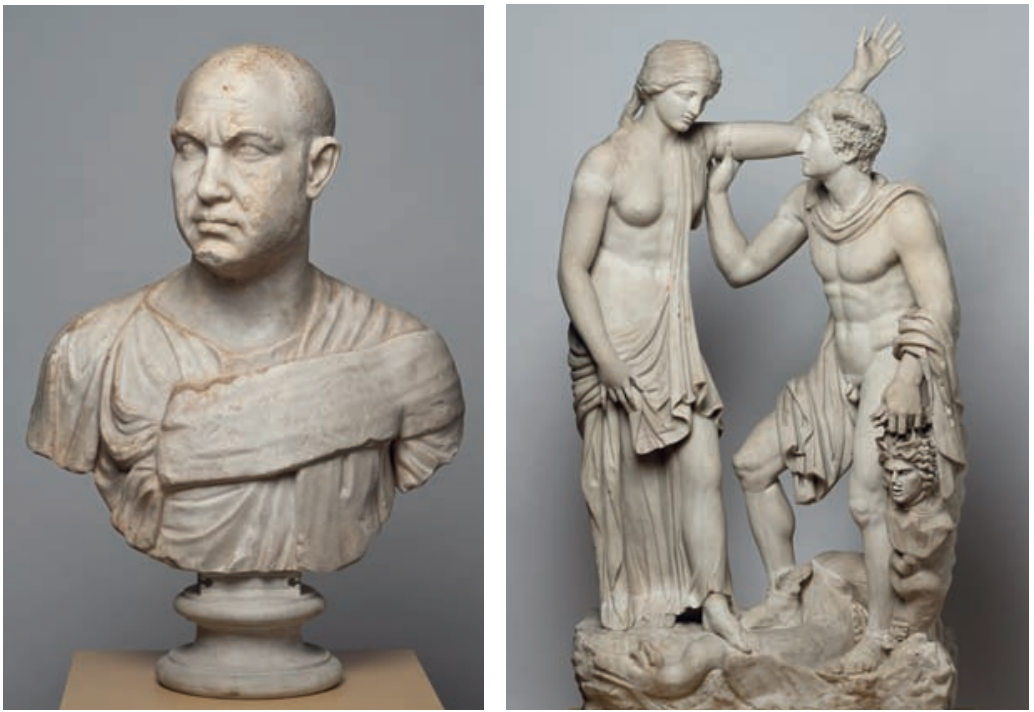


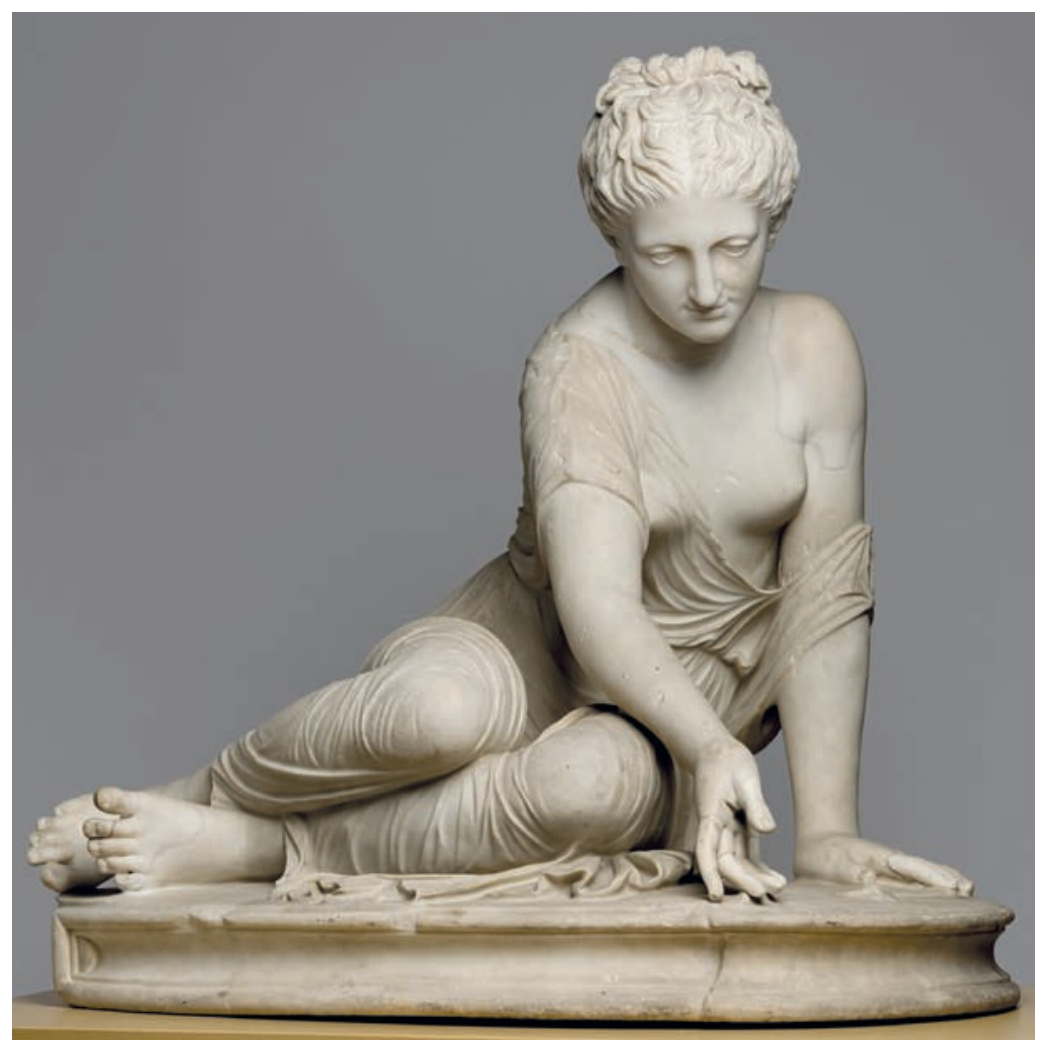

Among the collection's outstanding exhibits are the group Perseus frees Andromeda, the statue of a nymph seated on the ground (so-called Knucklebone Player), and a number of Roman portraits of particularly high quality.

\section{Daniel Graepler}

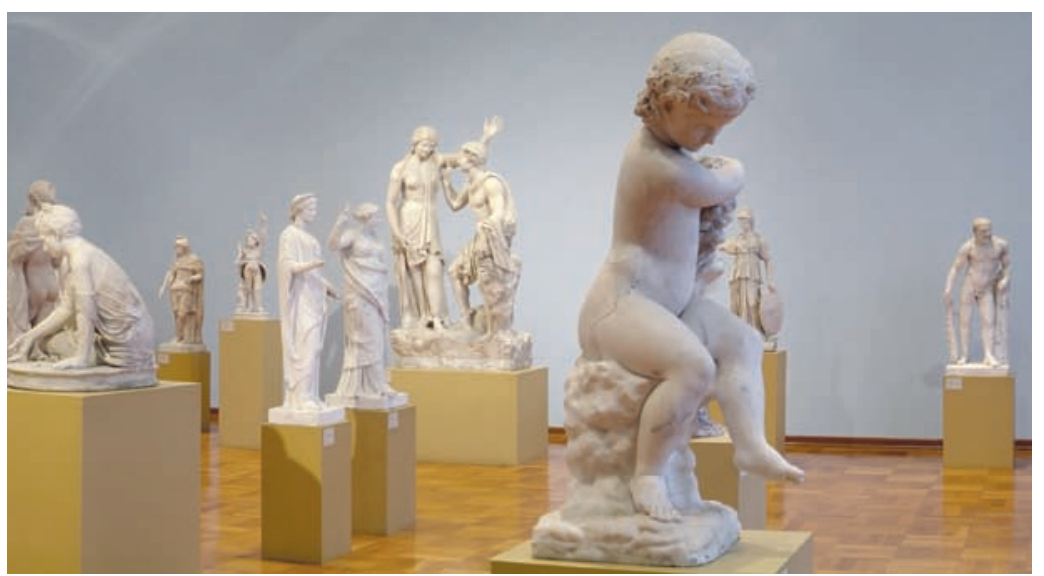

So-called Knucklebone Player, Roman copy dating from the 2nd century $\mathrm{AD}$ after a Greek original. The marble figure of a nymph, a companion of Artemis, goddess of the hunt, seated gracefully on the ground was unearthed in Rome in 1765 and purchased by Wallmoden. The head and other missing parts were expertly added in marble by Bartolomeo Cavaceppi.
View of the Wallmoden Collection 


\section{Numismatic Collection}

Institute of Archaeology, University of Göttingen

Nikolausberger Weg 15 • 37073 Göttingen • www.uni-goettingen.de/archaeology-collection

Medal coined upon the accession to the throne of Katharina II of Russia (1762) - one of more than 370 Russian medals donated to the Göttingen University by Baron Georg Thomas von Asch (1729-1807); photographs: Stephan Eckardt
Consisting of more than 40,000 items, Göttingen University's Münzkabinett, or Numismatic Collection, is Germany's third largest academic collection of coins and medals (after those of the Universities of Leipzig and Tübingen). The collection came into being in 1773, when the specimens and artefacts belonging to the Göttingen Professor of Natural History and Chemistry Christian Wilhelm Büttner were acquired; amongst these items was a large assemblage of coins. Under the direction of Christian Gottlob Heyne (1729-1812), the Royal Academic Museum was set up in Göttingen as a result. A classicist himself, Heyne was particularly interested in the coins of the Roman Republic, but from the very outset the collection also contained post-antiquity coins. A series of donations by the Russian Baron Georg Thomas von Asch (up to 1807), an important benefactor of the 'Georgia Augusta', enriched the collection considerably. Amongst many other items was a large group of Russian medals that formed the basis for the Göttingen medal collection. Until the founding of the Museum of the Province of Hanover it was usual for coins discovered in the Kingdom of Hanover to be assigned to the Göttingen collection. In 1842, the collection was ultimately granted its own budget, which lead to its rapid growth; this came about on the initiative of Friedrich Wieseler (1811-1892), in particular. During the 20th century, in addition to the holdings saved from the former Albertus University Königsberg, several sizeable private collections were received, including more than 9,000 German coins of medieval and modern times from the collection
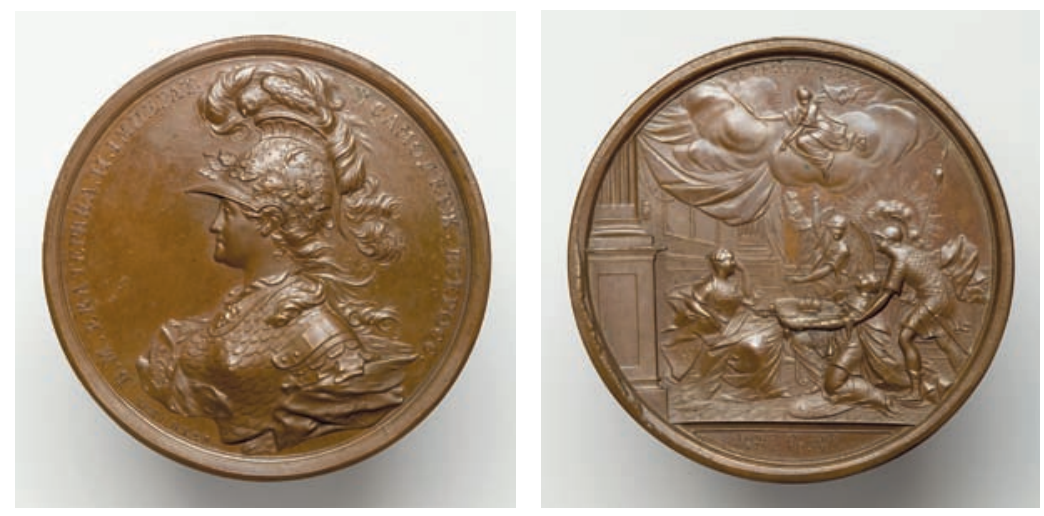

of Edward Schröder (1858-1942), a scholar of German studies, and most recently (1991) the Bachmann collection, which has an Islamic focus.

Today, the Göttingen Numismatic Collection contains approximately 5,900 Greek, 9,600 Roman, 950 Byzantine, 3,900 Oriental, 2,100 medieval 

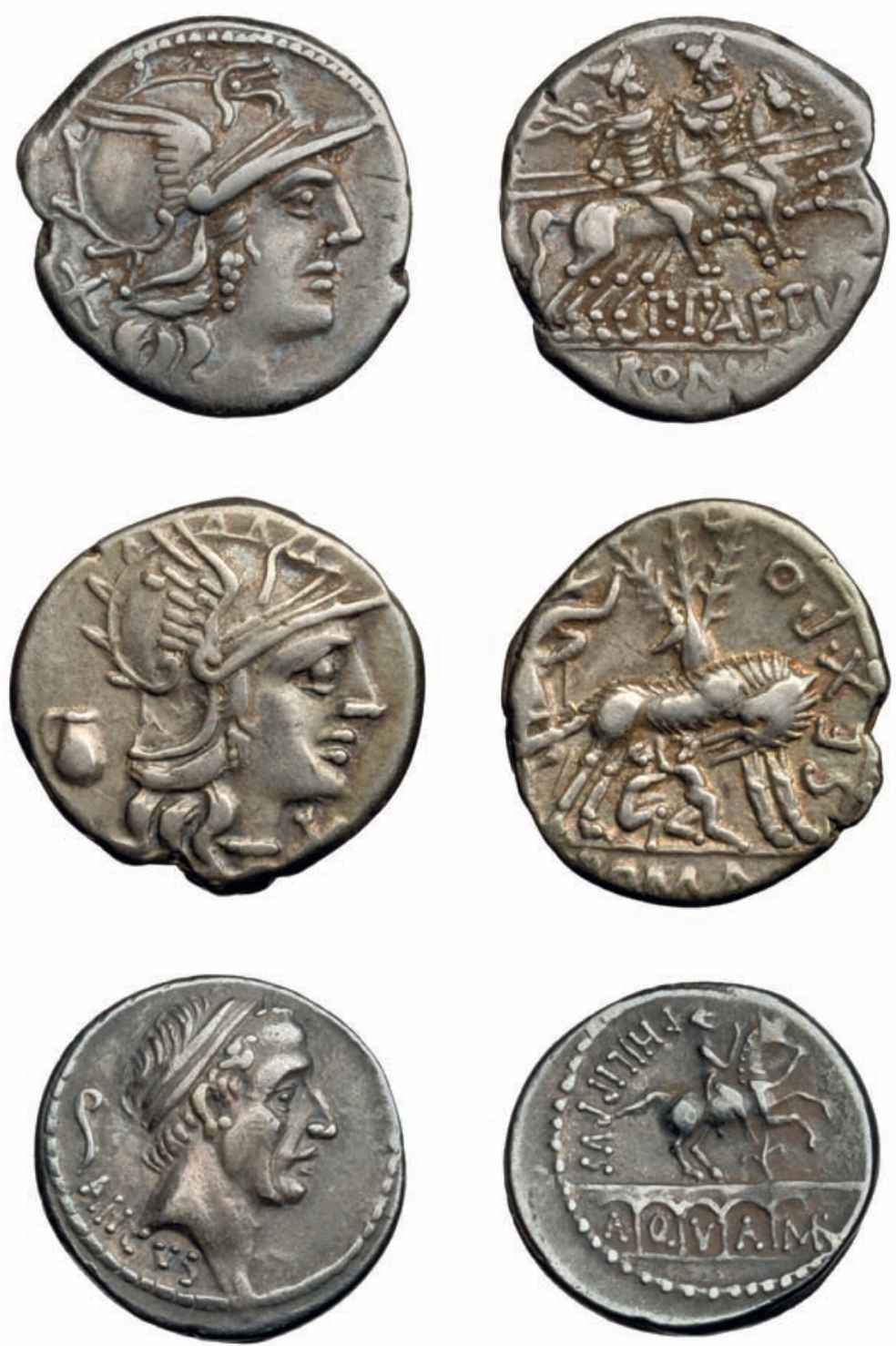

and 15,600 coins from modern times, as well as some 1,700 medals and tokens. In addition to these, the holdings include approximately 4,000 lead copies of coins from the modern period and numerous coin casts. Rarely found items, for example in the area of Greek bronze coins, attract much attention to the Göttingen Numismatic Collection on the part of international researchers. Due to its remarkably broad thematic range, the collection also offers outstanding material resources for use in academic teaching.
Three Roman silver denarii issued by Publius Aelius Paetus, 138 BC (top), Sextus Pompeius, 137 BC (middle), and Lucius Marcius Philippus, $56 \quad \mathrm{BC}$ (bottom). Coins of the Roman Republic from the Büttner collection created the basis for the Numismatic Collection of Göttingen University. Christian Gottlob Heyne published three important treatises on the subject in $1777 / 78$. 


\section{Teaching Collection for Pre- and Protohistory}

Department of Pre- and Protohistory, University of Göttingen

Nikolausberger Weg 15 • 37073 Göttingen • www.uni-goettingen.de/pre-and-protohistory-collection

So-called Face Urn (Gesichtsurne), a funerary vessel from Pomerania (7th century BC), which not only contained the ashes of the deceased but also represented the person. Gift from a private collection, original, exact location of discovery not known, height c. $33 \mathrm{~cm}$; photographs: Stephan Eckardt
Established: 1929

Number of items: c. 10,000

Public exhibition: no

Tours: by appointment

\section{Contact:}

Dr. Jens Schneeweiß

Tel.: +49551 39-5086

jschnee@gwdg.de

Simone Menck

Tel.: +49551 39-91276

simone@menck-online.de
The year 1929 saw the establishment of the Pre- and Protohistory Department at the University of Göttingen and with it, the creation of a collection of material for use in the teaching of prehistoric archaeology. This collection continues to play an essential role for academic teaching in this object-related subject, which deals explicitly with material culture. Objects on permanent loan from the Hanover Provincial Museum formed the cornerstone of the collection, many of them being of non-Hanoverian provenance and replicas. The first prehistoric objects had already begun to arrive at the University's Royal Academic Museum by the beginning of the 19th century, due to a steadily increasing interest in 'Germanic antiquity'. This is largely thanks to Johann Friedrich Blumenbach (1752-1840), who was in charge of the Royal Academic Museum at that time. In the second half of the 19th century, the holdings were distributed between various institutes and departments at the university. A large part was sent to Hanover, long before the study collection was established in Göttingen by the first tenured professor, Karl Hermann Jacob-Friesen (1886-1960), also Director of the Hanover Provincial Museum at the time. Thanks to him, part of the old Academic Museum collection returned to Göttingen. In 1967 the collection was substantially expanded through permanent loans from the Brunswick State Museum in Wolfenbüttel. Today, the collection has ceased to grow to any major extent, additional objects rarely being added since all new archaeological finds must be sent to the state museum for the region in which they are discovered.

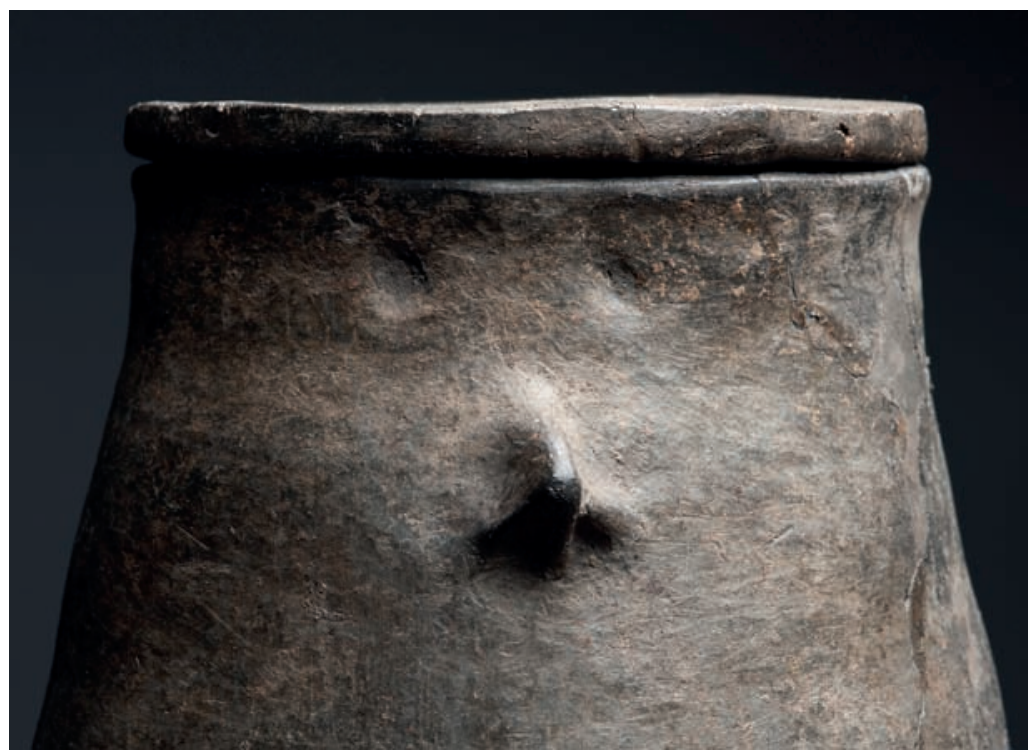




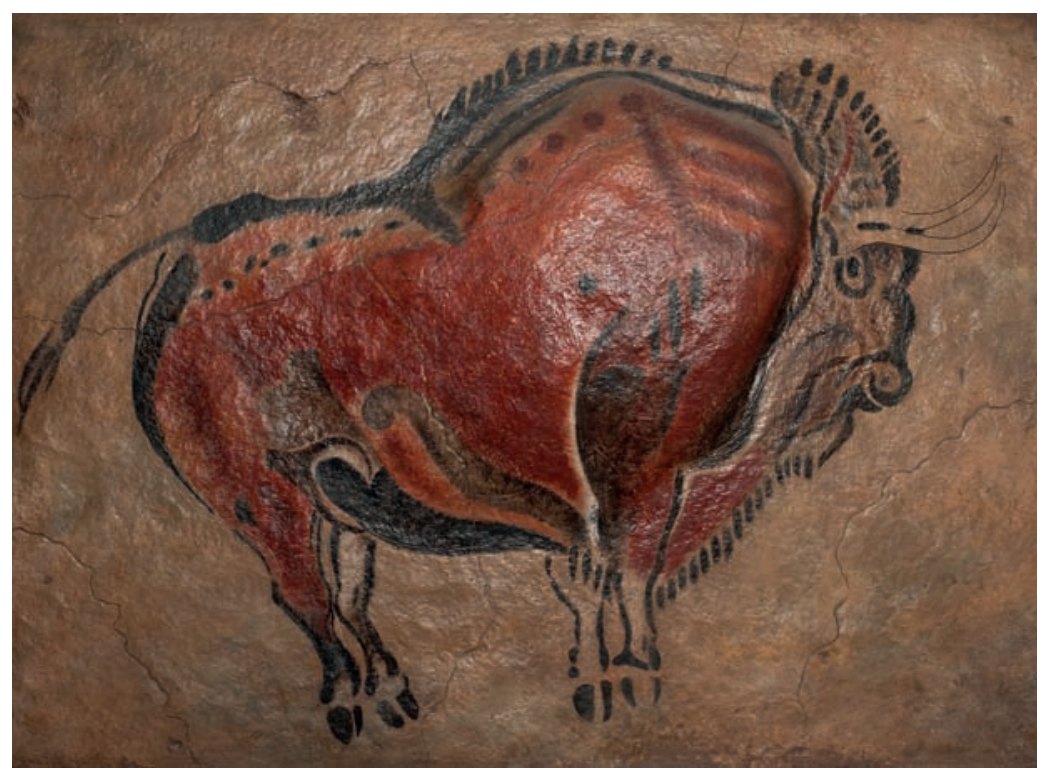

The collection currently consists of some 8,450 inventory numbers and although it cannot claim to deliver a representative picture of particular regions or periods, it provides a good overview of central European preand protohistory. In the context of teaching and learning, the objects are used primarily as visual and haptic aids for lectures and seminars and as study material. Due to limited space, the collection is not accessible to the public, but several display cases in the corridors of the department give an insight into its richness and diversity.

Jens Schneeweiß
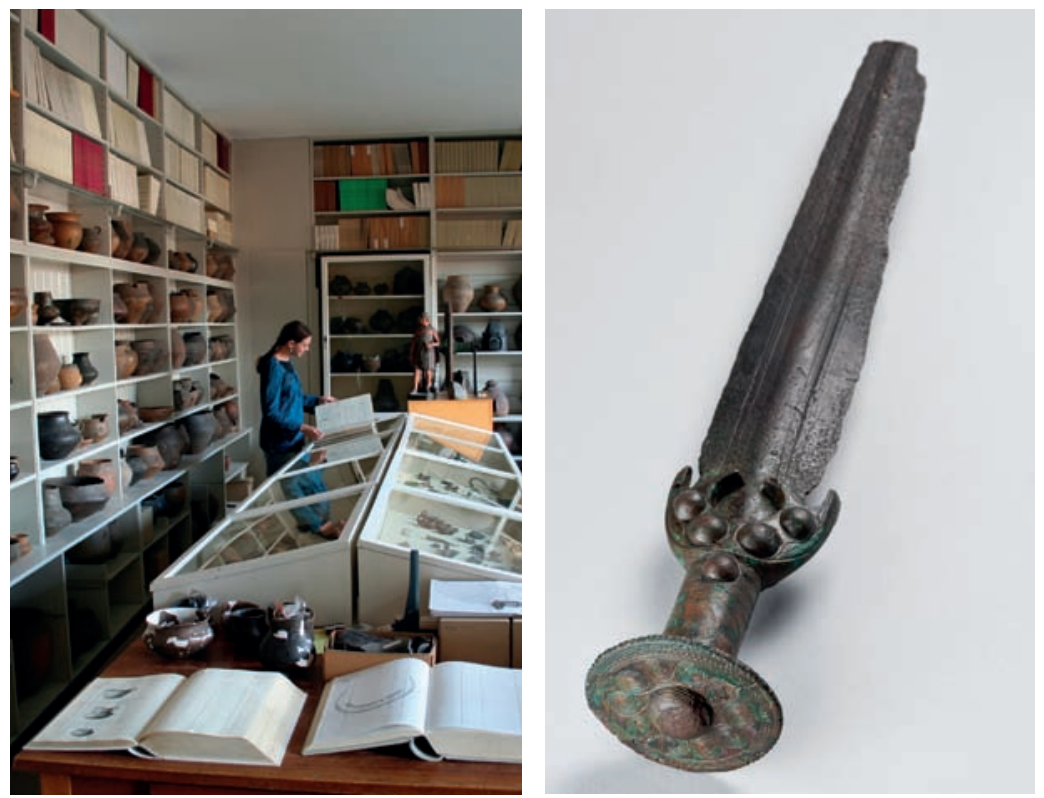

Coloured and form-accurate plaster replica of a wisent (European bison), originally painted 15,000 years ago by ice-age humans on the ceiling of the Altamira cave in modernday northern Spain, using red chalk, ochre and charcoal. Use of a bulge in the rock makes the animal appear particularly realistic. Replica produced in the Hanover Provincial Museum around 1930, scale 3:4, length $164 \mathrm{~cm}$, width $114 \mathrm{~cm}$

Part of the Teaching Collection is still housed in cabinets and display cases made especially for this purpose; photograph: Jens Schneeweiß

Bronze short sword of the Nordic Bronze Age period II (c. 1,400 BC. Found on Bornholm and donated as a 'sacrificial knife' to the Royal Academic Museum in Göttingen by Bishop Friedrich Münter in 1818. Original, length of extant object c. $34 \mathrm{~cm}$ 


\section{Apparatus Diplomaticus}

Centre of Cultural Studies, University of Göttingen

Heinrich Düker-Weg 14 • 37073 Göttingen • www.uni-goettingen.de/diplomatic-apparatus

Professor Hedwig Röckelein and PD Dr. Dr. Jörg Bölling study the Meister Eckhart Fragment dating from the early 14th century; photograph: Göttingen University

Imperial Charter, issued by Friedrich Barbarossa (1157); photographs: Martin Liebetruth

Musical fragment using early notation, 12th century

\section{Established: 1759}

Number of items: 875 original charters, 6 original manuscripts, 67 original seals, 144 seal casts and numerous facsimile editions, photographs, slides, digitalised images and maps

\section{Public exhibition: no}

Tours: by appointment

\section{Contact:}

Prof. Dr. Hedwig Röckelein Tel.: +49551 39-24669 hroecke@gwdg.de
The Apparatus Diplomaticus, a collection compiled for teaching and study purposes and unparalleled worldwide, consists of more than 1,600 written documents dating from Late Antiquity, the Middle Ages and the Early Modern periods. The majority of them are in Latin, but numerous other languages are also represented, including Middle High German, Middle Low German, Ancient Greek, Hebrew, Arabic, Persian, Turkish, Coptic, Tamil, Sinhalese and Ancient Javanese.

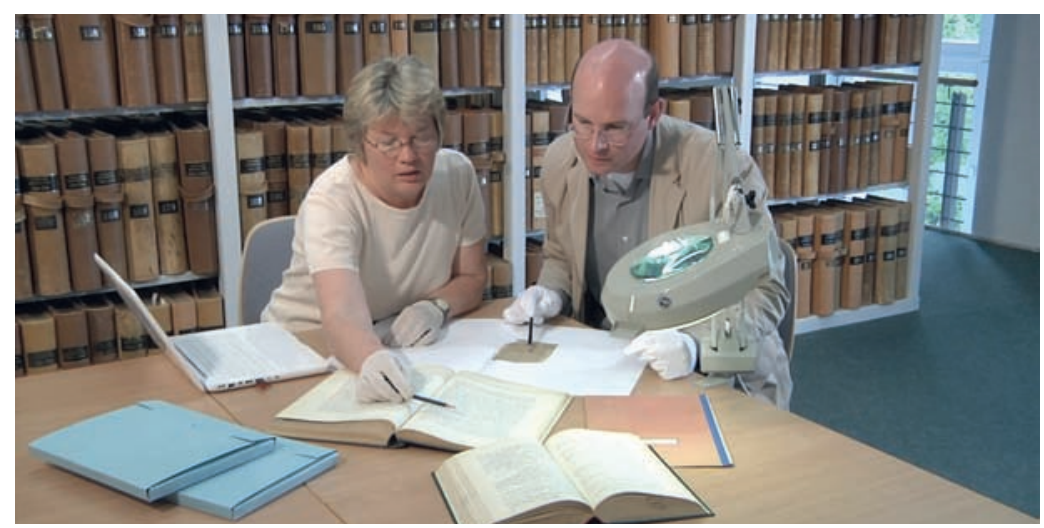

As early as 1759, a didactically structured Diplomatisches Cabinett was established to facilitate teaching in the subject of 'Diplomatic Studies', the documentation and research of official texts. In addition to charters and certificates, the collection also contained manuscripts, seals and

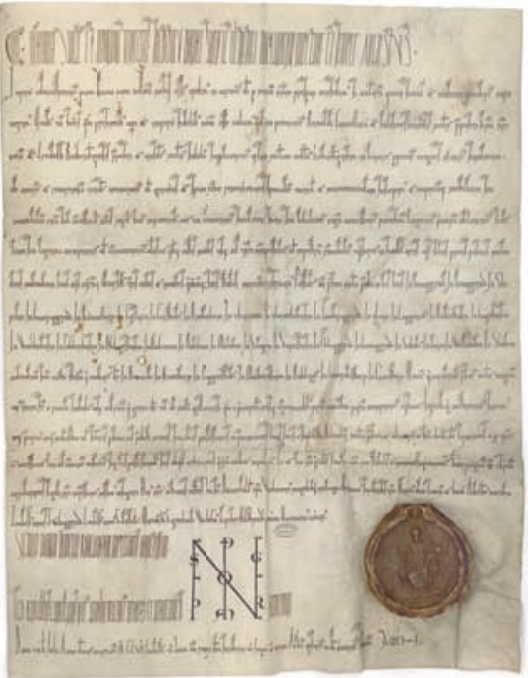




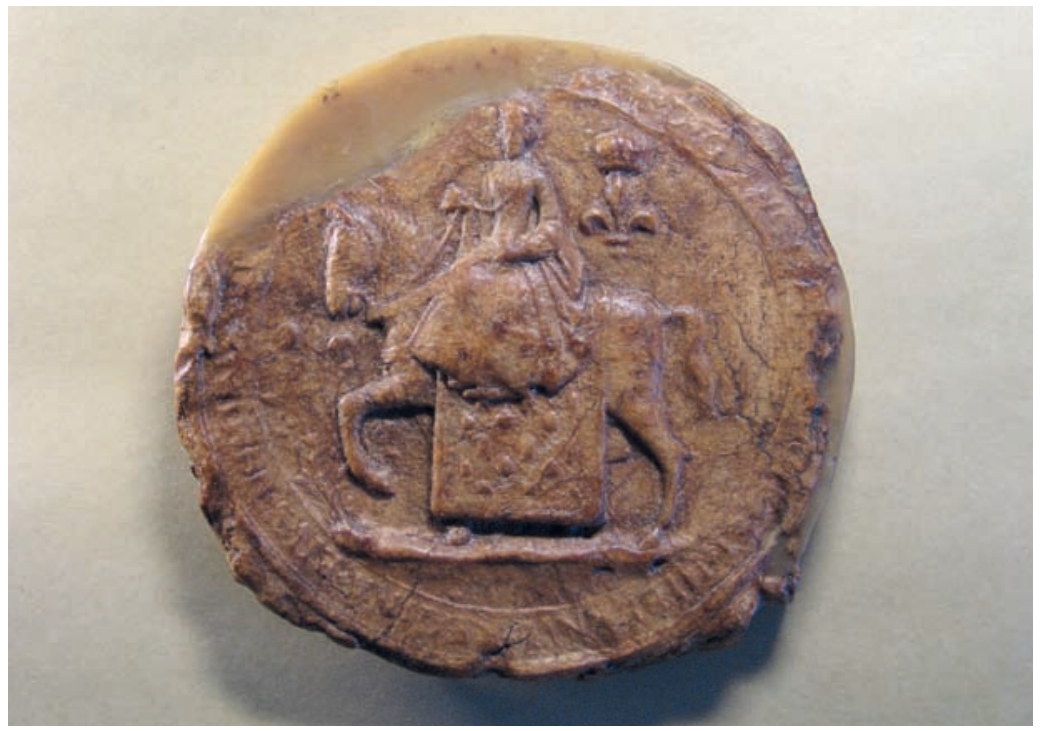

copperplate reproductions, and it was on this basis that the collection in its present form came into being in 1802. Today, the majority of the collection's items are papal, imperial and royal charters, as well as private charters of clerics, dynasties, municipalities and citizens. In the 19th and 20th centuries, the collection was enlarged by scholars seeking to combine research and teaching on the basis of illustrative materials. Numerous additions enriched the collection, including further charters, manuscripts, manuscript fragments and seals, as well as seal casts and photographs. A specialised academic library consisting of approximately 5,800 volumes complements the collection of original items.

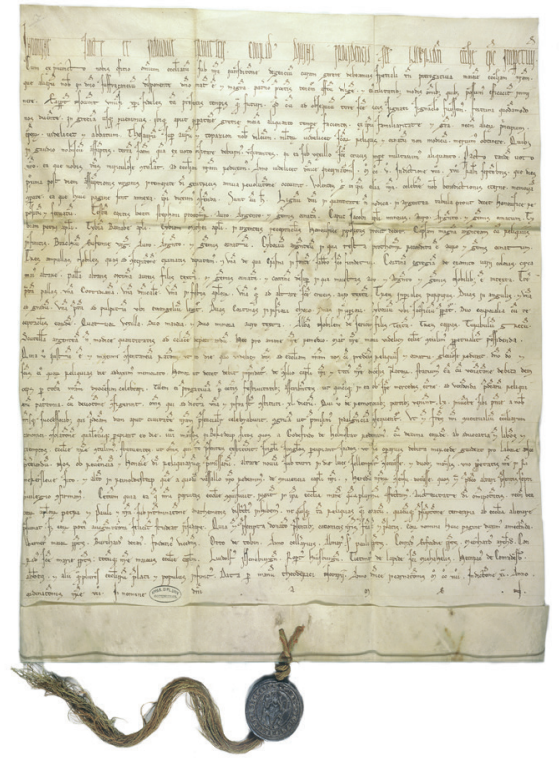

Among the directors of the institution were Johann Christoph Gatterer (1759-1799), initiator of the academic subject 'Historische Hilfswissenschaften' (auxiliary historical studies) in Göttingen and Germany, Jacob Grimm (1835-1917), Paul Fridolin Kehr (1895-1903), Karl Brandi (1902-1946), Alfred Hessel (1924-1935) and Hans Goetting (1964-1976). Since April 2007 the Apparatus has been directed by medievalist Hedwig Röckelein of the Department of Medieval and Modern History.

Hedwig Röckelein \& Jörg Bölling
Seal of Queen Mary of England, France and Ireland (1553/54); photograph: Bengt Büttner
Among the holdings of the Apparatus Diplomaticus are documents such as the Founding Charter of the Halberstadt Cathedral Treasury dating from 1208. 


\section{Ethnographic Collection}

Institute of Social and Cultural Anthropology, University of Göttingen

Theaterplatz 15 • 37073 Göttingen • www.uni-goettingen.de/ethnographic-collection

Memorial bust of an Edo Queen, Benin, 1897. Bronze, height 49 $\mathrm{cm}$, acquisition: Arthur Speyer, via the Ethnological Museum of Berlin, 1932; photograph: Andreas Schlothauer

Heva mourning dress, Tahiti. Such attire was a typical element of funeral rites for chieftains. The rare heirlooms were without exception in the possession of families. Worn by a priest or relative of the deceased, dress of this kind was intended to provoke reverence, respect and fear. The 'mourning man' incarnated the spirits that accompanied the deceased on the soul's journey into the mythical aboriginal home Hawaiki. Bark gum, mother-ofpearl, tortoiseshell, shell, wood, coconut, feathers, dog hair, height $224 \mathrm{~cm}$, acquisition: Cook collection, 1782; photograph: Harry Haase

\section{Established: 1773}

Number of items: c. 18,000 (including the European collection not on display)

Public exhibition: yes

Open: Sun. 10:00 - 16:00, Mon. to Fri. by appointment

Admission: $€ 3$, red. € 1.50, Sunday tours $€ 5$

Tours: by appointment

\section{Contact:}

Dr. Gundolf Krüger

Tel.: +49551 39-7894

gkruege1@gwdg.de
The Ethnographic Collection of Göttingen University, composed of portfolios relating to Asia, Oceania, America, Africa and Europe, is one of the most important teaching and research collections in the Germanspeaking world. The collection's origins can be traced back to the late Enlightenment period.

It was on the initiative of Göttingen natural scientist and Professor of Medicine Johann Friedrich Blumenbach $(1752-1840)$ that during the latter third of the 18th century cultural objects from foreign countries were brought to Göttingen. Blumenbach held the position of Deputy Director of the Royal Academic Museum from 1776 and became its director in 1812. The artefacts from Oceania originated from the three South Pacific expeditions (1768-1779/80) of the English explorer Captain James Cook (1728-1779), who was accompanied on his second voyage $(1772-1775)$ by the German naturalist Reinhold Forster (1729-1798) and his son Georg Forster (1754-1794).

On the instigation of Christian Gottlob Heyne (1729-1812), Director of Göttingen University Library, the university also came into possession of a collection formerly belonging to Baron Georg Thomas von Asch, a medical doctor from St. Petersburg. This collection consists primarily of cultural objects from the Arctic polar region. Due to their great age and rarity, these two historical holdings constitute the central focus
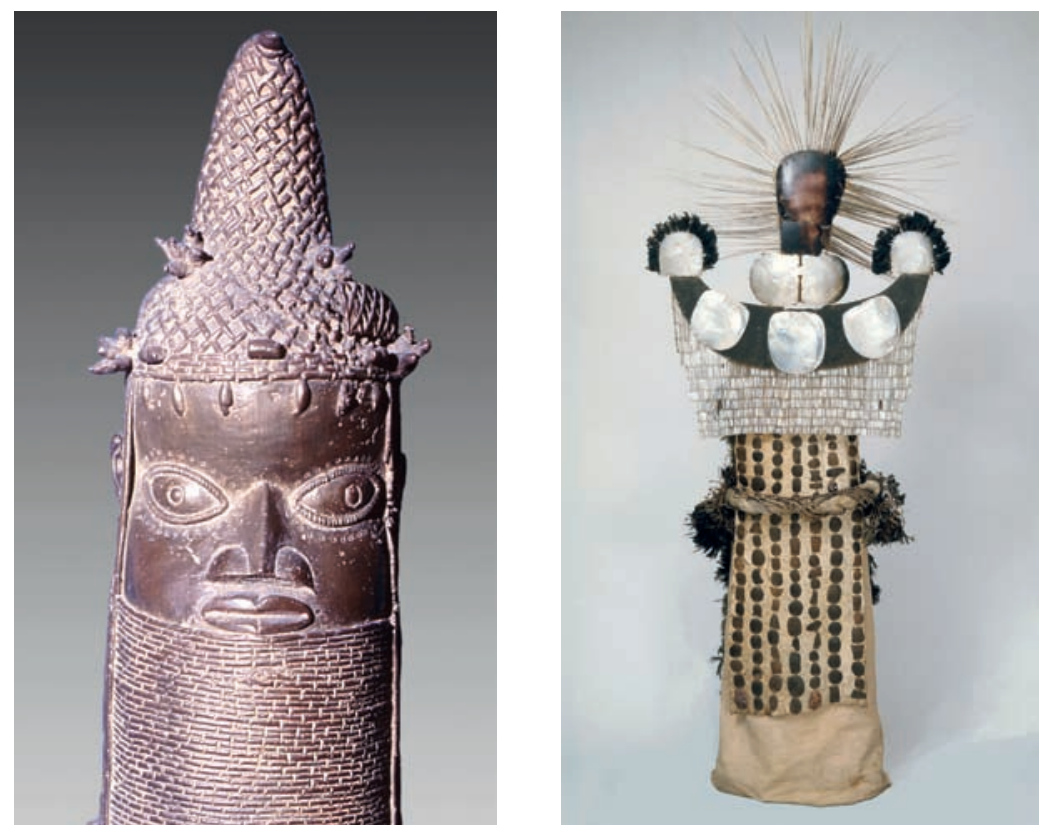


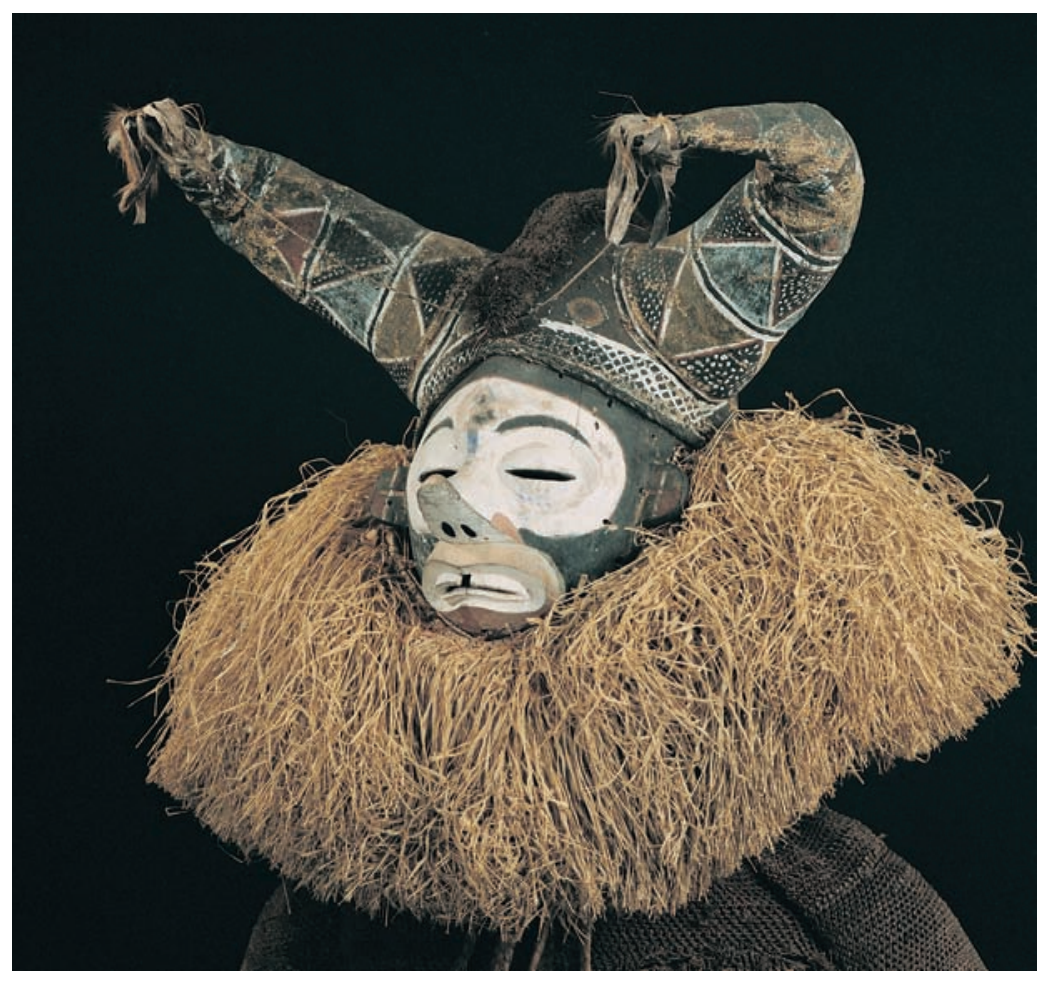

of the Ethnographic Collection and account for its prominence in the international domain.

Today, the objects from Asia, Oceania, America and Africa assembled over the course of more than three centuries provide insights into the cultural heritage and artefacts of a considerable number of nonEuropean ethnic groups. The items are employed regularly in research and academic teaching, as well as being in great demand for display in exhibitions throughout the world.

Gundolf Krüger

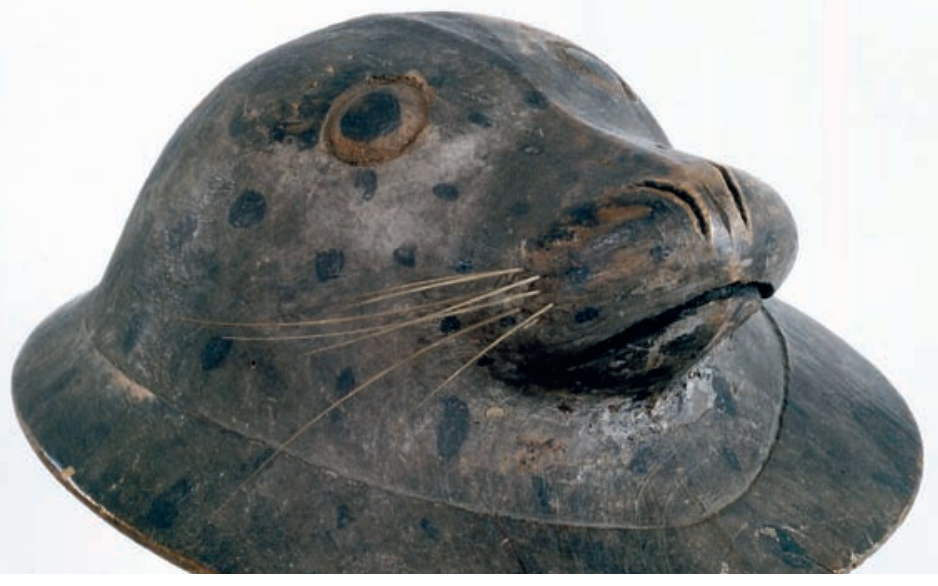

Costume mask of the Yaka (partial view), Angola. Context: initiation, jurisdiction and protection against spirits on burial grounds. Wood, plant fibres, height $98 \mathrm{~cm}$, acquisition: Sofie von Uhde, 1934
Anignak Seal hunter's decoy hat, Alaska (formerly Russian America), Prince William Sound. Headgear of this type was worn for seal hunting. Crafted in the form of a seal head, the headpiece transformed the wearer into a mighty huntsman, at the same time connecting him spiritually with the hunted animal. The pieces were crafted by a shaman, who furnished them with these powers. The headpieces were extremely rare as after the successful hunting season was over they were hidden in caves or destroyed. Wood, baleen, $32 \times$ $12 \mathrm{~cm}$, acquisition: Baron Georg Thomas von Asch, 1788/89 


\section{Asia - Ethnographic Collection}

Institute of Social and Cultural Anthropology, University of Göttingen

Theaterplatz 15 • 37073 Göttingen • www.uni-goettingen.de/ethnographic-collection

Kris (rotang binding, flamed damascened blade) with wooden sheath, Java, Indonesia. Length $40 \mathrm{~cm}$, acquisition: probably Christian Wilhelm Büttner, 1773; photograph: Robert Scheck
Cultural objects from eastern and south-eastern Asia form the backbone of the Asia Collection. Originally belonging to the private natural history collection of Göttingen naturalist Christian Wilhelm Büttner (1716-1801), these examples of chinoiserie and weapons, designated 'foreign objects of art', were purchased for the Academic Museum in 1773 by the Director of the University Library, Christian Gottlob Heyne (1729-1812).

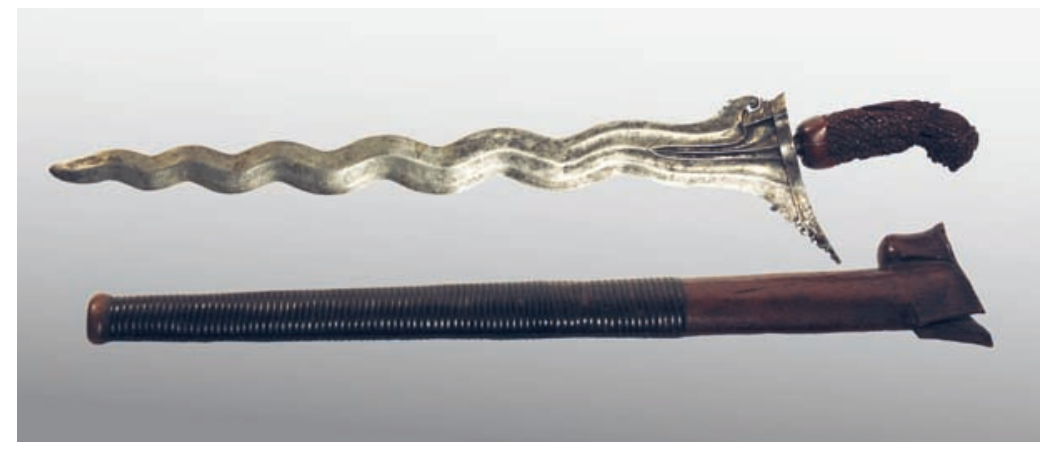

At approximately the same time, Heyne managed to arrange for the acquisition of extensive collections owned by the Russian medical doctor Baron Georg Thomas von Asch (1729-1807). As a result of Asch's close contacts with travelling researchers of the day, these donations, received between 1771 and 1807, contain items that are unique in the domain of cultural and natural history. The objects originate from the expansion areas
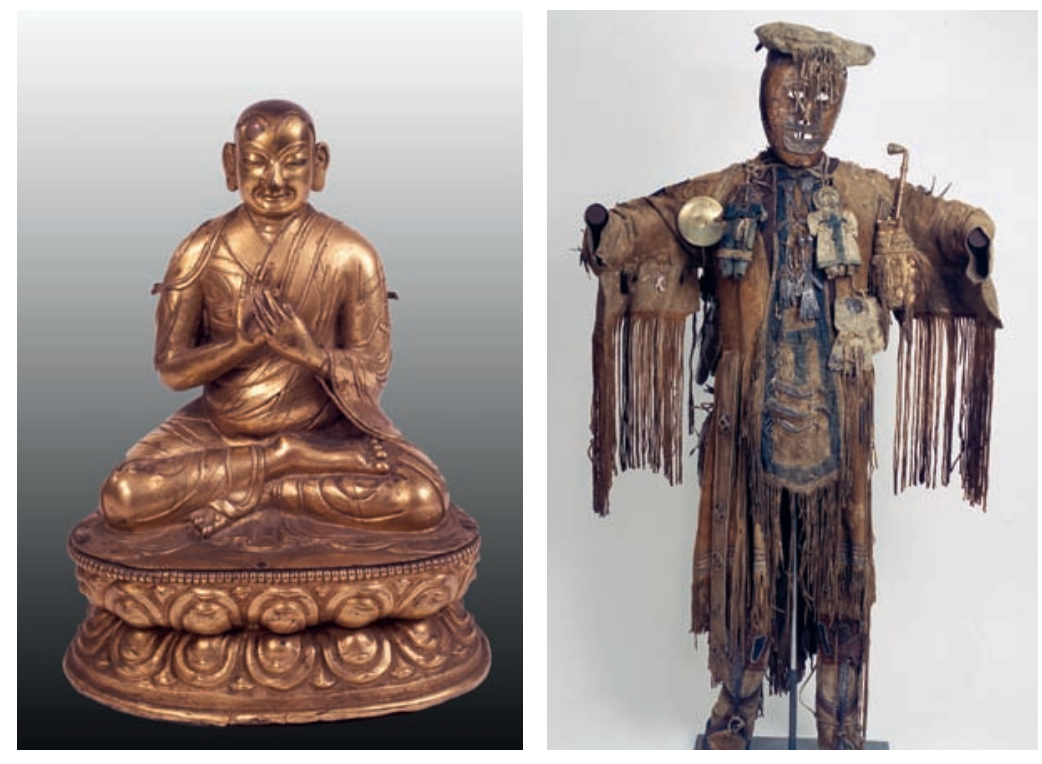

Lamaistic statue bla ma, Kalmyks, West Mongolian nomads. Context: Tibetan Buddhism. Gilded copper, height $20 \mathrm{~cm}$, acquisition: Baron Georg Thomas von Asch, 18th century; photographs: Harry Haase

Shaman's costume, Ewenks (Tungus), Siberia. Leather, iron, wood, plant fibres, fabric. Height 190 cm, acquisition: Baron Georg Thomas von Asch 


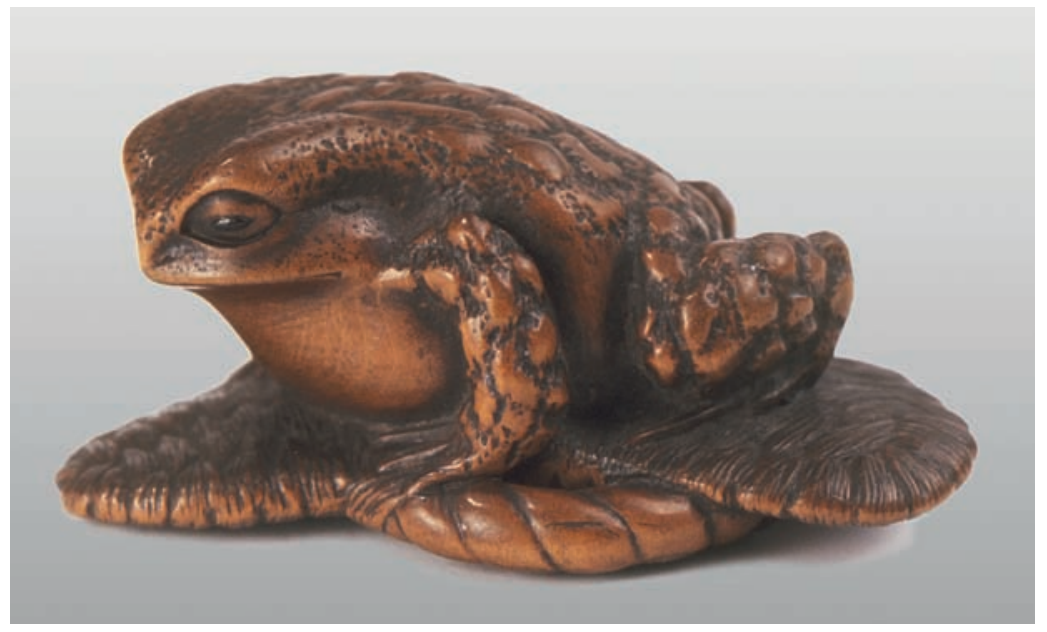

of the Russian Empire in Siberia and Russian America (today's Alaska, see the section on America), as well as from contact zones to China, Japan, Tibet and western Asia. A special focus of the Asch Collection, which consists of 181 ethnographical items, is the most extensive and oldest holding in existence worldwide of cultural and artistic objects from peoples of the Arctic. The items of daily life and ritual objects were collected in the period from 1785 to 1794 during the expedition of the Englishman Joseph Billings (1758-1806), who worked in the service of the Russian authorities. Among those taking part in this journey to the North Pacific, which was commissioned by Tsarina Katharina II, were German naturalists including Carl Heinrich Merck (1761-1799), Johann Gottlieb Georgi (1729-1802) and Peter Simon Pallas (1741-1811). The acquisition of valuable artefacts such as hunting equipment, textiles and items carved out of bone, from the Siberian Chukchi, Yamal and Yakut and the American Inuit peoples, and a Siberian shaman's costume of the Ewenks, can for the most part be traced back to these researchers.

The shrewd collecting policy of Johann Friedrich Blumenbach (1752 -1840) led to the Ethnographic Collection of the Academic Museum being enriched considerably during his term as curator, from 1776. Amongst the additions were valuable figural representations from the Hindu and Buddhist traditions, as well as scripts, pictures and amulets from the religious-social context of Southern and Eastern Asia.

From 1928, under the first Director of the Institute of Ethnography Hans Plischke (1890-1972), the Asia holdings grew rapidly. Numerous smaller mixed groups of items were obtained by purchase, exchange and donation. Among them are the Indonesian colonial period collections of Brunswick ruling Duke Johann Albrecht Heinrich zu Mecklenburg (1855-1920) and of the Göttingen church historian Carl Mirbt (1860-1929), and the collection of Japanese and Chinese art assembled by Claude du BoisReymond (1855-1925), a physician. Today, the Asia Collection consists of approximately 2,700 items.
Netsuke, belt fastening for kimono. Representation of a toad sitting on a sandal, root wood. The miniature sculpture $(2.3 \times 5 \mathrm{~cm})$ is by artist Ise Yamada Masanao, Japan, 19th century, acquisition: 20th century 


\section{Oceania (South Seas) - Ethnographic Collection}

Institute of Social and Cultural Anthropology, University of Göttingen

Theaterplatz 15 • 37073 Göttingen • www.uni-goettingen.de/ethnographic-collection

Feathered image ki'i hulu manu depicting Kuka'ilimoku, god of war. Hawaii, Polynesia, height $46.5 \mathrm{~cm}$, acquisition: Cook collection, 1782; photographs: Harry Haase

Wooden hook with ancestral depiction. Central Sepik region, New Guinea, 20th century, height 67 cm, acquisition: Hild, 1941

Mask as memorial to the dead, kepong, Malanggan festivals. Wood and plant fibres. New Ireland, Melanesia, height $75 \mathrm{~cm}$, acquisition: Wilkens/Kreibohm, 1887
The Oceania Collection has its roots in the three expeditions made to the South Seas (1768-1779/80) by the English Captain James Cook (1728-1779). During Cook's voyages, which took place on commission of the Royal Society to inform colonial policy and, in particular, to pursue goals in the domain of natural history, 2,000 ethnographical objects were assembled. Today, these are distributed among more than 40 museums and private collections. The majority of the items are from Polynesia (Gr.: 'World of Many Islands'), a region forming part of Oceania, and they were acquired in Tahiti and on the Society Islands, in the Island Kingdom of Tonga, on the Marquesas Islands and Easter Island, in New Zealand, and on the Hawaiian Islands.

In the Catologus Musei Academici (No. 39-41) drawn up in 1778 by Johann Friedrich Blumenbach (1752-1840), three ethnographical items from the South Seas region are listed, a piece of cloth made of bark, a fishbaiting lure, and a necklace. Today, these Polynesian cultural objects can be identified with certainty as the oldest objects in the possession of the former Academic Museum (1773-1840) to have originated verifiably from Cook's travels. They were brought to Göttingen from London via contact with the English naturalist Joseph Banks (1743-1820), a participant in the first of Cook's world voyages, shortly after his return. As a result, Blumenbach then took steps to acquire the large South Sea holdings known today as the Cook/Forster Collection. This remarkable assemblage of items was the outcome of amalgamating a royal donation by George III of Great Britain in 1782 with the estate of the German naturalist Johann Reinhold Forster (1772-1775), received in 1799. Together with his son Georg Forster (1754-1794), Reinhold Forster was invited to take part in Cook's second voyage (1772-1775). With its approximately 500 cultural objects
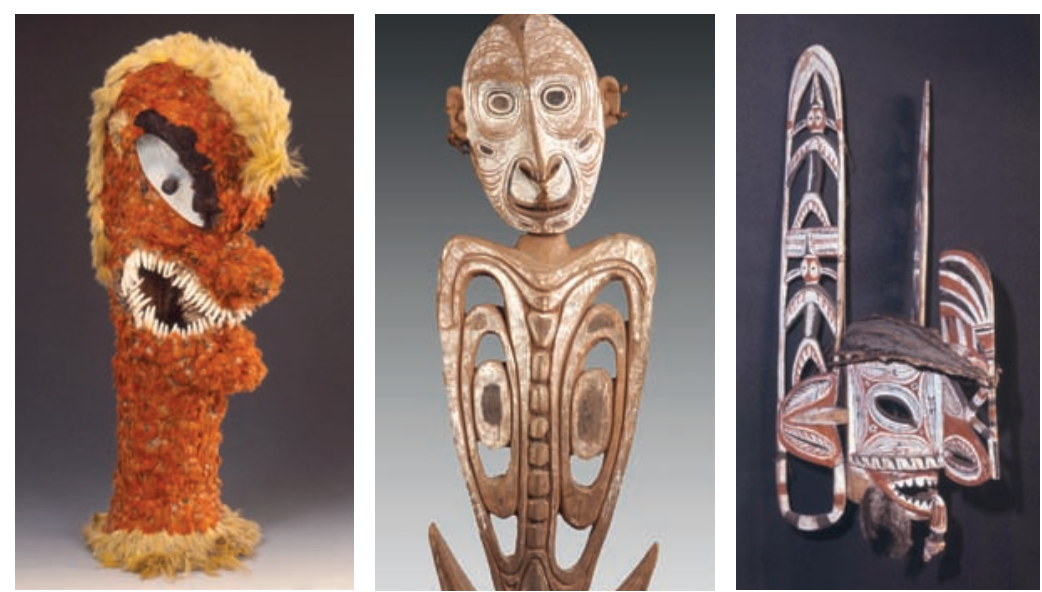


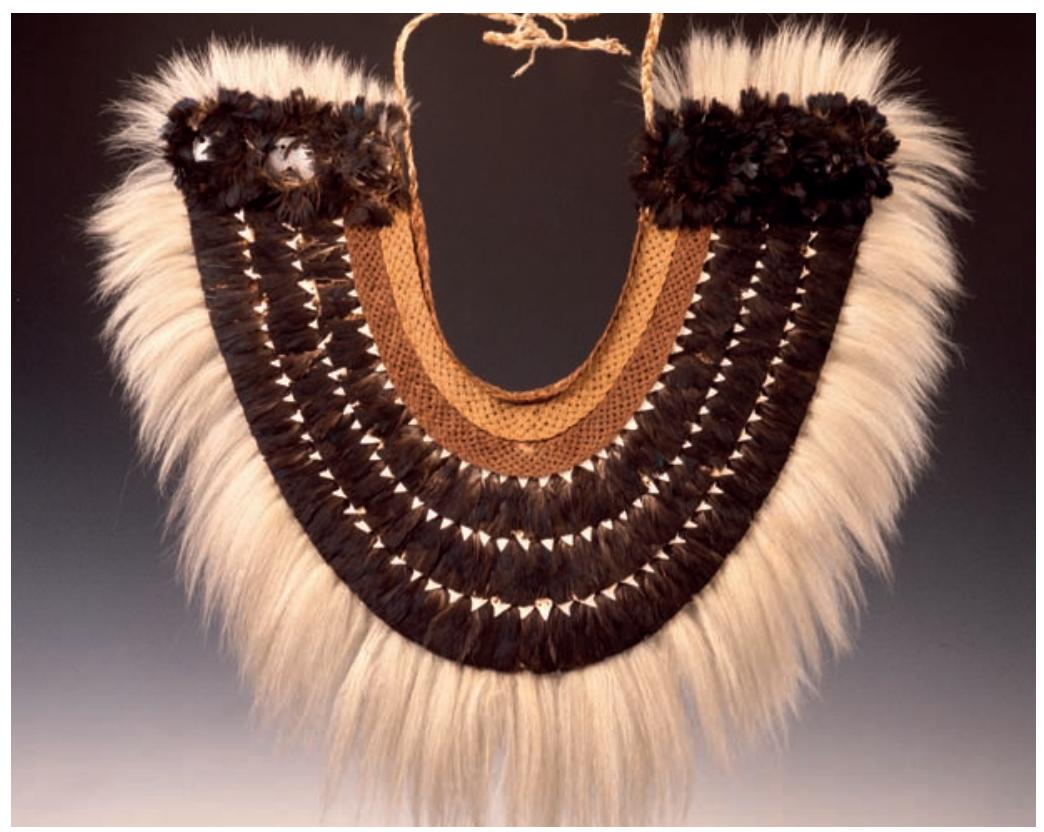

Breast ornament taumi symbolising respect for a warrior chief or priest. Weave of coconut fibre niu (cocos nucifera), with dog hair, mother-of-pearl, shark teeth and dove feather applications. Tahiti, Polynesia, $55 \times 52 \mathrm{~cm}$, acquisition: Cook Collection

from Polynesia and Melanesia, a second region of Oceania, and from the north-western coast of North America and southern coast of South America, Göttingen holds the most extensive Cook/Forster Collection in the world. At the heart of the collection are unique ritual objects and symbols of honour and respect arising from a social and religious life as yet completely untouched by European influence.

Extensive collections from the turn of the 19th/20th century supplement the initial historical holdings dating from the 18th century. These later additions consist on the one hand of items systematically collected by individual researchers on their travels or by participants in the German expedition to the South Seas (1908-1910) and the Sepik expedition (1912-1913), and, on the other, heterogeneous bequests, donations and purchases from mariners, adventurers, colonial civil servants and great trading houses such as Godeffroy in Hamburg. These acquisitions originate from the former German colonies of New Guinea and the Bismarck Archipelago, from Micronesia, the third region making up part of Oceania, and from the Polynesian group of Samoa islands, as well as from Australia. More recently, scientifically documented collections have been assembled over the past 60 years as representations of regional or local culture. These were undertaken in the course of ethnographic fieldwork (Gerd Koch: Samoa, Tonga, Tuvalu and Kiribati; Erhard Schlesier: Normanby Island, Southeast New Guinea; Hanns Peter: Gargar, Central New Guinea), or throw light on artistic traditions (Renate v. Gizycki: Samoa and Tonga; Brigitta Hauser-Schäublin: Abelam in New Guinea). Together with the objects, which number some 4,300, they provide an outstanding basis for the investigation and understanding of cultural transformation processes in various regions of Oceania. 


\section{America - Ethnographic Collection}

Institute of Social and Cultural Anthropology, University of Göttingen

Theaterplatz 15 • 37073 Göttingen • www.uni-goettingen.de/ethnographic-collection

Breast ornament, Mapuche, Valdivia, Chile. Silver, hammered and engraved, $6 \times 5.2 \mathrm{~cm}$, acquisition: Otto Bürger, 1903; photographs: Harry Haase

Portrait of Mikak (c. 1740-1795), Eskimo woman from Nain, Labrador region, eastern Canada, with her son Tutauk. She was an important intercultural communicator at the missionary base of the Herrnhut Brethren. Oil painting by John Russel, 1769. Acquisition: Johann Friedrich Blumenbach, 1797, gift from Joseph Banks
The America Collection encompasses a broad regional spectrum of objects from Alaska in the extreme north to Tierra del Fuego on the southern tip of South America. The oldest items, dating from the 18th century, are from the collection of Baron von Asch and the Cook/Forster Collection. They originate from Indian ethnic groups of the North American northwest coast and from the Arctic Inuit (Eskimo) and Aleut peoples. In line with the fundamental significance of maritime resources in this context, numerous objects present here are associated with marine mammal hunting and fishing.

Ornate carvings in walrus ivory crafted by Eskimo people of Labrador found their way to Göttingen via the physicist Karl Richard Koch (1852-1924). In $1882-1883$ he carried out meteorological studies on the coast of Labrador, and while doing so also prepared documentation on the life of the Eskimo people settled there. The presence of numerous ceramics of the Hopi Indians from the southwest region of the USA can be traced back to the Göttingen physiologist and prehistorian Max Verworn (1863-1921). These ceramics carry strongly emotive graphic elements and appear to have been collected by Verworn in connection with his studies on 'primitive art'. In 1880, the Institute acquired numerous objects originating from the Klamath people out of the collection of Swiss-born naturalist Alphonse Forrer (1836-1899). This people, resident in south-western Oregon, was reputed for their basketwork, and as a whole the collection offers unique insights into the everyday culture of the ethnic group at this time.

The splendid highlight of the South America holdings is the intensely colourful feather headgear from the Gran Chaco, the south Amazonian and
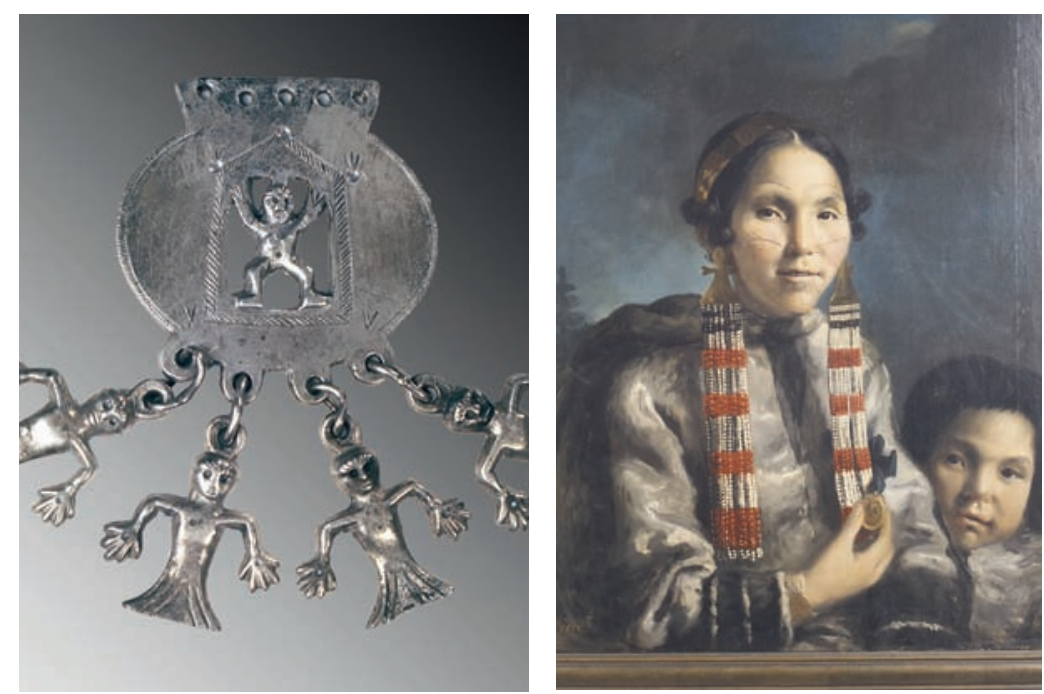


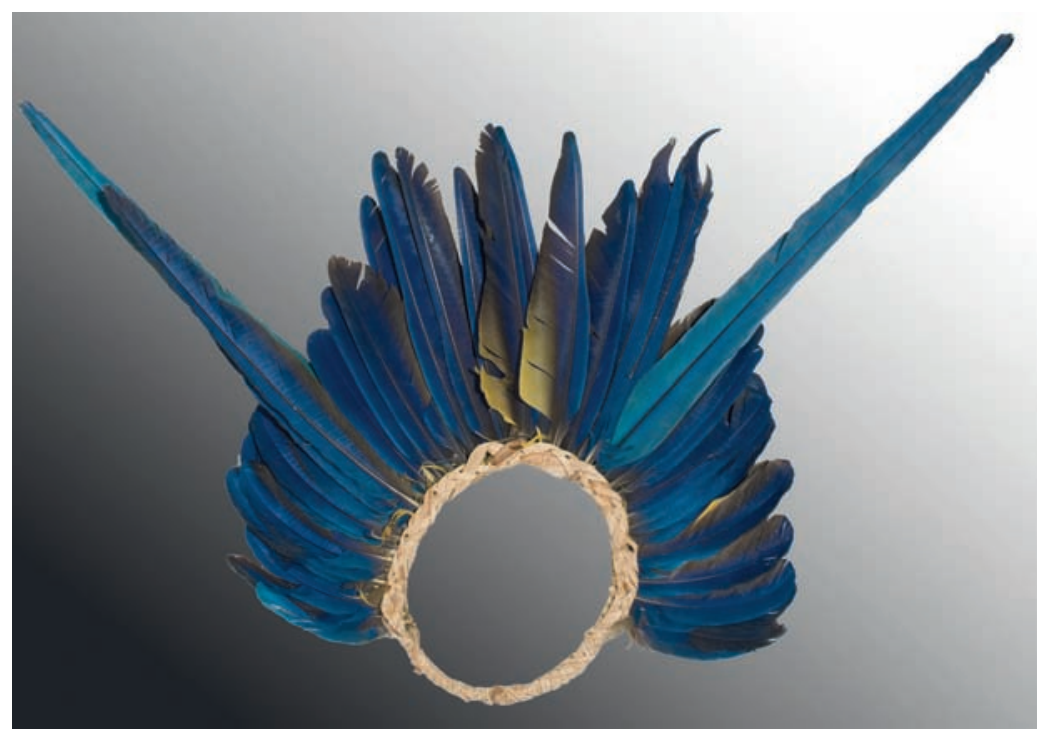

Feather crown of the Irantxe, Mato Grosso, Brazil. Sign of rank, length $66 \mathrm{~cm}$, acquisition: Fritz Toksdorf, 1961; photograph: Robert Scheck

the Rio Xingú regions. The earliest of these holdings is made up of Enlhet or Lengua objects from Paraguay acquired in 1894 by Jan Bohl (1863-1959), a Göttingen zoologist. A further group of items, Chama, Campa and Piro artefacts from the Rio Ucayali region in Peru, concerns a highly significant aspect of the collection's acquisition history. Together with other objects, these feather artefacts, formerly amongst the holdings of the museum in the Polish town of Lódz, were brought to Göttingen in 1942. The entire collection has been registered for several years as art looted by the Nazis listed in the 'Lost Art' online database, thereby making it available for negotiations concerning its return.

In the 1950s and 60s, Fritz Tolksdorf (1912-1992), a Brazilian with German roots, carried out field research in the Rio Xingú and Rio Araguaia regions. He accumulated a collection of more than 300 objects including numerous feather artefacts representing the material culture of local indigenous groups such as the Canoeiro (Canoe People) or Erigbaksta and the Irantxe. A further group of items significant for its historical dimension is the collection of silver jewellery of the Mapuche from central Chile collected by Otto Bürger (1865-1945), a zoologist and board member of the State Museum in Santiago de Chile. Until the 19th century, the Mapuche successfully withstood numerous conquest attempts, thereby preserving their cultural identity over a considerable period. Today, the America Collection constitutes the largest regional holding of the Institute of Social and Cultural Anthropology and in its entirety it displays a remarkable cross-section of collecting and acquisition history.

Insa Wendt 


\section{Africa - Ethnographic Collection}

Institute of Social and Cultural Anthropology, University of Göttingen

Theaterplatz 15 • 37073 Göttingen • www.uni-goettingen.de/ethnographic-collection

Sickle knife, Central African Republic. Context: ceremonial weapon of threat, bride token, bartering currency. Iron, wood, length $38 \mathrm{~cm}$, acquired from: Museum für Völkerkunde Leipzig, 1942; photographs: Harry Haase

Yombe power figure, Congo. Context: healing of the sick and defensive magic (so-called nail fetish). Wood, iron nails, twine, height $64 \mathrm{~cm}$, collector following Andreas Schlothauer: Robert Vissel, 1896-1904, acquired from: Museum für Völkerkunde Berlin, 1939
The earliest holdings of the Africa Collection date back to colonial times and were assembled during the second half of the 19th and early 20th centuries. But the majority of Göttingen's objects from Africa were not acquired until later, when ethnographer Hans Plischke (1890-1972) was active in this field. He was the first incumbent of the Chair of Ethnography at the University of Göttingen, taking up the position in 1934. Plischke's intensive contacts to museums, in particular the Museums of Ethnology in Berlin (1939) and Leipzig (1942/43), and his close connections with Arthur Speyer (1894-1958), a notable collector of ethnographical items, resulted in the acquisition between 1928 and 1959 - through purchase or exchange transactions - of valuable sculptures originating from Africa. Among them are works of art originating from the Congo region collected by the Berlin ethnographer Adolf Bastian (1826-1905) during the German Loango expedition of 1874, and masks of the Makonde from Tanzania. The latter collection can be traced back to an expedition by the Leipzig anthropologist Karl Weule (1864-1926) during the period 1906/07. Also worthy of mention is a memorial bust of an Edo Queen from the Kingdom of Benin that was originally plundered in the course of an English 'punitive expedition' in 1897 and hence may today be regarded as 'lost art'.

After World War II, Africa emerged as one of the major research foci at the Institute for Ethnography, alongside Oceania. Over the past half a century, highly regarded collections have been systematically
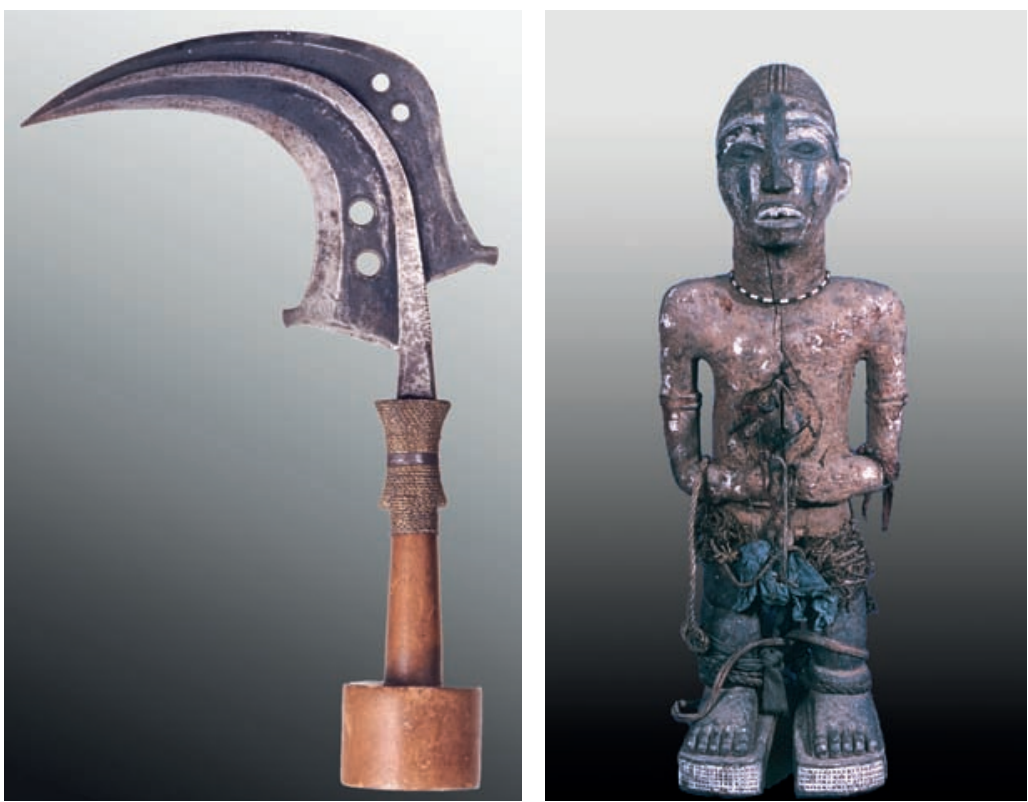


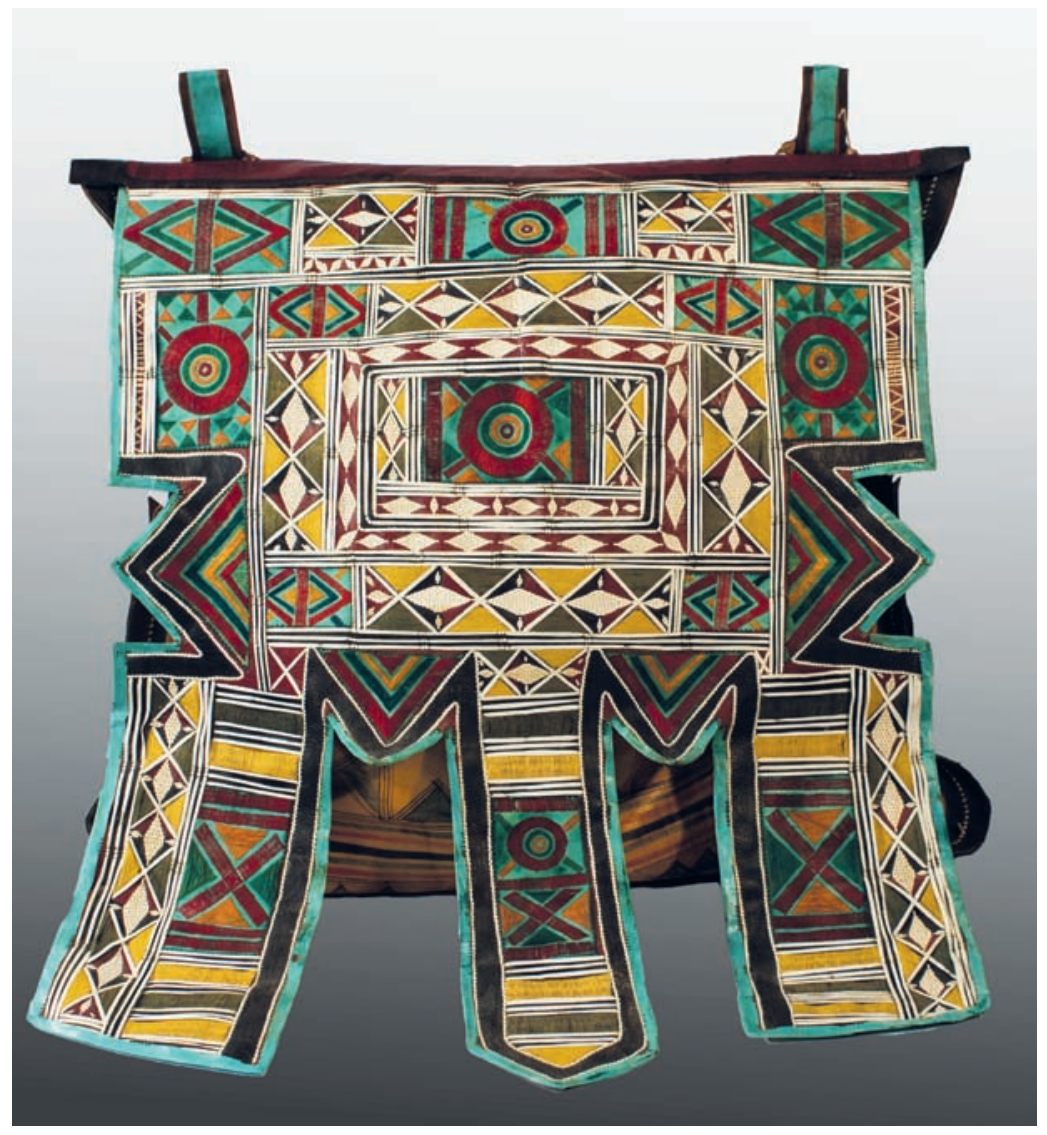

Saddlebag, Tuareg Kel Air, Agades, Niger. Goat leather, embellished with leather and cotton yarn applications, $76 \mathrm{x}$ $72 \mathrm{~cm}$, acquired by Peter Fuchs, 1977; photograph: Robert Scheck

assembled for Göttingen in the scope of several ethnographic field studies. These collections include portfolios unique worldwide for their comprehensiveness relating to indigenous groups in Chad, Sudan, Niger, Mauretania (collection of Peter Fuchs) and Ethiopia (collection of Ivo Strecker). Furthermore, smaller collections focussing on specific research topics have been added, complementing items relating to material culture already present in the collection. These include targeted acquisitions in the household, handicrafts, production, market and trade contexts collected by the cultural anthropologists Ulrich Braukämper (Ethiopia, Sudan, Nigeria) Editha Platte (Nigeria), and Werner Jopp (Namibia), as well as handicraft items from the creative tradition of Ethiopia collected by Brigitta Benzing. Today, equalling in size the South- and North-America Collection, the Africa Collection with its total of 4,800 objects belongs to Göttingen's most extensive ethnographical holdings. 


\section{Collection of Musical Instruments}

Department of Musicology, University of Göttingen

Kurze Geismarstraße 1 • 37073 Göttingen • www.uni-goettingen.de/musical-instruments-collection

Vielle à roue, French hurdygurdy with bowl corpus, 'buzzing bridge', two melody strings, four drone strings and four resonance strings, built by Jean-Baptiste (I) Pajot in Jenzat, Bourbonnais, southern central France, before 1863; photograph: Klaus-Peter Brenner

\section{Established: 1964}

Number of items: c. 1,900

Public exhibition: yes

Open: Sun. 10:00 - 16:00

Admission: $€ 3$, red. $€ 1.50$, children up to 7 free

Tours: by appointment

\section{Contact:}

Dr. Klaus-Peter Brenner Tel.: +49 551 39-5075

k.p.brenner@phil.uni-goettingen.de
Set up in 1964, the teaching and research collection at Göttingen University's Department of Musicology is one of the largest of its kind in Germany. Its holdings, broadly based in typological, historical and culture-geographical respects, encompass musical instruments from throughout the world, but the instruments originate predominantly from Europe, Asia and Africa (including Ancient Egypt). It was Heinrich Husmann (1908-1983) who established the collection by initiating the purchase of the private collection of Hermann Johannes Moeck (1896-1982) from Celle. Previously, other important collections including that of Hans Hickmann (1908-1968) from Cairo/Hamburg had already been incorporated into Moeck's. Since then, the nonEuropean holdings, in particular, have grown very substantially as a result of targeted purchases and loans, and the collection has been augmented particularly by field research collections assembled by Felix Hoerburger (1916-1997), Kurt Reinhard (1914-1979) and Ursula Reinhard (1915-2006), Rudolf Brandl (b.1943), and Klaus-Peter Brenner (b.1958). The European holdings were also expanded, notably through the collections of Martin Staehelin (b.1937) and Hermann Alexander Moeck (1922-2010), for example.

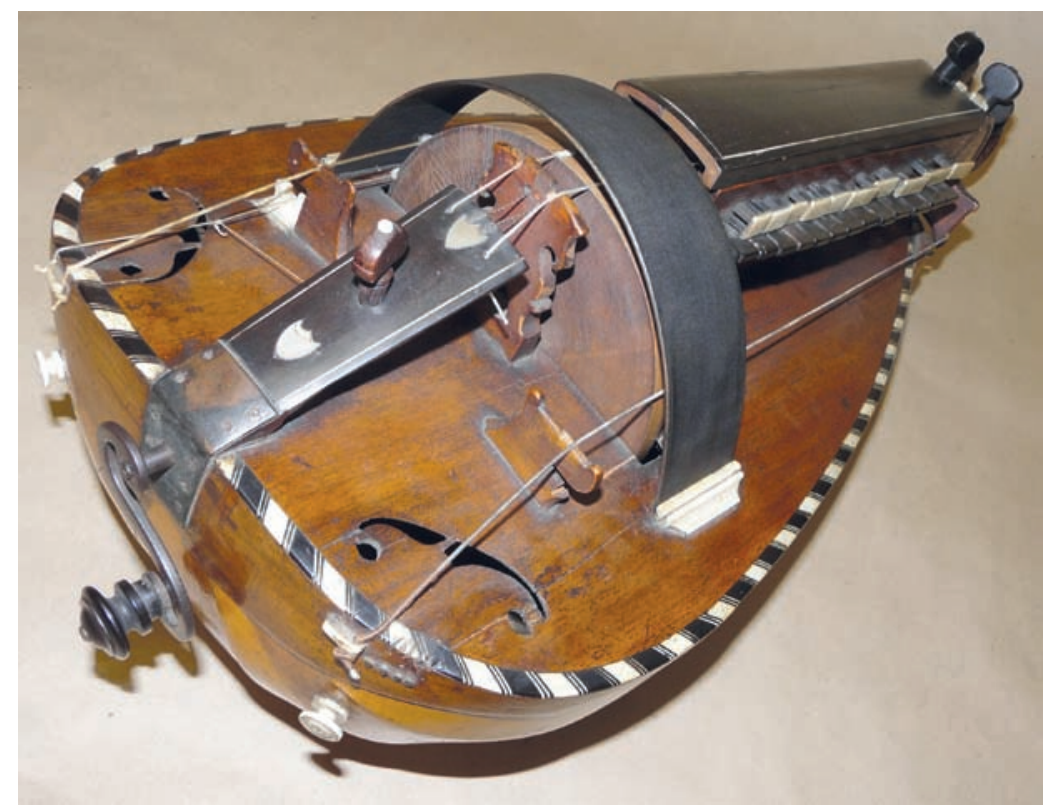

Among the exhibits are the 14th century recorder unearthed in Göttingen (on loan from the Göttingen Municipal Department of Archaeology), one of only seven extant 'Coptic lutes' (c. 3rd to 8th 


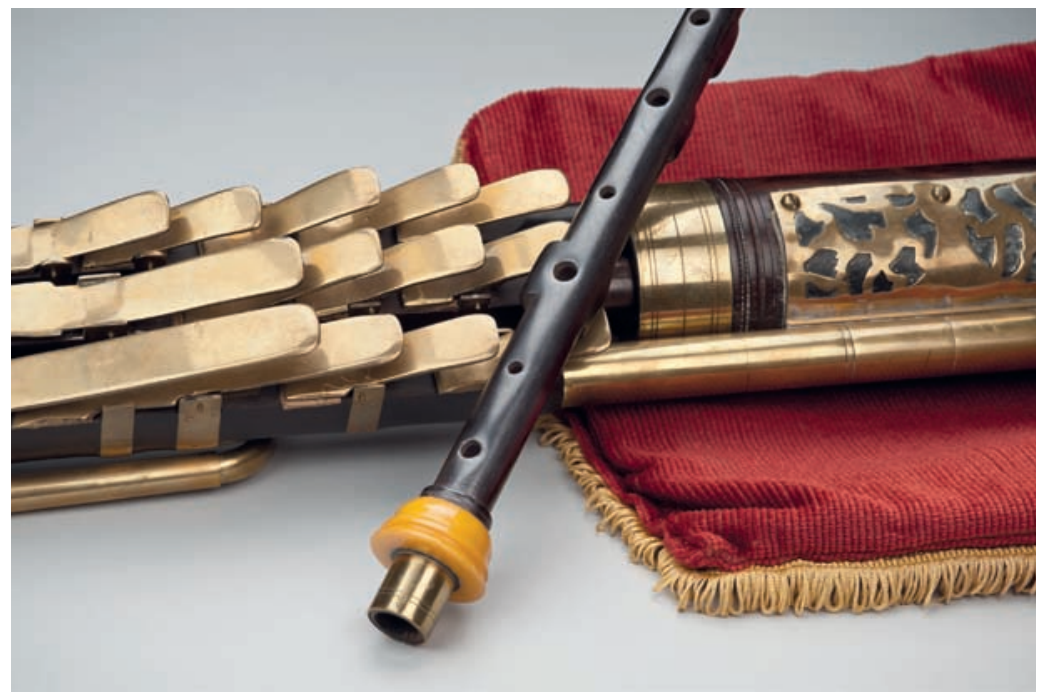

century AD), and an Ancient Egyptian arched harp (between 2,700 and 2,200 $\mathrm{BC}$ ) presumed to be the oldest surviving specimen of its kind. The complete inventory catalogue is available online. The collection's holdings and research profile reflect the fruitful collaboration between the three branch disciplines of Historical Musicology, Systematic Musicology and Ethnomusicology - manifested in Göttingen today as Historical, Social and Cultural Musicology.

Klaus-Peter Brenner

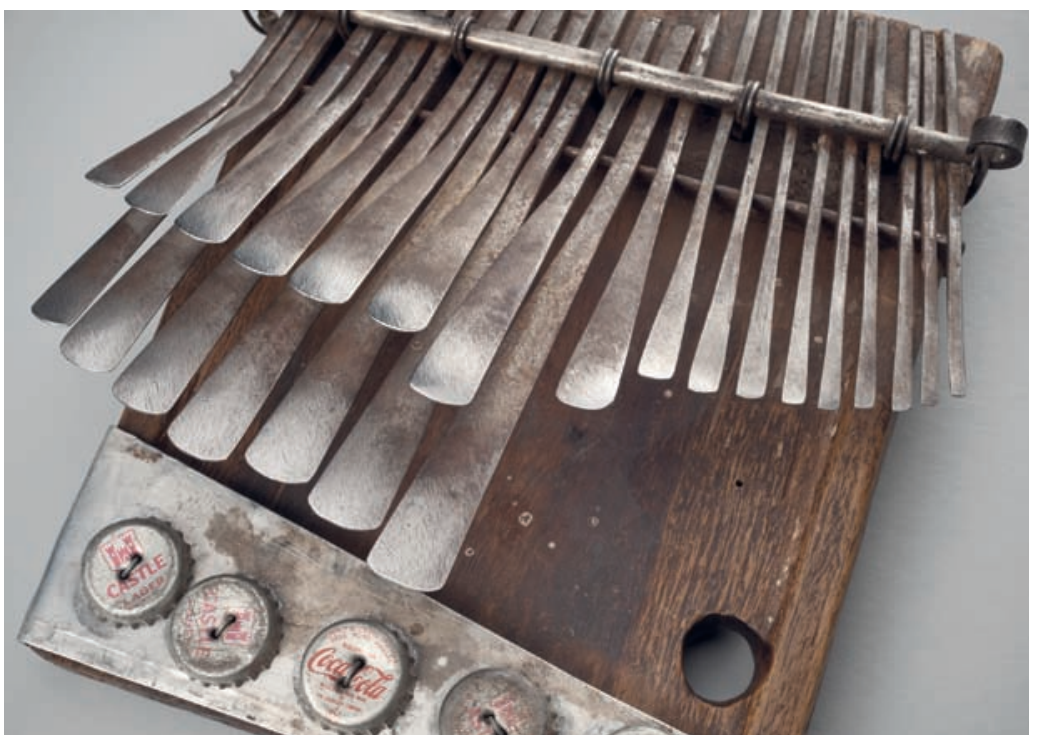

Close-up view of the Full Set of Uilleann Pipes, an Irish set of bagpipes consisting of the typical combination of a chanter similar to the Baroque oboe, with three drones and three regulators, built in Dublin in 1984 by Joe McKenna; photographs: Stephan Eckardt
Mbira dzaVadzimu, a specimen of the type of lamellophone commonly used in the ancestral cult tradition of the ZezeruShona people of north-eastern Zimbabwe, built c. 1980 by Rhinos Mukuwurirwa Simboti in Harare/township Mufakose, Zimbabwe 


\section{Collection of Historical Books for Children and Young Adults}

Department of German Philology • Didactics of German Language and Literature, University of Göttingen Room 0.143/0.147• Waldweg 26 • 37073 Göttingen • www.uni-goettingen.de/young-library

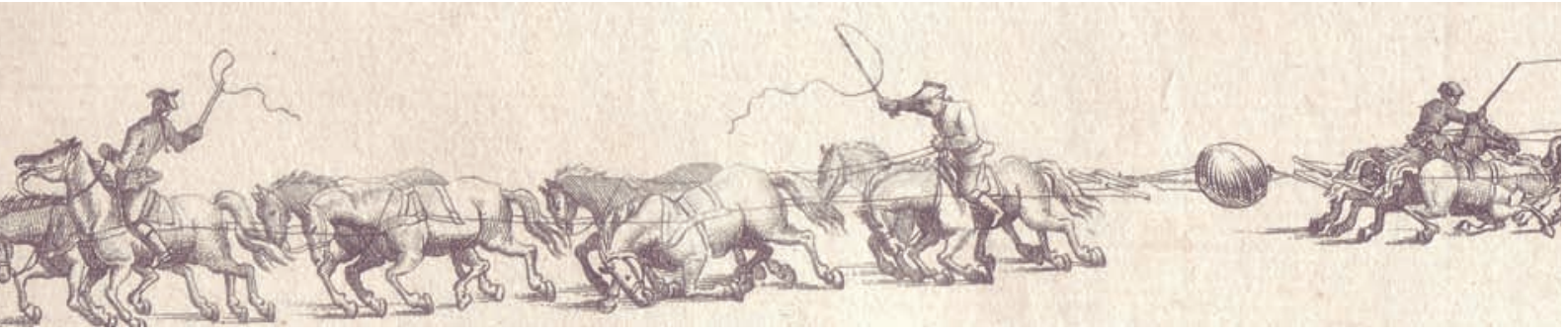

Set of copperplate engravings for Johann Bernhard Basdow's Elementarwerke für die Jugend und ihre Freunde (Elementary Books for the Young and Their Friends). Daniel Chodowiecki, Berlin et al, 1774, plate LXXXVIII, detail; photographs: Martin Liebetruth

\section{Established: 1960s}

Number of items: c. 16,000

Public exhibition: no

Open: by appointment

Tours: by appointment

\section{Contact:}

Prof. Dr. Christoph Bräuer Tel.: +49 551 39-21469

bibliothek.kjl@phil.uni-goettingen.de
It is extremely rare for books for children and young people to be the focus of collections at university libraries, which explains why sources on the culture of children's literature of past centuries are not widely available. But the University of Göttingen holds two such collections of historical works for children and young people, the Vordemann and Seifert Collections, as well as the Dahrendorf Library, and further extends its holdings of contemporary literature for children and young adults on an ongoing basis.

The Vordemann Collection, which was received by the university as a donation in the 1960s, goes back to the Einbeck protestant church superintendent Karl Vordemann (1850-1931). Consisting of approximately 1,000 volumes, the collection is remarkable not for its size but for the fact that it covers a period of some 200 years up to World War I, bringing together philanthropic literature, rare nature study textbooks and literature of the 19th century. In 2008, the Department of German Philology further acquired the Seifert Collection, an assemblage of very high value in academic terms and one of the most significant of its kind in the German-speaking world. Some 11,500 books covering the entire range of children's literature reflect its development from the very beginnings up to the early 1990 s. We owe the collection's unique quality above all to the collecting passion of Jürgen Seifert (1928-2005), Professor of Political Science in Hanover, who acquired not only beautiful volumes but also items of mass production, such as magazines. In line with Seifert's professional interests, one focus of the collection is literature for children and young people influenced by proletarian and National Socialist thinking.

Summer 2012 saw the further acquisition of the working library of German studies educationalist Malte Dahrendorf (1928-2008), authoritative scholar on books for the young. Complete with Dahrendorf's handwritten notes, this collection includes some 3,000 items of primary and research literature documenting writing for children and young adults and its research over the past 80 years. 

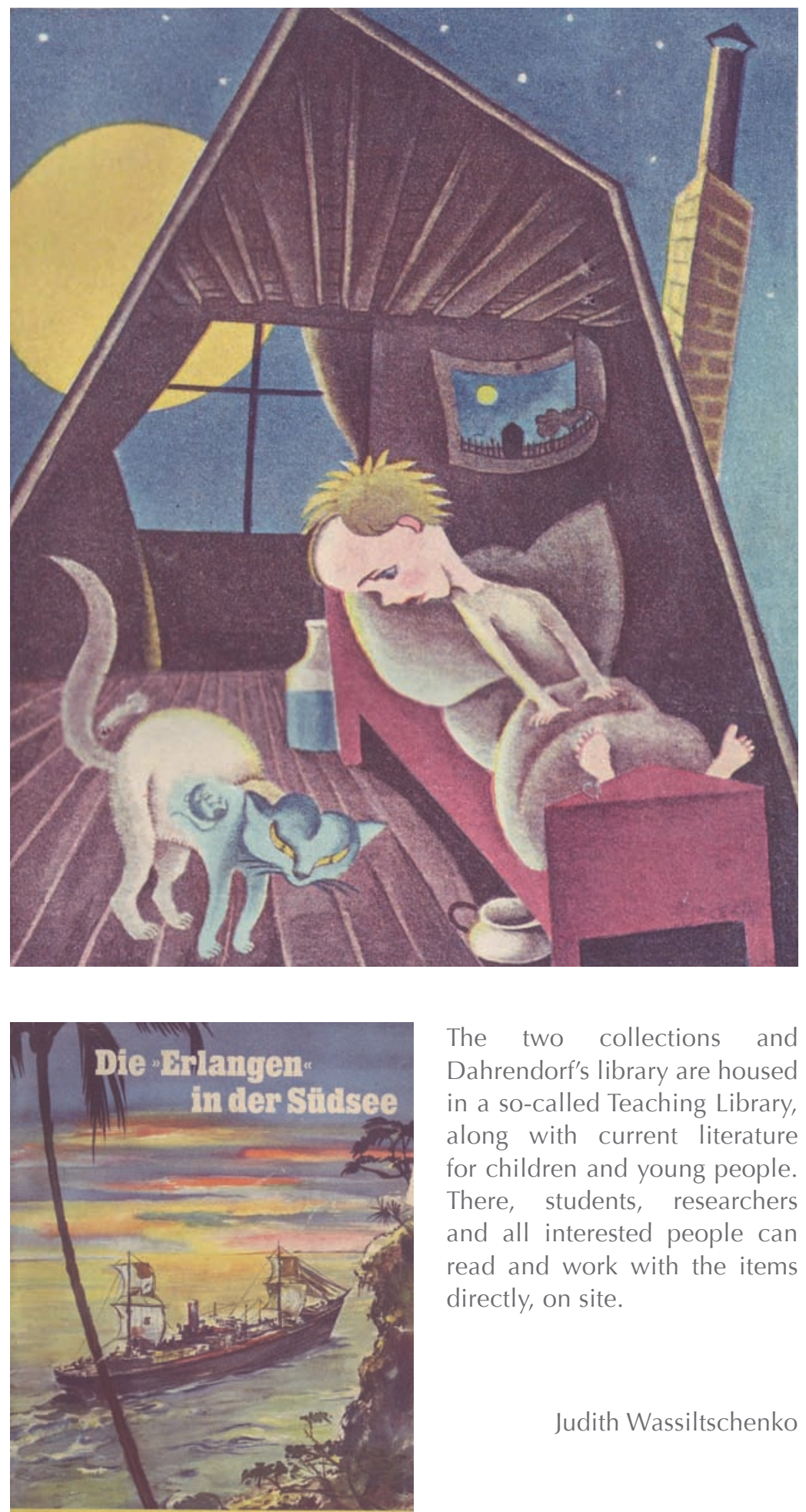

The two collections and Dahrendorf's library are housed in a so-called Teaching Library, along with current literature for children and young people. There, students, researchers and all interested people can read and work with the items directly, on site.

Judith Wassiltschenko
Béla Balázs: Das richtige Himmelblau (The Right Sky Blue). With 3 colour plates and 30 drawings by Tibor Gergely, Munich 1925, p. 9

Die 'Erlangen' in der Südsee Ohne Kohlen nach Chile (The 'Erlangen' in the South Seas - to Chile without coals). After the authentic records of the captain, freely retold by Wendelin Brugg. Kolonial-Bücherei, issue 3, Berlin c. 1940 , cover page; photograph: Judith Wassiltschenko 


\section{The Heinz Kirchhoff Collection - Symbols of Femininity}

University Medical Center Göttingen

Floor 0, Elevator B2 • Robert-Koch-Straße 40 • 37075 Göttingen • www.kirchhoff-sammlung.de

Weight depicting a birth scene, used to weigh out gold dust. Ethnic item of the Ashanti people, Ghana, brass, probably an artistic reproduction; photographs: Stephan Eckardt
Established: 1958

Number of items: 650

Public exhibition: yes

Open: throughout the day

Admission: free

Tours: by appointment

\section{Contact:}

Dr. Anita Schmidt-Jochheim info@kirchhoff-sammlung.de
The Heinz Kirchhoff Collection differs from other university collections in that it was assembled by one single collector only, gynaecologist Prof. Dr. Heinz Kirchhoff (1905-1997), Director of the Göttingen University Women's Hospital from 1954 to 1973. The collection is not designed to document a specific scientific issue or area, but is a unique assemblage of objects and statuettes demonstrating the many and diverse facets of femininity.

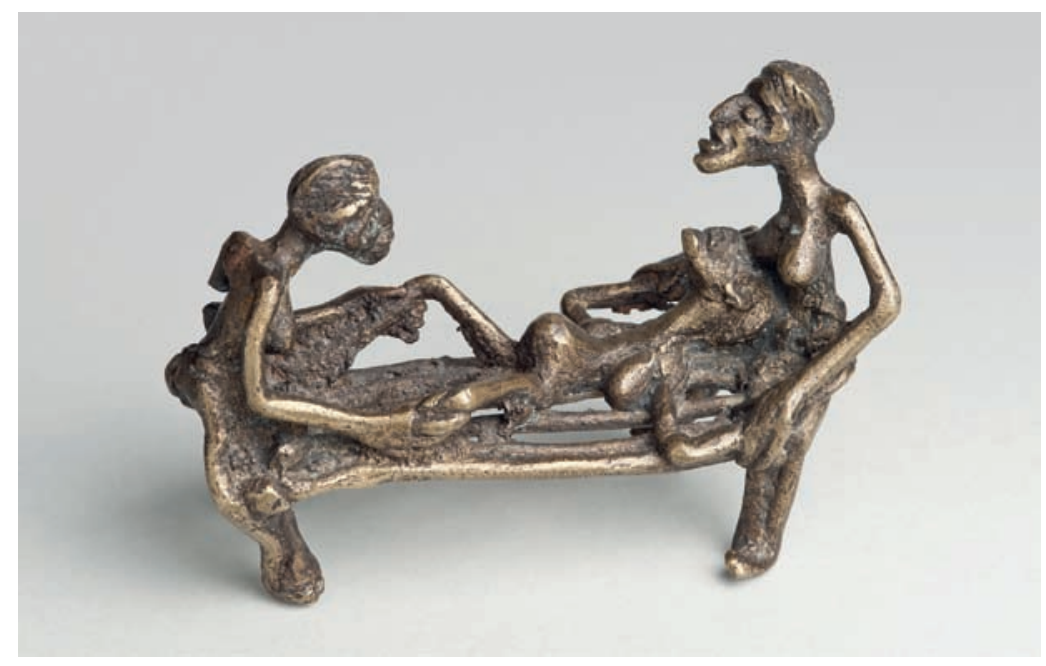

Motivated by the goal of achieving as complete a collection as possible ranging from the Stone Ages to the present day and encompassing different cultures, Kirchhoff went about accumulating his statuettes of women representing - in cultural form - the themes "Woman, mother goddess, fertility idol, maternity" from the late 1950s onwards. For him, what counted was the aesthetic presence of the figures and, above all, their connotations.

By presenting these figures as an exhibition with museum character, he sought to represent the great significance of women not only as the primaeval symbol of human life, but also demonstrating women's differing roles and hence the esteem in which they are held in each individual society. Combined with this was, in Kirchhoff's own words, "the wish, by demonstrating the diversity of historical and global examples of esteem or honour for the female sex, to make a contribution 


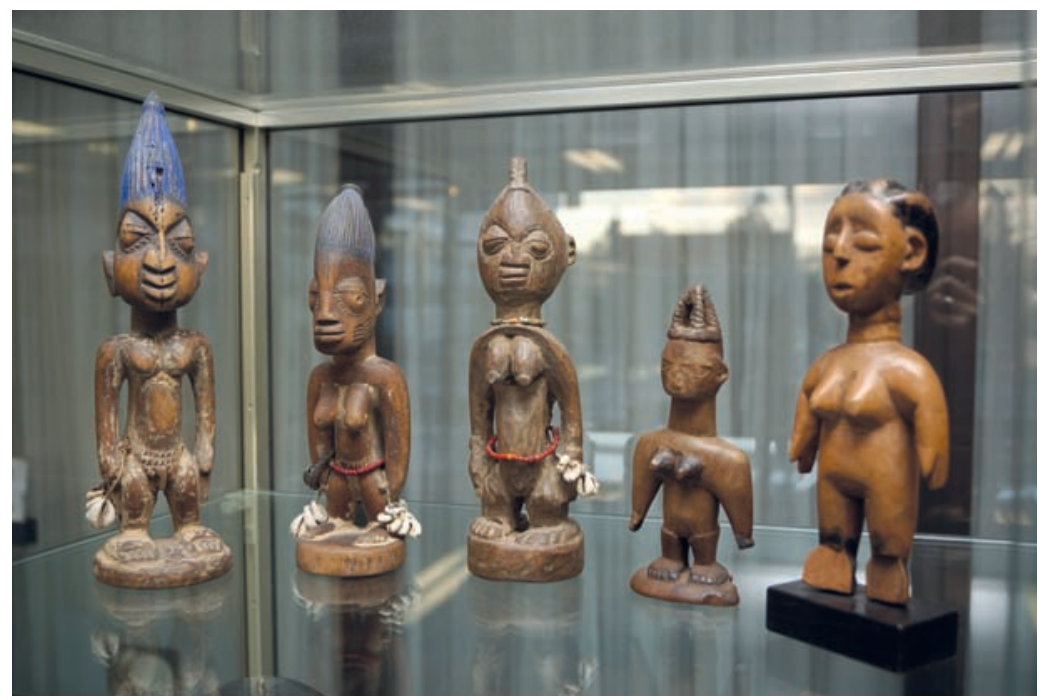

not only to reducing the unquestionable underestimation of the woman vis-à-vis the man that still exists today in spite of moves towards change, but to overcome it at last. (...) Achieving equality, equal respect and appreciation of women in every form, and creating the partnership that can only be developed in this way, belongs to the future."

The collection, parts of which are on display in the University Hospital, consists of some 650 objects, approximately half of them originals and the remainder museum replicas. Some of the items were purchased, while others were received as donations.

Adelgund Emons

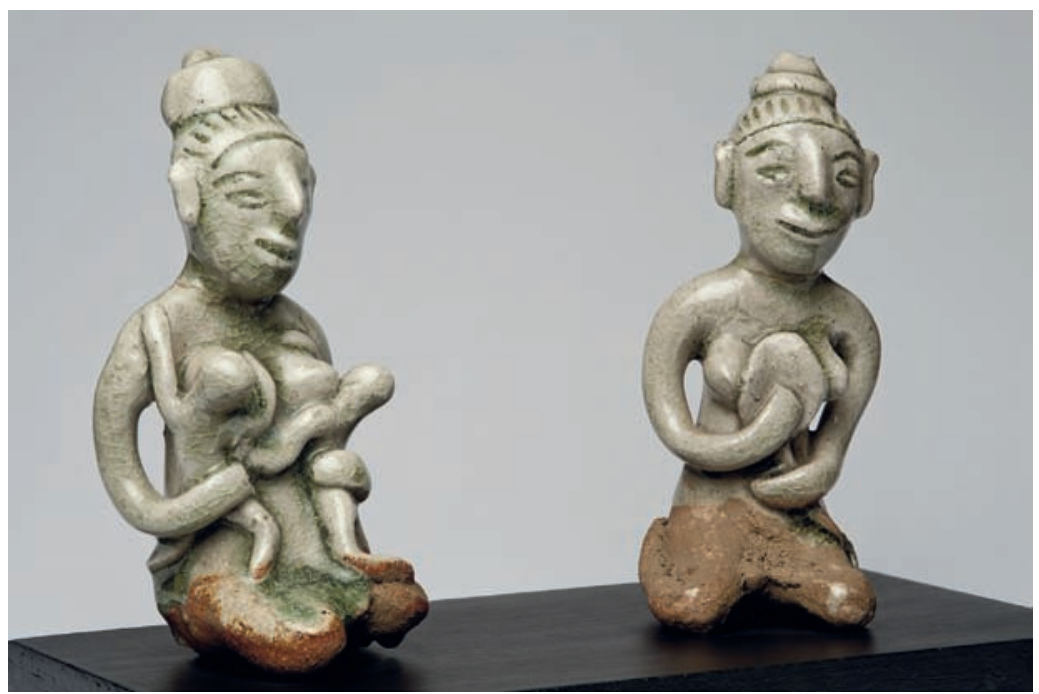

A view of the permanent exhibition showing carved African twin statuettes of the Ewe and Yoruba peoples of Togo and Nigeria. Meaning: if one twin dies in infancy, his or her memory lives on in the figure, which is honoured and cared for. Photograph: Frank Stefan Kimmel
Two glazed terracotta figures from Sawankhalok, northern Thailand, depicting nursing mothers. These figures were 'decapitated' and laid in the bed of the mother-to-be to fend off demons. After a successful delivery, the head was reattached. 


\section{Collection on the History of Obstetrics}

University Medical Center Göttingen - Department of Medical Ethics and History of Medicine Humboldtallee 36 • 37073 Göttingen • www.uni-goettingen.de/obstetrics-collection

The forceps, consisting of two separate spoons fixed into a lock, essentially remained unchanged over time. Models were developed with certain minor modifications, such as that after Franz Karl Naegele (1778-1851), left, or Adam Elias von Siebold (1775-1828), right; photograph: Ronald Schmidt

\section{Established: 1791}

Number of items: c. 1,200

Public exhibition: yes

Open: Mon. to Fri. 9:00 - 12:00 and by appointment

\section{Admission: free}

Tours: by appointment

\section{Contact:}

Kornelia Drost-Siemon Tel.: +49 551 39-9007, -9006 kdrost@gwdg.de
On the initiative of Albrecht von Haller (1708-1777), the institution that was probably the world's first University Clinic for Obstetrics came into being in Göttingen in 1751. Forty years later, the clinic was moved to a new building erected especially for the purpose in Geismarstraße 1, premises that today house the Department of Musicology. At the Accouchierhaus (House of Obstetrics), as it was called, scientific work was carried out in an area documented by a collection of specimens that can be traced back as far as Clinic Director Johann Heinrich Fischer (1759-1814).

This set of specimens formed the starting point for the impressive collection developed in particular by the famous Accouchierhaus Directors Friedrich Benjamin Osiander (1759-1822) and Eduard Kaspar Jakob von Siebold (1801-1861). Inventories and catalogues dating from the 18th century and still in existence today provide striking evidence of the extent of the collection, which in its heyday consisted of more than 5,000 objects.

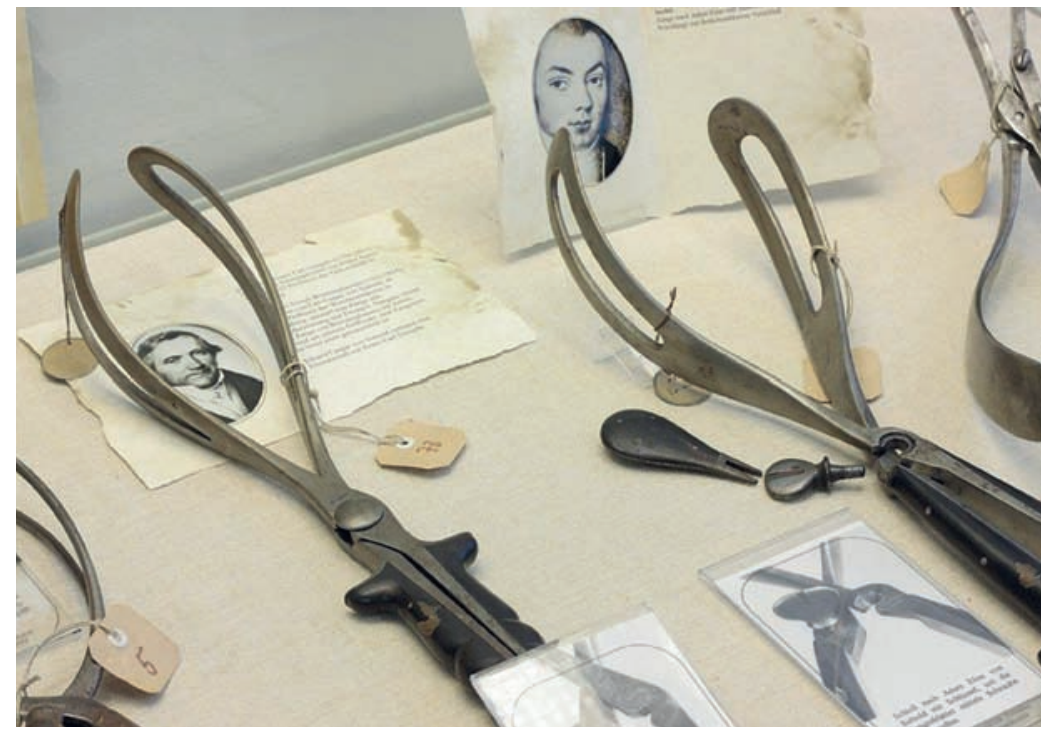

In 1995, a representative sample of the collection's now approximately 1,200 objects was selected for permanent display at the Department of Medical Ethics and History of Medicine. Amongst these exhibits are models of birthing chairs and birthing beds, obstetrical instruments including forceps and levers developed by famous obstetricians, demonstration models for clinical teaching, and items used in puerperal nursing, in particular by midwives. 


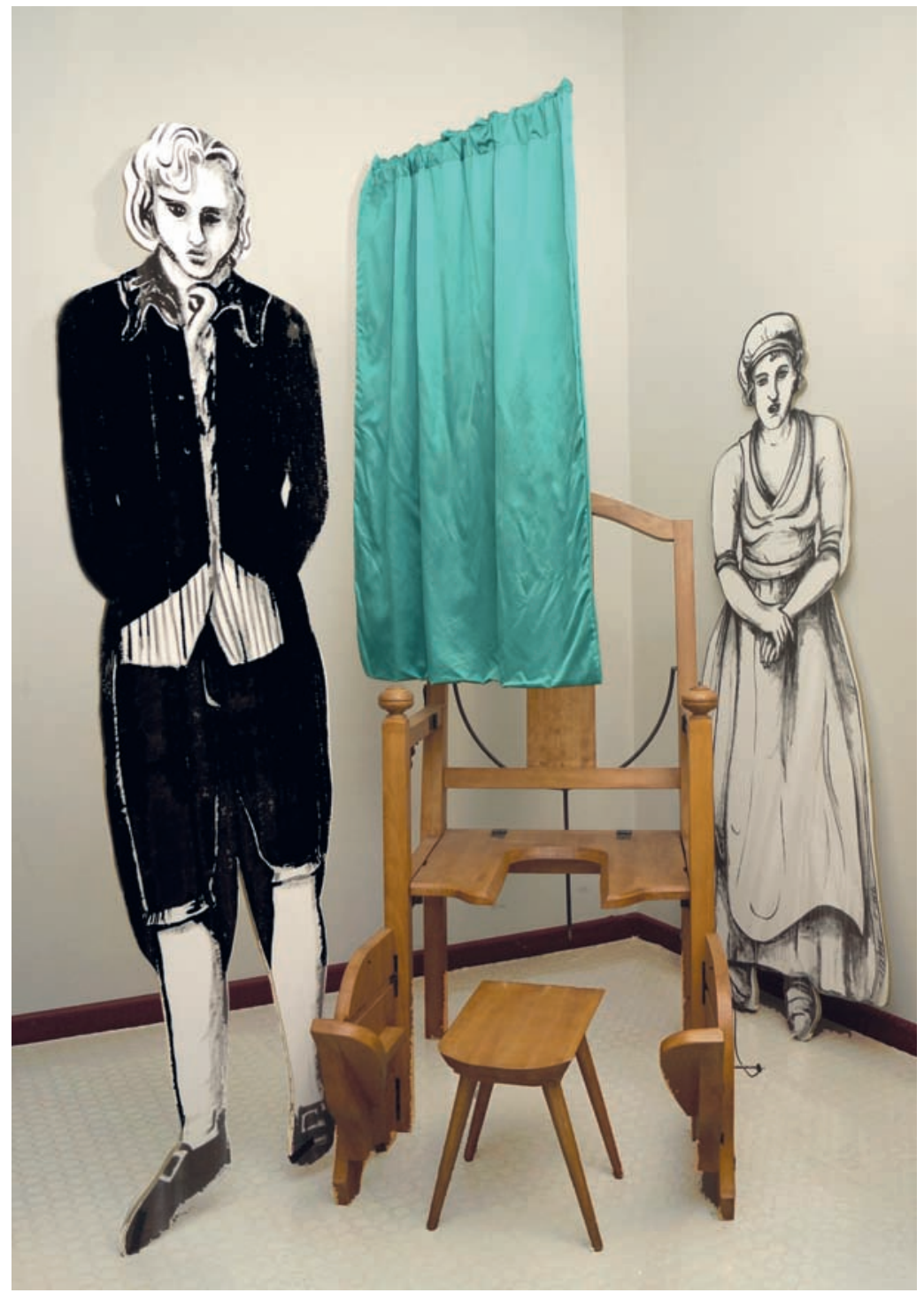

The exhibition takes a critical view of the role forced upon the pregnant patients treated at the clinic, the majority of whom were unmarried. They were obliged to make themselves available for practical exercises carried out by the trainee obstetricians. Also addressed the exhibition are the far-reaching changes in the range of tasks assumed by midwives, following the development of obstetrics as a medical specialty at the university. Visitors can expect to find answers to intriguing questions: why did doctors prevail over midwives? Who decided on the medical interventions to be undertaken in an emergency - the mother or the physician? What medical breakthroughs enabled development of the life-saving Caesarean section?
A scene reproduced: reconstruction of the birthing chair developed by Georg Wilhelm Stein the elder (1731-1803), modified by Friedrich Benjamin Osiander; photograph: Gerhard Hundertmark 


\section{Collection of Medical Moulages}

University Medical Center Göttingen • Department of Medical Ethics and History of Medicine

Humboldtallee 36 • 37073 Göttingen • www.uni-goettingen.de/moulages-collection

Syphilis moulage, makulopapular exanthema of the lower arms, syphilis, stage II, rash covering entire body; photograph: Stephan Eckardt

View of the exhibition, photograph: Lisa Frebel

\section{Established: 1917}

Number of items: c. 80

Public exhibition: yes

Open: Mon. to Fri. 9:00 - 12:00 and by appointment

\section{Admission: free}

Tours: by appointment

\section{Contact:}

Kornelia Drost-Siemon Tel.: +49 551 39-9007, -9006 kdrost@gwdg.de
Moulages are meticulously formed wax casts of body parts and areas of skin that have undergone changes as a result of disease. Illustrating a broad range of dermatological disorders, the Göttingen Collection of Moulages goes back to Professor Erhard Riecke (1869-1939), Director of Göttingen University's Department of Dermatology, which was set up in 1917. The approximately 80 moulages preserved from the teaching collection were prepared during the first third of the 20th century, by August Leonhardt (1891-1954), mouleur at the Department of Dermatology, and internationally reputed wax craftsmen and women such as Luise (Lotte) Volger (1883-1956), Alfons Kröner (d. 1937), Fritz Kolbow (1873-1946) and Carl Henning (1860-1917).
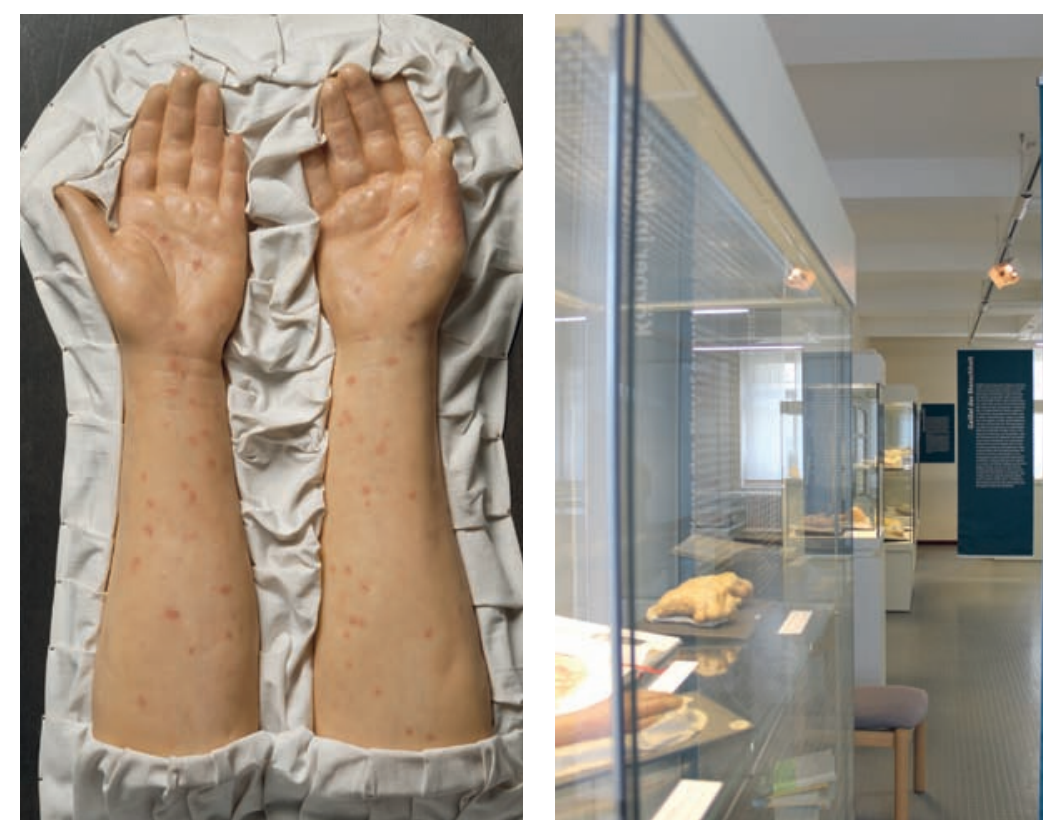

The aim of the craftsperson was to reproduce in wax the form, colour and texture of the affected body part as accurately as possible, with a view to documenting the diagnostic findings. It was not until the second half of the 20th century that photography replaced moulages as demonstration material in teaching. The casts were taken directly from the patient so that the three-dimensional reproductions convey - even today - a uniquely vivid clinical picture of historical and existent diseases. It is this extreme closeness to reality that renders the moulages so valuable for current didactic purposes, with the result that they have once again become important tools in clinical teaching. 


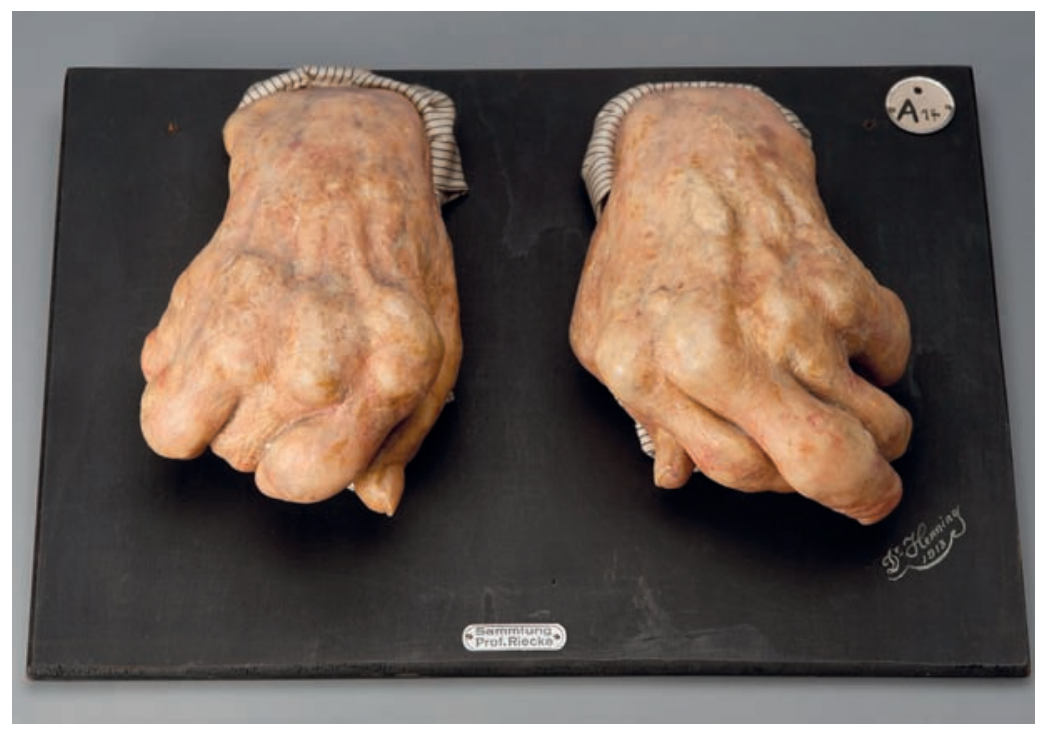

Since 2011 these unique objects have been accessible to the general public in a permanent exhibition. This is based on the special exhibition WachsBildKörper (WaxImageBody) that was presented by the Department of Medical Ethics and History of Medicine in cooperation with the Department of Dermatology, Venereology and Allergology and the Municipal Museum (Städtisches Museum, 2007). The exhibition took as its central theme the 'historical patient' behind the wax casts and the central importance of the skin as a human being's outer shell.

Kornelia Drost-Siemon \& Susanne Ude-Koeller
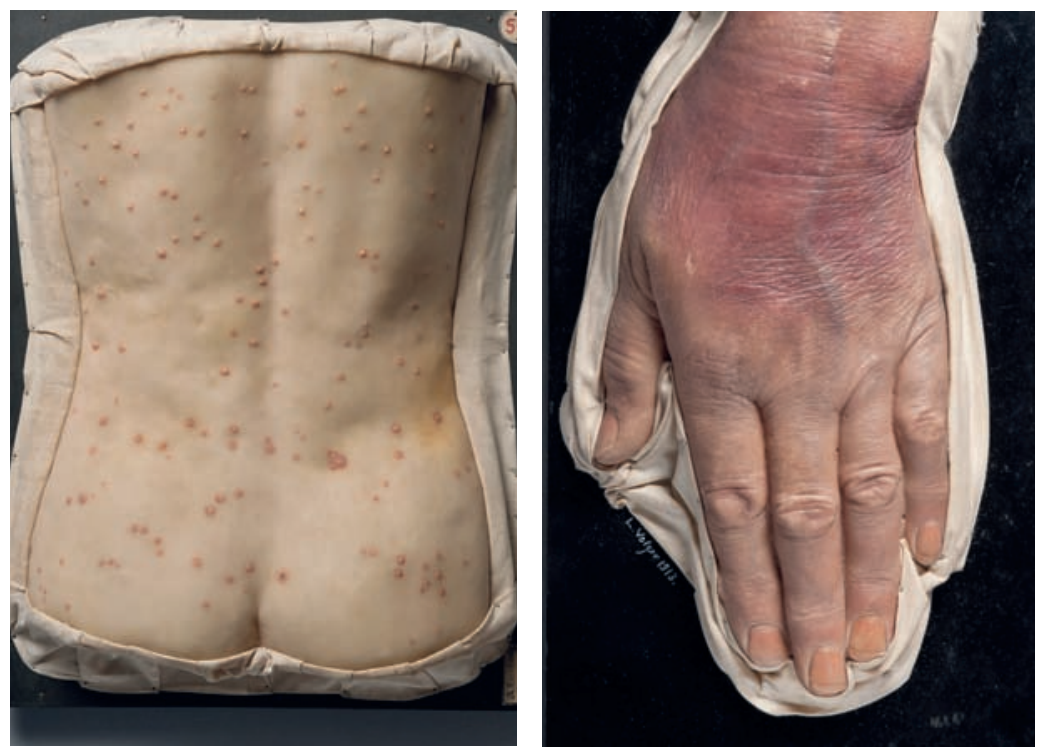

Arthritis moulage. Arthritis urica gravis manuum, Dr. Henning, Vienna, 1913; photograph: Stephan Eckardt

Syphilis moulage: syphilis II, papulopustulosa. Back and buttocks, stage II, A. Leonhardt, Göttingen; photographs: Peter Kaubisch

Borreliosis moulage, dermatitis atrophicans idiopathica progressiva diffusa, L. Volger, Zurich 


\section{Legal Medicine Collection}

University Medical Center Göttingen • Department of Legal Medicine

Robert-Koch-Straße 40 • 37075 Göttingen • www.uni-goettingen.de/legal-medicine

Fabric samples. Gunshot residues in fabric after firing at different, increasing distances: $3 \mathrm{~cm}, 5 \mathrm{~cm}, 10 \mathrm{~cm}$ and $15 \mathrm{~cm}$. Small bore Flobert pistol, $6 \mathrm{~mm}$. The aspect most easily distinguished is the spread of gunpowder particles as distance increases. Photographs: Stephan Eckardt
Established: 1906

Number of items: c. 440

Public exhibition: no

Tours: no

\section{Contact:}

Prof. Dr. Wolfgang Grellner Tel.: +49 $55139-4910$

grellner@med.uni-goettingen.de
The oldest whole-body exhibit in this collection is a mummy of a tradesman whose burial took place in 1677 during a sharp frost. It was found in this condition when his son was buried in the family tomb in 1714. Gravediggers put it on show, but it was not until 1791 that the mummy was assigned into the safekeeping of the University of Göttingen. Here, it ultimately found its place in the Legal Medicine Collection, which was established and structured after 1906 by Theodor Lochte (1864-1963), Extraordinary Professor and subsequently holder of the Chair at Göttingen University between 1906 and 1934.

In the volume Forensische Medizin. Eine 100-jährige Geschichte der Rechtsmedizin an der Georg-August-Universität Göttingen (Forensic Medicine. A 100-year History of Forensic Medicine at the University of Göttingen, Universitätsverlag Göttingen, 2004) we read: "At the beginning of the last century, the setting up of scientific collections was standard scientific practice in the areas of anatomy, pathology and legal medicine. At Göttingen University's Department of Legal Medicine, Lochte laid the foundations for one of the largest collections of this kind. Perfected by his successor, the collection was brought up to a very high standard, its exhibits being employed intensively for teaching and further training. Nowadays, the collection's significance is acknowledged in its documentation of medical history and it is maintained as such, but it is no longer used for teaching purposes. Yet public interest in the collection

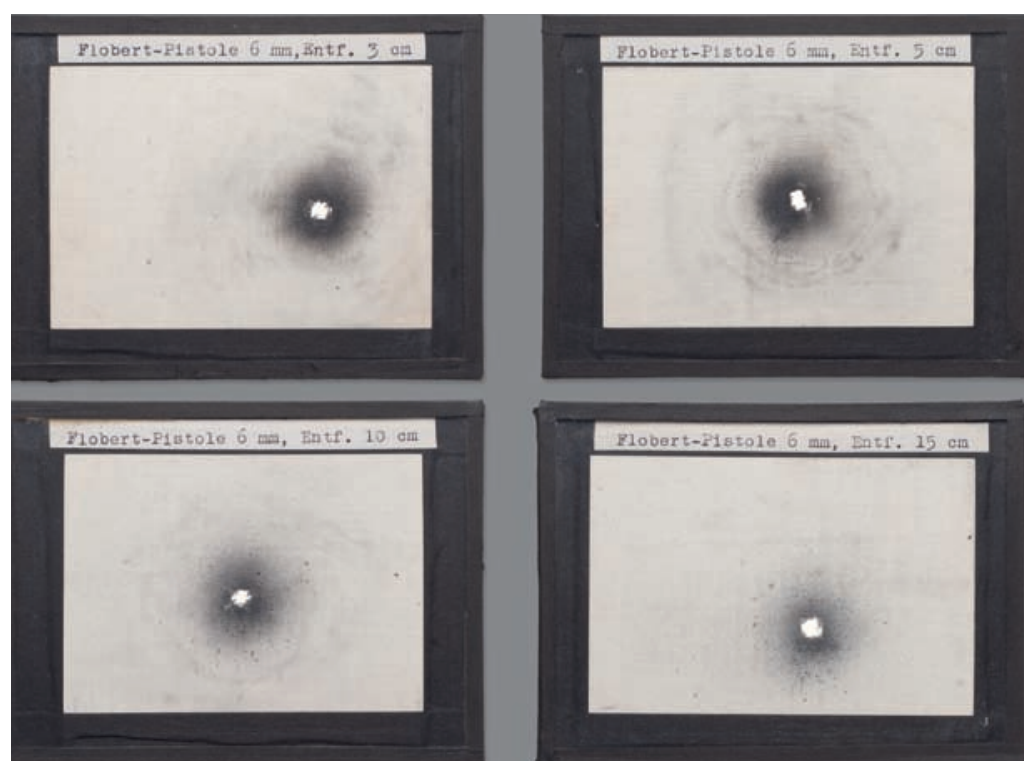




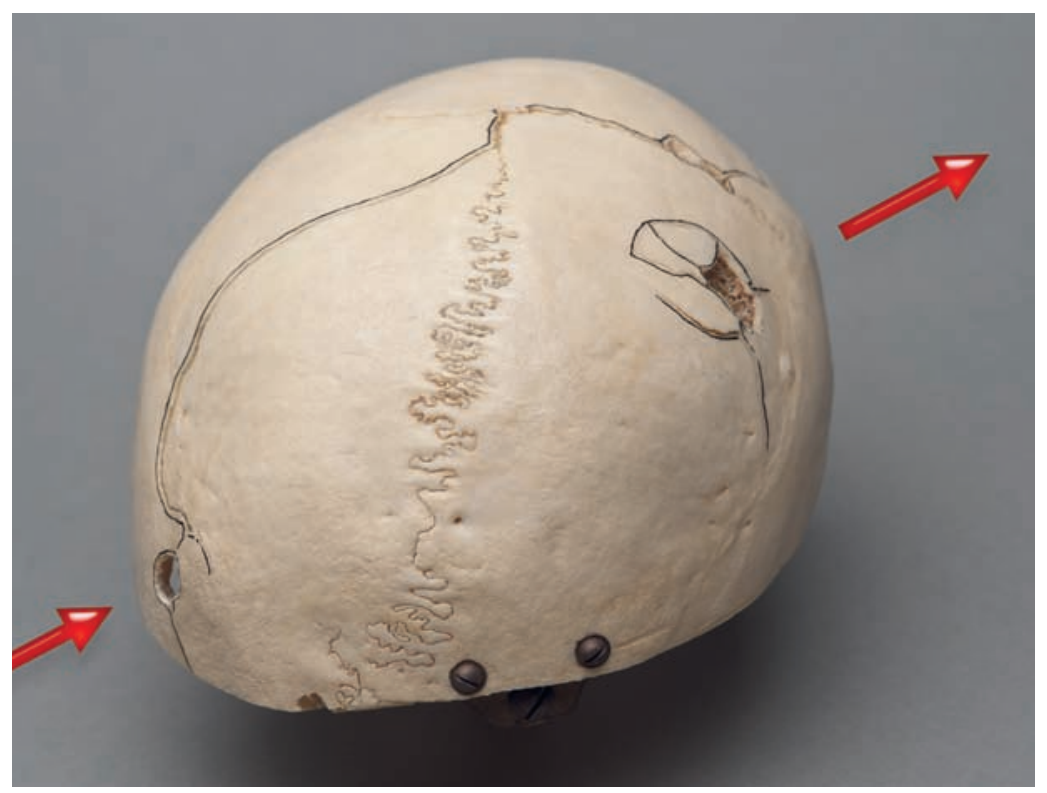

remains considerable - perhaps also due to the fact that it is no longer accessible."

A systematic approach similar to that employed for the collections of other faculties is not possible in this subject area. Instead, the collection generally illustrates particular settings, with the circumstances or practical aspects typically surrounding the committing of a particular (mis)deed (crime), as well as the legal categories.

The collection therefore brings together exhibits from which focal areas crystallize, such as thanatology, natural death and unnatural death

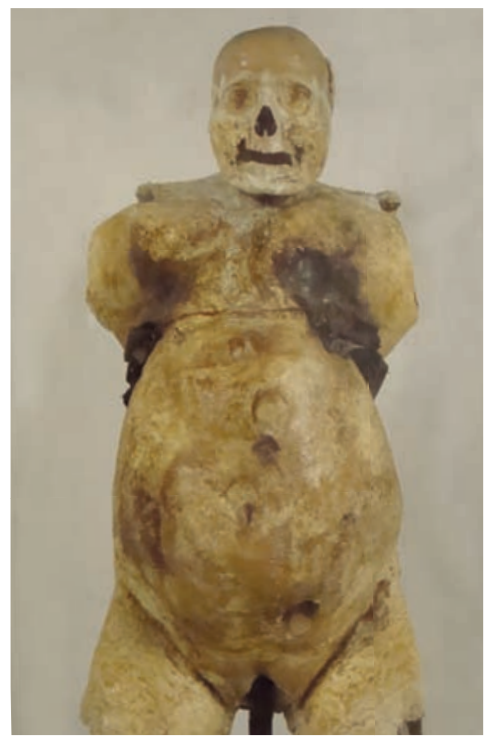
through accident, suicide, blunt trauma and sharp force including the use of weapons, and the effect of toxic substances. These are the very areas that traditionally define the content structure of the legal medicine curriculum.

Wolfgang Grellner \& Jürgen Sammler
Skullcap, viewed from behind. Shot pierced skull in upward direction from bottom left to top right, resulting in cranial fracture. Typical widening of the bone fracture in the vicinity of bullet entry and exit points, increasing in the direction of exit
Decomposition changes of a corpse under water, occurring over time. In the course of many months to years, the body fat is transformed into so-called adipocere (lipocere), thereby maintaining the body contours. Beneath, all that remains is the bony skeleton. Photograph: Jürgen Sammler 


\section{Human Embryology Documentation Collection (Blechschmidt Collection)}

University Medical Center Göttingen • Center of Anatomy

Kreuzbergring 36 • 37073 Göttingen • www.uni-goettingen.de/human-embryology-collection

Erich Blechschmidt, photograph: Göttingen University

Embryo with placenta (week 6); spontaneous abortion. This original preparation provides evidence of the difficulty of examining embryological form from the original. The observer is unable to detect external details of form even when using a magnifying glass; investigation of internal organs is not possible. Photographs: Hans-Georg Sydow, Jörg Männer

Established: c. 1949

Number of items: 65

Public exhibition: yes

Open: Mon. to Fri. 8:00 - 18:00

Admission: free

Tours: by appointment

\section{Contact:}

PD Dr. Jörg Männer

Tel.: +4955139-7032

jmaenne@gwdg.de
Research into the early stages of human development is highly dependent on collections of human embryos from chance-findings in hospital settings. Only a small number of collections of human embryos exist worldwide. The most significant is the Carnegie Collection in Washington D.C., which was established in the early 20th century by Franklin P. Mall (1862-1917), a pupil of the Leipzig anatomist

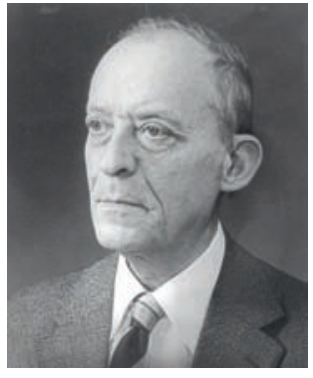
Wilhelm His (1831-1904). The Göttingen collection, well known throughout the world as the 'Blechschmidt Collection', dates from the period 1949 to 1972 and is the work of Erich Blechschmidt, Director of the Anatomy Institute at that time. Blechschmidt sought to follow in the footsteps of anatomist and embryologist Wilhelm His, who may be regarded as the founding father of human embryological research. In line with the tradition initiated by His, the 'Blechschmidt Collection' was designed to serve the research

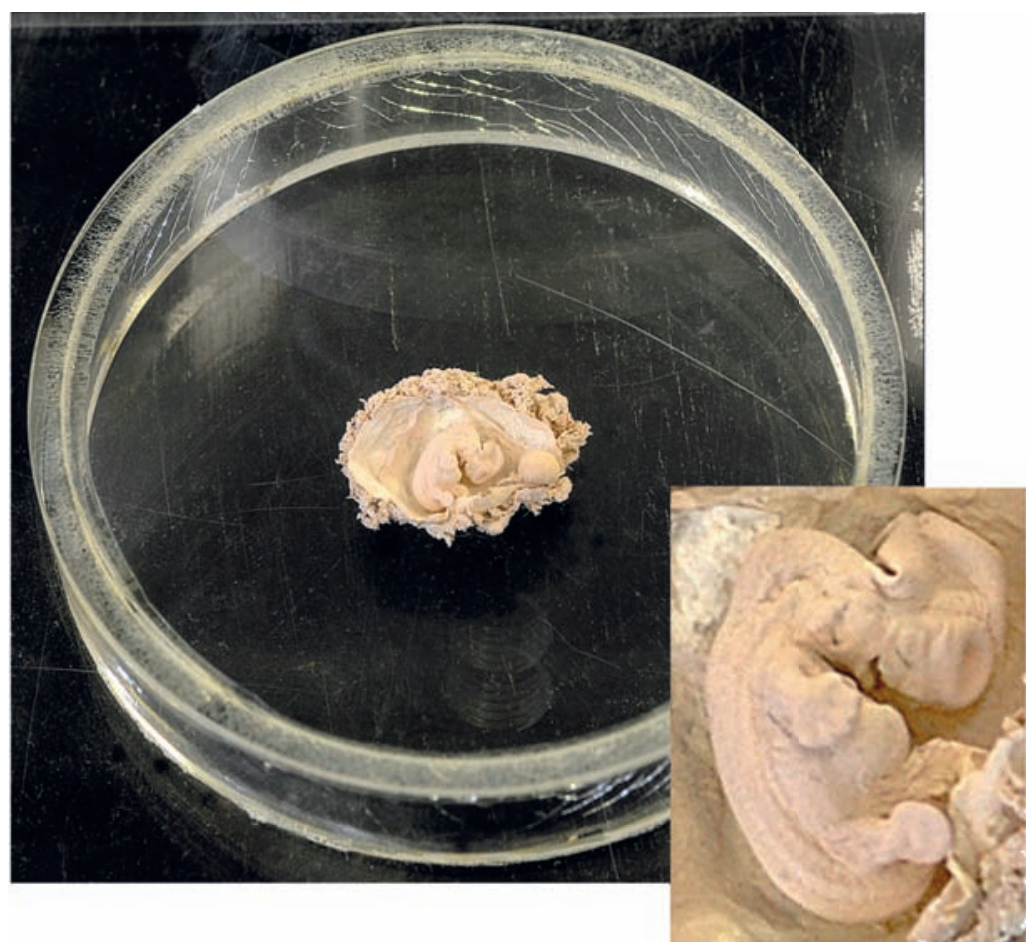




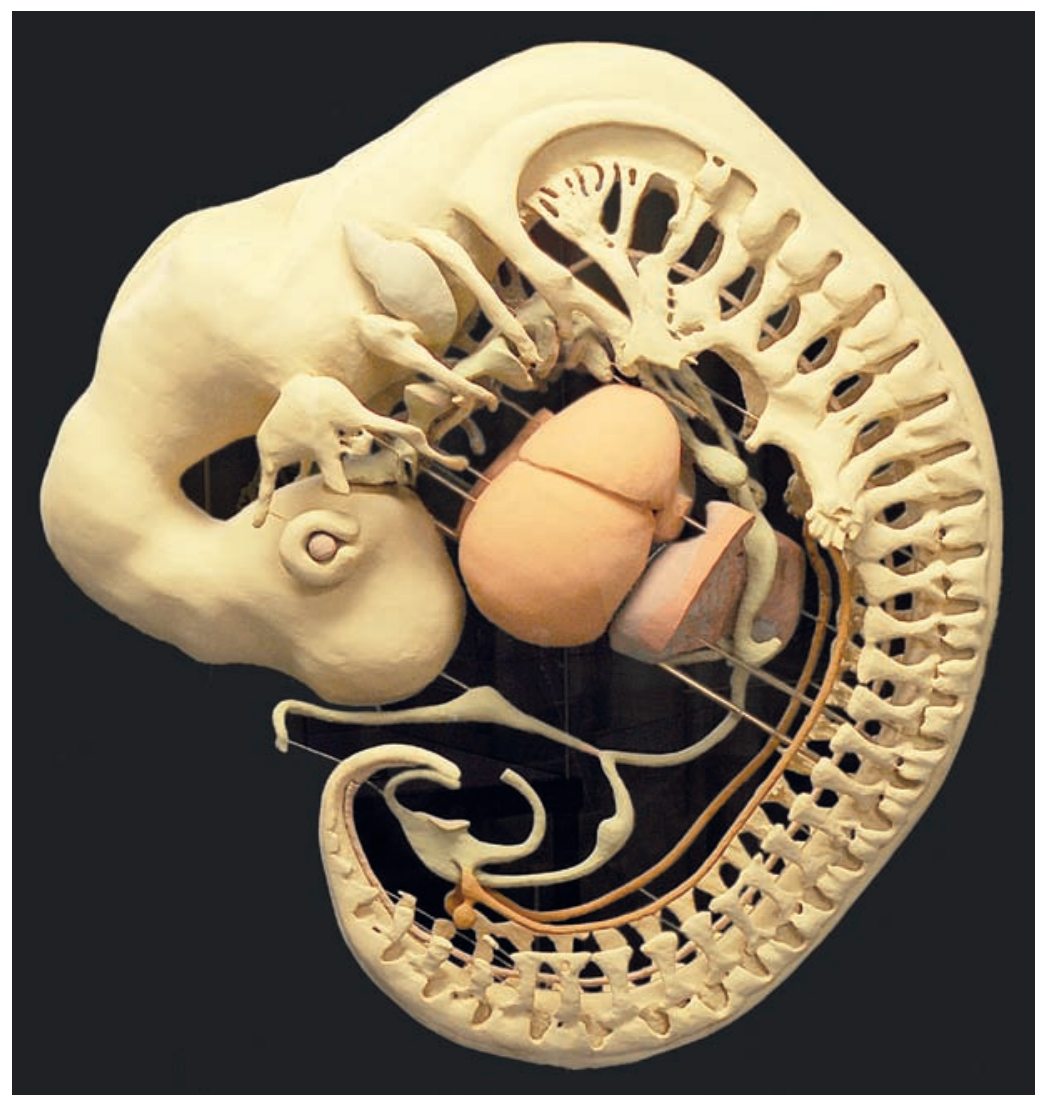

Reconstruction of a $6.3 \mathrm{~mm}$ embryo (week 5 of development). The model is approximately $75 \mathrm{~cm}$ high and documents various aspects of the internal formation of the embryo (e.g. nervous system and sense organs) at a scale perceptible to the human eye.

and documentation of the morphogenesis of human embryos - that is, the dynamic anatomy of human embryos. The aim was to render visible developing structures that were not visible to the naked eye. Following fixation, series of histological sections were prepared to enable researchers to carry out microscopic analysis of the internal structure of the embryo. On this basis, considerably enlarged (by 50 to 200 times) three-dimensional reconstructions were built from serial sections of selected well-preserved embryos. These models document in a perceptible manner the increasingly complex anatomical situation during embryogenesis. The 65 large reconstructions (c. $65-75 \mathrm{~cm}$ high) are presented in a dedicated viewing room and constitute a research and learning tool unique worldwide. They are arranged according to developmental age, enabling observers to experience in spatial terms the anatomy of the developing human embryo. 


\section{Blumenbach Collection of Skulls}

University Medical Center Göttingen • Center of Anatomy

Kreuzbergring 36 • 37073 Göttingen • www.uni-goettingen.de/blumenbach-collection

Skull employed for 'phrenology' demonstrations, a theory developed by Viennese physician Franz Joseph Gall (1758-1828), with contemporaneous designation of 'brain organs' described and identified by Gall; photograph: Tanja R. Stegemann
The collection of skulls initiated by Johann Friedrich Blumenbach (1752-1840), thought to be the oldest existing university collection of skulls in the world, is an exceptionally valuable item in the holdings of Göttingen University. In 1775, following work on his skull collection, Blumenbach wrote in his dissertation "about the natural differences evident in humankind" and on the four varying Hauptvarietäten (principal groups) of the anatomically modern human - he did not, therefore, establish 'a racial doctrine', as is often falsely claimed. In 1779, in the first edition of his Handbuch der Naturgeschichte (Handbook of Natural History), he adds a fifth and further group. These original skulls remain present among the collection's holdings to this day.

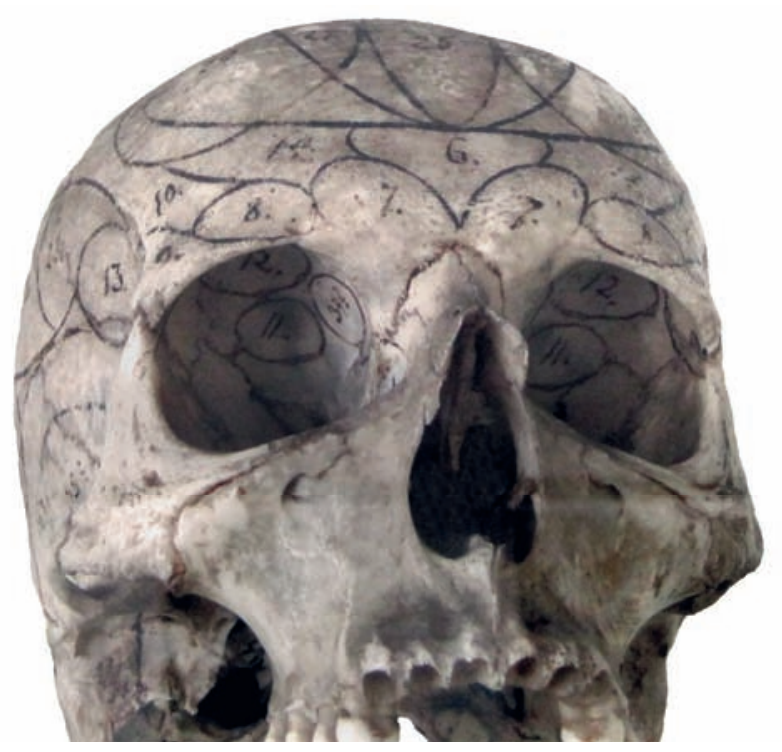

Many of Blumenbach's pupils, friends and colleagues regularly sent him human skulls or arranged for their delivery, such as Johann David Michaelis (1717-1791), Georg Thomas von Asch (1729-1807), Cardinal Stefano Borgia (1731-1804), Joseph Banks (1743-1820), Carl Peter Thunberg (1743-1828), Johann Wolfgang von Goethe (1749-1832), Samuel Thomas von Soemmerring (1755-1830), Franz Joseph Gall (1758-1828), Alexander von Humboldt (1769-1859), Georg Heinrich von Langsdorff (1774-1852), Martin Hinrich Lichtenstein (1780-1857), Prince Maximilian zu Wied-Neuwied (1782-1867), Christian VIII of Denmark and Norway (1786-1848), and Johann Friedrich Ludwig Hausmann (1782-1859). Since the material holdings of the collection fell clearly into the area of anatomical research and teaching, Blumenbach's natural history collections 


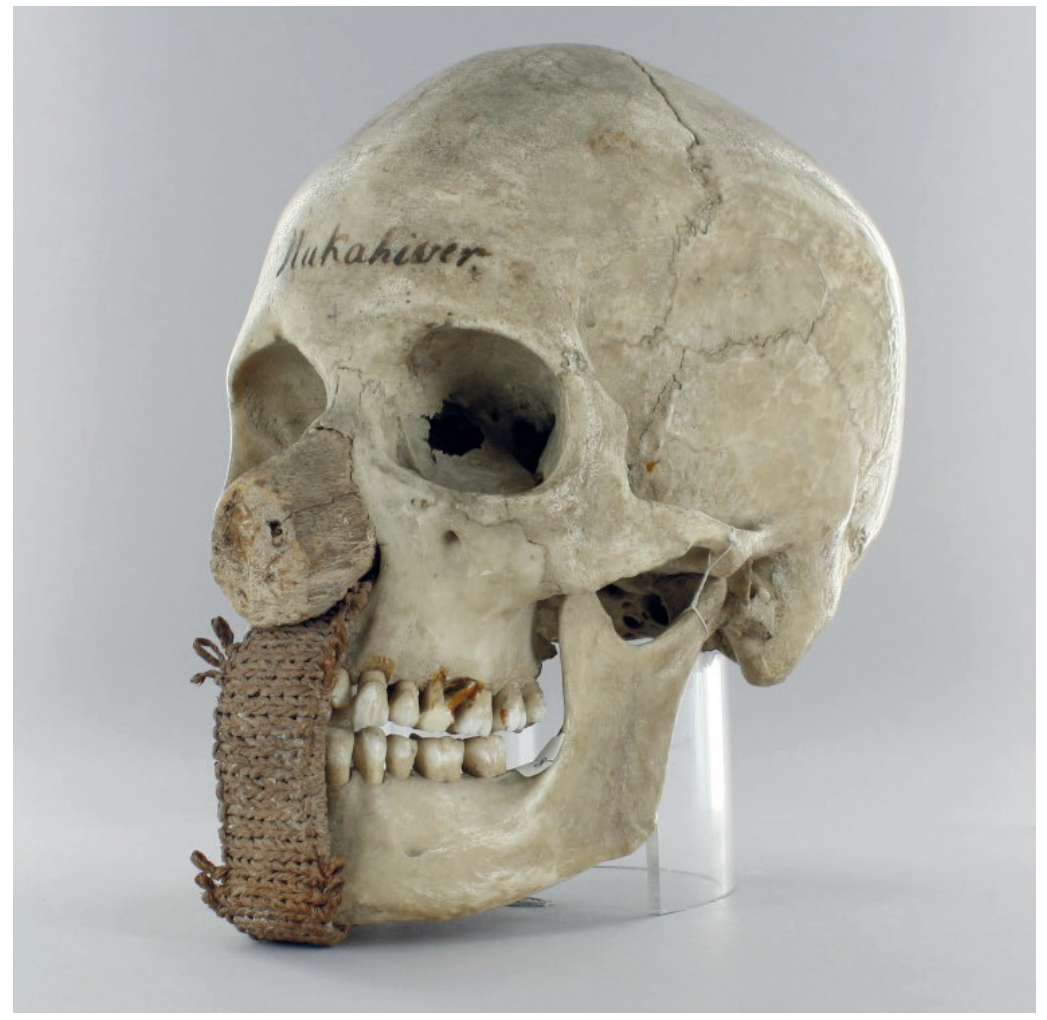

were acquired by the University of Göttingen in 1840 and a part of them was integrated by anatomist Bernhard von Langenbeck (1810-1887) into the collection at the Institute of Anatomy. Subsequently, Langenbeck and his successors Jacob Henle (1809-1954), Friedrich Merkel (1845-1919) and Hugo Fuchs (1875-1954) went on to augment it. In terms of the history of science, the significance of this collection is beyond doubt, since it contains items of considerable importance in the further contexts of archaeology and cultural history.

Yet the collection of skulls held in Göttingen is also of interest for ongoing scientific research. The skulls, which exhibit signs of malnutrition (e.g. scurvy), infectious diseases (e.g. syphilis), or the consequences of violence (trauma, trepanation, etc), bear witness to cases of illness and medical treatment in the late Modern Age, thereby offering a valuable comparative basis for research work in the areas of medical history and palaeopathology.

The extensive original catalogue was lost during World War II. The collection itself, however, remained unscathed, having been moved to a nearby but out-of-town location in Bremke, on the initiative of Erich Blechschmidt (1904-1992), then Director of the Anatomy Institute at Göttingen University. Today, the collection, which forms part of the holdings at the Center of Anatomy, consists of more than 840 skulls and casts.
Male trophy skull from the island of Nuku Hiva (Marquesas Islands, French Polynesia). Blumenbach received this skull in c. 1808 from the travelling researcher Georg Heinrich von Langsdorff, who acquired it during the first Russian circumnavigation of the world (1803-1806); photograph: Blumenbach-online project 


\section{The Old Botanic Garden: Plant Diversity from Throughout the World}

Old Botanic Garden, University of Göttingen

Untere Karspüle 2 • 37073 Göttingen • www.altgart.uni-goettingen.de

View of the evolution garden; photographs: Michael Schwerdtfeger

Glorious specimens from tropical South America: Aphelandra aurantiaca (left) and Eichhornia crassipes (right)

Established: 1736

Number of items: c. 18,000

Public exhibition: yes

Open: Mon. to Sun. 8:00 - 18:30 (garden), Mon. to Sun. 8:00 16:00 (greenhouses), admission limited during wintry weather Admission: free

Tours: see programme of themebased public events for the year, or by appointment

Contact:

Dr. Michael Schwerdtfeger Tel.: +49 551 39-5755, 9964651 mschwer@gwdg.de
Founded in 1736, the Botanic Garden on the Karspüle is as old as the University of Göttingen itself. Of the approximately one hundred botanic gardens in Germany, it is thus one of the few to have remained in the same location and performed the same function for over two hundred and fifty years. The garden was initially designed by the physician, poet and botanist

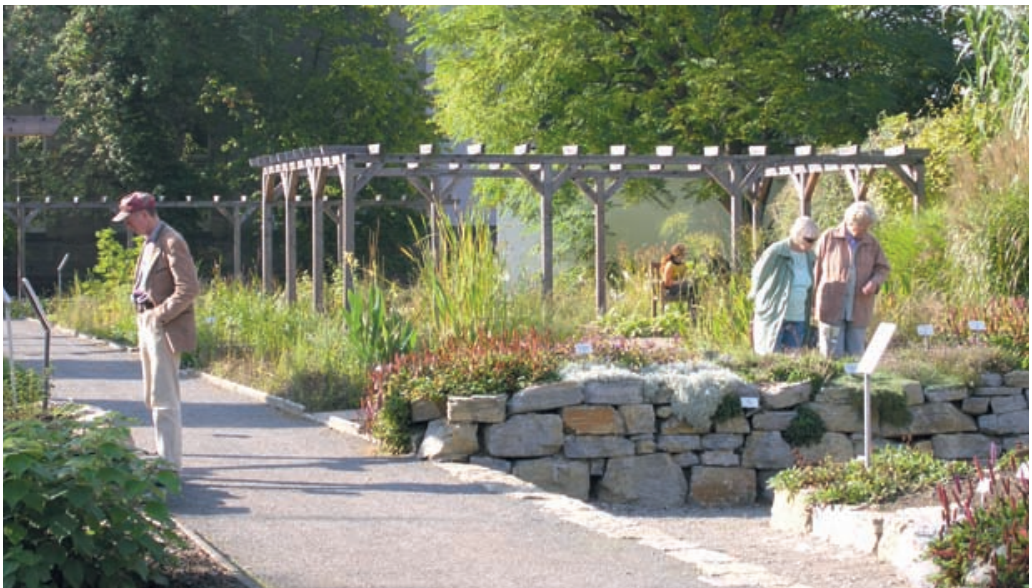

Albrecht von Haller (1708-1777) to be a Hortus medicus, but it quickly developed to function as much more than a medicinal garden alone. Haller himself was active in collecting plants from throughout the world and only
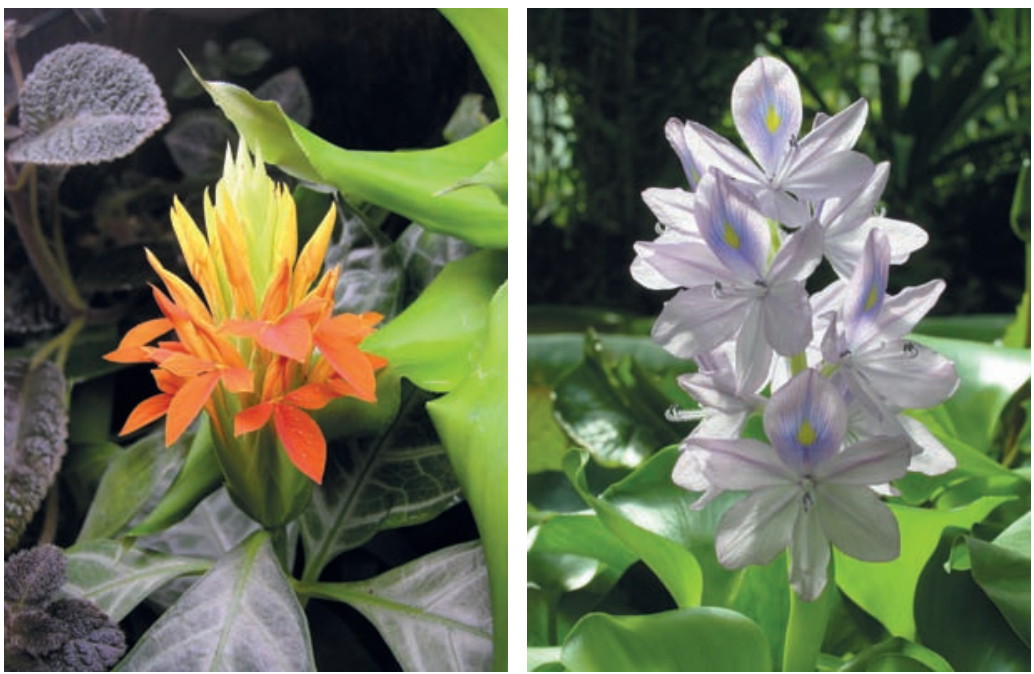


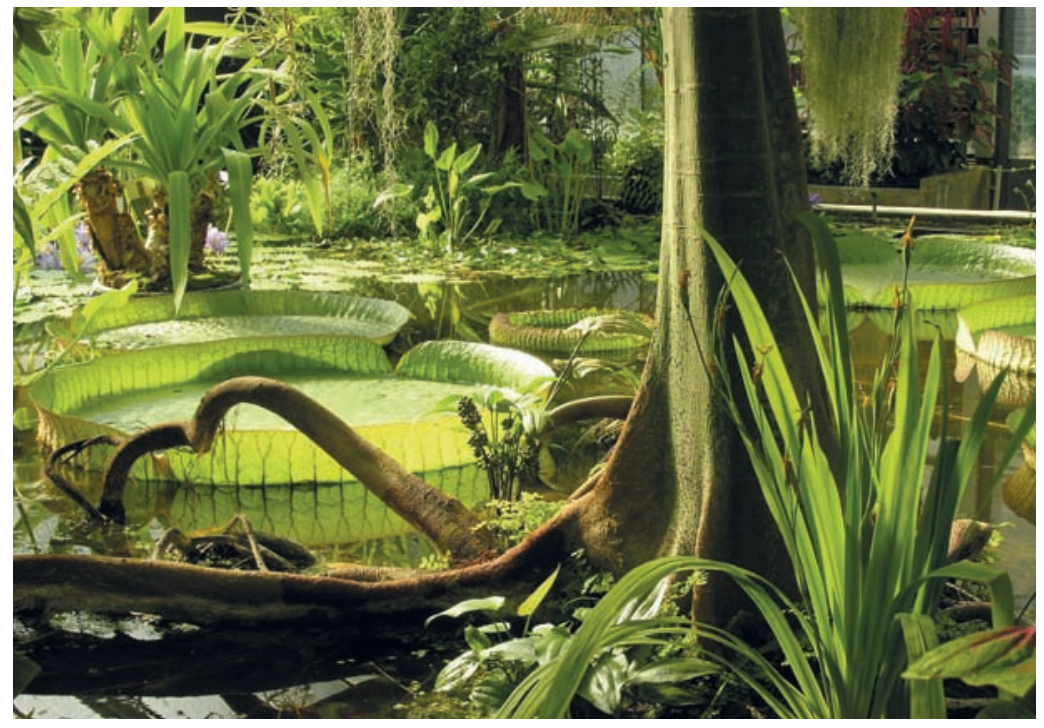

seven years after the opening of the garden, he published a catalogue listing 1,500 different species of plant. Notable directors succeeding Haller included Heinrich Adolf Schrader (1767-1836), Friedrich Gottlieb Bartling (1798-1875), Heinrich August Rudolf Grisebach (1814-1879) and Hermann Graf zu Solms-Laubach (1842-1915).

In the 19th century, the garden expanded onto land beyond the city wall and outstanding collections of plants were assembled, particularly as a result of the close contact with the Royal Gardens in HanoverHerrenhausen. Between 1900 and 1930, Master Gardener Carl Bonstedt (1866-1953) was in charge of the garden's development. His dedication as well as his skill in cultivating plants such as ferns, carnivorous plants, orchids and hydrophytes increased the garden's popularity greatly, particularly through the creation of the Victoria house and the fern house, as well as ponds and rockeries. This work culminated in the publication of the horticultural and botanical standard opus Pareys Blumengärtnerei (Parey's Flower Nursery).

The New Botanic Garden was created in the north area of the university campus in 1968, initially with the aim of replacing the Old Garden in the city. Today, however, the two gardens of the Faculty of Biology function synergistically, hand in hand with the Forest Botanical Garden. An extensive range of plants planted according to exceptionally diverse botanical themes continues to flourish in the centrally located Botanic Garden. As well as fulfilling its main purpose in the context of teaching and research, this charming historical facility also offers students and the public a 'window into nature'. Offering a lively programme of public outreach events and attracting some 100,000 visitors annually, the garden is the university's most popular facility.
A favourite among visitors: giant water lily (Victoria cruziana) in the Victoriahaus 


\section{The Historical Fern House and Fern Collection}

Old Botanic Garden, University of Göttingen

Untere Karspüle 2 • 37073 Göttingen • www.altgart.uni-goettingen.de

In 1857, a Victorian-style wintering house, a so-called Orangerie, was erected in the Botanic Garden. Later, in the period from 1910, the building was converted into a Fern House, under the direction of Professor Albert Peter (1853-1937) and Master Gardener Carl Bonstedt (1866-1953), "in order that the unique biological nature of this plant group could be exhibited in a special manner".

The historic greenhouse with its distinctive scale-type glazing and the Gründerzeit late nineteenth century cast-iron construction survived both world wars unscathed. Thanks to a renewed public interest in botanical gardens, it was restored in 1999/2000, protecting the structure from deteriorating with age. As a result, this listed building has now been providing an insight into the fascinating world of ferns and related species from tropical regions around the world for 100 years. In geological terms, ferns are an extremely old plant group. Unlike many other plants, they reproduce using microscopic spores rather than flowers or seeds and some have remained largely unchanged for around 300 million years. The Fern House is therefore not only a testament to Victorian architecture, research expeditions, and plant collection in general. It also gives students and visitors alike a living impression of fern woodlands from the Carboniferous period, long before the Mesozoic era when dinosaurs lived on earth and at the end of which the first flowering plants appeared. The restoration of the Fern House gave new impetus to fern cultivation

The prehistoric world of nonflowering plants on display in the Fern House. Photographs: Michael Schwerdtfeger
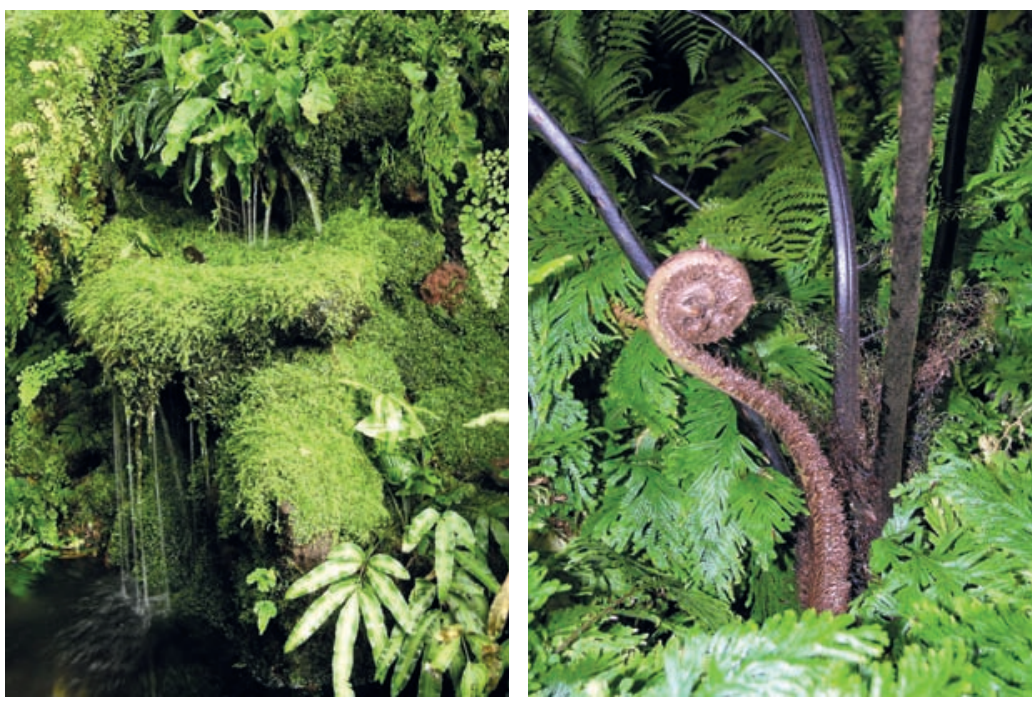


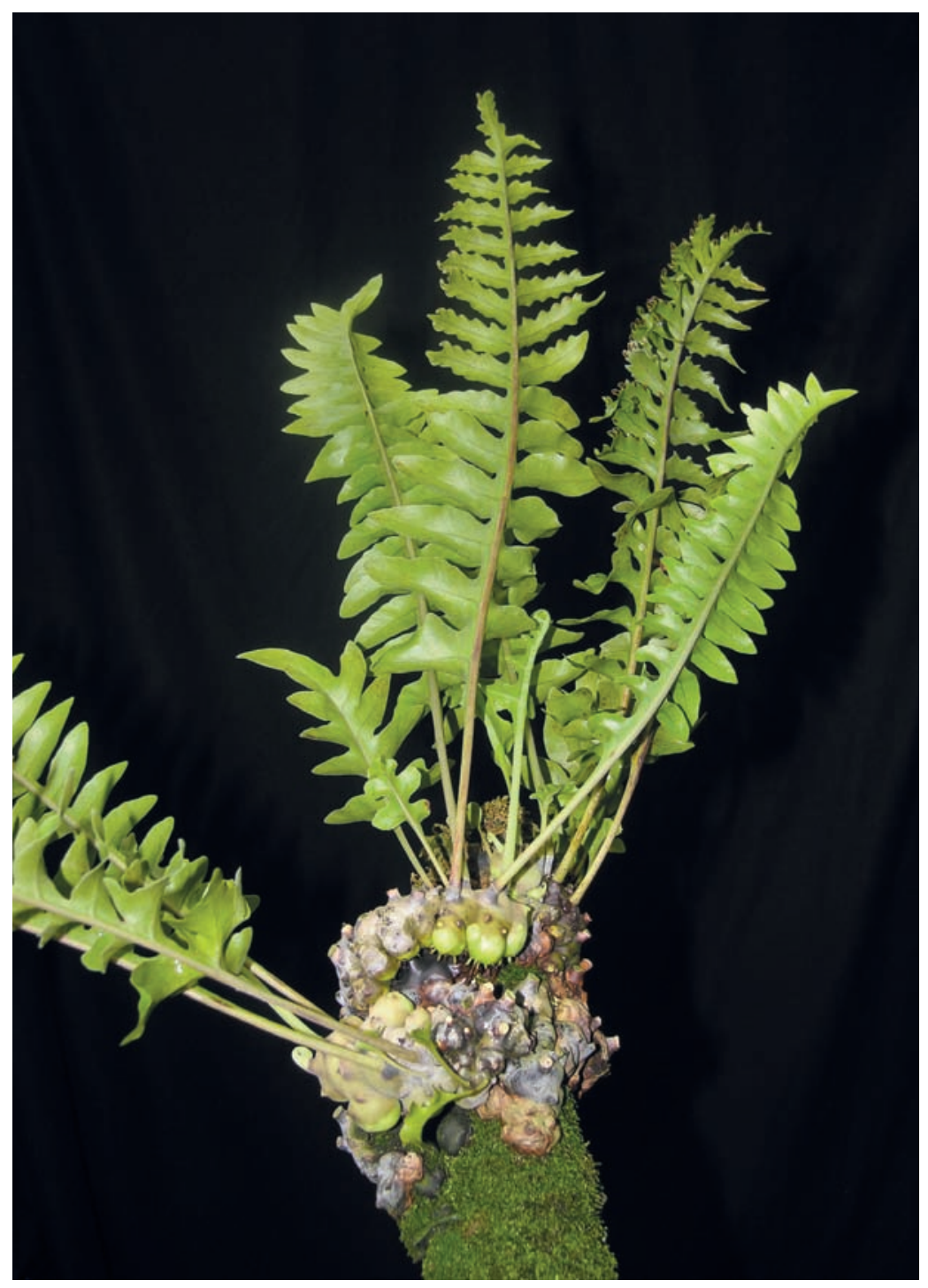

In the natural environment, Lecanopteris luzonensis lives in symbiosis with ants, which inhabit its unusual-looking fleshy rootstock

in Göttingen and through the use of spores from around the world, a substantial collection of ferns became available for study only a few years later. Adopting morphological and molecular-genetic methods, scientific research using this collection has resulted in numerous publications that have appeared in high-ranking journals over recent years.

Michael Schwerdtfeger 


\section{Special Collection of Bromeliads}

Old Botanic Garden, University of Göttingen

Untere Karspüle 2 • 37073 Göttingen • www.altgart.uni-goettingen.de

Many bromeliads display attractive, long-lasting and colourful inflorescences during their blooming period: Aechmea biflora, Aechmea veitchii; photographs: Michael Schwerdtfeger
In the tropical forests of Central and South America, Africa and SouthEast Asia, the vegetation is not only characterised by plants growing side by side in the soil. To avoid the shady forest floor and be closer to the sunlight, many species grow on the trunks and boughs of trees: these are known as epiphytes. Early tropical explorers such as Humboldt and Darwin wrote enthusiastically of the wealth of "glorious flowering parasitic plants" in the trees. Today, however, we know that these plants are in fact not parasites at all, since they do not harm the trees on which they live, but simply use them as a means to find 'a place in the sun'.

As well as ferns, begonias, peperomias, aroids and orchids, bromeliads play a particularly important role in the tropical forests of the New World. Famous gardening expert Jürgen Lautner began collecting bromeliads for the University of Göttingen in 1967. In order to enlarge the collection, this outstanding horticulturist conducted several expeditions to Central America, where he gathered specimens not only for scientific research, but also with a view to cultivating these valuable plants. He also discovered several new species of plants during his expeditions.

Today, the collection at Göttingen contains around 3,000 species of the pineapple family. Due to the high number of excellently documented wild plants it is of great importance scientifically and is renowned worldwide for the outstanding condition of the cultures, some of the plants now being decades old. The university exchanges information with
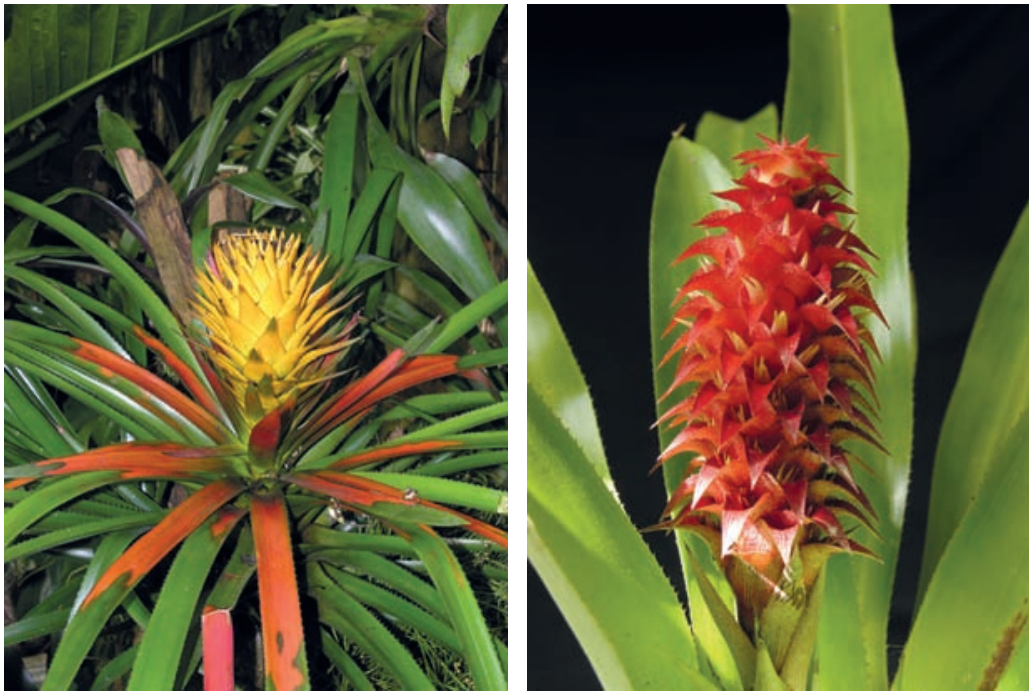


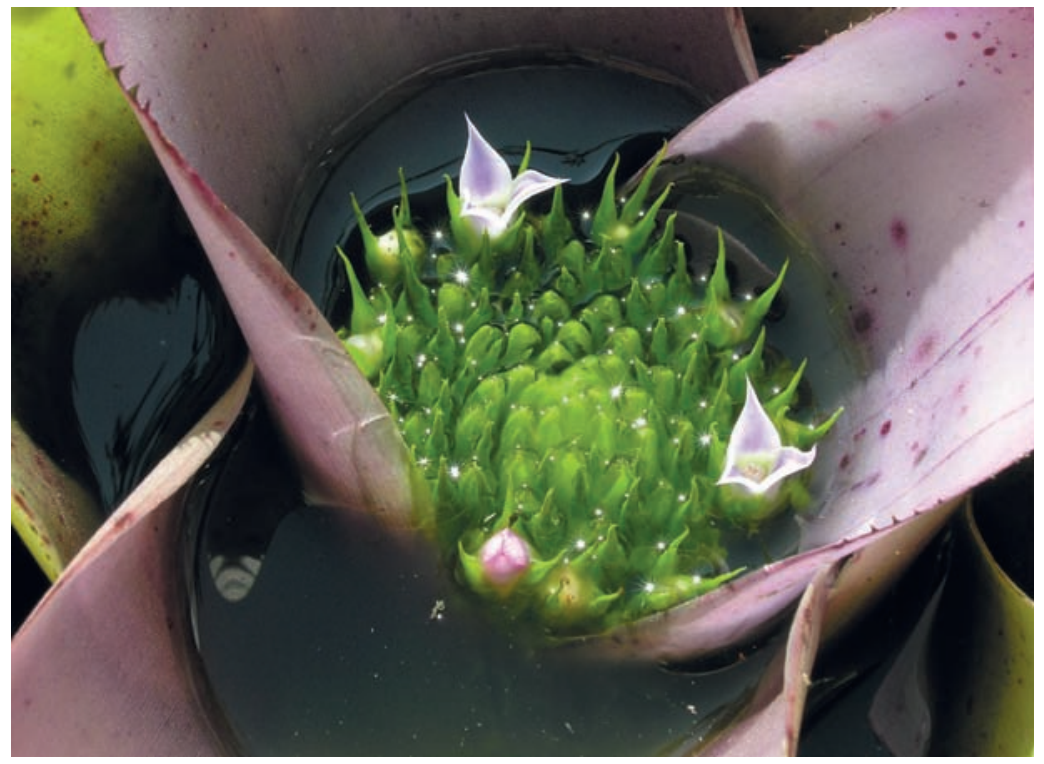

the most prominent bromeliad collections in Europe and the collection at Göttingen is regularly visited by groups of experts from around the world.

Although a large number of the many thousands of plants are kept 'behind the scenes', the spectacular Tillandsia, Billbergia, Neoregelia and Aechmea genera, which are on show in the Victoria, Cycad and Rainforest houses give the public an insight into the fascinating world of tropical epiphytes.
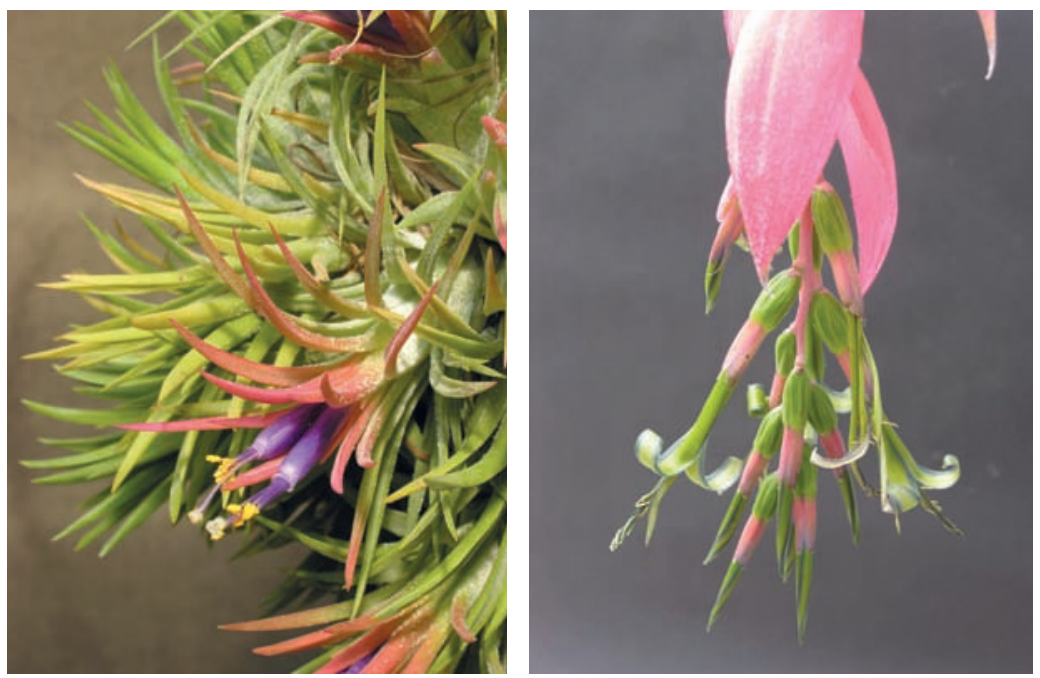

Neoregelia concentrica from the coastal rainforests of Brazil
Michael Schwerdtfeger

Tillandsia ionantha from Mexico, Billbergia nutans from Argentina 


\section{Herbarium of Göttingen University}

Albrecht von Haller Institute for Plant Sciences

Untere Karspüle 2 • 37073 Göttingen • www.uni-goettingen.de/herbarium

A fern from the Georg Forster Collection. This plant was gathered by Forster in the course of James Cook's second voyage to the South Seas (1772-1775). The Forster specimens are among the Herbarium's most valuable items. Two numbers are to be seen on the label: Forster marked the items allocated to Göttingen University with a serial number (here: 305). The second number (424) comes from his publication Florulae Insularum Australium Prodomus. Photograph: Herbarium Göttingen
The Herbarium of Göttingen University is one of the largest and most important entities of its kind in Germany. It houses some 800,000 dried and archived plants from all parts of the world. Among them are more than 12,000 type specimens, items that provided the basis for the first scientific description of a plant species.

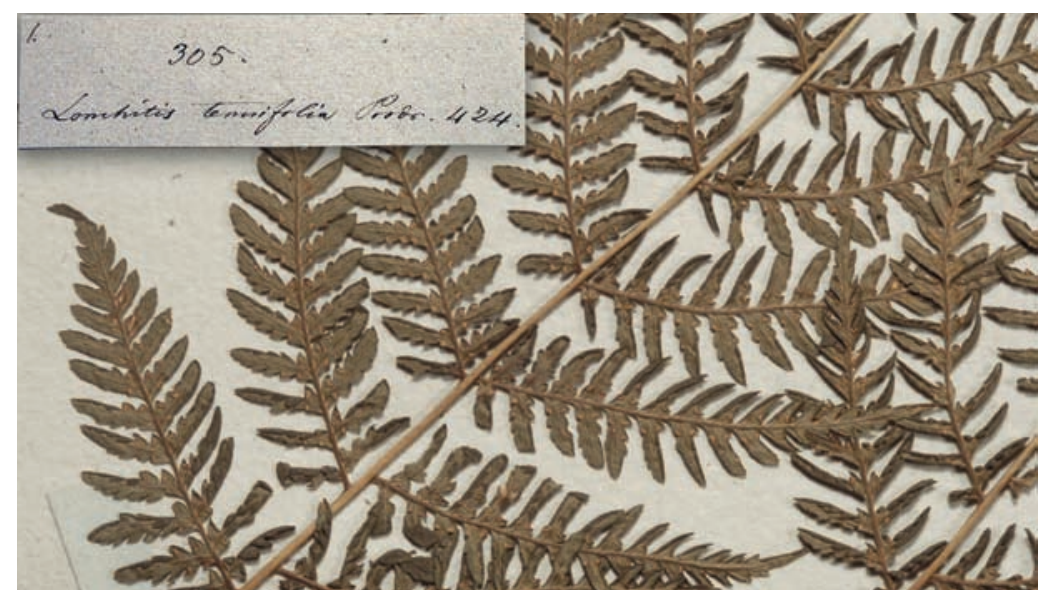

Friedrich Gottlieb Bartling set up the collection in 1832, but the Herbarium's oldest items date back as far as the 18th century, among them plants that were collected by Georg Forster (1754-1794) during the second South Seas voyage led by James Cook (1728-1779). Further important items from this period are the Plantae Malabaricae, one of the first large-scale collections from south-western India, and the specimens assembled by the polymath Albrecht von Haller (1708-1777), founder of Göttingen University's Botanic Garden. Forming the centerpiece of this Göttingen collection is the herbarium of plant geographer, systematist and taxonomist August Grisebach (1814-1879). This contains not only his specimens from Europe, but also extensive collections from South America, the West Indies, Asia and northern Africa.

The herbarium is in constant use today for research purposes. Specimens are made available on loan, enabling researchers to undertake investigations involving particular specimens from the collection. In recent years, the Göttingen Herbarium has played an active role in a worldwide initiative to digitise important plant specimens. High-resolution scans of the nomenclatural types were integrated into an online database, thereby making them accessible to scientists all over the world. 


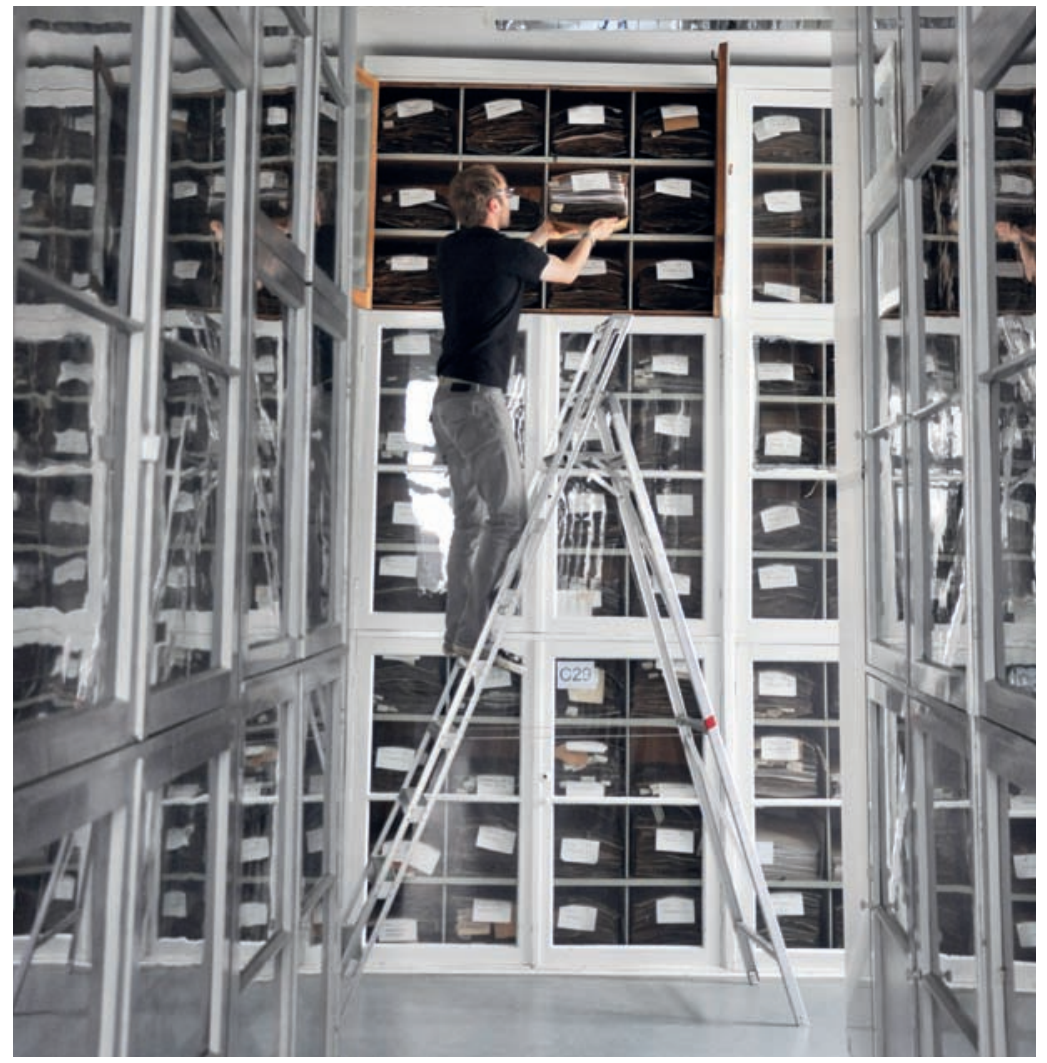

In addition to providing the material basis for classical botanical studies such as revisions, monographs and flora treatments, the plant specimens in the Göttingen Herbarium are used for molecular research addressing research topics in the areas of evolutionary biology and biogeography

Marc Appelhans \& Jochen Heinrichs

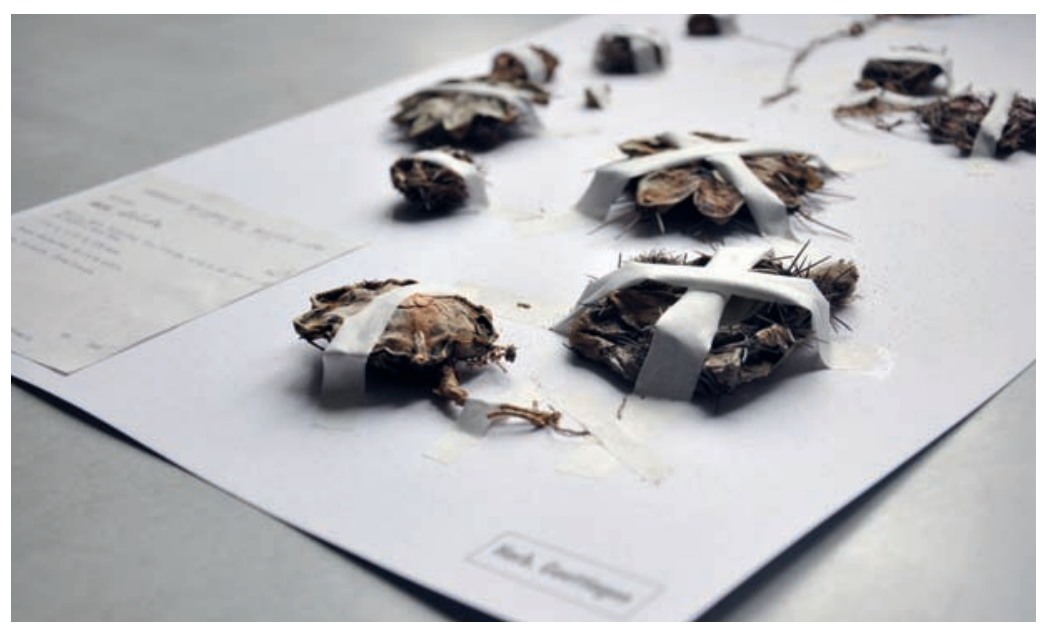

View of one of the four collection rooms. The plant specimens are bound together into fascicles and organised on the basis of their evolutionary relationships. Photographs: Marc Appelhans
Recalcitrant plants. Not all plants can be easily pressed. In the case of cacti it is usual for the plant to be cut into slices or conserved in a jar containing alcohol, rather than mounted on a herbarium sheet. For plants with large leaves or inflorescences such as palms, large format sheets of paper are frequently used or the leaves are cut into pieces, which are then mounted on several sheets. 


\section{Pharmacognostic Collection}

Albrecht von Haller Institute for Plant Sciences

Untere Karspüle 2 • 37073 Göttingen • www.uni-goettingen.de/pharmacognostic-collection

Roots of the great yellow gentian (left) and a ginger plant (right). The original seal of the gentian specimen is still present. Photographs: Marc Appelhans

Fruit and seed exhibits. Examples of medicinal plants. From left to right: poppy fruits, seeds of the castor bean, fruits of dill and coriander
Göttingen University's Pharmacognostic Collection was established in 1836 by the Göttingen pharmacologist Heinrich August Ludwig Wiggers. The collection served primarily as reference material in the identification of plants for production of medicines. By the time of Wiggers' death, the collection had grown to some 5,000 items. The estate left by Carl F. W. Mettenheimer, an apothecary resident in Giessen, expanded the collection further by approximately 1,900 items. After the pharmaceutical department of Göttingen University ceased operations in 1935, the Pharmacognostic Collection was forgotten. Packed into wooden crates, it survived in the attic of the Botanical Institute until its chance rediscovery in 1997. The objects were then examined, entered in a database and housed in a collection room in the department of Systematic Botany.

Today, the collection consists of around 8,500 items, 7,543 of which are registered in the collection catalogue. Although the collection has no curator's position as such, the holdings are made available for research purposes by the department of Systematic Botany.

The Pharmacognostic Collection contains a cross section of the medicinal plants dating from the 19th century, many of them preserved in their original jars and boxes carrying the original labels and seals. In addition to pharmaceutical plants, which are present primarily in the form of leaves, seeds and bark, the collection contains some items of animal origin such
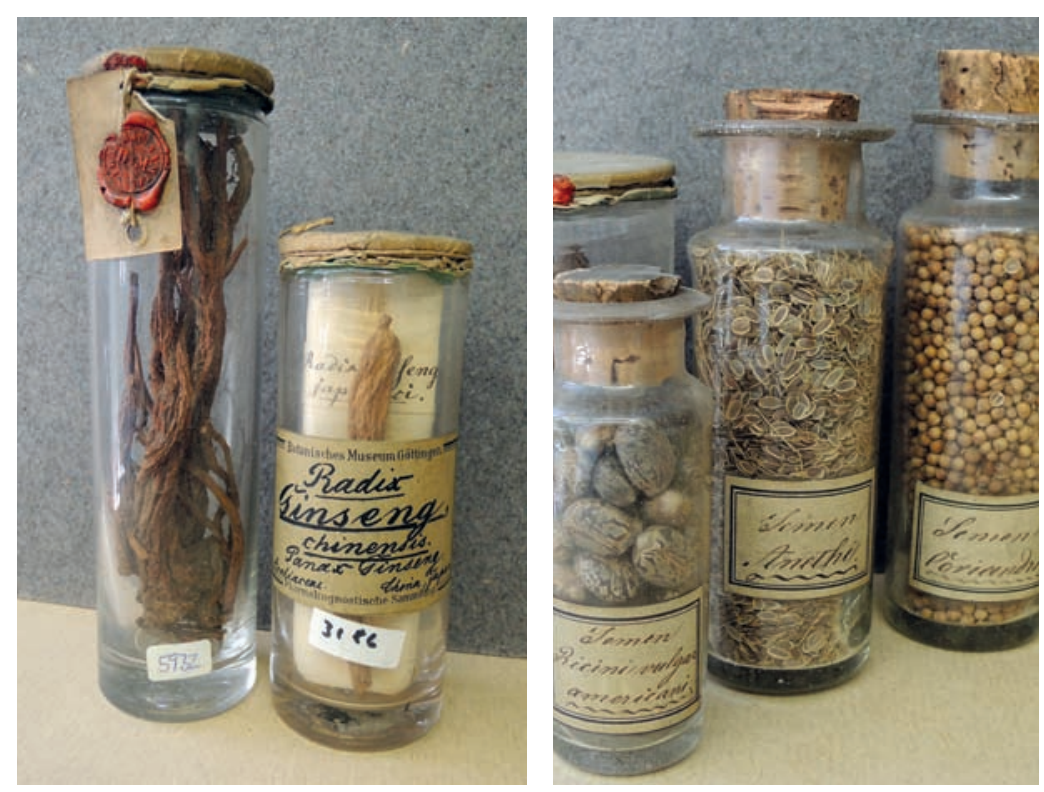

Established: 1836

Number of items: c. 8,500 $(7,543$ catalogued)

Public exhibition: no

\section{Contact:}

Dr. Marc Appelhans

Tel.: +49 551 39-22220

Marc.Appelhans@biologie. uni-goettingen.de 


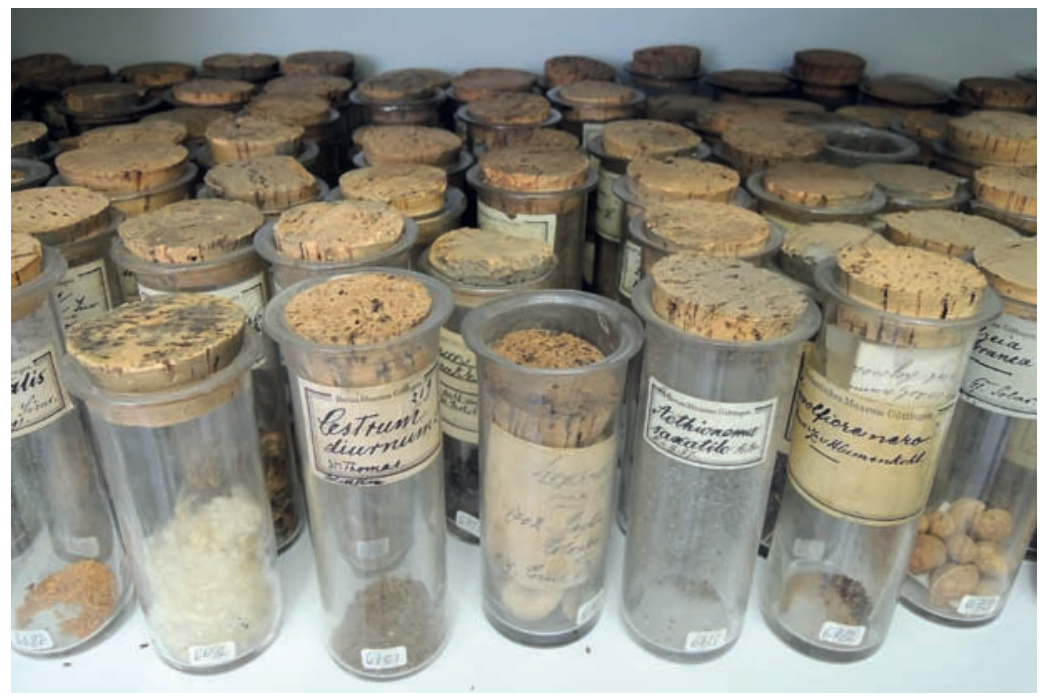

as musk glands, elk hoofs, cochineals (scale insects) and sponges. The collection also holds some especially noteworthy individual items such as the first arrow poison, which arrived in Germany during the 19th century and was analysed by Justus Liebig, a piece of bark from the 'monkey pot tree' collected by Alexander von Humboldt in South America, and oddities such as lizards in lavender flowers. A jar full of raw opium that originally formed part of the collection has in the meantime been handed over to the police.

Marc Appelhans

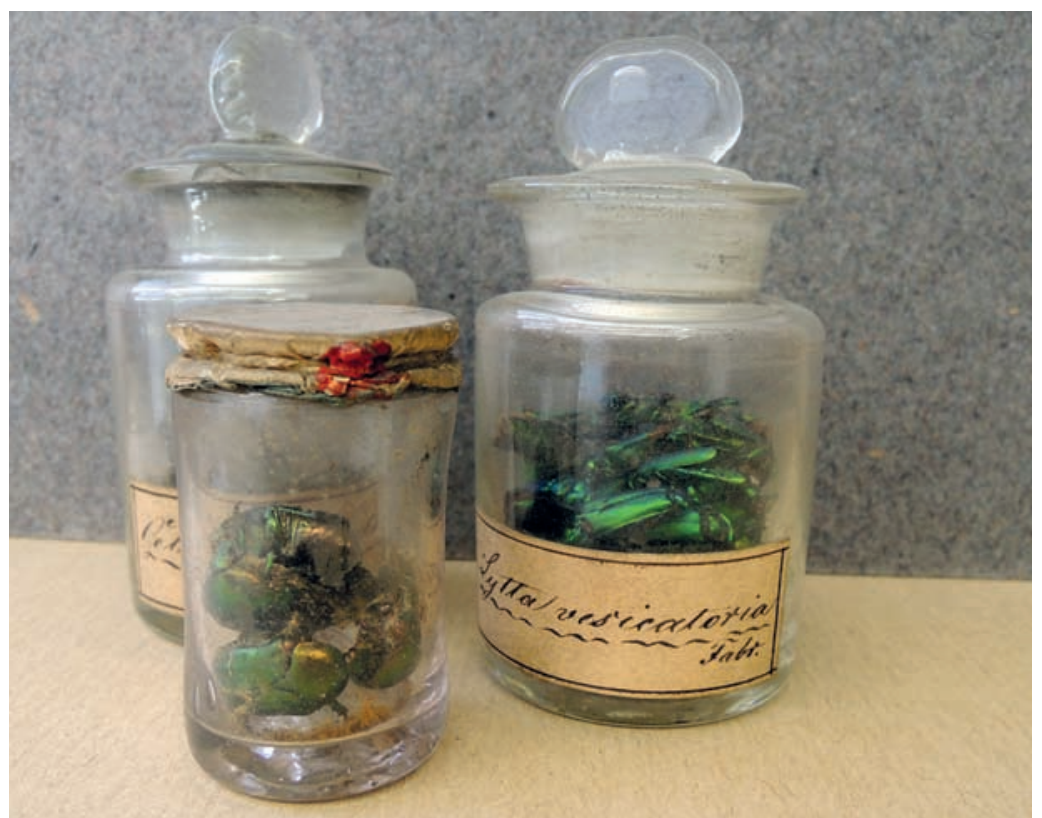

View into a collection cabinet. In total, 7,543 collection items have already been catalogued and assigned a serial number. The numbers are to be seen at the base of the glass jars.
Zoological items. The great majority of the items making up the pharmacological collection originate from the world of plants. But specimens of animal origin are also present. The beetles in the jar, right, bear the name 'Spanish fly'. These creatures were ground up and utilised as potency remedies. 


\section{Culture Collection of Algae}

Albrecht von Haller Institute for Plant Sciences

Nikolausberger Weg 18 • 37073 Göttingen • www.epsag.uni-goettingen.de

Many green algae of the especially beautiful order Desmidiales are seriously endangered in their typical habitats, the low-nutrient moorlands, due to human activities and climate change. The culture of the desmid Micrasterias crux-melitensis SAG 153.80 was isolated in France in 1968. It is used as a model organism in school and university teaching. Cell diameter c. $0.1 \mathrm{~mm}$; photographs: SAG

\section{Established: 1954}

Number of items: c. 2,400

Public exhibition: no

Tours: by appointment

\section{Contact:}

Dr. Maike Lorenz

Tel.: +49 551 39-7870, -5740 epsag@uni-goettingen.de and mlorenz@uni-goettingen.de
Algae are present almost everywhere - in all forms and colours. In order that their particular characteristics can be investigated in the laboratory, living and reproducible algae cultures are required. The Culture Collection of Algae at Göttingen University (Sammlung von Algenkulturen der Universität Göttingen, SAG) is amongst the largest and longest-standing collections of microscopic algae in the world, containing more than 2,400 strains of microalgae and cyanobacteria that represent over 500 genera and 1,400 species. These were isolated worldwide, primarily from terrestrial habitats and fresh water. A fifth of the algae strains held in Göttingen are type references of particularly high value.

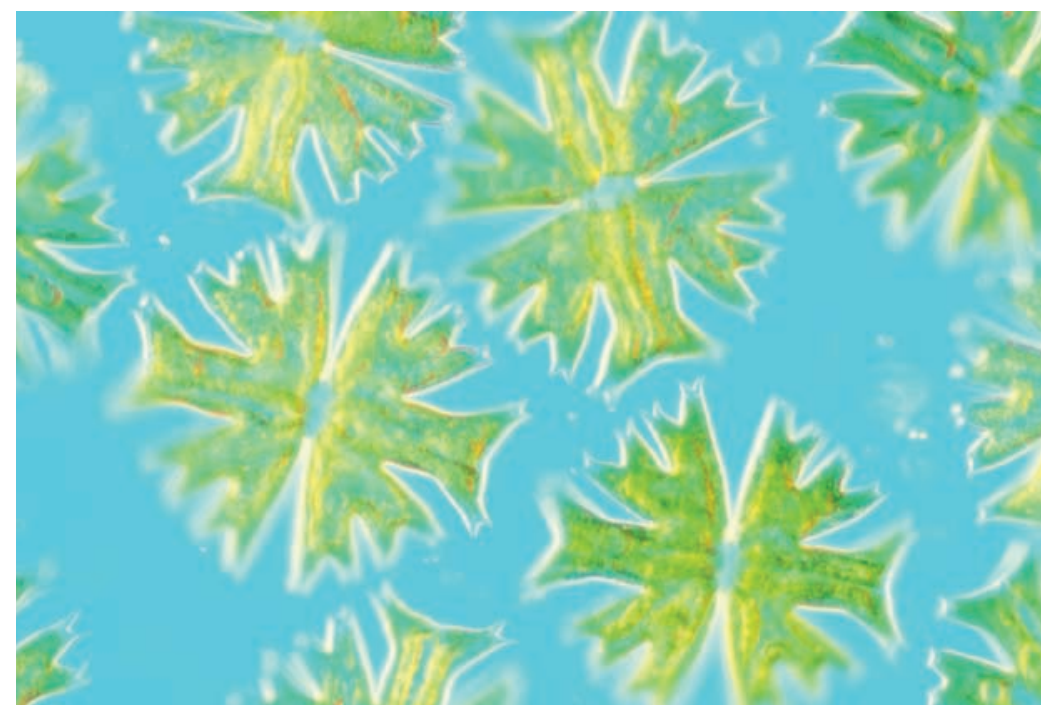

The collection was first established at Göttingen University in 1954 by Ernst Georg Pringsheim (1881-1970), a pioneer of algae research. It has been growing steadily ever since. As a centre of biological resources and competence it has enjoyed international standing for decades. The central tasks of the collection include the preservation, research and expansion of the holdings and associated data, as well as the further development of specialist methods.

Only through microscopic observation or even molecular analyses can the special nature and diversity of many microalgae and cyanobacteria be made accessible. The algae strains maintained for the long term and reliably identified in Göttingen are available for this purpose as valuable reference material. 


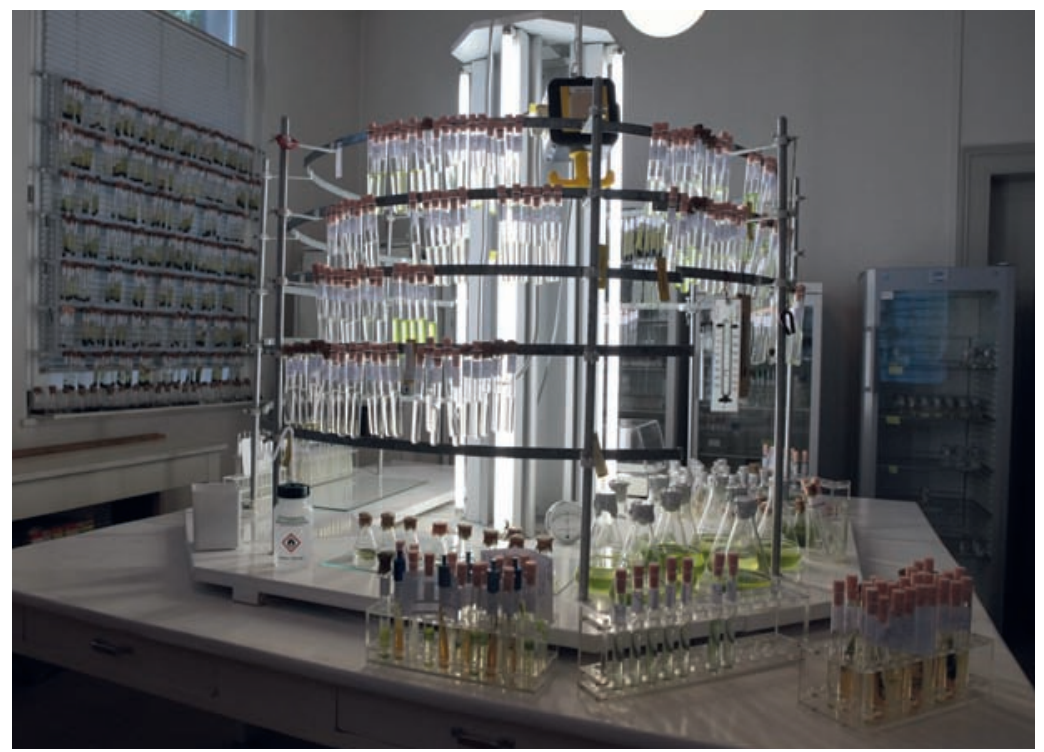

An unlimited number of identical cultures can be cultivated from each strain. In this way, the SAG's holdings are accessible for research, teaching and biotechnology purposes worldwide. They are presented in an online catalogue together with the relevant scientific information. Staff working at the collection dispatch some 2,300 algal cultures to more than 600 institutions every year. The biological material from the Göttingen collection thus constitutes a research resource intensively used in the international arena. Of special current significance are DNA signatures, which have already been identified and published in the case of half of the Göttingen algae cultures.

Maike Lorenz

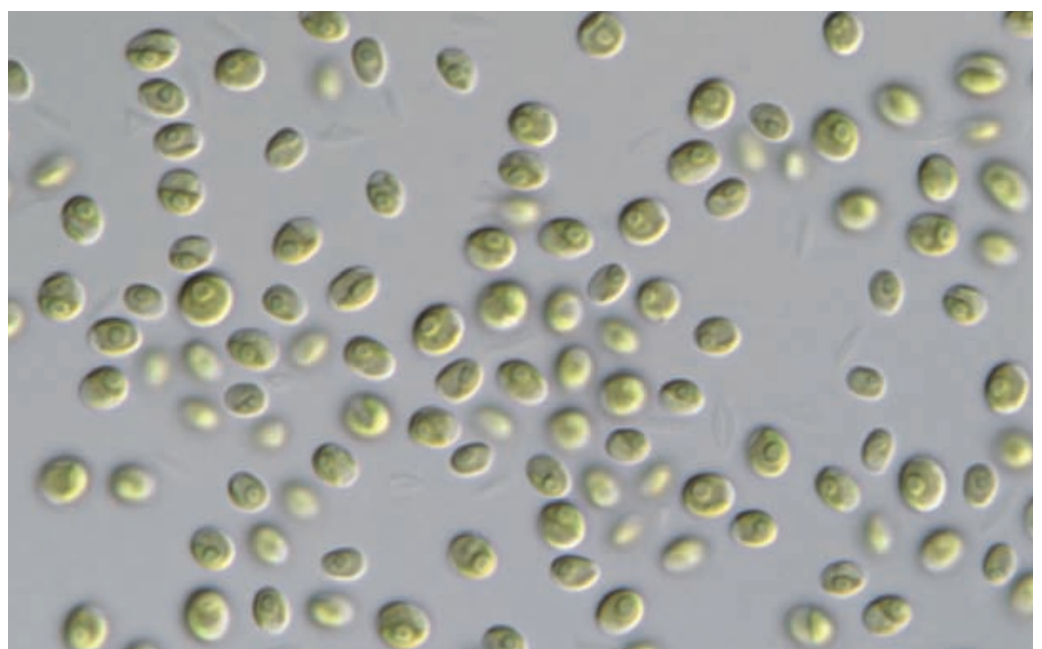

View into one of the three temperature-constant culture chambers at the Göttingen Culture Collection of Algae; photograph: Sascha Bubner
Microscopic image of the single-cell green algae Chlorella vulgaris. The type strain SAG 211-11b was isolated in 1889 by Martinus W. Beijerinck. It is the oldest surviving isolate in the world and in intensive use to this day in research and biotechnological contexts. Cell diameter c. $0.008 \mathrm{~mm}$ 


\section{Palaeobotanical Collection}

Geoscience Museum

Goldschmidtstraße 1-5 • 37077 Göttingen • www.geomuseum.uni-goettingen.de

Fossil leaf of a willow (Salix) from the Miocene fossil lagerstätte Öhningen in Baden, c. 13 million years old, width of object c. $19 \mathrm{~cm}$; photographs: Gerhard Hundertmark

Horsetail plant (Equisetites burchardti) from early Cretaceous strata of Lower Saxony, c. 138 million years old, width of object c. $8.5 \mathrm{~cm}$

\section{Established: 1777}

Number of items: c. 40,000

Public exhibition: in part

Open: Mon. to Fri. 9:00 - 17:00,

Sun. 10:00 - 16:00

Admission: free

Tours: by appointment

\section{Contact:}

Prof. Dr. Joachim Reitner Tel.: +49 551 39-7951

Dr. Alexander Gehler Tel.: +49 551 39-7998 geomuseum@gwdg.de
The first objects of Göttingen University's Palaeobotanical Collection were collected as far back as in the 17th century. These objects, originating from the Naturalienkabinett (Natural History Cabinet) of Gottfried Wilhelm Leibniz (1646-1716), came into the hands of the university in 1777.

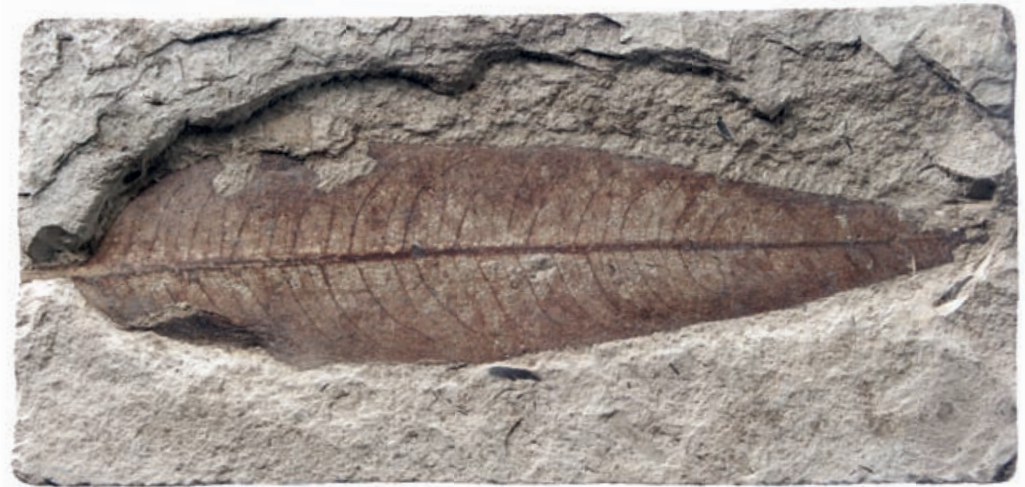

Since then, the collection has grown to number more than 40,000 macropalaeobotanical objects, micropalaeobotanical and palynological

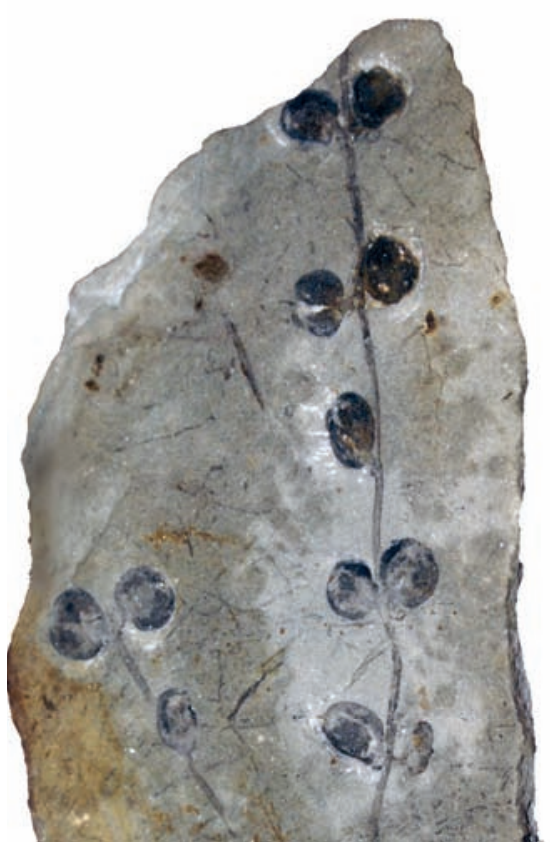
samples, slides and series from almost all geological eras and all continents (with Europe as the main regional focus).

A part of the holdings came into the possession of the university via donations or purchases of part-collections belonging to eminent palaeobotanists such as Constantin Freiherr von Ettingshausen (1826-1897), Hermann Graf zu SolmsLaubach (1842-1915) and Paul Boguslav Richter (1854-1911). Much of the material held in Göttingen was prepared for study by, for example, August Schenk (1815-1891), Henry Potonié (1857-1913), Walter Gothan (1879-1954), Hermann 


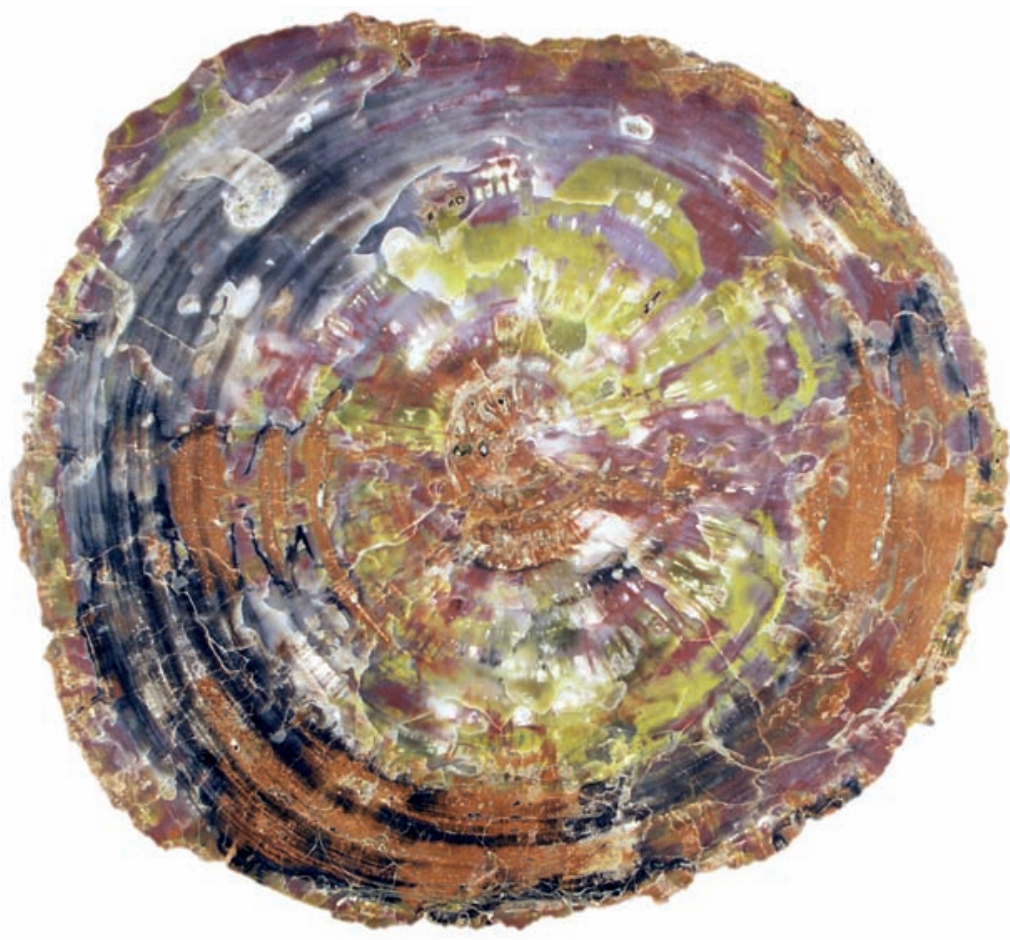

Weyland (1888-1974), Richard Kräusel (1890-1966), Rudolf Florin (1894-1965) and Adolf Straus (1904-1986). Among these items are numerous originals and type specimens going back to the earliest days of palaeobotany (Blumenbach 1779 et seqq., Berger 1832, Zenker 1833, Schenk 1867 et seqq.). In addition, the Amber Collections and several other collections from various fossil sites contain a significant portion of palaeobotanical specimens.

Mike Reich \& Tanja R. Stegemann
Polished cross-section of silicified araucaria wood of the Upper Triassic period from Arizona, USA, c. 210 million years old, object width c. $56 \mathrm{~cm}$

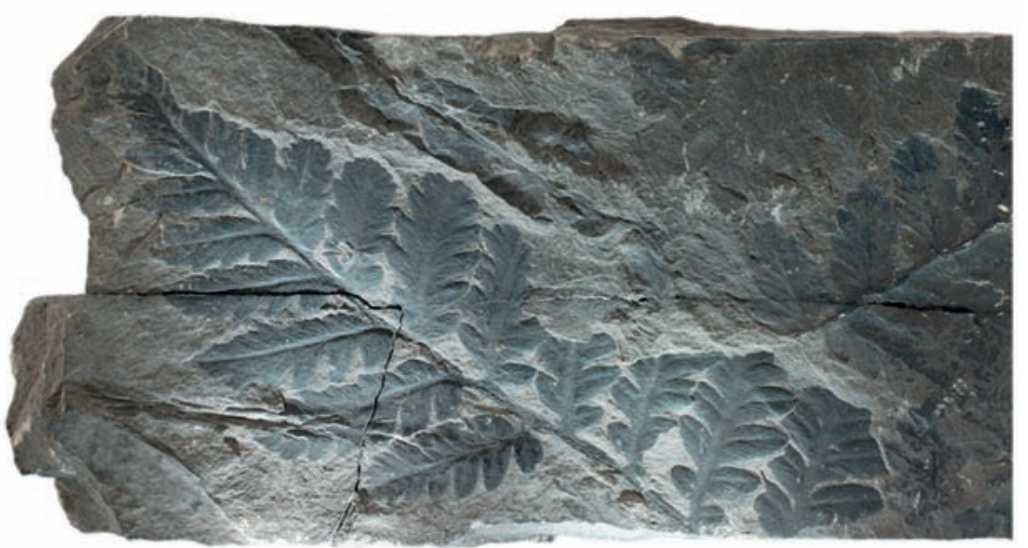

Seedfern leaf (Mariopteris) from the late Palaeozoic (Upper Carboniferous, c. 310 million years old) of the Ruhr area in Germany, object breadth c. $10 \mathrm{~cm}$ 


\section{Museum of Zoology}

Johann Friedrich Blumenbach Institute

Berliner Straße 28 • 37073 Göttingen • www.uni-goettingen.de/zoology-museum

Skeletons of various hoofed animals, in the 'Skeleton Room'. Some of the skeletons are mounted in movement poses. Photographs: Christian Fischer
The collections in the Museum of Zoology date from the Royal Academic Museum Göttingen that was founded in 1773 to preserve the collections of Christian Wilhelm Büttner (1716-1801), following their purchase. In subsequent years, Johann Friedrich Blumenbach (1752-1840), Deputy Director of the Academic Museum at that time, sorted and catalogued the collection, which had previously been in a state of total disorder. Blumenbach also went on to expand the collection significantly through purchases and donations over the ensuing period. However, only a small number of these initial items remain present in the Museum of Zoology today.

In the meantime, the holdings of the Museum of Zoology have grown to number well over 100,000 objects. Important additions were made especially during the second half of the 19th century and shortly after the turn of that century. Worthy of mention in this context is, amongst others, the physician Rudolf Schütte (1835-1886). After emigrating to Australia, Schütte donated numerous animals representing Australian fauna to the Museum of Zoology. Professor Otto Bürger (1865-1945) brought back a large amount of material collected during his journey to South America, and the bird collection of Heinrich Kirchhoff (1789-1871) from Nienburg (Weser), one of the most important ornithological collections in Europe, was purchased in 1877. In addition, the collection was significantly enriched when a large quantity of marine organisms were received from the marine research station in Naples, where numerous Göttingen scientists were active. Furthermore, some of the biological specimens

gathered during the first German deep-sea expedition 'Valdivia',

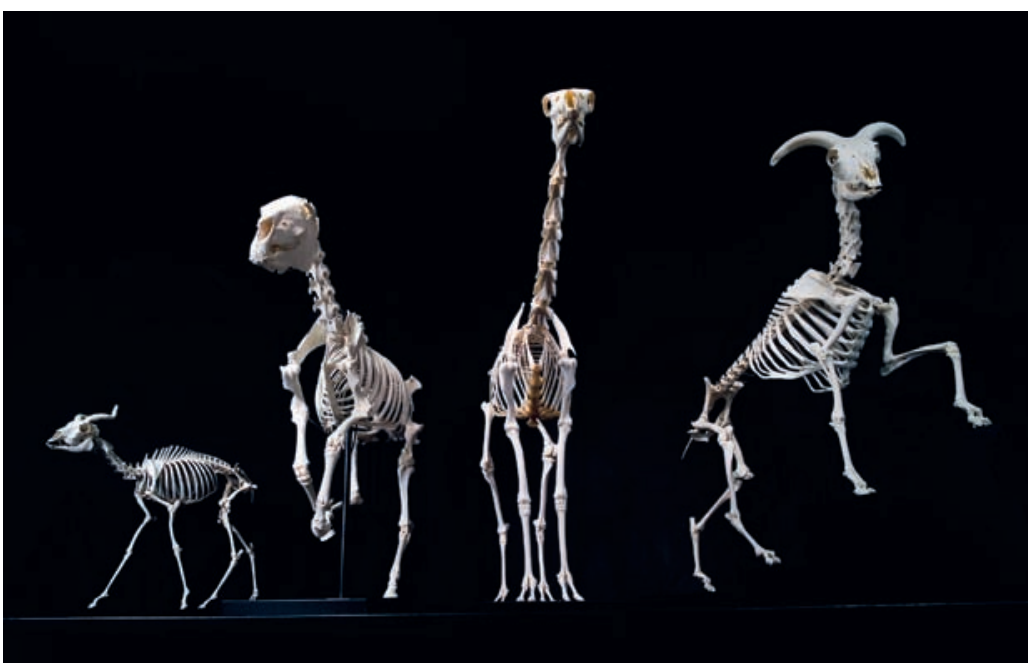

Established: 1773

Number of items: c. 150,000

Public exhibition: yes

Open: Sun. 10:00 - 16:00

Admission: $€ 1$

Tours: Mon. to Fri. by appointment

\section{Contact:}

Dr. Gert Tröster

Tel.: +49551 39-5524

gtroest@gwdg.de 


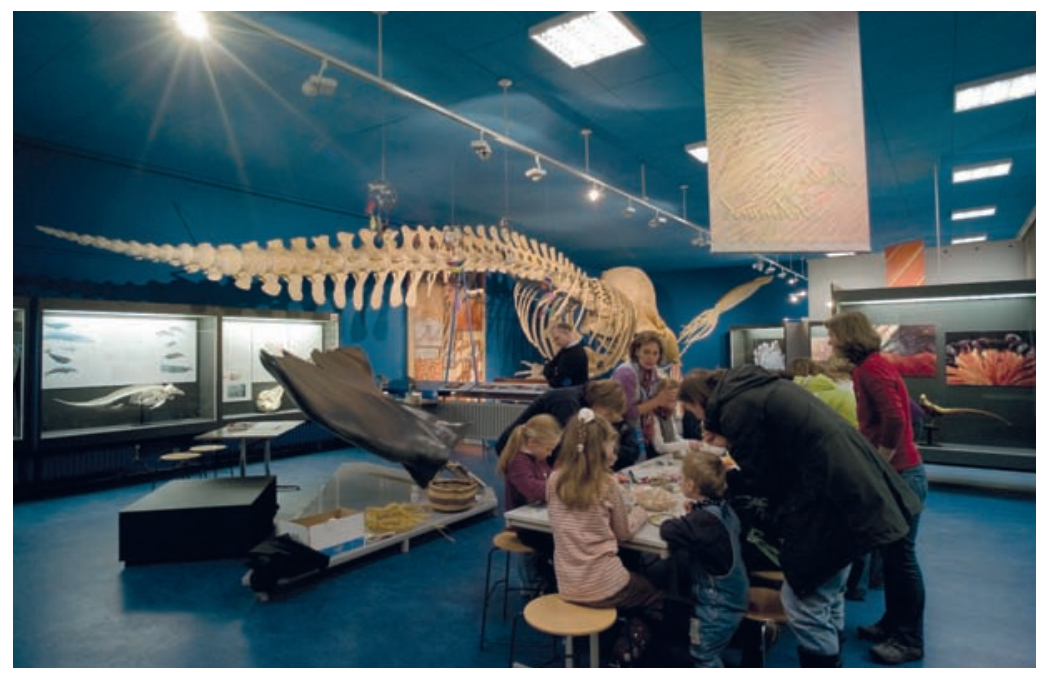

undertaken in 1898/99 in the Atlantic and Indian Oceans, are held in Göttingen.

More recently, the holdings have continued to grow. The Museum of Zoology has received several regional collections of insects and a bird collection as donations. Several thousand insect and spider species from Madagascar and a portion of the biological findings from an Arctic expedition of the research ship 'Polar Stern' have been incorporated. Today, the Göttingen Museum preserves a host of items and assemblages of special scientific value, one of them being the type specimen collection of crustacean species and flatworms that have resulted from many years of research work carried out at the Institute of Zoology.

Gert Tröster

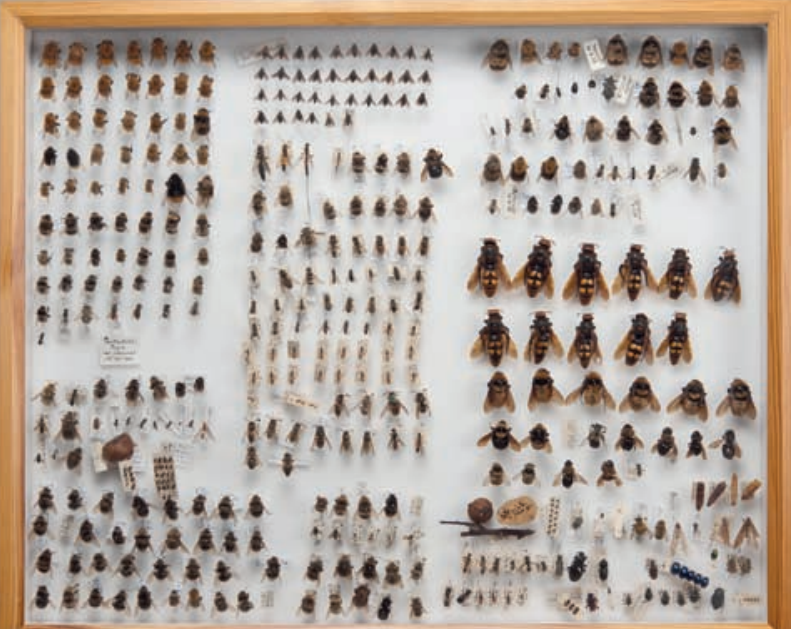

The Whale Room 


\section{Bird Collection}

Johann Friedrich Blumenbach Institute

Berliner Straße 28 • 37073 Göttingen • www.uni-goettingen.de/zoology-museum

Bird skins from the collection of Heinrich Kirchhoff (1789-1871); photographs: Christian Fischer
Established: 1773

Number of items: c. 6,000

Public exhibition: yes

Open: Sun. 10:00 - 16:00

Admission: $€ 1$

Tours: Mon. to Fri.

by appointment

\section{Contact:}

Dr. Gert Tröster

Tel.: +49551 39-5524

gtroest@gwdg.de
The ornithological collection of the Museum of Zoology consists of several thousand specimens, most of which originate from the mid to end 19th century. Outstanding researchers of that period working in the area of ornithology left valuable items or indeed entire collections to the Museum of Zoology, among them the physician and researcher of African birds Carl Johann Gustav Hartlaub (1814-1900) and the merchant and travelling researcher Friedrich Herrmann Otto Finsch (1839-1917). The latter undertook journeys primarily in the Australian region and New Guinea and parts of Asia. A particularly extensive collection of birds originating from Columbia was contributed to the collection by Professor Otto Bürger (1865-1945). This included numerous species of humming birds and tanagers, brilliantly colourful treasures otherwise to be found only on the American continent.

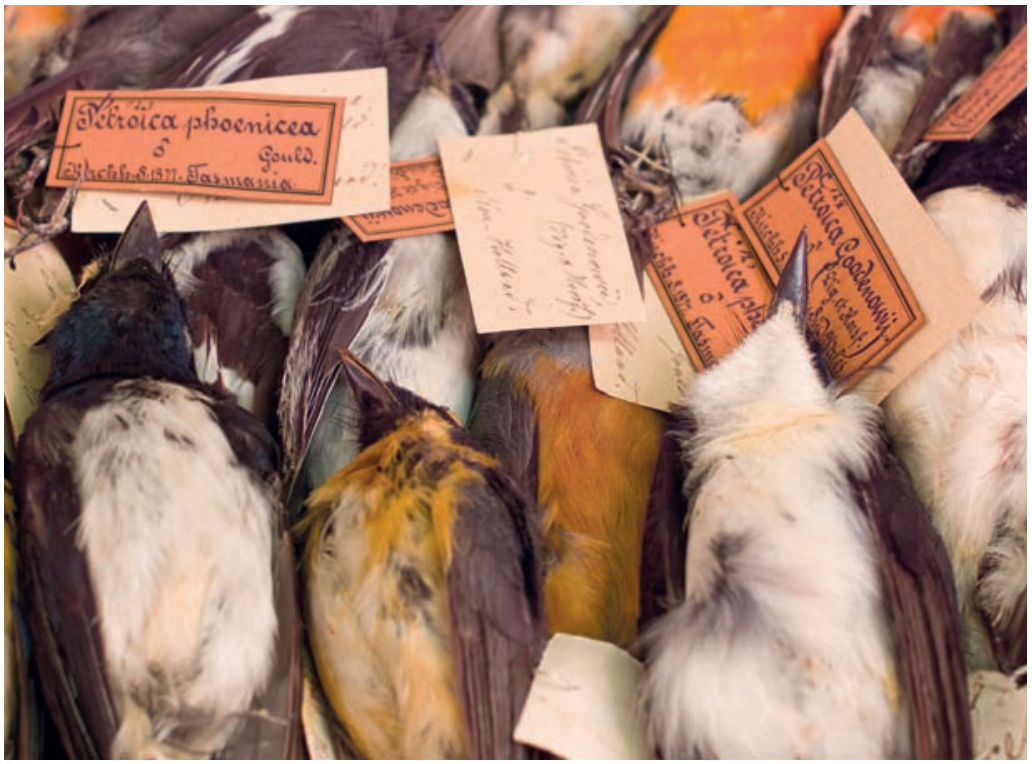

The major part of the ornithological collection originated from the large collection of Heinrich Kirchhoff (1789-1871). In only a matter of years, he compiled one of Europe's most significant collections at the Domäne Schäferhof near Nienburg on the river Weser and sold it to the Museum of Zoology already in his lifetime.

Among the most valuable items in the collection are undoubtedly the kaka from the Norfolk Islands, a pair of huias from New Zealand, and 


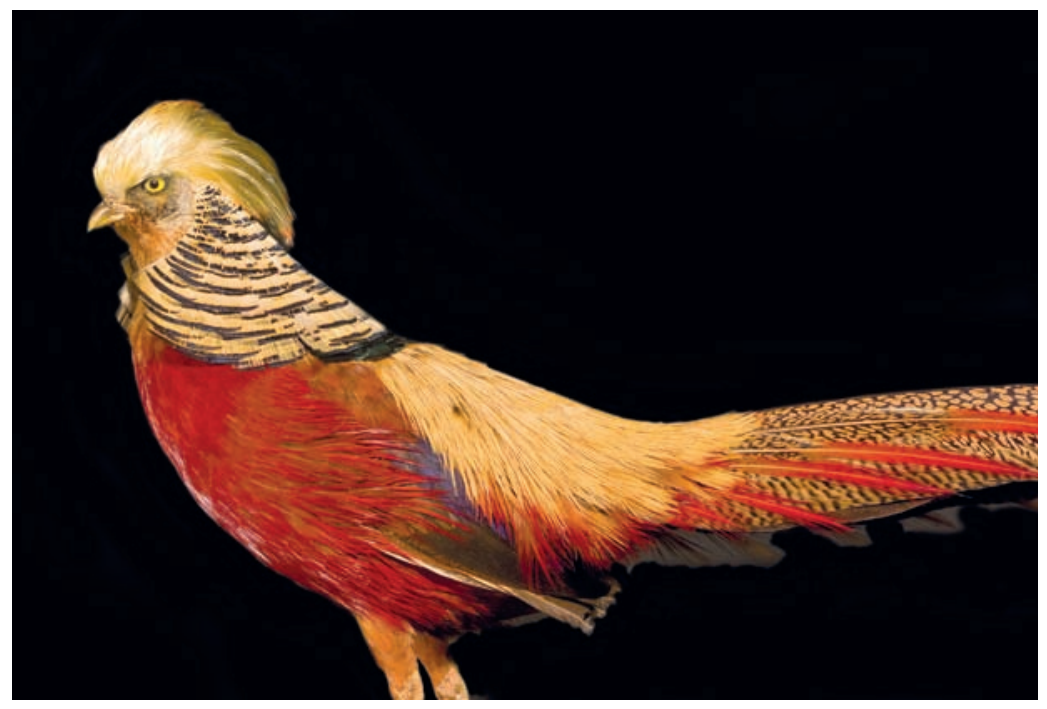

the North American passenger pigeon. All these bird species have been extinct for over a century, therefore the specimens still preserved in old collections are all that remains to bear witness of their existence. The skeleton of the extinct great auk is equally precious. Long after the death of the last living creature of the species, this skeleton was pieced together from bones found in what used to be the habitat of this bird species, small islands in the North Atlantic.
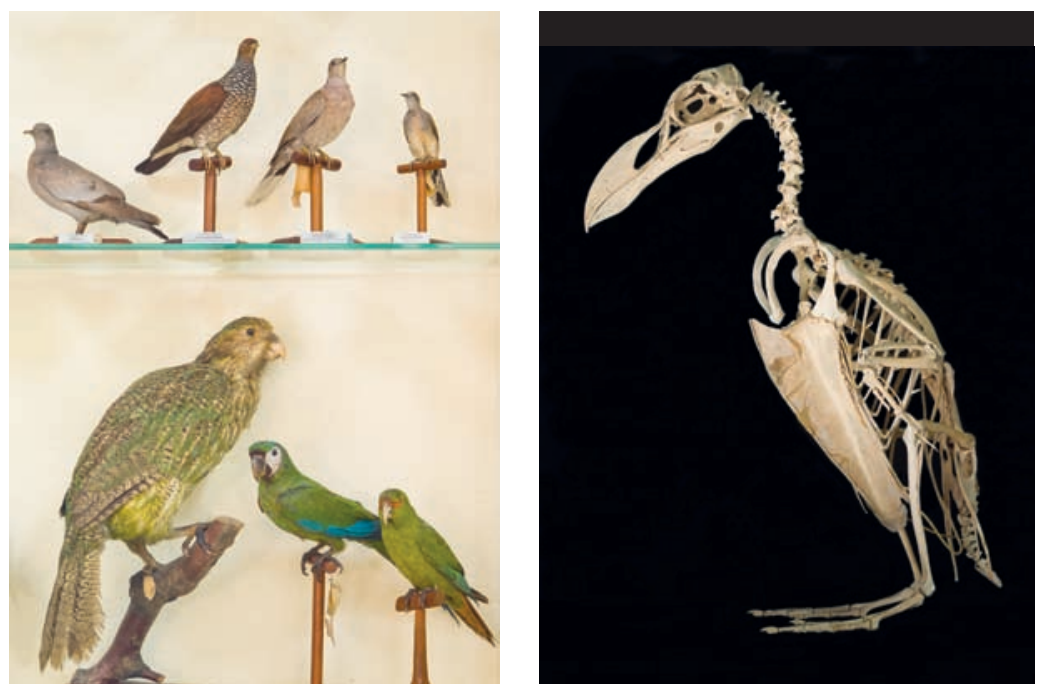

Male golden pheasant (Chrysolophus pictus) from the subtropical mountain jungle of China
Mounted birds from the Kirchhoff Collection (1789-1871)

Great auk (Pinguinus impennis) from North Atlantic islands, extinct 


\section{Anthropological Collection}

Johann Friedrich Blumenbach Institute

Bürgerstraße 50 • 37073 Göttingen • www.uni-goettingen.de/anthropology-collection

Casts of hominids, left: Homo habilis, centre: Australopithecus boisei, right: Homo erectus; photographs: Stephan Eckardt
The Anthropological Collection of the Department for Historical Anthropology and Human Ecology is - in relative terms - one of the university's younger collections. In the 1950s, its foundations were laid when the university received an extensive collection of human skulls from the Hamburg Museum of Ethnology (Museum für Völkerkunde). This assemblage was augmented in the 1970s by a collection of primate skulls originating from the Remane Collection in Kiel. The present collection is comprised of numerous skeletal series dating from different time periods and regions of Germany. In addition, there is a steady influx of (pre)historic skeletons for which reburial is not foreseen.

A prominent feature of the collection are Bronze Age bone finds that are kept in frozen storage and utilized to establish a genetic archive. A collection of specimens exhibiting skeletal pathologies as well as numerous casts of the world's most significant hominid finds complement the collection. Much of the skeleton material is in constant use not only in academic teaching but also for research work conducted in the areas of morphology, histology and molecular genetics.

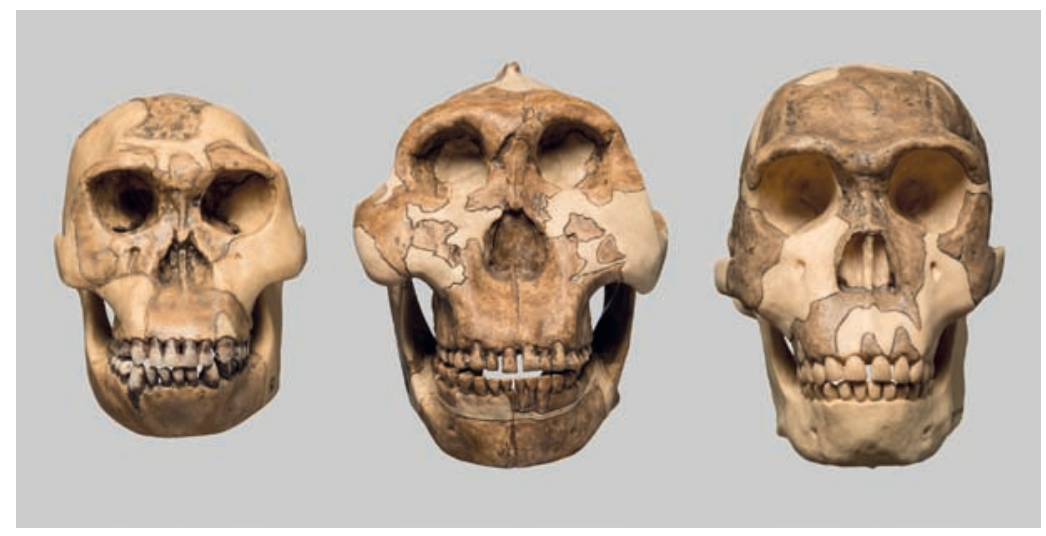

A prehistoric Guanche mummy from Tenerife that was brought to Göttingen in 1802 formerly belonged to the Blumenbach Natural History Collection. The same applies in the case of two Egyptian mummies. One of these was a gift from the Duke of Coburg-Gotha and his brother Prince Friedrich to Johann Friedrich Blumenbach (1752-1840). The other mummy was given to Blumenbach by the King of Denmark. Further mummies in the present collection originate from pre-Columbian South America. The mummies thus represent an element of the collection with deep roots in tradition. Interestingly, one of the Egyptian coffins, 


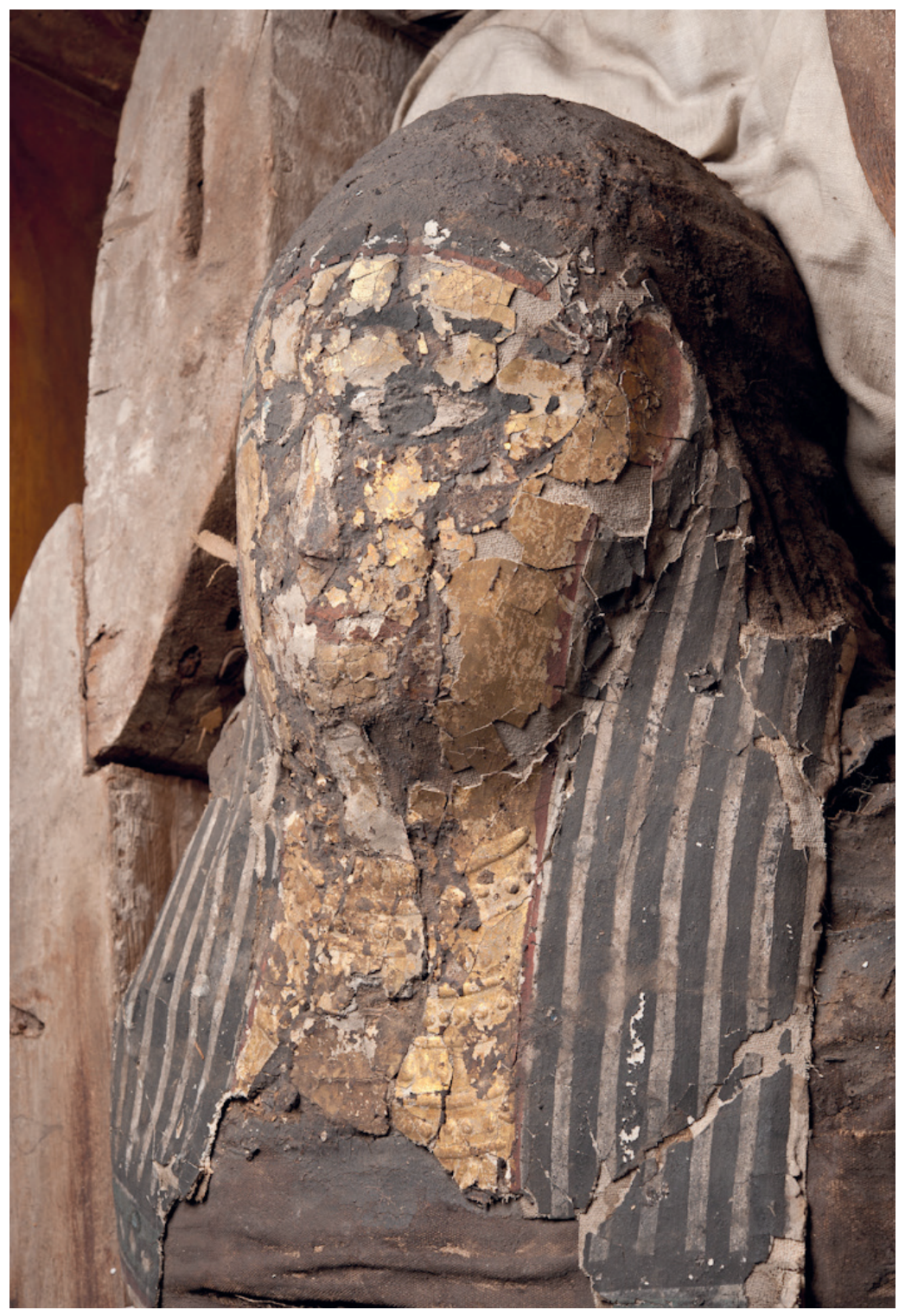

Egyptian mummy from Blumenbach's natural history collection

crafted from sycamore wood, is located in the Department for Historical Anthropology, while the second belongs to the Collection at the Institute of Archaeology.

Birgit Großkopf 


\section{Forest Zoology and Wildlife Biology Collections}

Büsgen Institute • Department of Forest Zoology and Forest Conservation

Büsgenweg 3 • 37077 Göttingen • www.uni-goettingen.de/forest-zoology

Regional bird species presented in the teaching collection on birds: red-backed shrike, hawfinch and robin; photograph: Richard Schütz

Racoons. The release of a pair into the wild in 1934 is the founding event for this 'invasive species', a night-active small mammal from North America whose preferred habitat in middle and northeast Germany lies in urban areas. Photograph: Gerrit Holighaus
Both of these collections have their origin in the research and teaching activities of the Forest Academy, which was founded in 1868 in Hannoversch Münden. Individual collections were immediately set up for use in the subjects taught at that time - entomology, general zoology, ornithology and mammalogy. Expanded considerably, these collections have survived over the years and give a comprehensive view of insects, birds and game - in this case on the basis of skulls, antlers and horns - indigenous to the region of southern Lower Saxony. Exhibits from the Königlich Hannoverscher Jägerhof, which ceased operations in 1868, vividly bear witness to hunting traditions. Rare items such as the Père David's deer Elaphurus davidianus and the extinct Schomburgk's deer Rucervus schomburgki are also present. Worthy of special note is the extensive historical collection of birds of prey, owls and wildfowl from Lower Saxony built up by Wilhelm Georg Glimmann (1802-1876).
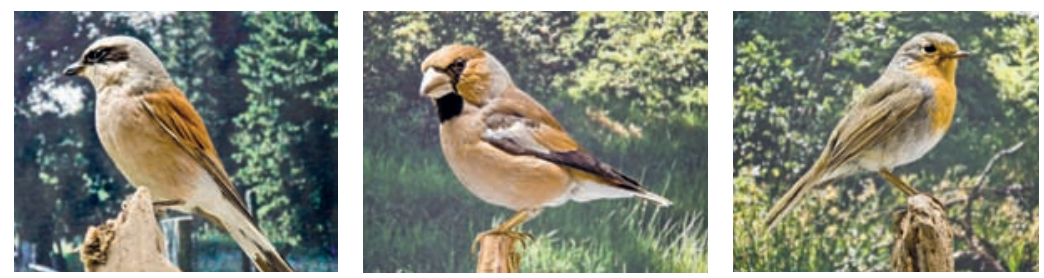

Established: mid 19th century

\section{Number of items:}

Bird Collection c. 700

Wildlife Biology Collection c. 3,000 Insect Collection c. 35,000

\section{Public exhibition: yes}

Open: Bird Collection by appointment, wildlife biology collection currently only for teaching and research

\section{Admission: free}

Tours: by appointment

\section{Contact:}

Dr. Bernhard Weissbecker Tel.: +49551 39-33687 bweissb@gwdg.de
Preserved in excellent condition, birds constitute a major part of the teaching collection in use today. Far larger yet in numerical terms, however,

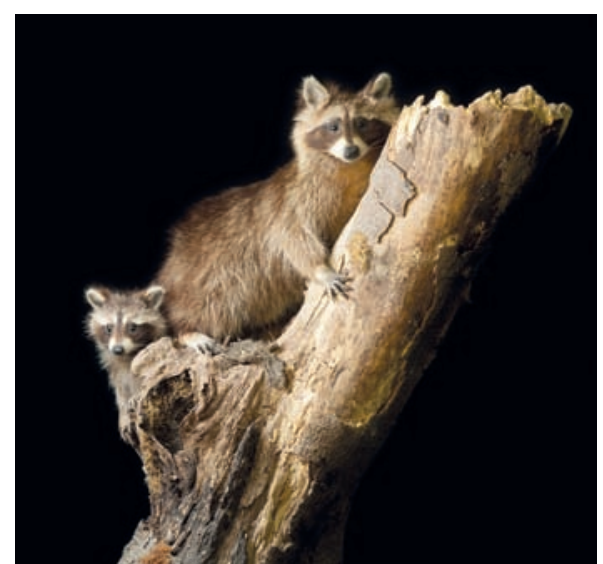
is the Wildmarkenkartei catalogue begun in 1904 and the scientific insect collection consisting of 35,000 specimens. In addition to type species, the latter contains items of particular interest such as wasps from the collections of Julius Theodor Christian Ratzeburg (1801-1871) and Arnold Förster (1810-1884). Ratzeburg, a student of Alexander von 


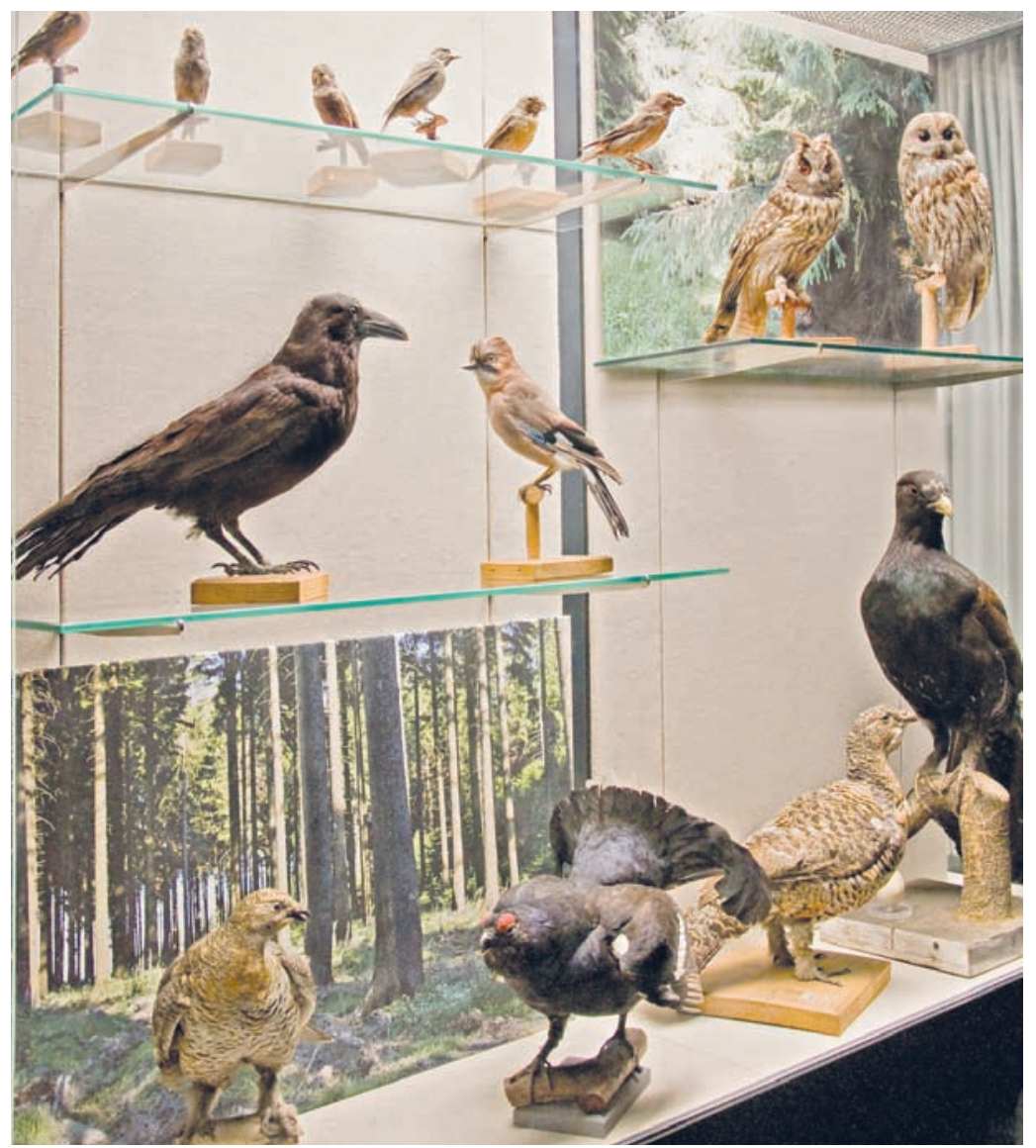

Humboldt, is regarded as one of the earliest ecologists and a founder figure of forest entomology, the study of forest insects.

Gerrit Holighaus

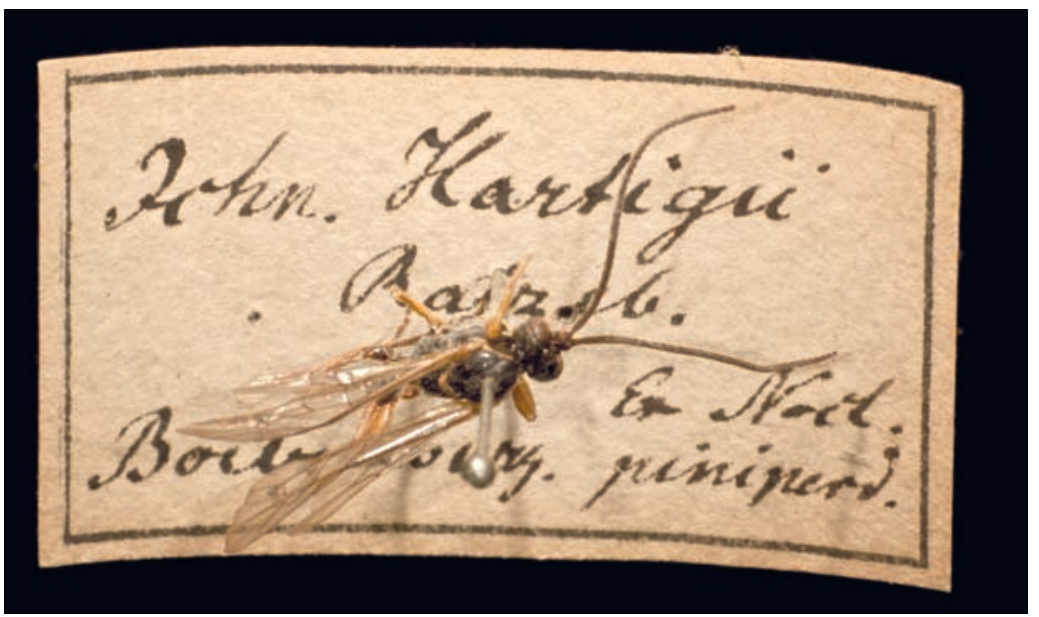

The conifer forest - one of the display cases arranged according to biotopes; photograph: Richard Schütz
Ichneumonid wasp with original label by Julius Theodor Christian Ratzeburg. In his seminal work 'Die Forst-Insecten' it was described as a parasite of a pine moth and named /chneumon bilineatus var. Hartigii, presumably after Theodor Hartig (1805-1880), son of one of the founding fathers of the forest sciences. Photograph: Gerrit Holighaus 


\section{Palaeozoological Collections}

Geoscience Museum

Goldschmidtstraße 1-5 • 37077 Göttingen • www.geomuseum.uni-goettingen.de

View into the permanent exhibition in which numerous palaeozoological specimens of the Geoscience Museum are on display; photographs: Gerhard Hundertmark
The Göttingen Palaeozoological Collections are among the oldest, most extensive and most tradition-rich of their kind in Europe. Their historical origins predate the university's founding in 1737. Consisting of several parts or partial collections, they contain fossils of all stratigraphic periods of the Phanerozoic (541 million years old and younger) from every continent and also earliest material from the Meso- and Neoproterozoic (up to 1.6 billion years old) of Europe, Asia, Africa and Australia.

Systematic focus areas of the Invertebrate Collection (c. 250,000 items) are sponges, molluscs and echinoderms. The first group is represented by the collections of Hermann Rauff (1853-1900), Anton Schrammen (1869-1953) and Joachim Reitner (b. 1952). The Mollusc Collection was accumulated by Heinrich Ludolf Wissman (1815-1892), Adolf von Koenen (1837-1915), Roland Brinkmann (1898-1995) and Otto Heinrich Walliser (1928-2010), among others. Echinoderms were accumulated and processed by, for example, Reimund Haude (b. 1939) and Mike Reich (b. 1973).

The main focus of the fossil Vertebrates Collection (c. 100,000) are primarily fish, accumulated by Walter Robert Gross (1903-1974) and Hans-Peter Schultze (b. 1937), reptiles, and mammals of the Pleistocene. Researchers such as Johann Friedrich Blumenbach (1752-1840), Otto Jaekel (1863-1929) and Friedrich Freiherr von Huene (1875-1969) worked on numerous objects and series of the vertebrate collection. In the scope of comparative research projects, collections were set up containing skeletal specimens of extant species (c. 1,000), as well as alcohol-preserved and dry specimens of marine organisms from throughout the world (c. 10,000).

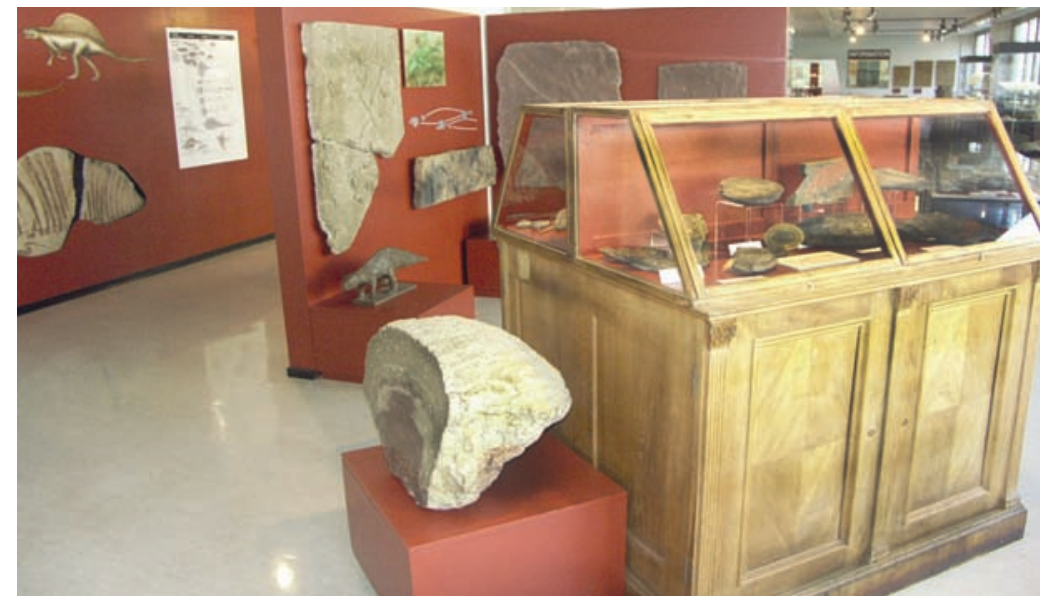

Established: 1734

Number of items: c. 2,472,000 in 6 partial collections

Public exhibition: yes

Open: Mon. to Fri. 9:00 - 17:00

Sun. 10:00 - 16:00

Admission: free

Tours: by appointment

\section{Contact:}

Prof. Dr. Joachim Reitner

Tel.: +49 551 39-7951

Dr. Alexander Gehler

Tel.: +49 551 39-7998

geomuseum@gwdg.de 


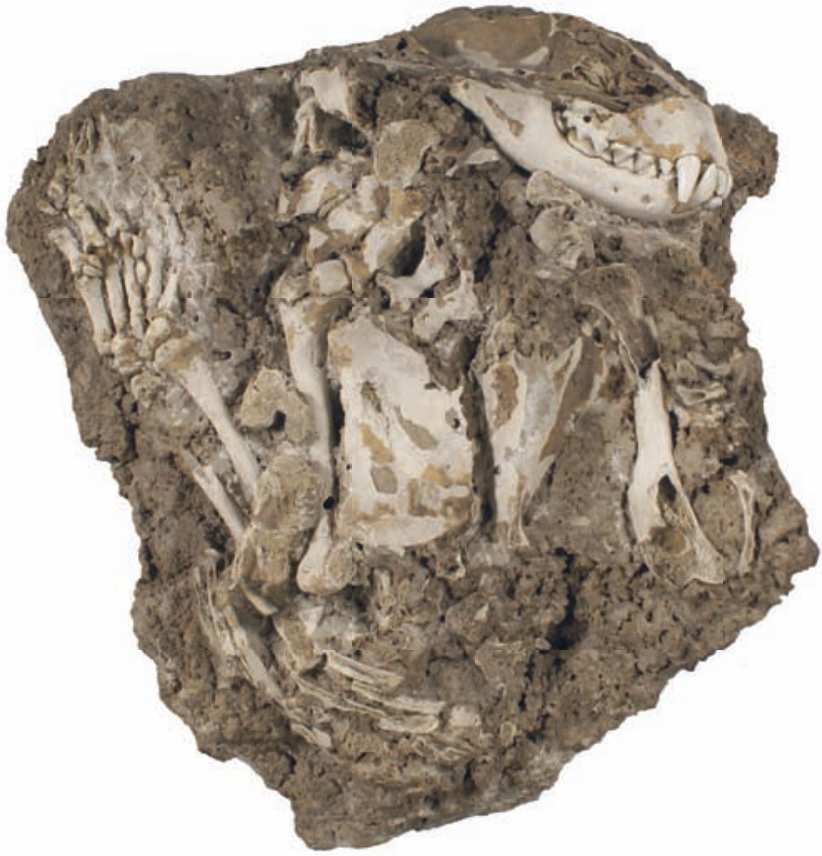

With respect to trace fossils and tracks (12,000 items), large parts of the collected material originate from Othenio Abel (1875-1946), Hermann Schmidt (1892-1978), Kurt Fiege (1897-1983) and Adolf Seilacher (1925-2014).

The Micropalaeontological Collection containing many thousands of slides and series with millions of individual objects consists in large parts of microfossils and microscopic remains of macrofossils. Here, the emphasis is on ostracodes of all periods collected by Ernst Lienenklaus (1849-1905), Johannes Wolburg (1905-1976), Erich L. Brand (19142011), Arnold Rabien (1918-2011), Helga Groos-Uffenorde (b. 1938) and Henning Uffenorde (b. 1941). A further focus is on foraminifers of the Mesozoic and Cenozoic, studied by Georg Bornemann (1831-1896) and Sigfried Ritzkowski (b. 1933), among others. Also present are conodonts of the Palaeozoic from the extensive holdings of Hermann Schmidt, Otto

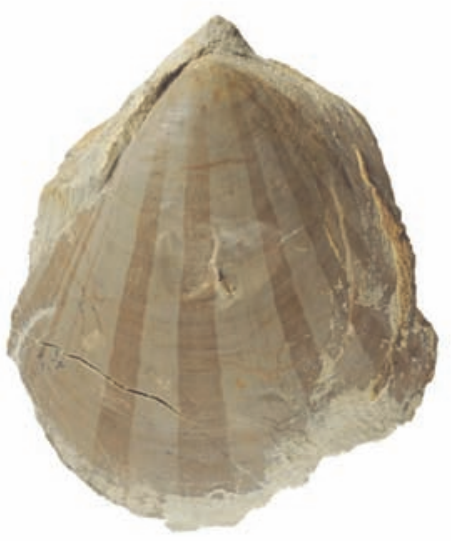

Heinrich Walliser and Dieter Meischner (1934-2012).

The documentary evidence and type material archived here (c. 100,000 items) relate to almost 3,000 articles published since the earliest years of the 18th century. Among the oldest published objects still held here are those by Eberhard Friedrich Hiemer in 1724 and Gottfried Wilhelm Leibniz in 1749.

Mike Reich \& Tanja R. Stegemann
Fossil European badger (Meles meles) in Quaternary travertine from Weimar, Thuringia, c. 125,000 years old, object width c. $32 \mathrm{~cm}$
Fossil bivalve shell (Pleuronectites laevigatus) from the Middle Triassic of Lower Saxony, c. 230 million years old; colour pattern remains clearly recognisable, object width c. $7 \mathrm{~cm}$ 


\section{Geological Collections}

Geoscience Museum

Goldschmidtstraße 1-5 • 37077 Göttingen • www.geomuseum.uni-goettingen.de

Unusually well-preserved fossil wood mouse (Apodemus), former soft tissues mineralised, from the Pliocene fossil site Willershausen, Lower Saxony, c. 3 million years old, specimen width c. $13 \mathrm{~cm}$; photographs: Gerhard Hundertmark

\section{Established: 1734}

Number of items: c. 1,155,500 in 4 partial collections

Public exhibition: in part

Open: Mon. to Fri. 9:00 - 17:00,

Sun. 10:00 - 16:00

Admission: free

Tours: by appointment

\section{Contact:}

Prof. Dr. Joachim Reitner

Tel.: +49 551 39-7951

Dr. Alexander Gehler Tel.: +49 551 39-7998 geomuseum@gwdg.de
Alongside the Palaeontological Collections, the Geological Collections contain very extensive holdings within the geoscientific collections of the University of Göttingen, the number of objects and series exceeding a million. Consisting of an exceptionally wide range of partial collections in the areas of geology, stratigraphy, sedimentology, petrography and petrology (c. 1,100,000 objects and series), as well as objects of various fossil sites (c. 50,500) and natural stones (c. 5,000), these collections were assembled over the course of the last four centuries from all continents, making available an inexhaustible reservoir of material for ongoing research work. The samples, which represent almost all known types of rock from throughout the world, originate in large parts from Germany, Scandinavia, Africa, Asia, South America, Antarctica and the Atlantic Ocean.

The natural stone collection includes numerous specimens from Germany and Europe, almost all of them formatted, smoothed and polished. This reference collection represents both historical natural stone sites and localities currently under excavation.

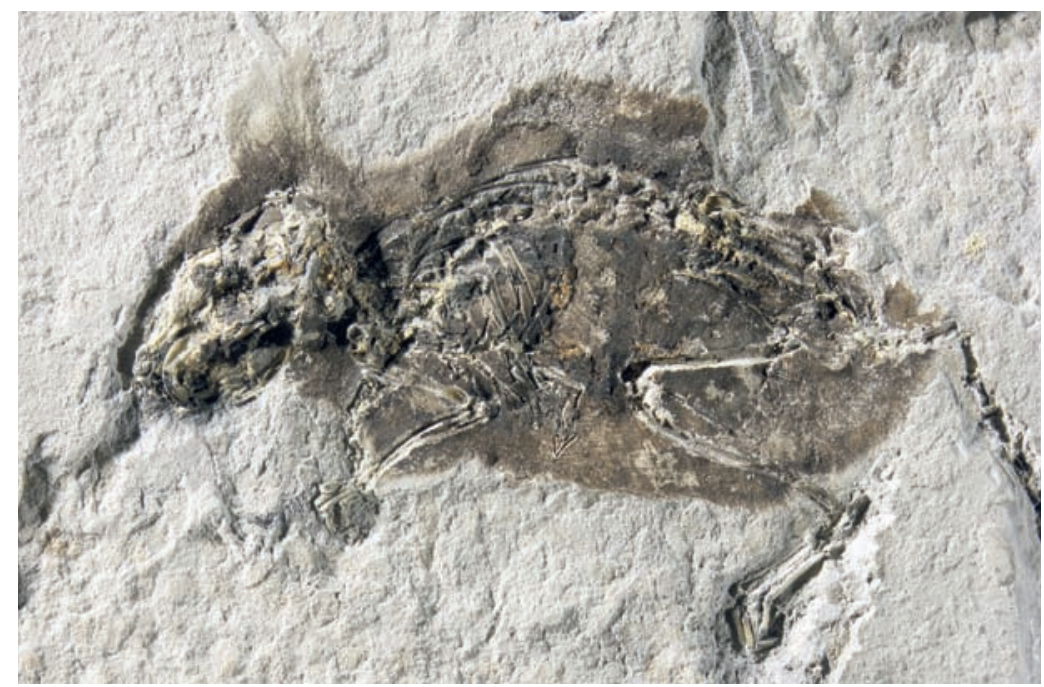

A further extensive partial collection contains stones and fossils from a wide range of fossil sites. Such locations where exceptionally wellpreserved fossils have been discovered open up important insights into the history and development of life on our planet. The research of these sites from various geological periods enables researchers to reconstruct ecosystems of the earth's history almost completely. 

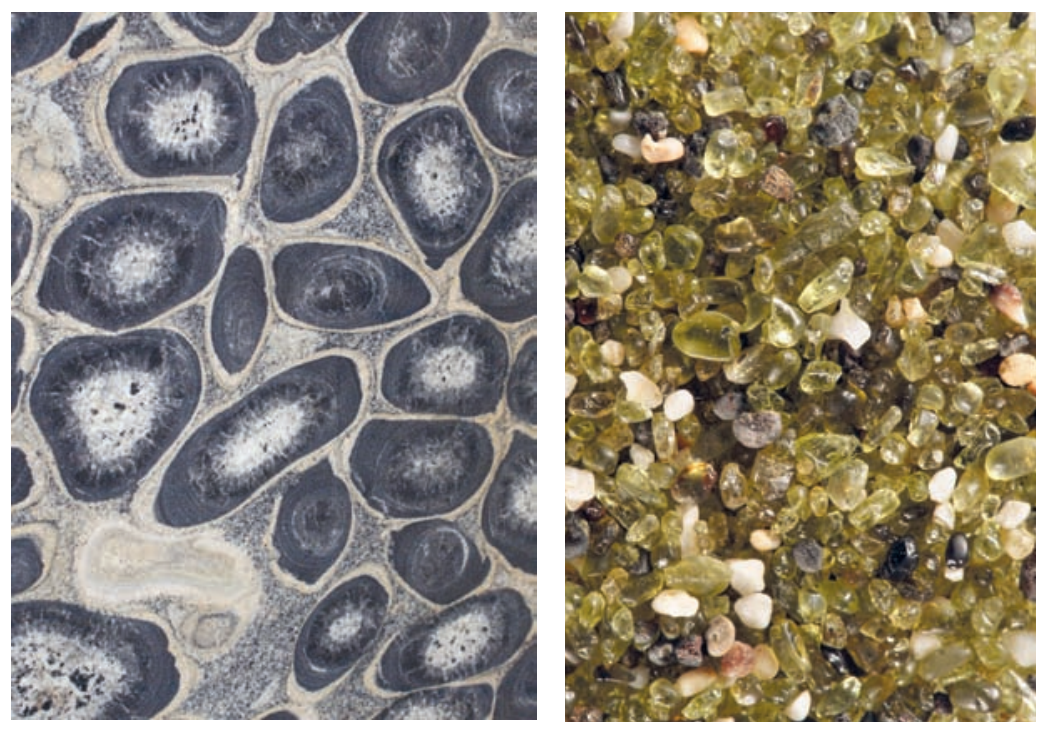

The Göttingen collections contain specimens from numerous Proterozoic and Phanerozoic marine fossil sites worldwide, for example the Ediacaran (Namibia, Russia, Ukraine, China, Australia), Maotianshan Shale (Lower Cambrian, Canada), Burgess Shale (Mid Cambrian, Canada), Hunsrück Slate (Lower Devonian, Germany), Mazon Creek Formation (Upper Carboniferous, USA), Posidonian Shale of Southern Germany (Lower Jurassic, Germany), the Solnhofen Plattenkalk (Upper Jurassic, Germany), the Crato Formation (Lower Cretaceous, Brasil), the Fish Shale of Lebanon (Upper Cretaceous) as well as Monte Bolca (Eocene, Italy) and the Moler Formation site (Eocene, Denmark). Various German limnic fossil sites are also represented, including Messel (Eocene), Rott and Sieblos (Oligocene), Öhningen (Miocene) and Willershausen (Pliocene); the collection in Göttingen originating from the latter source is the most extensive in the world by far (c. 45,000). A number of these collection holdings relate to particular persons and found their way to Göttingen as a result of donation or purchase. Among these are, for example, the collections of Georg Landgrebe (1802-1873; purchase), Friedrich Ernst Witte (1803-1872; donation), Wilhelm (Guillermo) Bodenbender (1857-1941; donation) and Adolf Straus (1904-1986; purchase).
Orbicular granite from Kuru, Finland, sample section c. $28 \mathrm{~cm}$

Olivine sand from Green Sand Beach, Hawaii (Big Island), image width c. $5 \mathrm{~cm}$ 


\section{Forest Botanical Garden and Phytogeographical Arboretum}

Forest Botanical Garden and Phytogeographical Arboretum of Göttingen University Büsgenweg 2 • 37077 Göttingen • www.uni-goettingen.de/forest-botanical-garden

Bark of the Himalaya Birch (Betula utilis) in the China section of the Arboretum; photographs: Volker Meng
Established: 1973

Number of items: c. 2,000

Public exhibition: yes

Open: Mon. to Sun.

Admission: free

Tours: by appointment

\section{Contact:}

Prof. Dr. Andrea Polle

Dipl. Ing. Volker Meng

Tel.: +49 551 39-3382 / -33492

apolle@gwdg.de

vmeng@gwdg.de
At the Forest Botanical Garden and the Phytogeographical Arboretum of Göttingen University, more than 2,000 species of trees and shrubs grow on approximately 40 hectares of land. This constitutes one of the largest collections of woody species in the German-speaking world. In the early 1970s, the School of Forest Sciences was relocated from Hannoversch Münden to Göttingen. As a result, under the direction of Professor Walter Eschrich (1924-2005) the Forest Botanical Garden was established between 1968 and 1993 on the Faßberg near Göttingen, furnishing the university with a special woody plant collection in addition to the Old Botanic Garden already in existence. Following a period during which mainly cultivars were planted, today the focus of the directors Professor Andrea Polle and Volker Meng is on wild species of defined origin. Covering 17 hectares, the plants in the Forest Botanical Garden are arranged systematically according to their phylogeny. Among them are not only the entire range of indigenous tree and shrub species but also a large selection of exotic varieties. Predominantly ecological methods of forest management and incorporation of dry grassland help to give rise to a remarkable diversity of wild flowers, insects, reptiles, small mammals and birds.

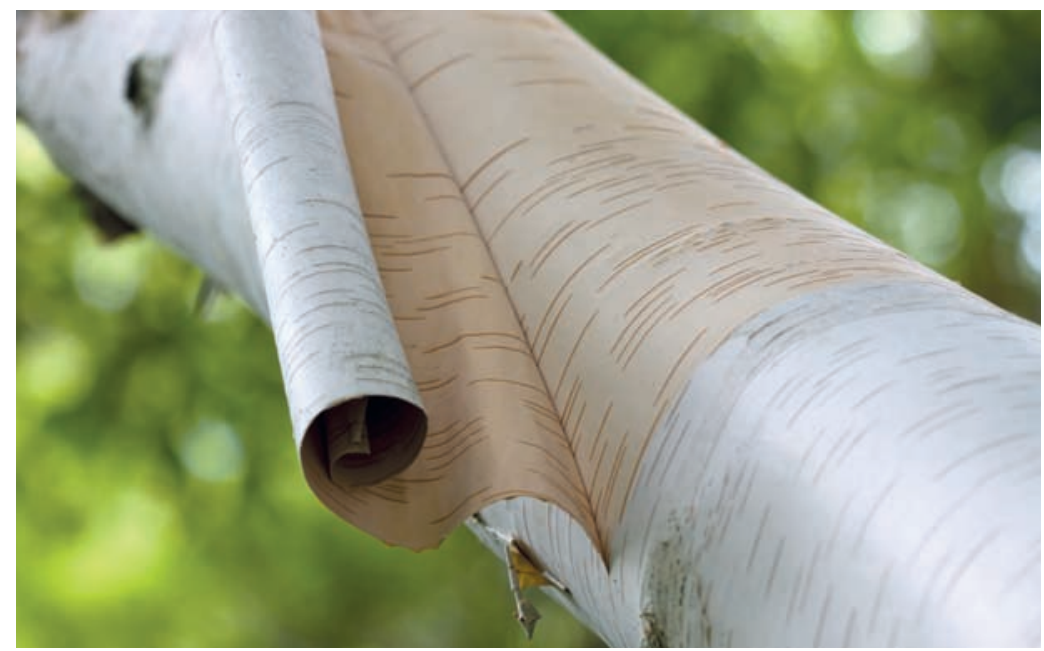

The Phytogeographical Arboretum covers the university's north campus and is subdivided into the five areas relating to North America, China, Japan, Korea and the Caucasus/Asia Minor. The Arboretum is thus one of only a rare number of collections worldwide to contain most of the 


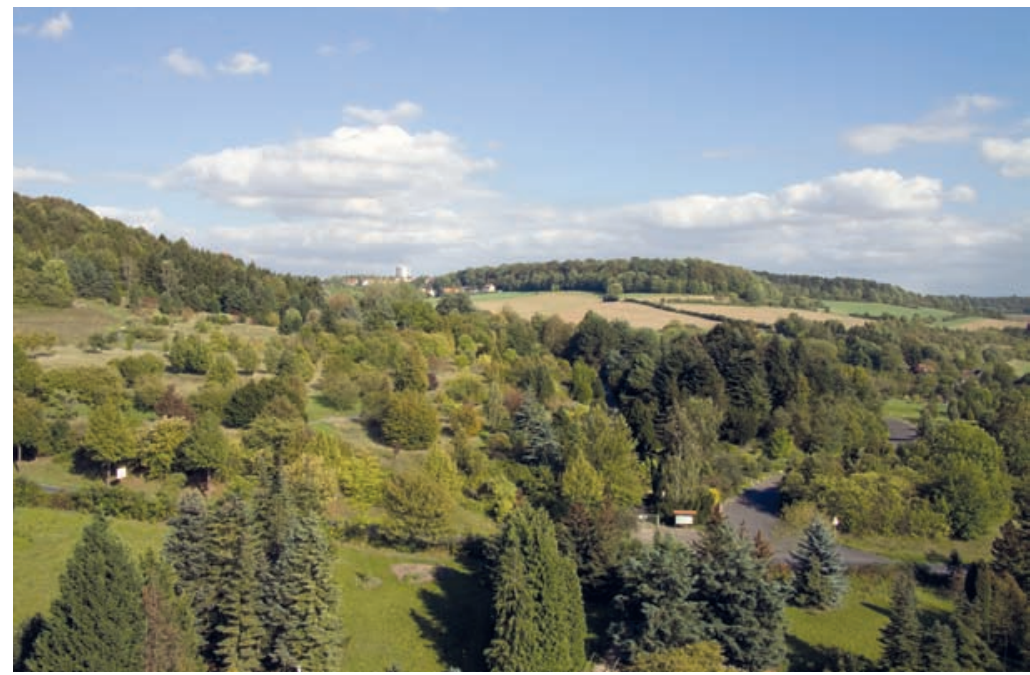

tree flora of the northern hemisphere. The collection is in use for both teaching and research purposes within the framework of various scientific subjects. In conjunction with botanical gardens all over the world, gene reservoirs of populations threatened with extinction in the wild are being preserved. The Japan, Korea and Caucasus/Asia Minor areas have been declared National Protected Collections by the Verband Botanischer Gärten (Association of Botanical Gardens) and hence make a significant contribution to the preservation of plant biodiversity.

In terms of floristic beauty, the period of early spring blossom in January/ February, followed by the cherry blossom in April and then the apple blossom in May are particularly impressive. In late summer and autumn, the rich array of fruits on the trees and the profusion of 'Indian summer' colours make the Forest Botanical Garden a site of particular glory.

Volker Meng \& Andrea Polle
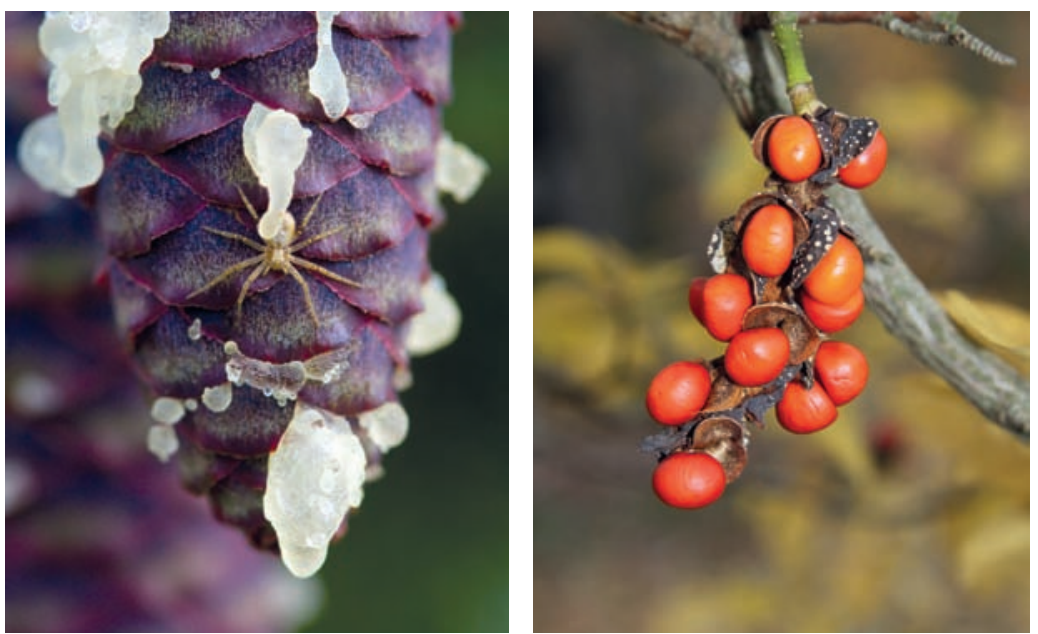

View of the central area of the Forest Botanical Garden
Resinous cone of the Sachalin spruce (Picea glehnii) in the Forest Botanical Garden on the Faßberg

Follicle fruit of the Kobushi magnolia (Magnolia Kobus) in the Japan section of the Arboretum 


\section{Geopark}

Geoscience Centre, University of Göttingen

Goldschmidtstraße 1-5 • 37077 Göttingen • www.geomuseum.uni-goettingen.de

Detail of fossil mammoth tree stump from the Tertiary period, found in Saxony (c. 28 million years old) and exhibited in the Göttingen Geopark; photographs: Gerhard Hundertmark
Established: 1990

Number of items: c. 200

Public exhibition: yes

Open: Mon. to Sun. 6:00 - 19:00

(at visitor's own risk)

Admission: free

Tours: by appointment

\section{Contact:}

Prof. Dr. Joachim Reitner

Tel.: +49 551 39-7951

Dr. Alexander Gehler

Tel.: +49 551 39-7998

geomuseum@gwdg.de
These park-like grounds covering more than five hectares provide an exhibition area for large geological objects, artistic models and woodyplanting - objects that originate from the distant and very recent past of our planet. The trees were cultivated in cooperation with the Forest Botanical Garden and the Arboretum. The grounds are located in the area surrounding the Geoscience Centre on the university's north campus.

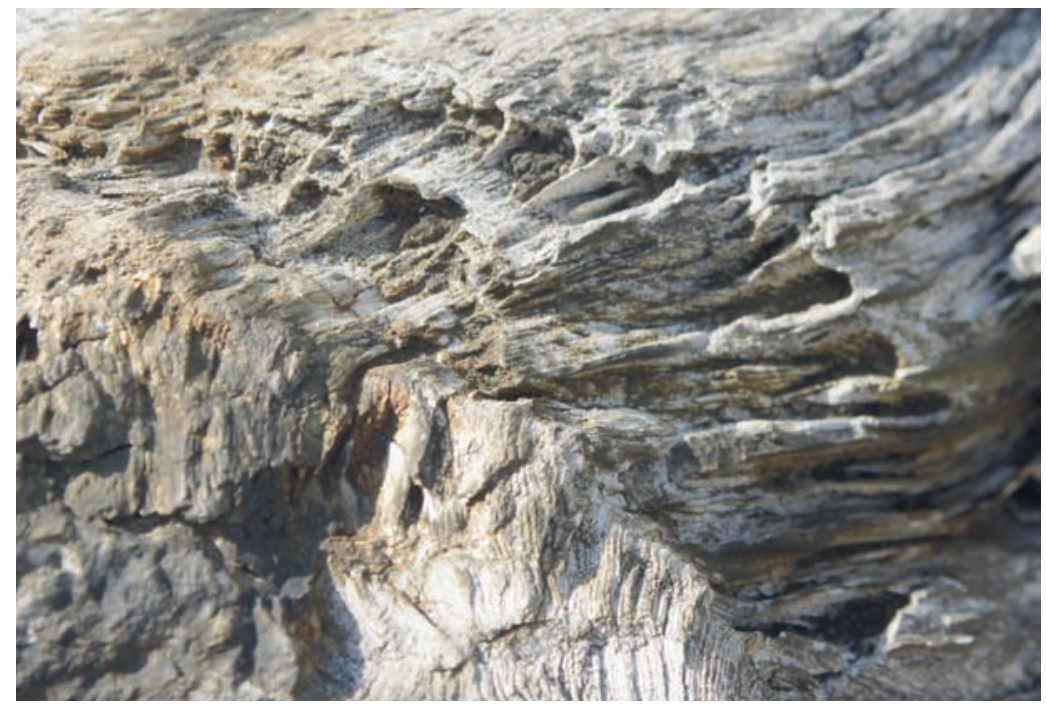

The plans and designs for the Göttingen Geopark came into being between 1988 and 1989. Since 1990, more than 20 different thematic groups of objects have been composed, consisting of more than 200 large-scale specimens; thematic foci addressed so far have been (1) sedimentary rocks, (2-3) plutonic and volcanic rocks, and (4) fossil vertebrate tracks. In addition to the work carried out through the centre itself, realisation of the plans was made possible through donations from a wide variety of companies and institutions, in terms of objects, services and financial contributions.

Here, the visitor encounters objects of the earth at first hand. Large and small rocks, specifically chosen to document the history of the earth and life upon it, enable the planet's history to be legible and grasped with the help of simple explanations. In its rhythmic layering, rocks that once were ocean floors, for example, deliver evidence of climate changes. Limestones with their content of frame-building corals, on the other hand, could be recognised as former reefs, and document, 


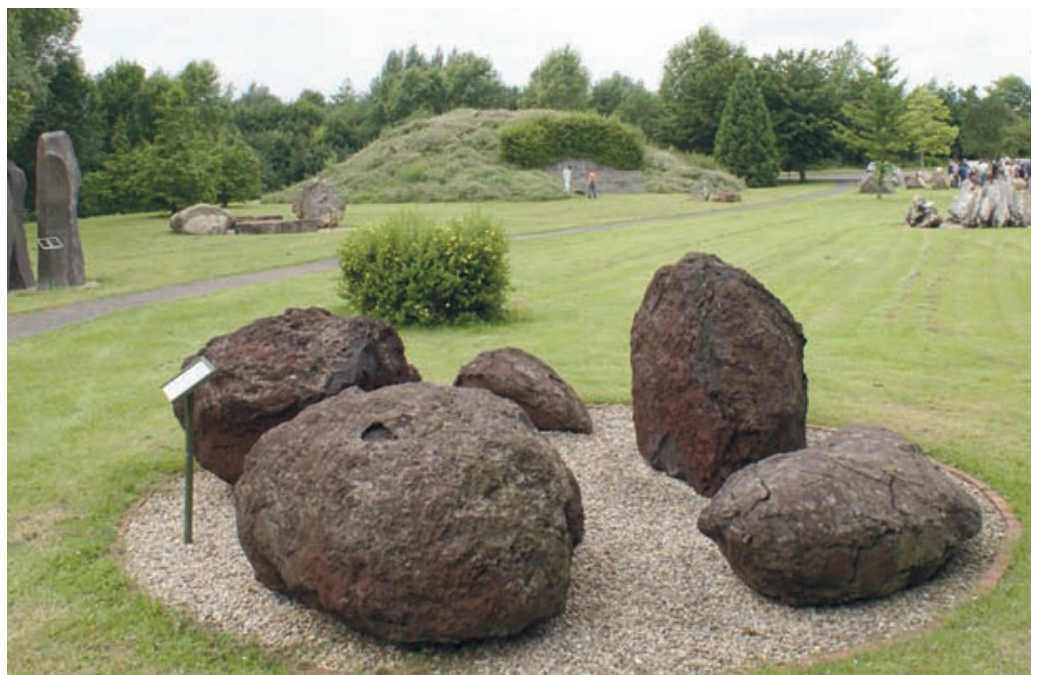

for example, periods when the earth had no ice caps and the climate was warmer worldwide. Folded and broken rocks show the interested visitor in miniature how the earth's crust changed its structure on the large scale, a process that still continues. Grounded and polished stone slabs illustrate how these rocks came into being through liquefaction and solidification in the depths of the earth. The various ensembles also include large erratic blocks that were transported during the last ice age by glaciers from Scandinavia and the Baltic region to north and central Germany. These are juxtaposed with ancient tree species such as the ginkgo and mammoth tree (Sequoia), which are regarded today as living fossils.

Among the artistic models are a large bronze fountain crafted as a gate and designed to reflect the basic principle of episodic processes. The Geopark

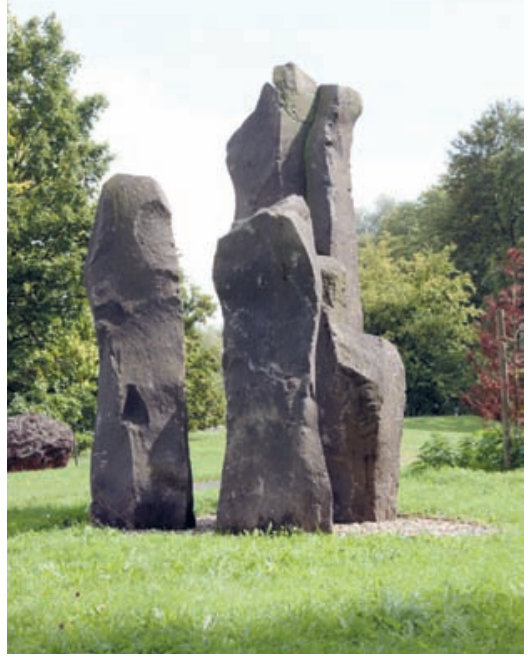
is intensively used for teaching and public relations activities at the Faculty of Geosciences and Geography at the University of Göttingen. Every year it is visited by thousands of people.

Mike Reich \& Tanja R. Stegemann
Volcanic bombs from Andernach in the Rhineland-Palatinate, exhibited in the Geopark
Basaltic columns in the Geopark, c. 13,000 years old, from the Eifel area, Rhineland-Palatinate 


\section{The Experimental Botanic Garden - An Ecological Research Garden}

Experimental Botanic Garden, University of Göttingen

Grisebachstraße 1a • 37077 Göttingen • www.uni-goettingen.de/eb-garten

View of the Experimental Botanic Garden; photographs: Rolf Callauch
The Experimental Botanic Garden is Göttingen University's 'plant laboratory': here, scientific research, plant breeding for use in academic teaching, the preservation of endangered species, environmental education, and provision of information for the general public all have their place. The Experimental Garden was set up in 1967 by Professor Heinz Ellenberg (1913-1997), expanded significantly by his successor Professor Michael Runge, and extensively modernised by the current Director, Professor Christoph Leuschner. Rolf Callauch was in charge as curator from 1984 until 2014, when he was succeeded by Dr. Lars Köhler.

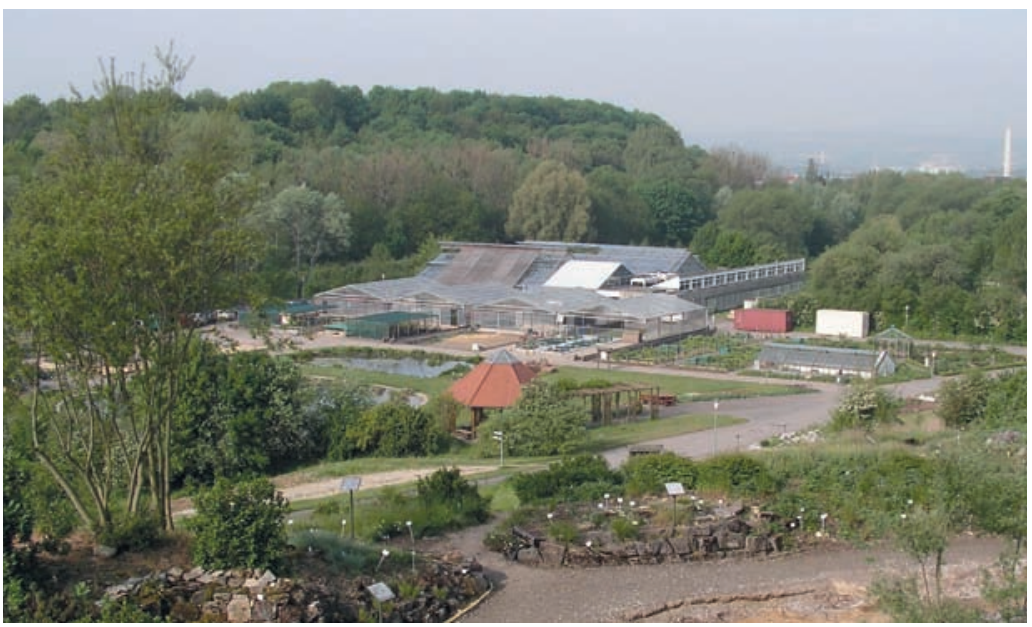

The garden makes available experimental beds for ecological research, both in the open and under retractable roof cover. These are used in particular for studies relating to population dynamics. The climate chambers, propagation house and experimental house offer appropriate conditions for research groups working at the institute on current environmental problems (ecosystem research). Climate chambers enable ecological experiments to be carried out throughout the year. The root laboratory, an institution unique nationwide where research is carried out on plant growth underground, is employed primarily for studies addressing the impact of changing climatic conditions (global warming) on the growth of trees. In progress since 1968, the Sukzessionsversuch (succession experiment) is a long-term experiment to analyse the development of vegetation on fallow land under undisturbed conditions. It is a facility unparalleled in Europe, in particular as concerns experimental duration. 


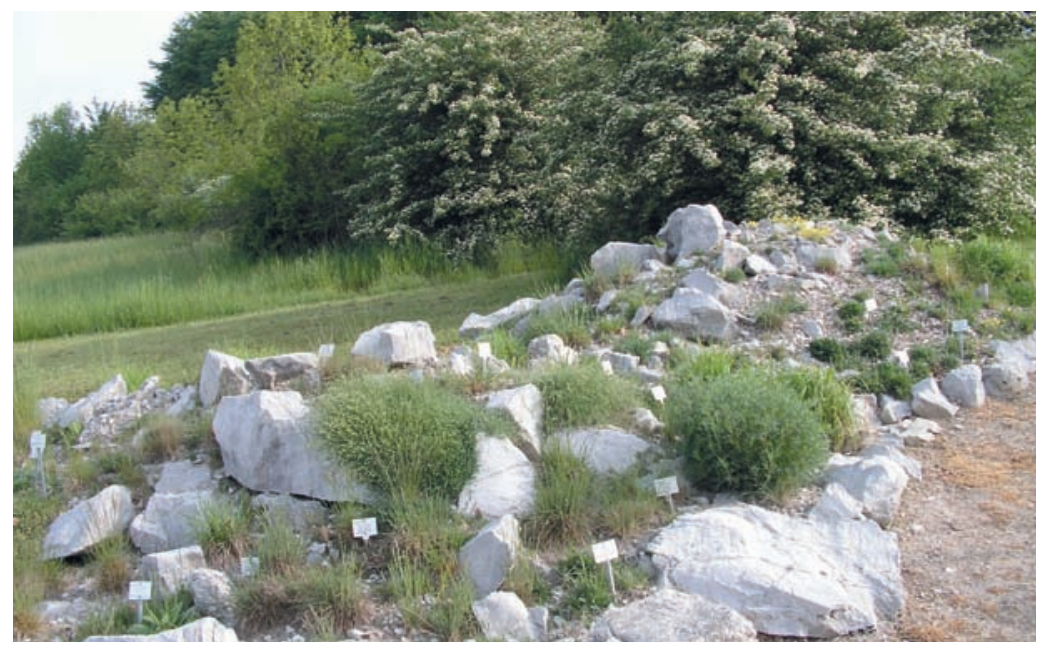

Inestimable quantities of data on species dissemination, impoverishment of soils and reforestation have been gathered here in the context of degree and doctoral thesis work. Endangered wild plants and their natural 'neighbours' are preserved in beds and established in biotopes especially created for this purpose. Currently, so-called Red List Species are being cultivated over the long term, for example, thereby safeguarding their continued existence. The computerised documentation of the collections supports rapid exchange of information and cooperation on collecting foci with other botanical gardens; it provides the basis for the Index Seminum that is published annually. Numerous guided tours for students or the general public and a regular event series take place every year to raise awareness among individuals concerning endangered nature. An active friends' association supports the gardens in both material and non-material ways and organises a large number of botanically based journeys and walks.

\section{Rolf Callauch}
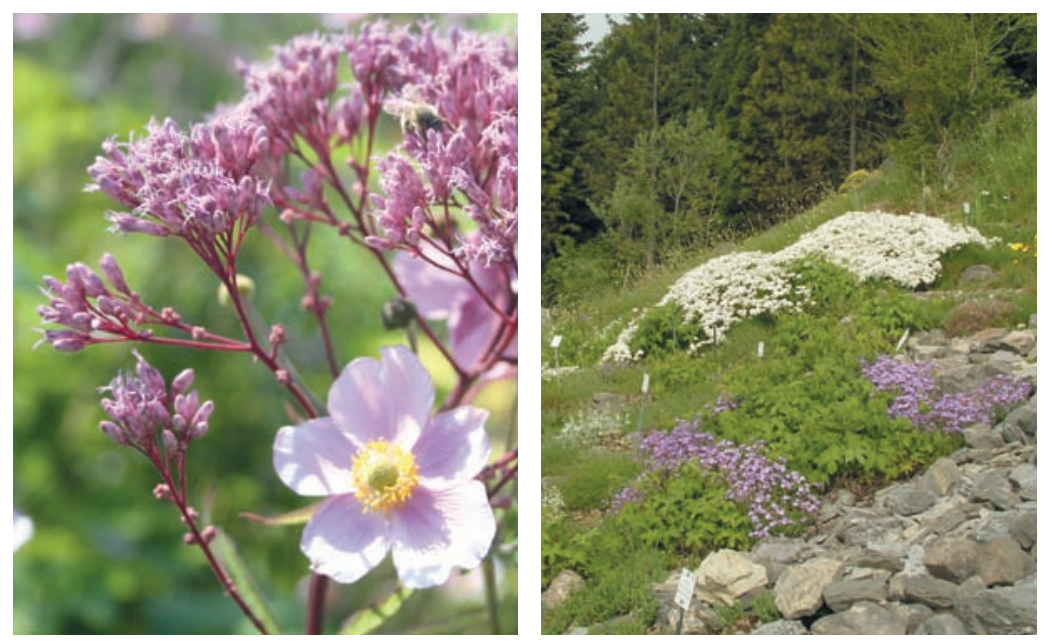

The vegetation composition depends on the geological substrate (soil differences) which is demonstrated in the Geobeds.
Hemp agrimony and hupeh anemone at the garden pond

Phytogeographical alpine garden with forest surroundings 


\section{Amber Collections}

Geoscience Museum

Goldschmidtstraße 1-5 • 37077 Göttingen • www.geomuseum.uni-goettingen.de

Various figurines from among the Schwarzort findings - the oldest known amber carvings (Baltic amber) from the Baltic Sea area, end Neolithic, c. 2,500 BC (Kurisches Haff near Schwarzort/ East Prussia, today Juodkrante// Lithuania), width of picture c. $25 \mathrm{~cm}$; photographs: Gerhard Hundertmark
Established: 1773

Number of items: c. 30,000

Public exhibition: in preparation

Tours: by appointment

\section{Contact:}

Prof. Dr. Joachim Reitner

Tel.: +49 551 39-7951

Dr. Alexander Gehler

Tel.: +49 551 39-7998

geomuseum@gwdg.de
The largest part of Göttingen's Amber Collections consists of the former Königsberg Amber Collection (Baltic amber, succinite), which has been held in trust and preserved for the Stiftung Preußischer Kulturbesitz (Prussian Cultural Heritage Foundation) by Göttingen's Geoscience Museum, as it is known today, since 1958. This collection is made up primarily of specimens with animal and plant inclusions. However, the collection also contains archaeological findings and objects documenting art and cultural history.
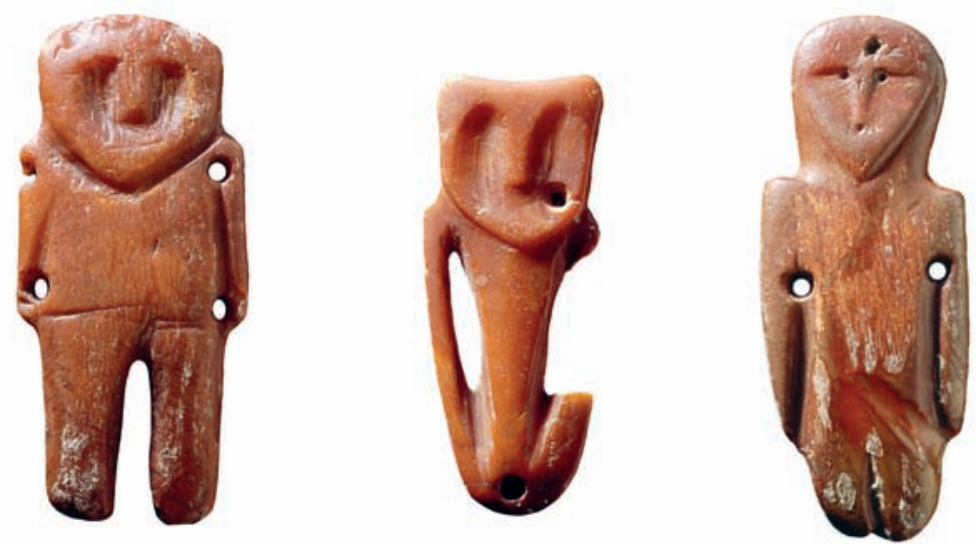

The world famous Königsberg Amber Collection of the former Prussian University of Königsberg (Albertus University), which formerly numbered some 100,000 items, resulted from the combining of various collections and dates back to the late 18th century. The main part of the collection had its origin in holdings purchased in 1899 from the mining company Stantien \& Becker (Memel; today Klaipèda, Lithuania). To these items were added those in the ownership of the Physikalisch-ökonomische Gesellschaft (Physical Economic Association), the Ostpreußisches Provinzialmuseum (East Prussian Provincial Museum), as it later came to be called, and various private collections. The most significant addition, purchased in 1926, was undoubtedly that acquired from geologist and pharmacologist Richard Klebs (1850-1911). In November 1944, the most valuable pieces were packed into crates by the current Director Karl Andrée (1880-1959) and brought to the Albertina's partner university, the University of Göttingen. Together with other art treasures, books and material in the university collections, these were stored in the Volpriehausen potash mine. Fortunately, the wooden boxes containing the amber were retrieved before explosions destroyed the mine shafts in September 1945. Until their return, these were held for over a decade in several Zonal Fine Arts Repositories administered by the occupying forces. 


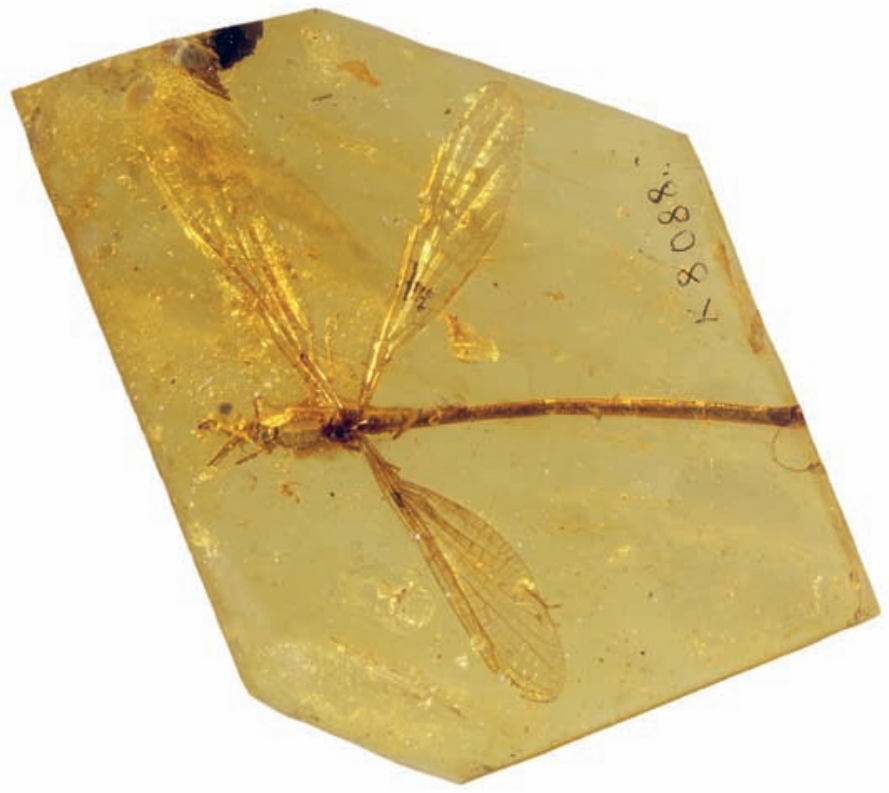

Further amber partial collections in Göttingen originate from such persons as Johann Friedrich Blumenbach (1752-1840), Erich Mascke (1876-year of death unknown) and Manfred Kutscher (b. 1943).

All the amber collections presented here contain numerous and significant type material of fossil plants and animals. There are also amber specimens of most diverse types (succinite, beckerite, glessite, copal, simetite and stantienite, among others) dating from Mesozoic and Cenozoic times and originating from all around the world.

Due to the historical significance of Göttingen's Amber Collections and their immense scientific importance worldwide, numerous amber researchers make their way to the University of Göttingen from within

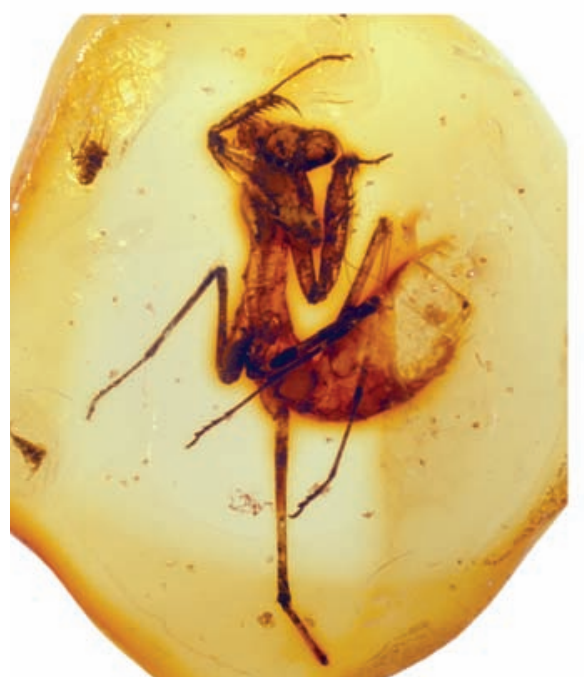
and outside Germany. The holdings of type and published material thus continue to grow steadily. Since the 1970s, small parts of the collections have frequently been on display at special exhibitions in Germany and beyond. A permanent exhibition dealing with Göttingen University's Amber Collections is currently in preparation.

Mike Reich, Alexander Gehler \& Tanja R. Stegemann
Dragonfly in Baltic amber from the former Königsberg Amber Collection, object width c. $11 \mathrm{~cm}$
Praying mantis (Mantis) in Bitterfeld amber from the recently acquired amber collection of Manfred Kutscher, object width C. $3 \mathrm{~cm}$ 


\section{Geological Collection of the Adolfinum Bückeberg}

Geoscience Museum

Goldschmidtstraße 1-5 • 37077 Göttingen • www.geomuseum.uni-goettingen.de

Original specimen and depiction of bone positions (drawing of the dorsal side) of the small herbivore dinosaur Stenopelix valdensis from the Lower Cretaceous of the Harrl near Bückeburg in Lower Saxony, the most complete skeleton from this time period found in Germany, c. 138 million years old. Width of original specimen c. $65 \mathrm{~cm}$; photographs: Gerhard Hundertmark
The Geological Collection of the Adolfinum Bückeberg (including the Ballerstedt Collection) contains objects and original specimens of high scientific importance from the early days of dinosaur research in Germany. Since 1976, the great majority of these have been in the charge of the University of Göttingen, on long-term loan from the District of Schaumburg.

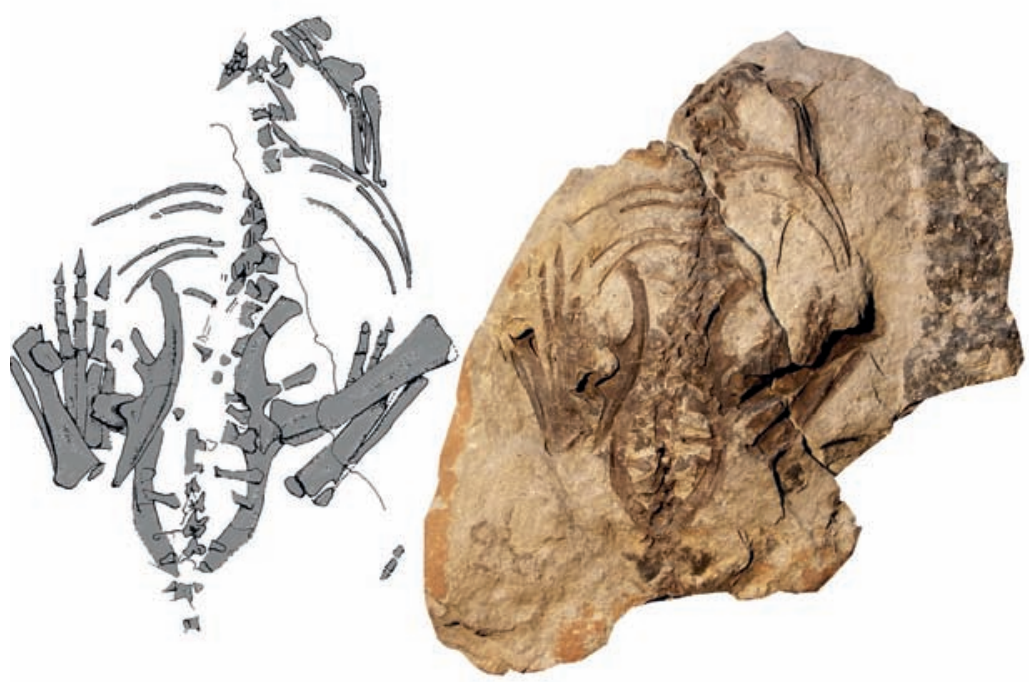

The collection can be traced back to a Conchylien- und Petrefaktensammlung (Mollusc and Fossil Collection) of the Fürstliches Naturalienkabinett (Sovereign Natural History Cabinet) established by Georg Wilhelm Fürst zu Schaumburg-Lippe (1784-1860). Run by school teachers as a Naturwissenschaftliche Sammlung des Gymnasiums (Natural History Collection of the grammar school), it experienced a first heyday between 1840 and 1875 under the direction of F. Wilhelm Burchard (1804-1887). This period saw the first spectacular discoveries of fossil crocodiles and dinosaurs from the Bückeburg area, which were described in the mid 19th century by the pioneer of German vertebrate palaeontology, Hermann von Meyer (1801-1869), and which are still preserved in the collection. After Burchard's retirement, only a few additions were made to the collections for almost a quarter of a century. But when Max Ballerstedt (1857-1945) took charge in 1900, he grasped the initiative and collected untiringly, above all at innumerable quarries 


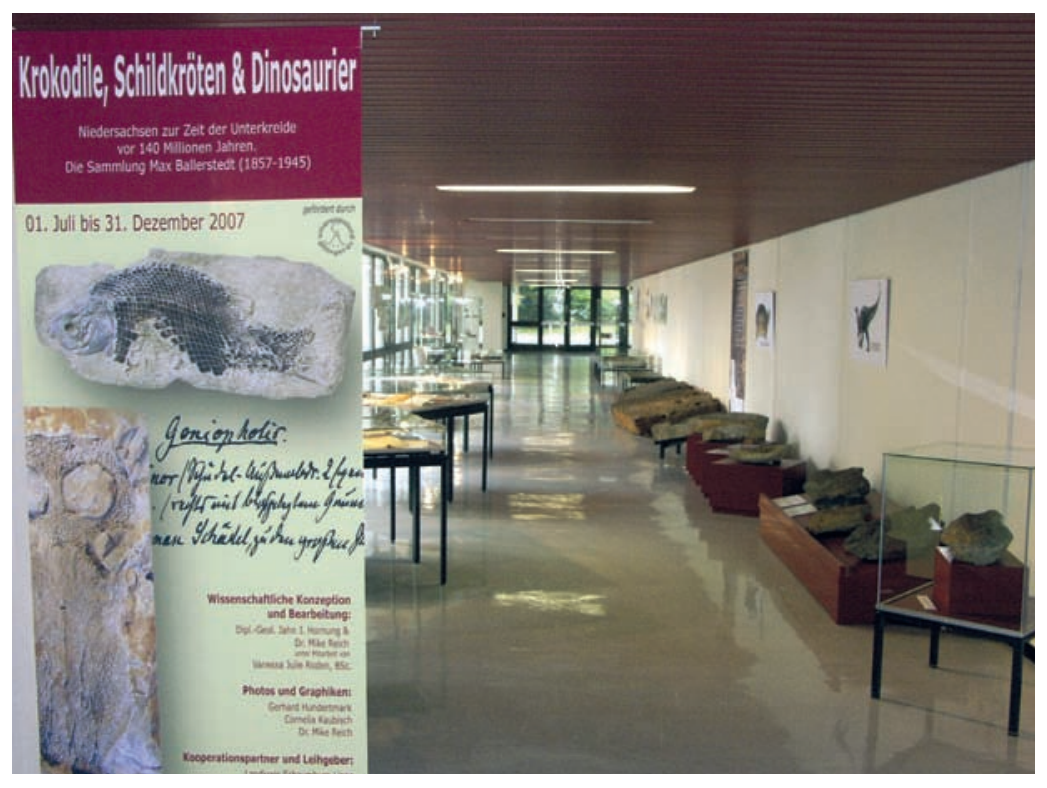

in the vicinity of his home town (Harrl and Bückeberg). Ballerstedt's achievements are impressive: together with the Adolfinum specimens unearthed previously, his collection contains almost 1,500 objects from Lower Saxony's early Cretaceous ('Wealden'). Ballerstedt stored the greater part of his collection in the school; moreover, his own apartment was packed with such findings. Having initially handed over the collection to the Fürstlich Schaumburg-Lippische ministry in 1906, he donated it to the state government there in 1940, together with his library. In doing so, he placed the collection in the custody of the Adolfinum.

After a chequered history in the post-war years and the death of the long-standing curator Hilrich Bernhards in 1971, the question of the collection's future location and supervision came under discussion with various museums and universities. Once the contractual negotiations had been concluded, the geoscientific holdings of the Adolfinum were brought to Göttingen in 1976. Shortly afterwards, other parts of the former Adolfinum's natural history collections were passed to other institutions in Lower Saxony, for example the Herbarium (Hanover) and the Mollusc Collection (Brunswick).

A small geoscientific exhibition and practice collection used for teaching purposes at the school is still present in the Adolfinum Bückeberg. Special exhibitions displaying these and other holdings took place in 2007 and 2010 at the Geoscience Museum, Göttingen.
View into the special exhibition Krokodile, Schildkröten \& Dinosaurier - Niedersachsen zur Zeit der Unterkreide vor 140 Millionen Jahren (Crocodiles, Turtles \& Dinosaurs - Lower Saxony in the Lower Cretaceous 140 Million Years Ago), held in 2007-2008 in the Geoscience Museum. Objects shown at the exhibition were predominantly from the Geological Collection of the Adolfinum Bückeburg/ Max Ballerstedt Collection 


\section{Mineralogical Collections}

Geoscience Museum

Goldschmidtstraße 1-5 • 37077 Göttingen • www.geomuseum.uni-goettingen.de

View into the permanent exhibition of the former Mineralogical Museum showing a variety of minerals and rocks; photographs: Gerhard Hundertmark
Steeped in a rich tradition, the Mineralogical Collections of Göttingen University are among the oldest in Europe. Of the more than 4,600 different minerals and mineral varieties that have so far been described worldwide, the University of Göttingen houses samples of almost 50 per cent of all today's known types. Type material and originals of more than 70 new minerals are also present here.

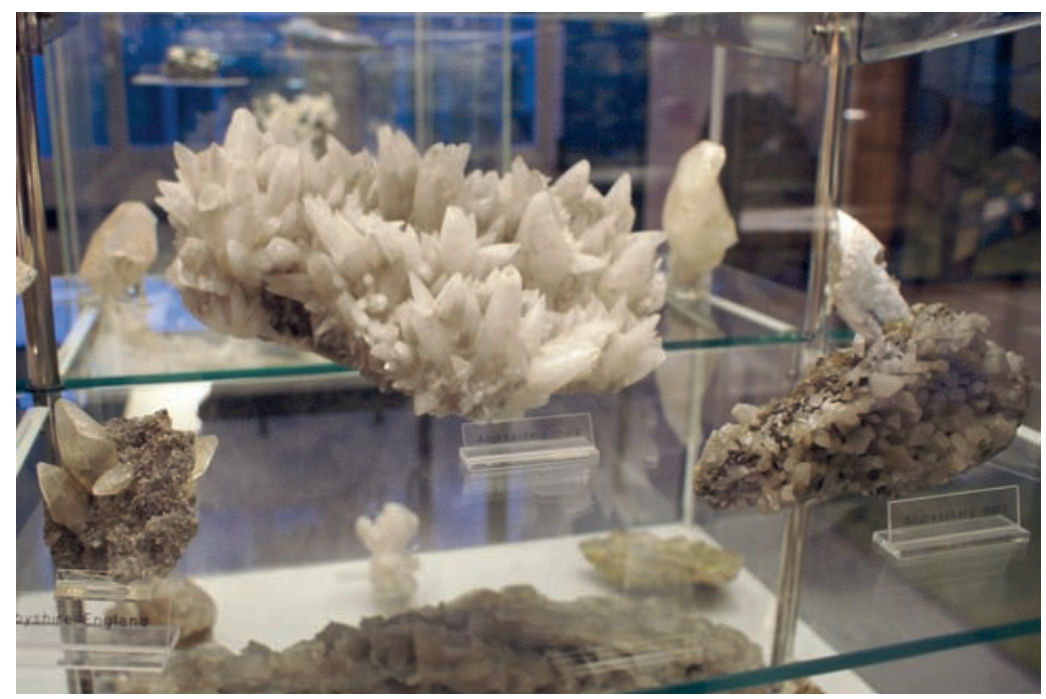

Numerous well-known mineralogists, geologists, chemists and naturalists donated or exchanged material with researchers at this university, among them Georg Thomas von Asch (1729-1807), Sir Joseph Banks (1743-1820), Martin Heinrich Klaproth (1743-1817), Karl Ludwig Giese(c)ke (1761-1833), Alexander von Humboldt (1769-1859), Jöns Jakob Berzelius (1779-1848), Wilhelm Karl Ritter von Haidinger (1795-1871), Gustav Rose (1798-1873), Ignacy Domeyko (1802 - 1889), Charles Upham Shepard (1804-1886), Rudolf Hermann (1805-1879), Theodor Scheerer (1813-1875), Adolf Erik Freiherr von Nordenskiöld (1832-1901), Albin Weisbach (1833-1901), Waldemar Chistofer Brøgger (1851-1940), Jakob Schetelig (1875-1935), Percy Dudgeon Quensel (1881-1966), Karl Franz Johann Chudoba (1898-1976) and Hugo Strunz (1910-2006).

Yet also many researchers at work in Göttingen ensured that the collections were steadily enlarged, occasionally producing descriptions of minerals unknown hitherto. Among them were Friedrich Stromeyer (17761835), Johann Friedrich Ludwig Hausmann (1782-1859), Friedrich 


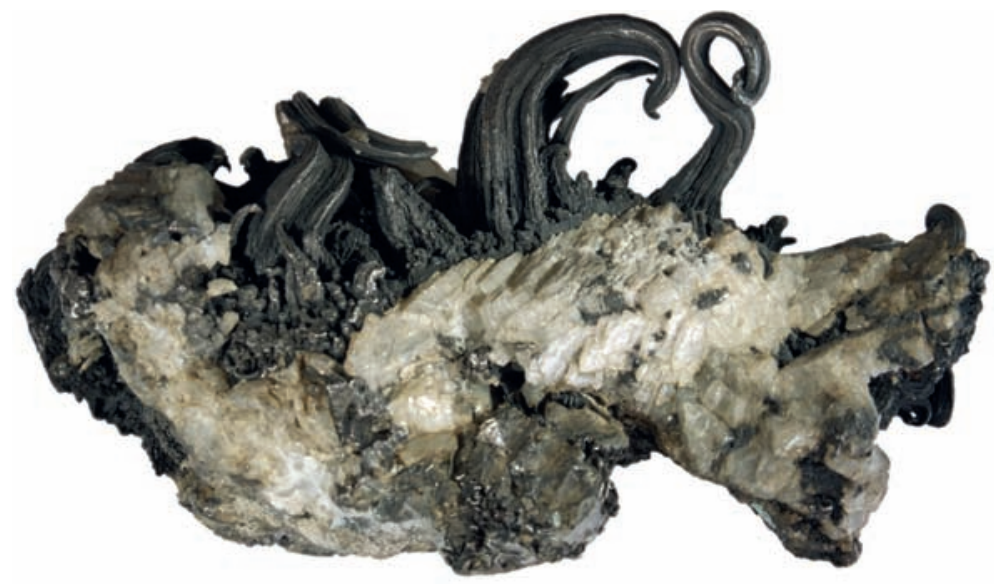

Wöhler (1800-1882), Woltgang Sartorius Freiherr von Waltershausen (1809-1876), Adolf von Koenen (1837-1914), Friedrich Rinne (1863-1933), Helmut G. F. Winkler (1905-1980), Wolf Jürgen von Engelhardt (1910-2008), Sigmund Koritnig (1912-1994), Otto Braitsch (1921 -1966), Josef Zemann (b.1923), Friedrich Lippmann (1928-1998), Vladimir Kupčik (1934-1990), Arno Mücke (b.1937), Peter Süsse (later Susse; 1939-2008) and Günther Schnorrer (b.1941). Further material, some of it unique, found its way into the collections via purchases, such as the extensive collection of Wilhelm Maucher (1879-1930) that was acquired in 1938. Maucher had operated the Süddeutsche Mineralienzentrale (Southern German Minerals Centre) in Munich.

The collections' main areas of focus in geographical terms are Germany (Lower Saxony, Hesse, Harz Mountains etc.) and Europe as a whole.

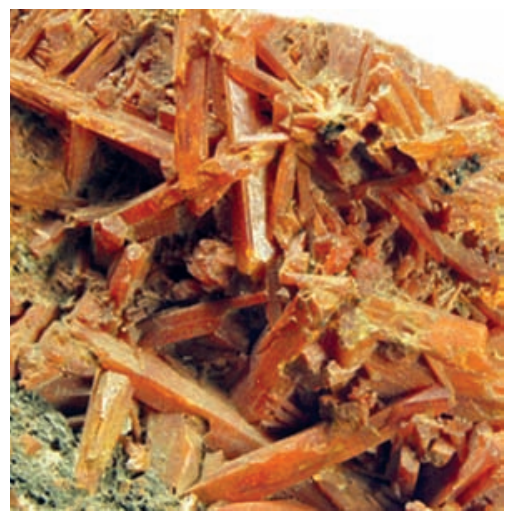

These objects, which can be classified under the heading of 'Systematic Mineralogy', make up a collection consisting of almost 300,000 objects and series. But the Mineralogical Collections also encompass further assemblages addressing other, related, subject areas such as ore deposits and economical geology (c. 30,000), technical mineralogy (c. 5,000) and crystallography (c. 2,000).

The permanent exhibition of Göttingen University's former Mineralogical Museum (opened in 1971) is currently undergoing refurbishment and is hence accessible only to a limited extent.

Mike Reich, Alexander Gehler \& Tanja R. Stegemann
Native silver in a quartz matrix from the historical mining district at Kongsberg in Norway, specimen width c. $15 \mathrm{~cm}$
Red lead ore (crocoite) from the Ural Mountains, Russia, with typical long prismatic crystals, part of specimen shown c. $5 \mathrm{~cm}$ 


\section{Collection of Precious Stones}

Geoscience Museum

Goldschmidtstraße 1-5 • 37077 Göttingen • www.geomuseum.uni-goettingen.de

Reproductions of famous large diamonds: Blue Hope (45.5 carat, now in Washington), Le Grand Condé and Regent (50 and 140.5 carat, both now in France) and the Grüne Dresden (41 carat) at actual size. Produced in Rock Crystal and glass with varying cuts, image width c. $20 \mathrm{~cm}$; photographs: Gerhard Hundertmark

Ring (mid 18th century) set with precious stones - a red pyrope (middle) as well as four yellow zircons and four small white diamonds with varying cuts, image width c. $2 \mathrm{~cm}$
'Stones' have been used for jewelry since time immemorial - and verifiably since Palaeolithic times (the Old Stone Age). In addition to gold and silver, the crafting of, above all, 'precious stones' into jewelry goes back to ancient times. Among the stones employed are not only the well-known types such as the diamond, ruby, sapphire and topaz, but also a wide variety of gemstones (also termed semi-precious stones) that are not necessarily stones or minerals at all but can consist of molten glass or have organic origins (pearl, mother of pearl or precious coral, for example).

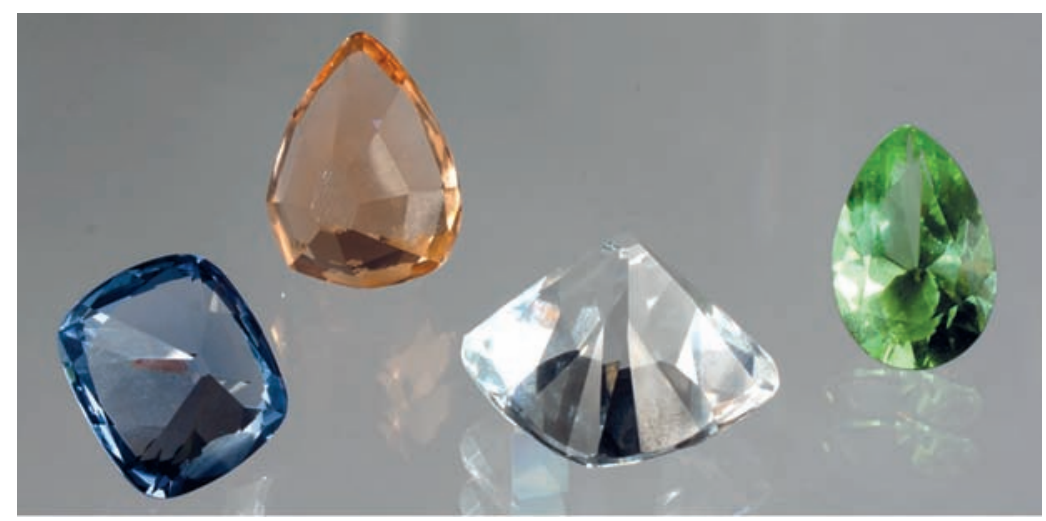

The earliest accessions to the Precious Stone Collection of Göttingen University go back to the 18th century. Numerous pieces in both unworked and processed states provide evidence of the highly diverse topics of gemmology. In addition to objects demonstrating systematics and provenance and the various types of gem cuts, our reference collection

Established: 1773

Number of items: c. 1,000

Public exhibition: under reconstruction

Tours: by appointment

\section{Contact:}

Prof. Dr. Joachim Reitner

Tel.: +49 551 39-7951

Dr. Alexander Gehler

Tel.: +49 551 39-7998

geomuseum@gwdg.de

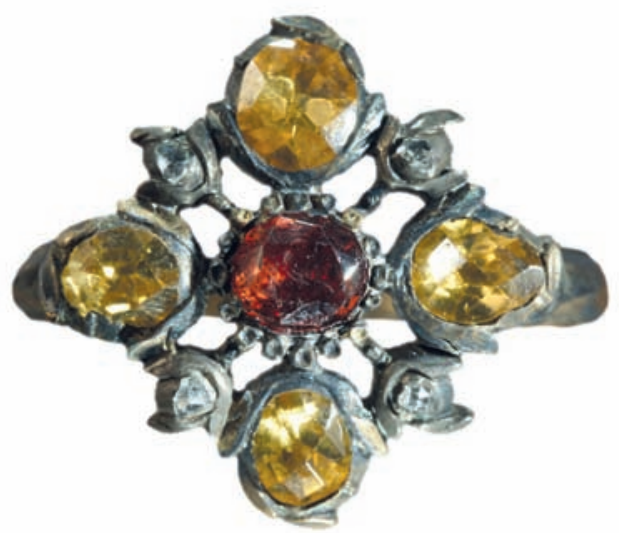




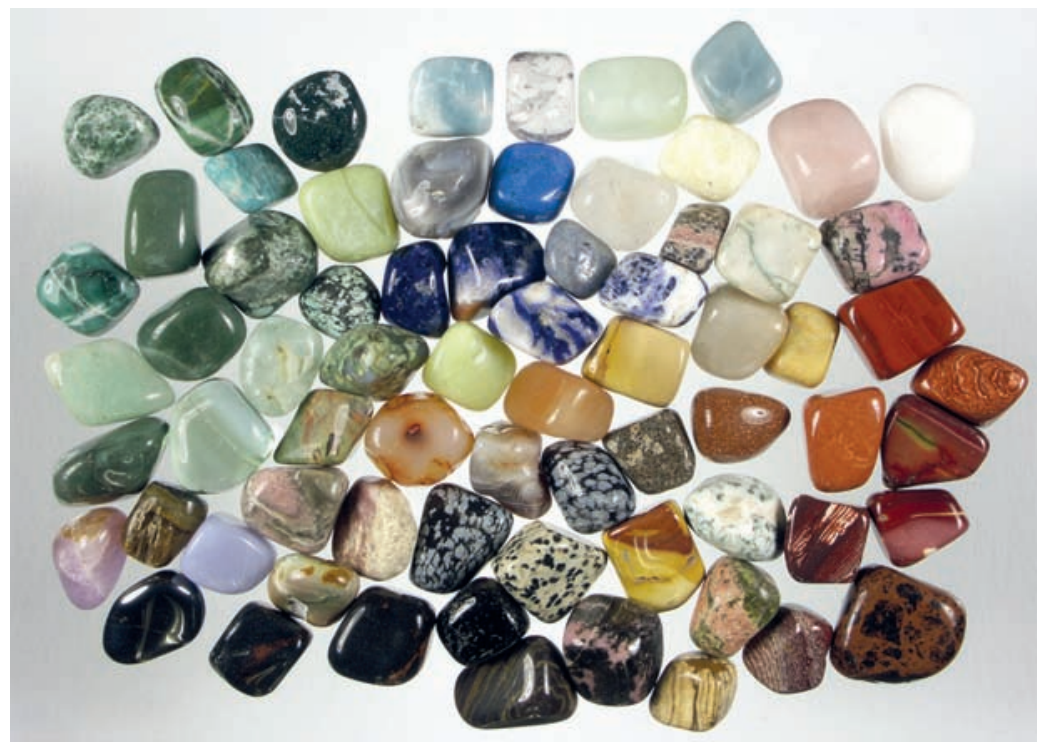

also contains material that can help to clarify whether stones are natural or synthetic, or whether the precious or gemstones have been subjected to artificial changes for purposes of colour or purity enhancement.

The majority of the highly diverse range of items present in the precious stones collection originates from various collections, donations or

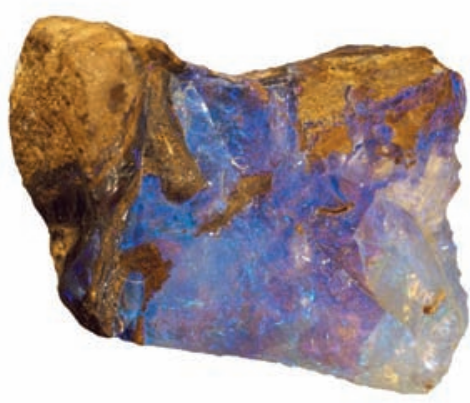
purchases. Individuals significantly associated with these acquisitions include Christian Wilhelm Büttner (1716-1801), Georg Thomas von Asch (1729-1807), Johann Wolfgang von Goethe (1749-1832), Johann Friedrich Blumenbach (1752-1840), Wolfgang Sartorius Freiherr von Waltershausen (1809-1876), August von Janson (1844-1917), Wilhelm Maucher (1879-1930) and Karl Burhenne (dates not known, estate 1918). In regional terms, the collection is focussed on Germany, Russia, South East Asia and South America.
Selection of various tumbled gemstones (semi-precious stones), image width c. $25 \mathrm{~cm}$
Precious opal in stone matrix from New South Wales, Australia, object width c. $7 \mathrm{~cm}$ 


\section{Collection of Meteorites}

Geoscience Museum

Goldschmidtstraße 1-5 • 37077 Göttingen • www.geomuseum.uni-goettingen.de

Fragment from the L'Aigle meteorite shower (stony meteorite, ordinary chondrite, H6), France, (date of fall: April 26th, 1803) with original label. Gift from French physicist JeanBaptiste Biot to Göttingen natural scientist Johann Friedrich Blumenbach, image width $10 \mathrm{~cm}$; photographs: Gerhard Hundertmark

Slice of the Martian meteorite Dar al Gani 476 (stony meteorite, achondrite, shergottite) from Libya (found: May 1st, 1998), image width c. $15 \mathrm{~cm}$

\section{Established: 1777}

Number of items: c. 2,000

Public exhibition: yes

Open: Mon. to Fri. 9:00 - 17:00,

Sun. 10:00 - 16:00

Admission: free

Tours: by appointment

\section{Contact:}

Prof. Dr. Joachim Reitner

Tel.: +49551 39-7951

Dr. Alexander Gehler

Tel.: +49551 39-7998

geomuseum@gwdg.de
Standing in a long and rich tradition, the Collection of Meteorites at Göttingen University is one of the oldest in the world. Its history dates back to the year 1777, when the Schlüter Collection (Christoph Andreas Schlüter, 1668-1743) from Hanover was donated to the Königliches Academisches Museum (Royal Academic Museum) - and with it also the first meteorite to find its place therein. As a result of further donations to

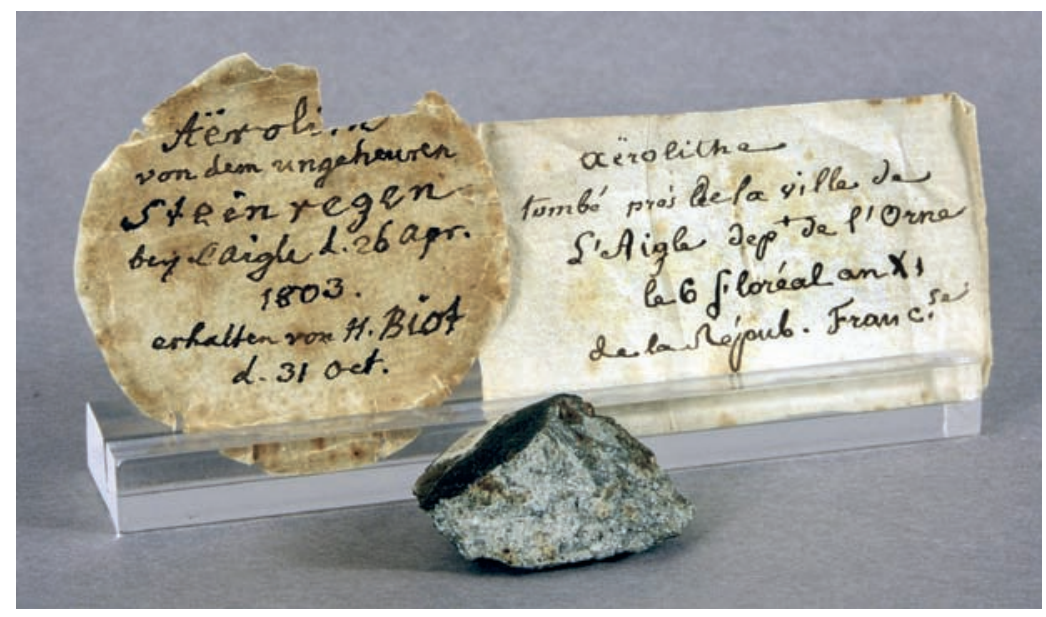

the Academic Museum, or to Johann Friedrich Blumenbach (1752-1840) personally, the collection grew to a remarkable extent, especially under the latter's direction and, somewhat later, under that of mineralogist Johann Friedrich Ludwig Hausmann (1782-1859). Among the donators were such eminent personages as Georg Thomas von Asch (1729-1807), Sir Joseph Banks (1743-1820), Martin Heinrich Klaproth (1743-1817), Franz Xaver Freiherr von Zach (1754-1832), Ernst Florens Friedrich Chladni (1756-1827), Karl Ludwig Giese(c)ke (1761-1833), Alexander

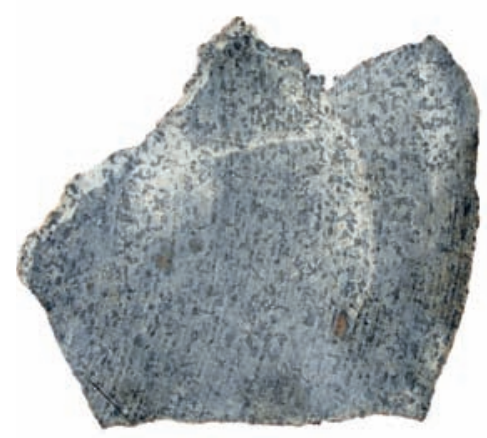
von Humboldt (1769-1859), JeanBaptiste Biot (1774-1862), Karl von Schreibers (1775-1852) and Crown Prince Ludwig von Bayern (1786-1868). The collection received further significant additions in 1835 , through the estate of chemist Friedrich Stromeyer (1776-1835), and in 1860, when the collection was united with those of Wolfgang 


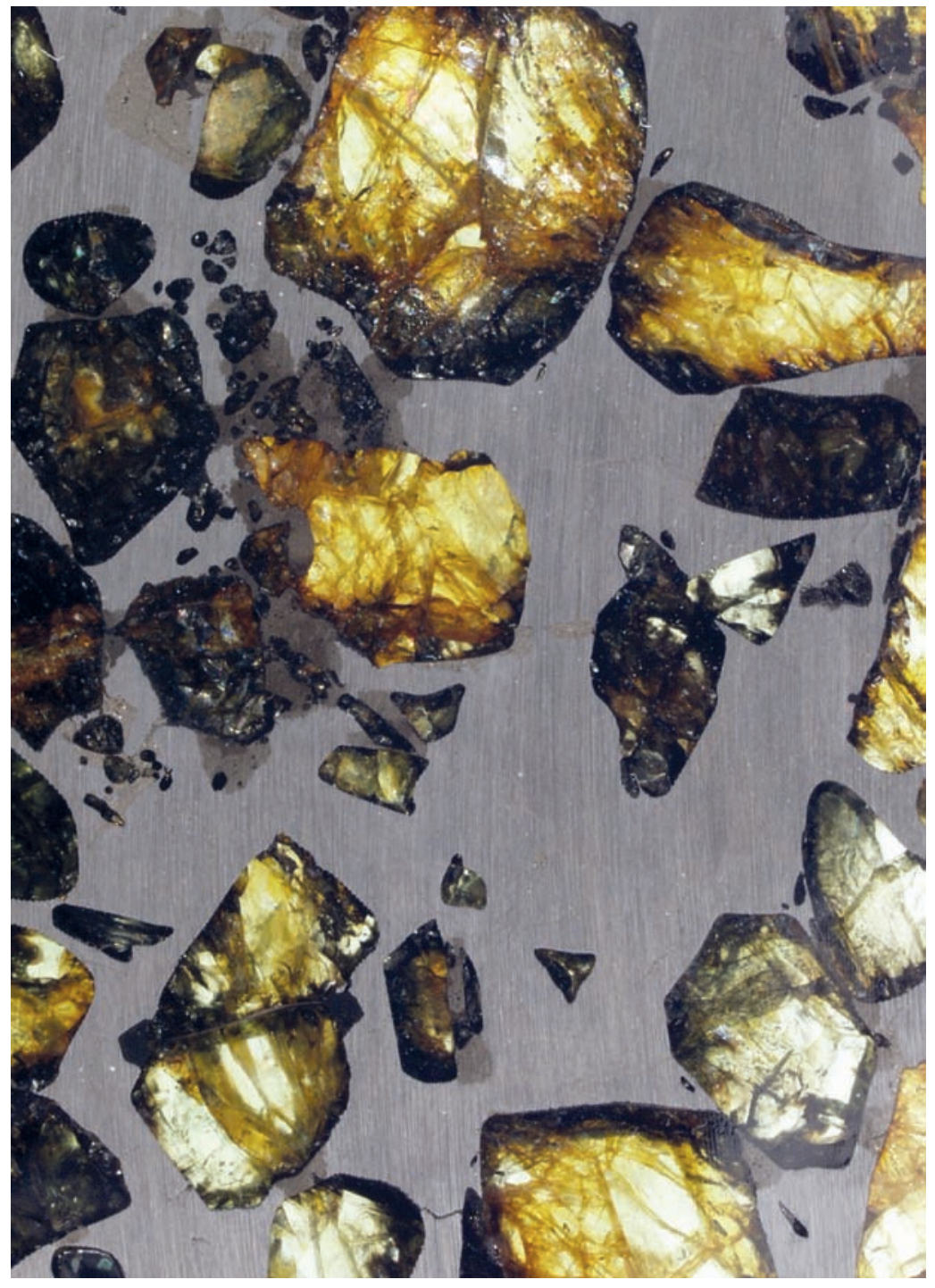

Sartorius Freiherr von Waltershausen (1809-1876) and those of Friedrich Wöhler (1800-1882). In 1864 the latter published a first catalogue of the meteorites present.

Thanks to targeted purchases, donations and exchange, the collection has grown to number almost two thousand objects today, including meteorites, tektites and impact glasses from more than 300 different localities. Worthy of special note are various Lunar and Martian meteorites and the main masses of four of the 50 officially recognised German meteorites (Erxleben, Tabarz, Bremervörde and Emsland).
Polished slice of stony-iron meteorite Esquel (pallasite), found 1951, Argentina, image width c. $5 \mathrm{~cm}$ 


\section{Historical Geosciences}

Geoscience Museum

Goldschmidtstraße 1-5 • 37077 Göttingen • www.geomuseum.uni-goettingen.de

Ausbeute-Münze (mining coin) made from the silver sulphide mineral argentite. Historical collection of Christoph Andreas Schlüter, in wooden box with original inscription, object diameter c. $6 \mathrm{~cm}$; photographs: Gerhard Hundertmark

Plant fossil from Carboniferous strata of Zwickau, Saxony, original specimen from the collection of Gottfried Wilhelm Leibniz with historical label in the handwriting of Blumenbach, object width C. $10.5 \mathrm{~cm}$

\section{Established: 1734}

Number of items: c. 10,000 and c. 80,000 further archived objects and convolutes

Public exhibition: in part

Open: Mon. to Fri. 9:00 - 17:00,

Sun. 10:00 - 16:00

Admission: free

Tours: by appointment

\section{Contact:}

Prof. Dr. Joachim Reitner

Tel.: +49 551 39-7951

Dr. Alexander Gehler

Tel.: +49 551 39-7998

geomuseum@gwdg.de

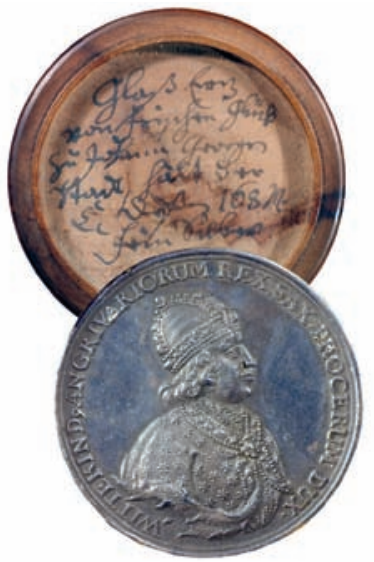

These collections unite fossils, minerals and rocks from the early days of Göttingen University and the Königliches Academisches Museum (Royal Academic Museum; before 1840), with objects from the collections of no lesser figures than, for instance, philosopher and polymath Gottfried Wilhelm Leibniz (1646-1716) and the Göttingen professors Samuel Christian Hollmann (1696-1787), Christian Wilhelm Büttner (1716-1801), Georg Christoph Lichtenberg (1742-1799) and Johann Friedrich Blumenbach (1752-1840). Likewise, among those whose efforts in this domain contribute today to Göttingen's Historical Geoscience collections were Hanoverian court counsellors including August Johann von Hugo (1686-1760) and Georg August Ebell (1745-1824) and Bergmeister (mine managers) as well as private collectors of this time, among them Christoph Andreas Schlüter (1668-1743), Eberhard Friedrich Hiemer (1682-1727), Johann Georg Keyssler (1689-1743), Georg Andreas Stelzner (1725-1802), Georg Sigismund Lasius (1752-1833) and Johann Carl Wilhelm Voigt (1752-1821). The holdings consist of more than 10,000 objects and series. These include large-scale donations made to the University Museum or directly to Blumenbach himself, who as the keeper and curator of the museum played the pivotal role in steering the museum's development. In doing so, Blumenbach was able to draw on his extensive network of colleagues, friends, former pupils, collectors and others. This circle included numerous important and well-known names such as Peter

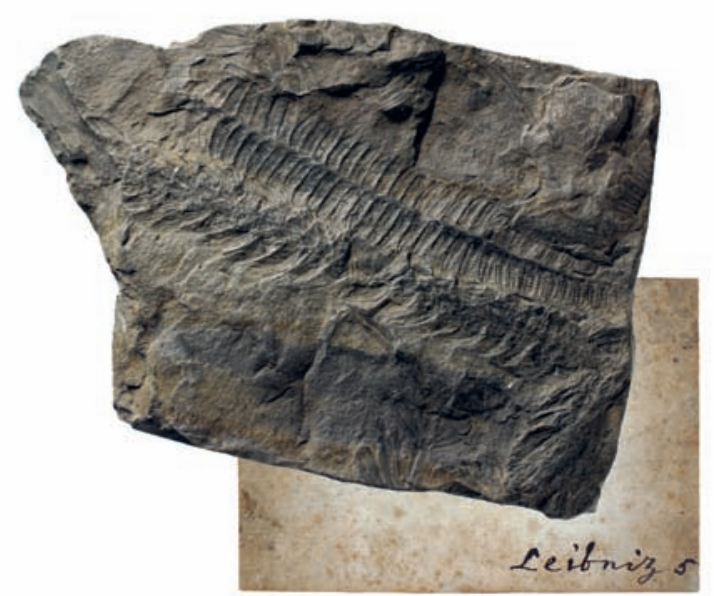




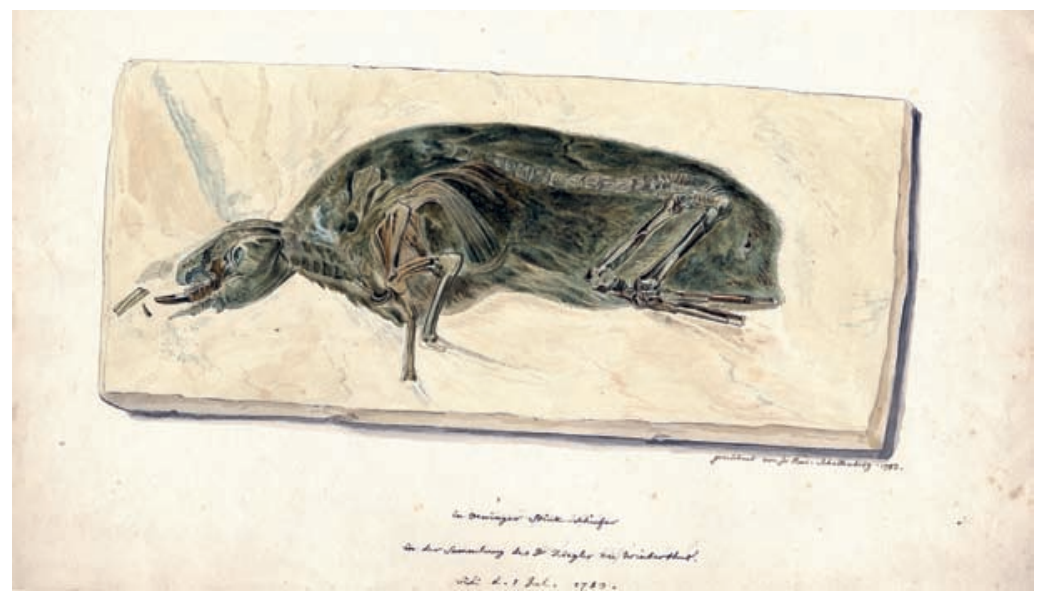

Camper (1722-1789), Jean-André Deluc (1727-1817), Johann Albrecht Euler (1734-1800), Peter Simon Pallas (1741-1811), Sir Joseph Banks (1743-1820), Johann Wolfgang von Goethe (1749-1832), Samuel Thomas von Soemmerring (1755-1830), Carl Heinrich Merck (1761-1799), Georges Cuvier (1769-1832), Alexander von Humboldt (1769-1859), Wilhelm Gottlieb Tilesius von Tilenau (1769-1857), Alexandre Brongniart (1770-1847), Leopold Freiherr von Buch (1774-1853), Prinz Maximilian zu Wied-Neuwied (1782-1867), Christian VIII of Denmark and Norway (1786-1848) and Ludwig I von Bayern (1786-1868).

Furthermore, many objects originating from early academic and scientific expeditions of the 18th, 19th and 20th centuries found their way to Göttingen University. Among these are specimens brought back from the (German-) Danish Arabia Expedition (1761-1767), the South Sea Voyages of Captain Cook (1769-1780), the Billings-Saryčev Expedition (1785-1795) to East Siberia and Alaska, the first Russian circumnavigation of the globe (18031806) under Adam Johann von Krusenstern (1770-1846), the first German (1868, 1869-1870) and Swedish (1872) North Polar Expeditions, the German Atlantic Expedition on the research vessel 'Meteor' (1925-1927), and the German Himalaya Expedition (1934).

A further 80,000 archived documents (including letters, manuscripts, drawings, personal copies of publications, photographs, photographic plates and guest books) of Göttingen geologists, mineralogists and other natural scientists provide an insight into the history and development of the geosciences at Göttingen University.

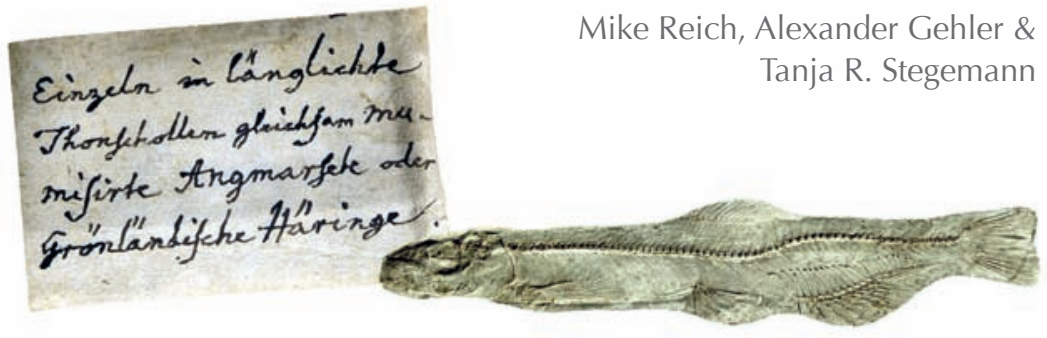

Hand coloured drawing of a fossil pika (Prolagus) from the Miocene fossil lagerstätte Öhningen (Baden), prepared by Johann Rudolph Schellenberg (1740-1806) in 1783, from the collection of Johann Friedrich Blumenbach, object width C. $35 \mathrm{~cm}$
Fossil fish from western Greenland, from the collection of Johann Friedrich Blumenbach, with original label in his handwriting, image width c. $15 \mathrm{~cm}$ 


\section{Göttingen Museum of Chemistry}

Faculty of Chemistry, University of Göttingen

Tammannstraße 4 • 37077 Göttingen • www.museum.chemie.uni-goettingen.de

Samples from the chemical laboratory of Professor Otto Wallach, Walther Borsche, 1898; photographs: Stephan Eckardt

\section{Established: 1979}

Number of items: c. 1,000

Public exhibition: yes

Open: by appointment

Admission: free

Tours: by appointment

\section{Contact:}

Dr. Ulrich Schmitt Tel.: +4955139-33114 uschmit@gwdg.de
Established in 1979, Göttingen University's Museum of Chemistry at the Faculty of Chemistry contains numerous and wide-ranging historical objects and documents relating to the subject's history at Göttingen since the university's founding in 1737. This notable collection continues to expand steadily through purchases and donations. The Museum receives support from an association of friends, many of whose members are past or present lecturers in chemistry at Göttingen University, or who graduated here in the subject.

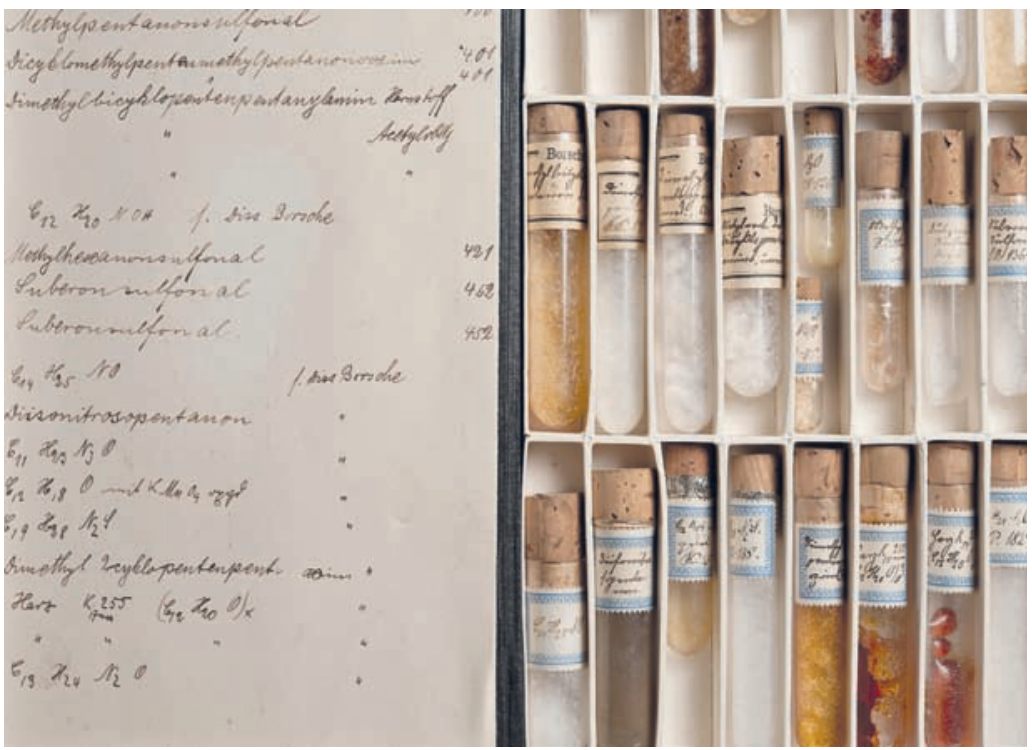

Göttingen University's Faculty of Chemistry has a long tradition. Private lectures in chemistry were being held while the university was still in its infancy and in 1783, the first official chemistry laboratory was set up. Scientists such as Johann Friedrich Gmelin (1748-1804), Friedrich Stromeyer (1776-1835), Friedrich Wöhler (1800-1882), Hans Hübner (1837-1884), Victor Meyer (1848-1897), Gustav Tammann (1861-1938) and Nobel Laureates Otto Wallach (1847-1931), Walther Nernst (18641941), Richard Zsigmondy (1865-1929) and Adolf Windaus (1876-1959) played decisive roles in the institution's advance to become one of the world's leading centres of chemical research.

The collection encompasses several hundred historical objects, photographs, books and documents on the history of chemistry, with Göttingen as the focus. Among the oldest and finest items are eighteenth- 


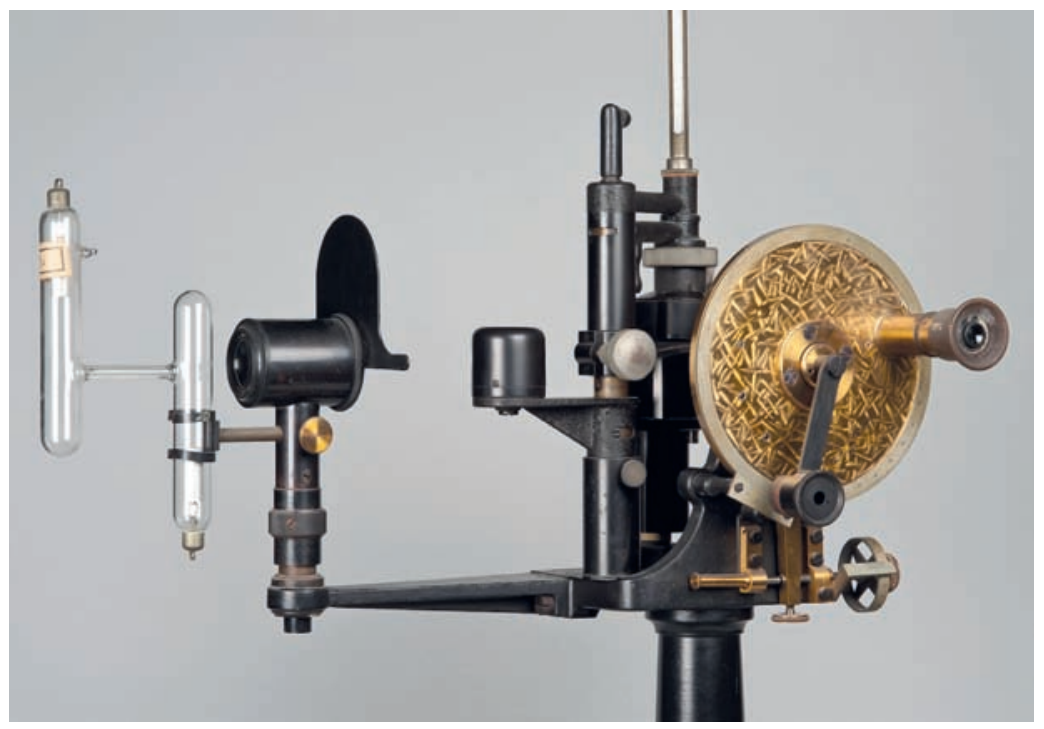

century chemistry textbooks, some in Latin, the Doctoral Certificate of Friedrich Wöhler (1823), a precision balance from the workshop of Moritz Meyerstein, who also built instruments for Carl Friedrich Gauß, and optical measuring devices such as refractometers and polarimeters. In addition, the holdings include chemical samples from the laboratory of Otto Wallach and early analytical balances from the factory of Florenz Sartorius.

The permanent exhibition on the subject of the history of chemistry is accessible for the public and can be visited by appointment. The Museum also holds special exhibitions and participates in cross-section presentations.
Pulfrich refractometer, Carl Zeiss, Jena, 1895

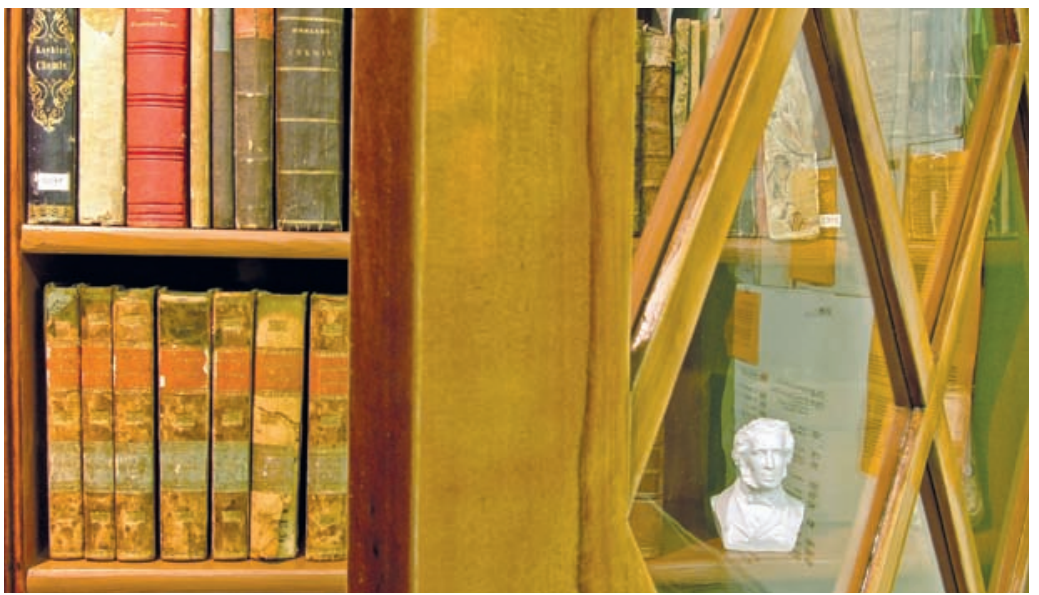

Historical textbooks in the Museum; photograph: Gisa Kirschmann-Schröder 


\section{Collection of Historic Physical Apparatus 'Physicalisches Cabinet'}

Faculty of Physics, University of Göttingen

Friedrich-Hund-Platz 1 • 37077 Göttingen • www.uni-goettingen.de/physics-collection

Lichtenberg's electrophorus with Lichtenberg figure, c. 1780; photograph: Manfred Mahn
At the centre of this collection of historic physical apparatus are instruments acquired by Georg Christoph Lichtenberg (1742-1799) out of private funds. In work carried out in the spirit of the Enlightenment, the devices served him in his demonstrations of physical phenomena. Lichtenberg was the first Professor of Experimental Physics at the University of Göttingen, which was still in its early days. Particular highlights of the collection are a vacuum pump manufactured by Naire \& Blunt, London, the Magdeburg hemispheres, and a bell mechanism for demonstrating sound dissemination. The experiments cover the entire spectrum of topics from mechanics and optics to electricity and magnetism, conveying a strong and lively impression of this period.

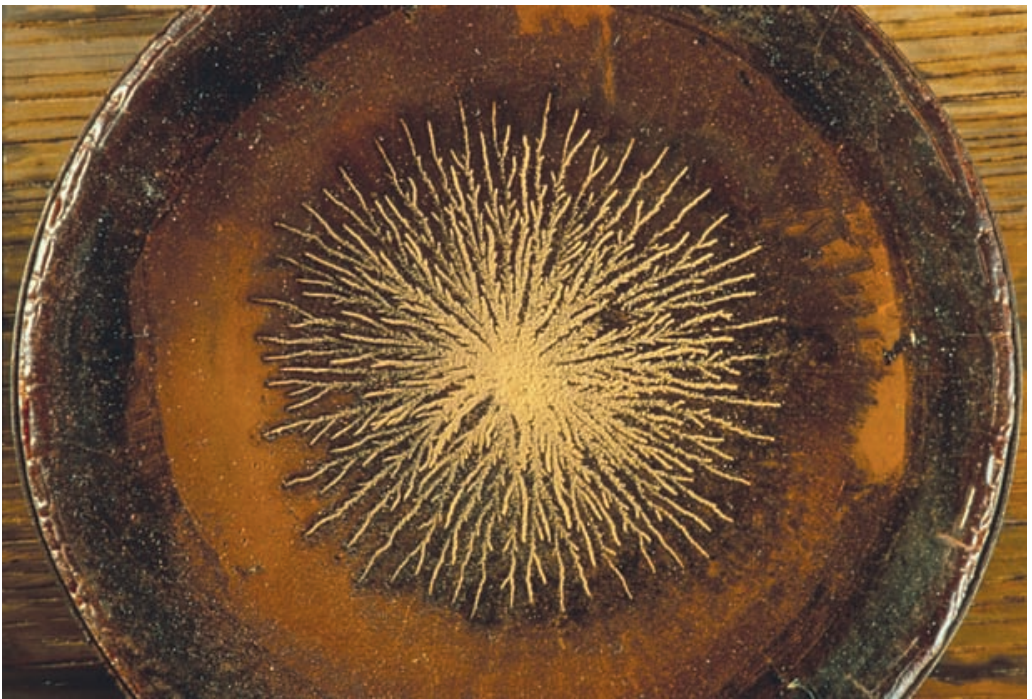

A varied range of devices relating to the areas of quantitative electricity, electrical measuring systems and magnetism dates back to the days when Wilhelm Eduard Weber (1804-1891) was at work in Göttingen. Together with Carl Friedrich Gauß (1777-1855), Weber investigated the phenomenon of terrestrial magnetism and the absolute unit system, the CGS (centimetre-gram-second) system. Together, Weber and Rudolf Kohlrausch (1809-1858) delivered experimental proof that electrical charges are connected with the magnetic field via a maximal speed c (speed of light). The experiments with Gauß led to the development of the first electromagnetic telegraph, which dates from the year 1833. In the 


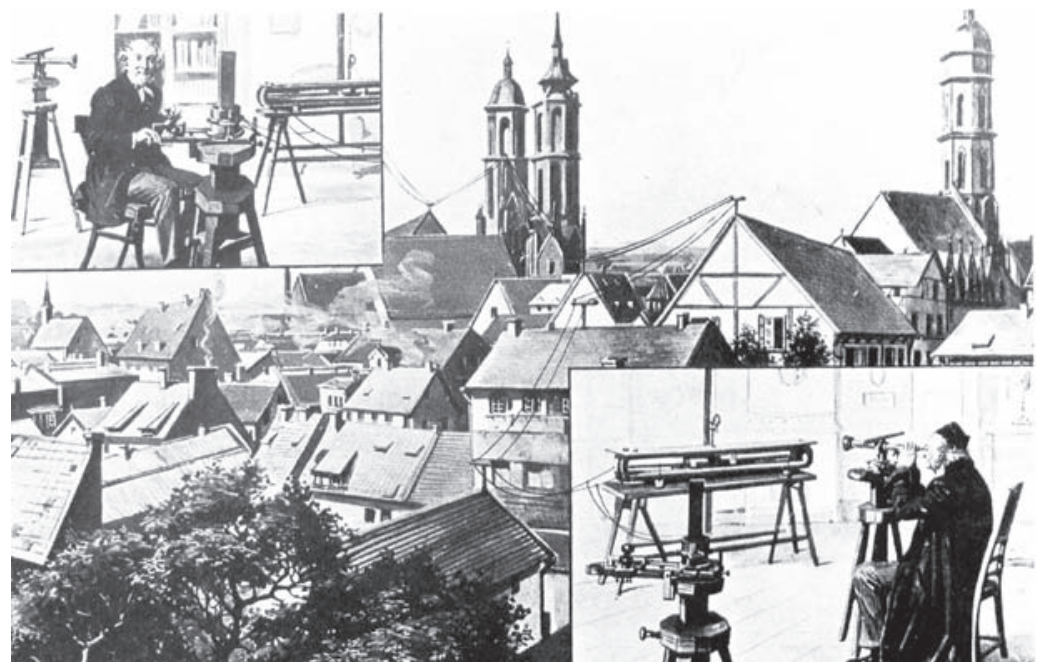

field of geodesy, the collection includes the sextant developed by Gauß. This device made it possible to measure angles precisely, with the help of sunlight, over a distance of up to 100 kilometres.

Dating from more recent times, the Cabinet holds a collection of spectrometers, crystal goniometers and electron and X-ray tubes from the late 19th and early 20th centuries, instruments that paved the way for quantum mechanics. The Museum also houses experimental facilities from the earliest days of solid state and low temperature physics: a crystal growing room from the 1920s.

Markus Münzenberg
Gauß-Weber telegraph in a historical representation

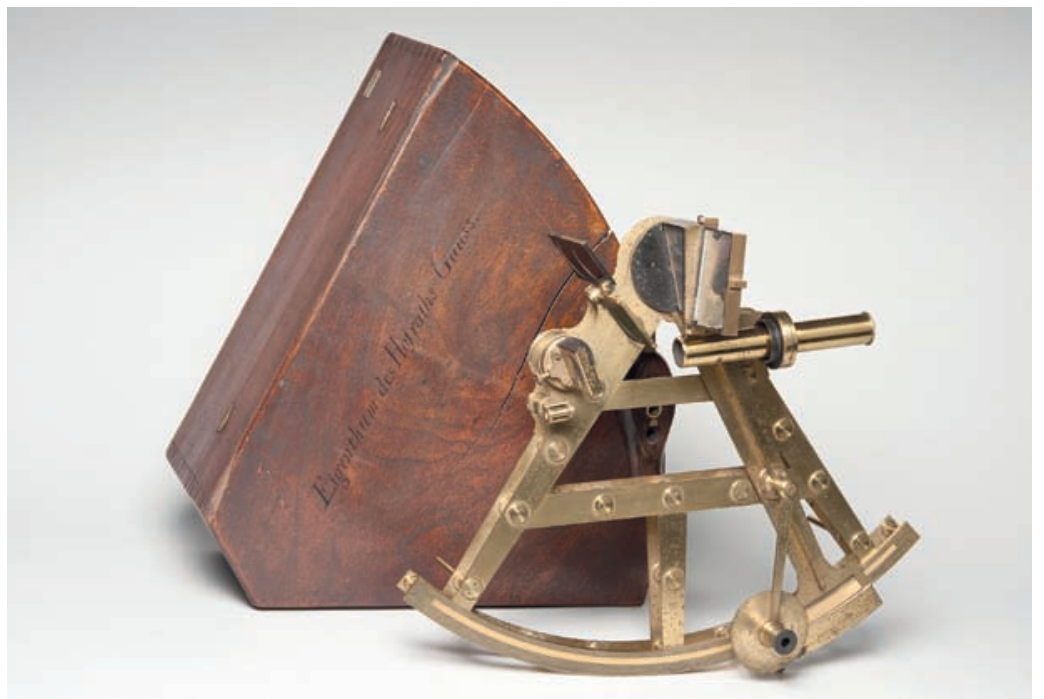

Vizeheliotrop for the refraction of sunlight (Greek heliotrop). Manufacture: workshop E. Troughton (1753-1835), London, remodelled in 1821 by Carl Friedrich Gauß (1775-1835). The sextant was depicted on the old 10 Deutschmark note. Photograph: Stephan Eckhardt 


\section{Beckmann Collection}

Faculty of Physics, University of Göttingen

Friedrich-Hund-Platz 1 • 37077 Göttingen • www.uni-goettingen.de/beckmann-collection

Portrait of Johann Beckmann, with kind permission of the Herzog August Bibliothek Wolfenbüttel

Vier-Spezies-Rechenmaschine (Stepped Reckoner) by Gottfried Wilhelm Leibniz, with kind permission of the Gottfried Wilhelm Leibniz Bibliothek, Hanover

Established: 1763

Number of items: 25

Public exhibition: individual objects (Hanover)

Admission: free

\section{Contact:}

Prof. Dr. Konrad Samwer Tel.: +49551 39-7602 physik1@uni-goettingen.de
One of Göttingen University's oldest collections is the Modellkammer. Of the original set of items it contained, 25 are still present today. Mathematicians such as Abraham Gotthelf Kästner (1719-1800) took charge of this collection, which, augmented and maintained by craftsmen in the employ of the university, was used and admired by numerous professors, students and visitors.

Until well into the 20th century, models were regarded as outstanding vehicles for the communication of knowledge. The approximately 150 models that once formed part

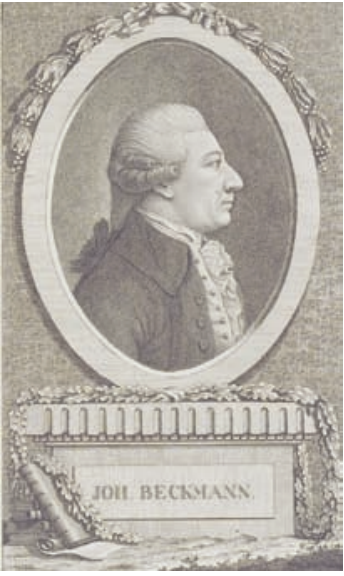
of the collection served first and foremost as demonstration tools used for the training of senior civil servants in the areas of engineering and mining, agricultural and water engineering. The Modellkammer thus fitted naturally into the reform concept of Göttingen University, which - fully in line with the ideas of Leibniz - maintained the link to the practical domain. It is therefore hardly surprising that one of the most precious items in the Modellkammer was Leibniz' calculating machine. Alongside the models, the collection also contained scientific equipment for measurement of land and for use in astronomy.

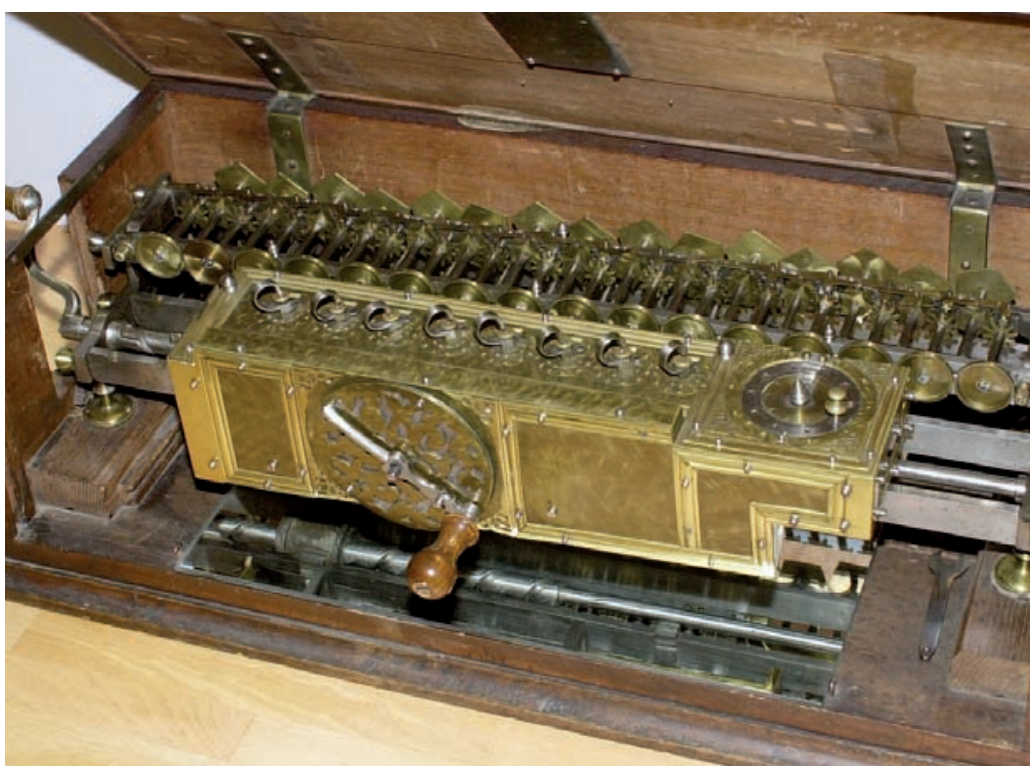




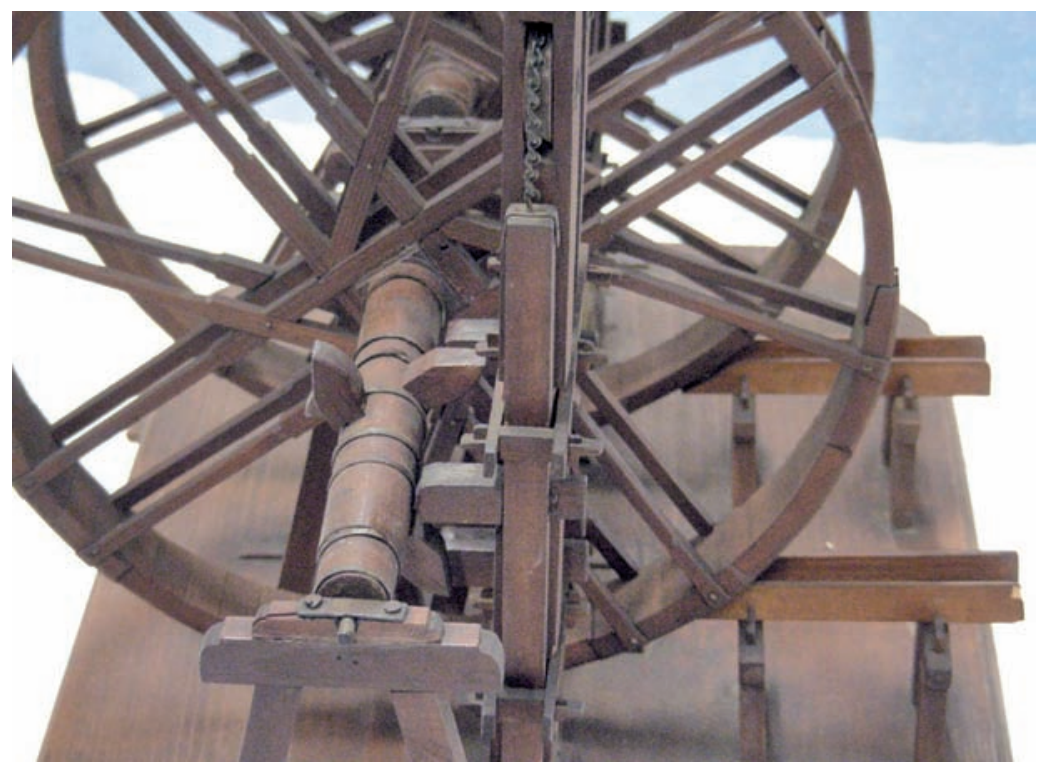

A highly reputed lecturer at Göttingen University, economist Johann Beckmann (1739-1811) is frequently associated with the Modellkammer. Beckmann indeed made intensive use of the collection not only in the context of his technology lectures, but also to prepare his students for excursions. These study trips were designed to help them grasp practical aspects of the mining operations carried out in the Harz region, or of business enterprises run in the vicinity of Göttingen.

The name Modellkammer refers to a place rather than to the collection itself. In practice, though, the items were distributed throughout the entire university. This remained the case until the founding of the Academic Museum, in which rooms were made available to house the models.

Oliver Zauzig

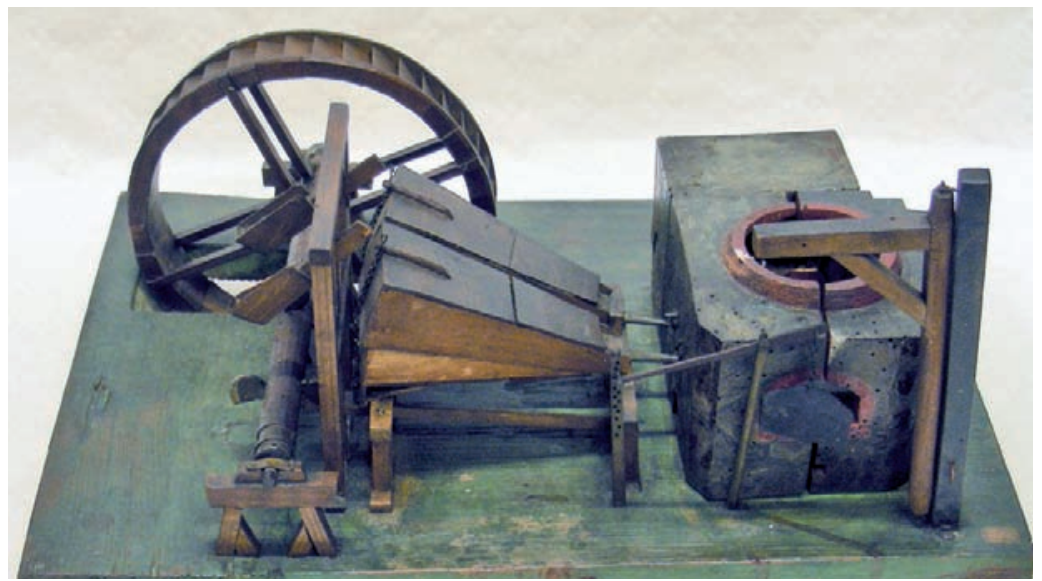

Model of a pumping station driven by two undershot waterwheels; photograph: Oliver Zauzig
Model of a Harz lead melt furnace from Beckmann's Collection 


\section{Collection of Historical Instruments at the Institute of Geophysics}

Institute of Geophysics, University of Göttingen

Friedrich-Hund-Platz 1 • 37077 Göttingen • www.uni-goettingen.de/sammlung-geophysik

Seismogram of the 1906 San Francisco earthquake, Wiechert's astatic $1200 \mathrm{Kg}$ seismograph; photographs: Stephan Eckardt

Inclinator developed by Meyerstein to measure the terrestrial magnetic field, 1847

Established: 1997

Number of items: c. 50

Public exhibition: yes

Admission: free

Tours: by appointment

Contact:

Rainer Hennings

Tel.: +49 551 39-7460

rainer.hennings@geo.physik.

uni-goettingen.de
The origins of geophysics as an academic subject in Göttingen go back to the 'Department of Magnetism' at the university's astronomical observatory. The collection therefore contains, first and foremost,

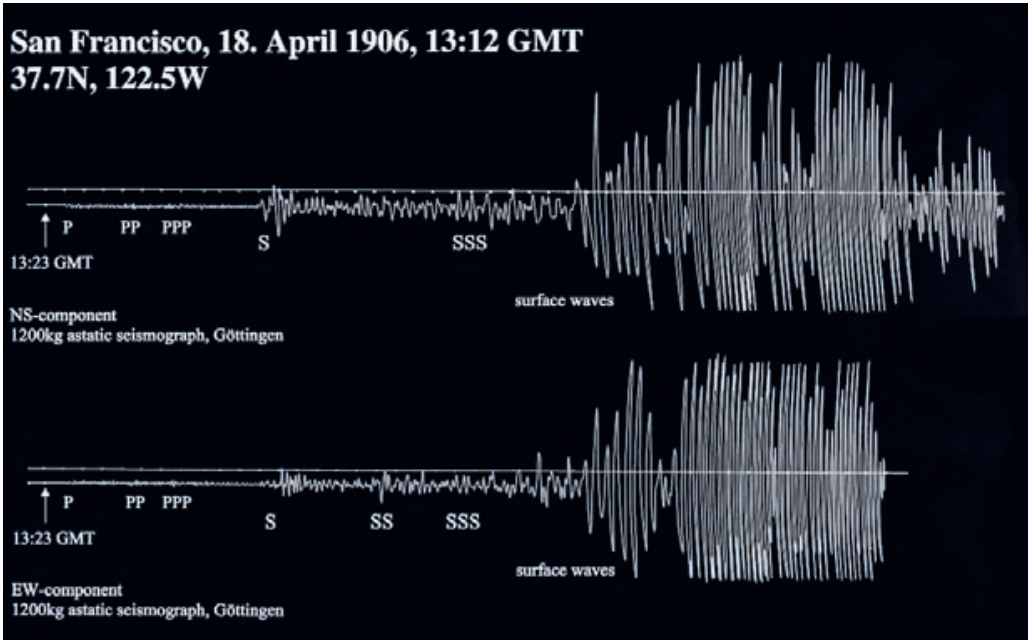




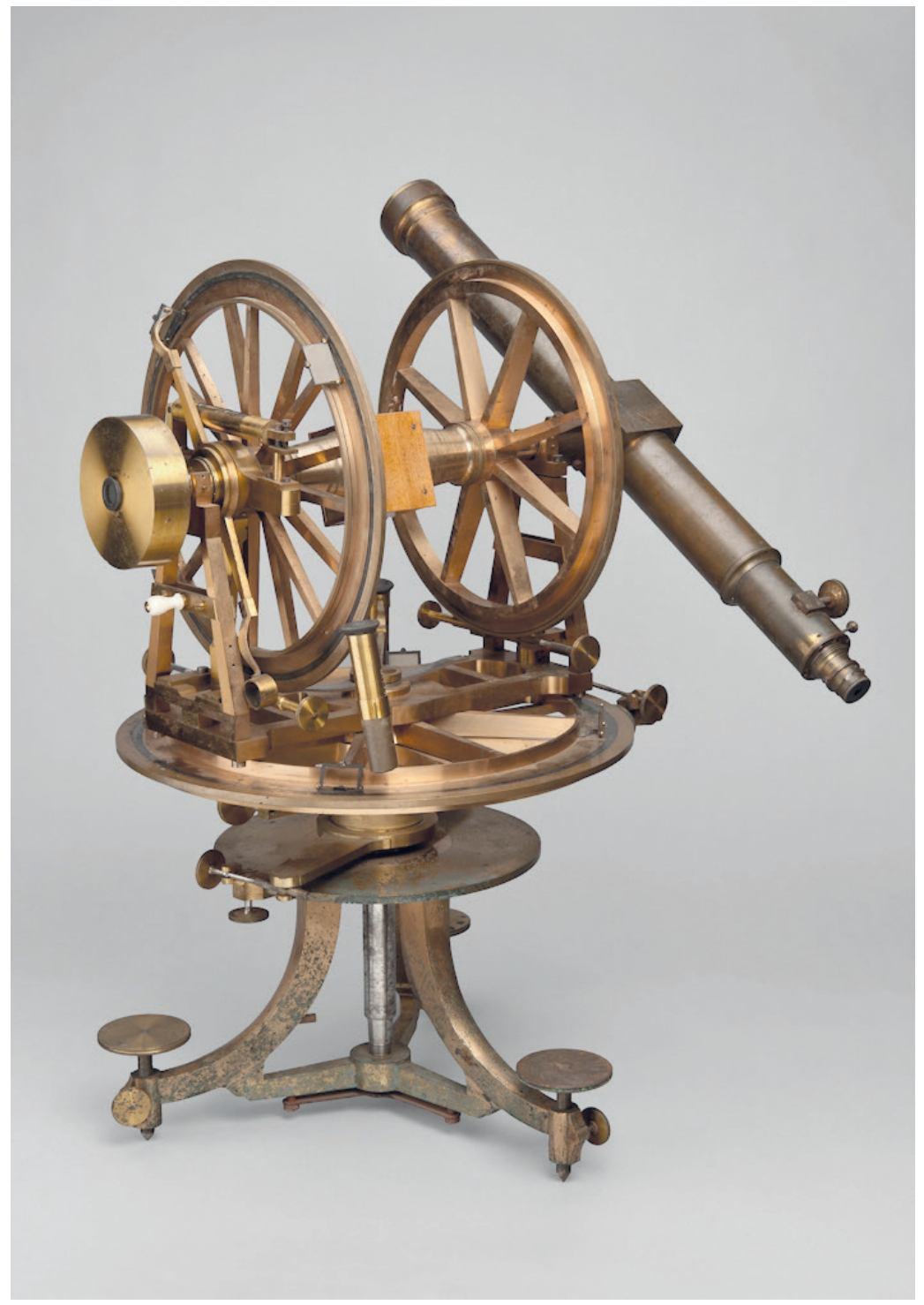

Theodolite by Reichenbach and Ertel (1947). Acquired by Gauß in 1820 and used for the geodetic survey of Hanover

equipment and apparatus for geodesic and geomagnetic measurement dating from the 19th and early 20th centuries.

However, the seismographs built by Emil Wiechert (1861-1928) from 1904 onwards no longer form part of the collection at the Institute of Geophysics. This is due to the fact that as immovables, they could not be transferred from the building that housed the Department of Geophysics until 2005, to the new Physics Faculty building at Friedrich Hund Platz, where the Institute is now located. 


\section{Collection of Historical Items at the Institute of Astrophysics}

Institute of Astrophysics, University of Göttingen

Friedrich-Hund-Platz 1 • 37077 Göttingen • www.uni-goettingen.de/astrophysics-collection

Heliotrope, second type, built by Moritz Meyerstein, Göttingen University mechanicus, c. 1870; photographs: Gisa Kirschmann-Schröder

Established: 1748

Number of items: c. 300

Public exhibition: yes

Open: by appointment, tours for the public approximately once per month

Admission: free

Tours: by appointment

\section{Contact:}

Dr. Klaus Reinsch

Tel.: +49551 39-4037

reinsch@astro.physik.uni-

goettingen.de
The origins of this collection go back to one of the oldest institutions of Göttingen University, the Observatory, which was founded in 1748. It attests to two and a half centuries of science history, as well as to the work of outstanding Göttingen scientists, among them Tobias Mayer (1723-1762), Carl Friedrich Gauß (1777-1855), and Karl Schwarzschild (1873-1916). The collection consists of a large number of objects and instruments dating from the 17th to the 20th centuries, the equipment having been used for astronomical and geodesic measurements and for other scientific investigations carried out at the Göttingen Observatory. The astronomical items that form the cornerstone of the collection came to Göttingen University around 1750 as a bequest from the Hanoverian Privy Councillor and High Bailiff, Joachim Heinrich Freiherr von Bülow

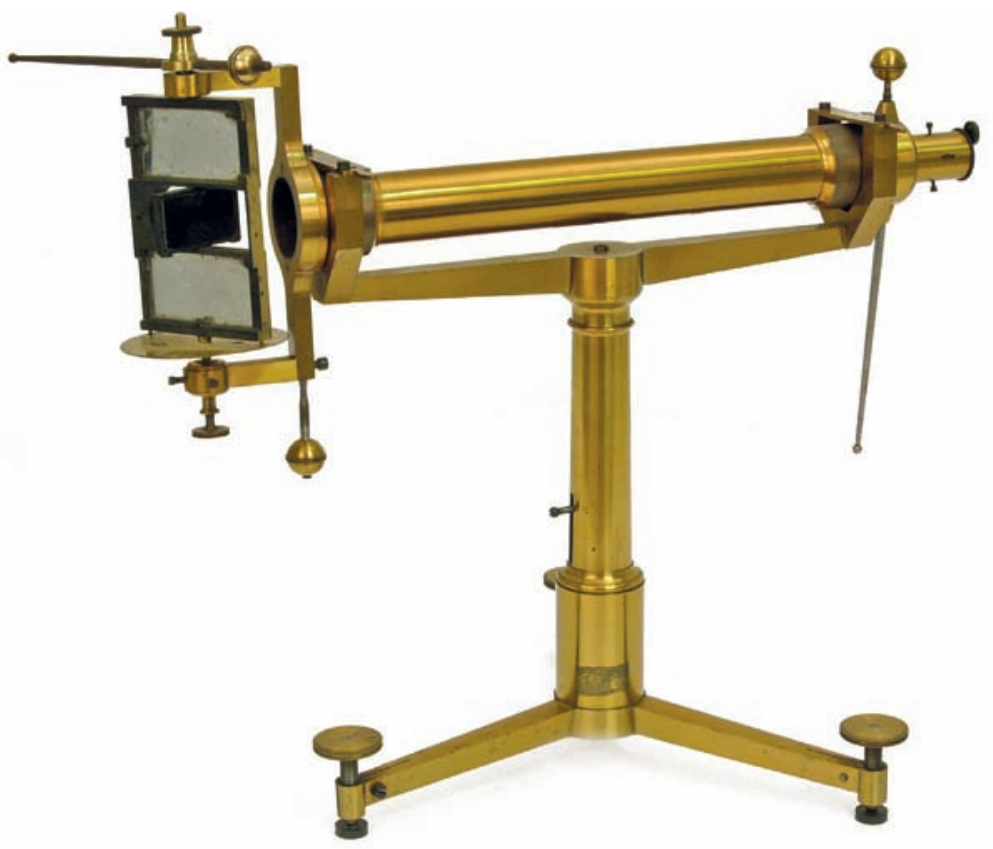

(1650-1724). Over the course of time, further instruments found their place in the Observatory through donations from private individuals and members of various royal families with connections to the university. Other instruments were commissioned specifically for use at the Observatory. These pieces of equipment were built by some of the most highly reputed instrument makers of their day, among them various mechanics from 


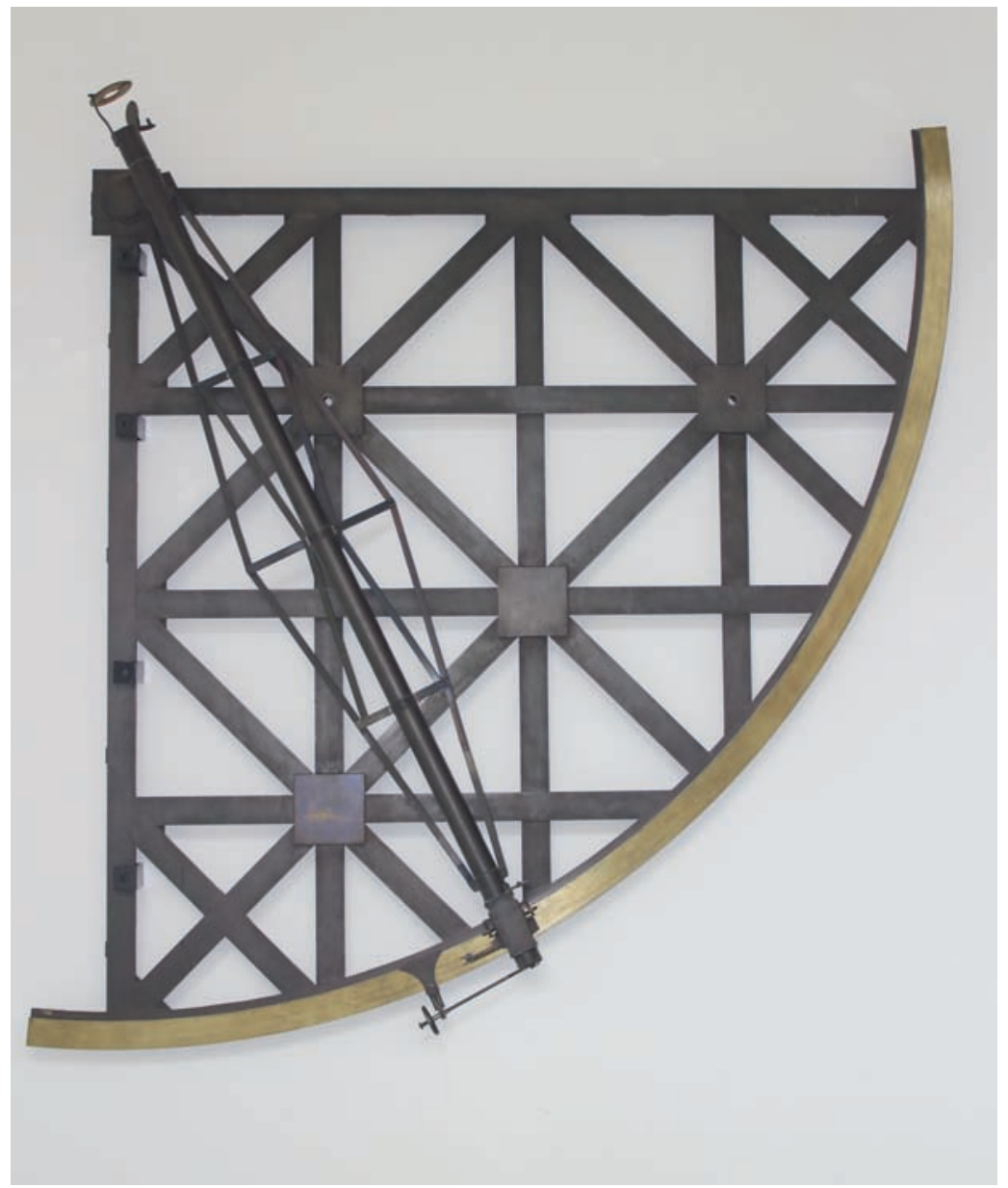

Göttingen in the employ of the university. Many illustrious names such as Bird, Fraunhofer, Gauß and Herschel are represented by items that have come down to us. In addition, the Institute holds memorabilia relating

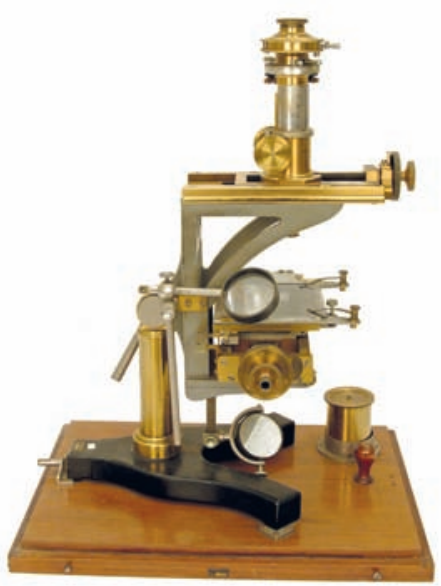
to Carl Friedrich Gauß, the first Director of the new (now historical) Observatory building completed in 1816. In 2005, the collection was transferred to the new building of the Physics Faculty on the University's north campus during the relocation of the Institute for Astrophysics. Since then, part of the collection has been exhibited in the entrance area and library of the Institute for Astrophysics, and is thus publicly accessible, if only to a limited extent.

Klaus Reinsch
Six-foot mural quadrant constructed by John Bird (17091776) in London for the first Göttingen Observatory. Using this instrument between 1756 and 1758, Tobias Mayer measured the positions of almost 1,000 stars of the zodiac region with, for that time, a very high degree of accuracy. Later, Carl Friedrich Gauß also used this quadrant. Since 2005 the mural quadrant has been mounted in the stairwell of the Institute of Astrophysics; photograph: Klaus Reinsch
Measuring microscope by Otto Töpfer, Potsdam, for the evaluation of photographic plates, 1911 


\section{Collection of Mathematical Models and Instruments}

Institute of Mathematics, University of Göttingen

Bunsenstraße 3-5 • 37073 Göttingen • www.uni-goettingen.de/mathematics-collection

Harmonic analyser by Coradi and Henrici, no. 557, designed c. 1895 by Max Küntzel and produced at the Coradi workshop; photographs: Stephan Eckardt

Kummer surface with four real nodes, no. 125, plaster of Paris

Established: 1881

Number of items: c. 1,000

including a collection of photographic slides

Public exhibition: yes

Open: Mon. to Fri. 8:00 - 19:00

Admission: free

Tours: by appointment

Contact:

Prof. Dr. Laurent Bartholdi sammlung@uni.math.gwdg.de
More than 500 objects are on display, among them many geometrical models made of plaster, wood, cardboard, thread or metal, as well as calculators, drawing machines, integraphs and cinematic and mechanical models. The oldest models are polyhedra in cardboard dating from 1780, but a large part of the objects date from between 1870 and 1920. These provide vivid insights into the mathematics of this period, when Göttingen emerged as one of the most important centres of mathematics in the world.

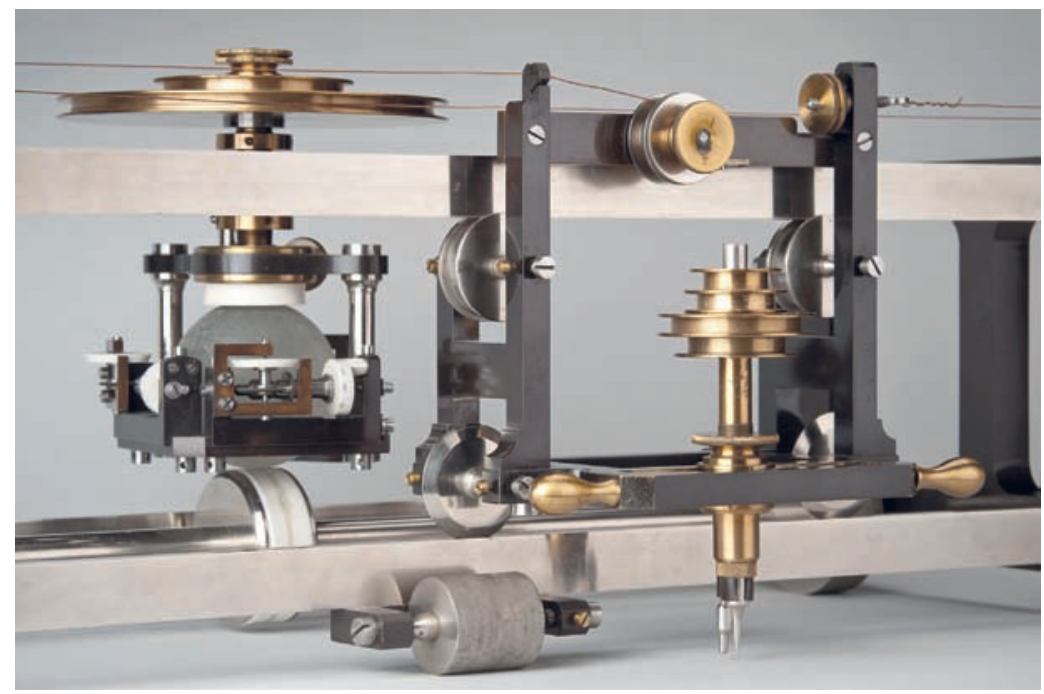

Several leading figures are especially closely associated with the collection's inception. Important impulses came from Alfred Clebsch (1833-1872); Hermann Amandus Schwarz (1843-1921) is regarded as the collection's founder,

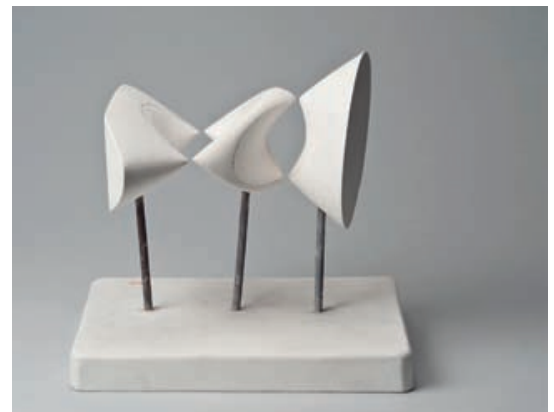
and Felix Klein (1849-1925) enlarged it with new models.

Mathematics deals with abstract structures. It is crucially important to visualise them and hence, during the 19th century, professors and students constructed models to gain a better intuition of surfaces and 


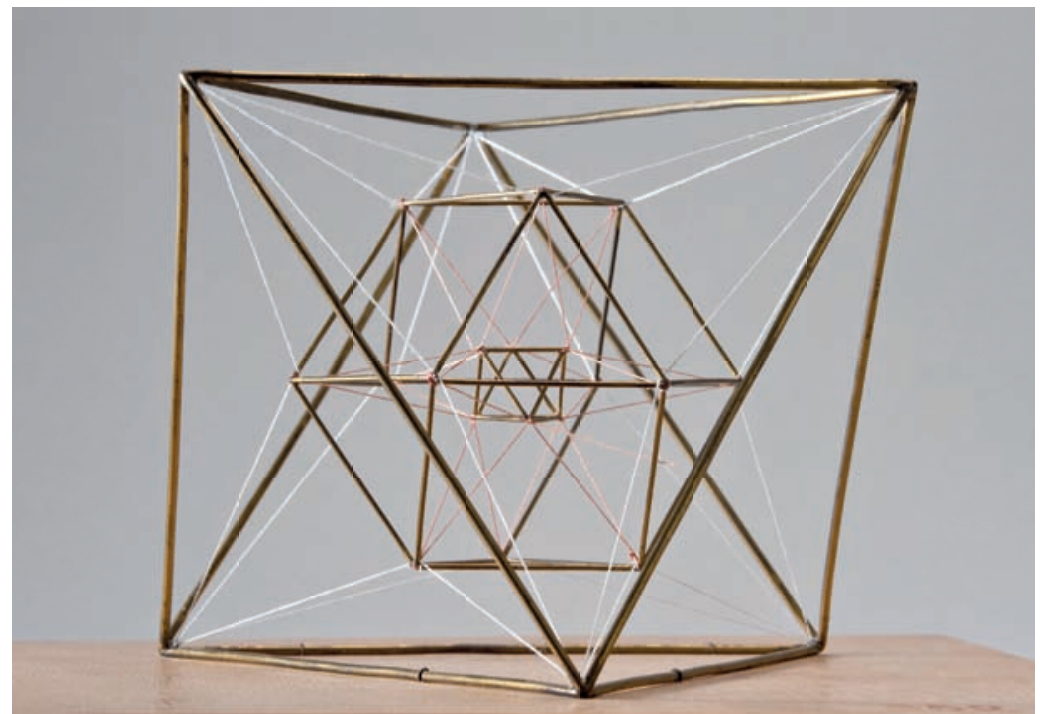

other mathematical objects. Many of these were made in series, and were purchased by universities for teaching purposes. They were also used in mathematical research. Nowadays, the models are of great scholarly interest not only to historians of science. In addition, they are currently being rediscovered for mathematical education. Finally, the models constantly awaken the interest of artists, who draw inspiration from them.

Ina Kersten

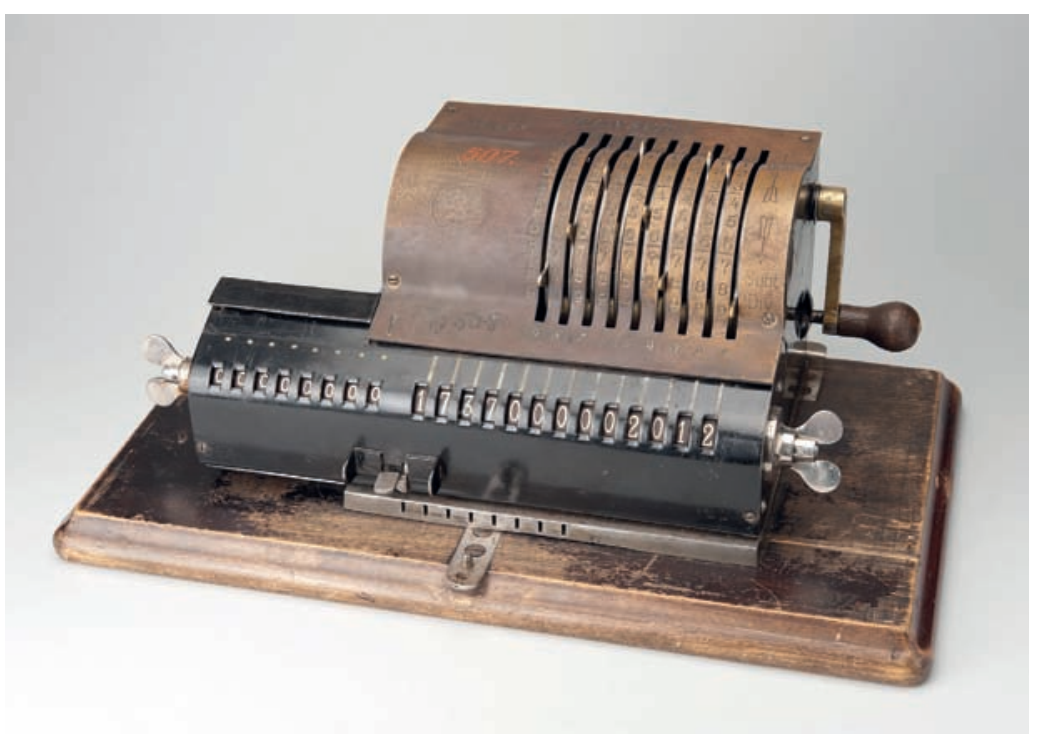

Projection of the regular fourdimensional 24-cell in threedimensional space, no. 352
Brunsviga calculating machine, no. 507 , built in 1892 


\section{Computing Museum of the GWDG}

Gesellschaft für wissenschaftliche Datenverarbeitung mbH Göttingen

Am Faßberg 11 • 37077 Göttingen • www.uni-goettingen.de/computing-museum

UNIVAC 1108 ICR. Integrated circuit register board of the UNIVAC 1108 computer, 1965; photographs: Uwe Nolte

G3-KSP. One of 40 arrays with 1,024 ferrite cores from the main memory of the Göttingen computer G3

UNIVAC 1108 main memory. Core memory module (capacity $32 \mathrm{~K}$ half words à 18 bits) of the UNIVAC 1108 computer, 1965

\section{Established: 1980}

Number of items: c. 500

Public exhibition: yes

Open: Mon. to Fri. 7:00 - 21:00

Sat. and Sun. 10:00 - 18:00

Admission: free

Tours: by appointment

\section{Contact:}

Dr. Thomas Otto

Tel.: +49551 201-1828

thomas.otto@gwdg.de
When in 1980 the Gesellschaft für wissenschaftliche Datenverarbeitung mbH Göttingen (GWDG) was celebrating its first decade in existence, parts of old computing equipment were placed on display to decorate the walls of otherwise bare corridors and to catch the attention of visitors. Such parts were well suited to awakening interest in computing history even among non-experts, since the technical components of a computer system, with its basic constituent parts (valves, transistors, flip-flops, AND gates, etc), could

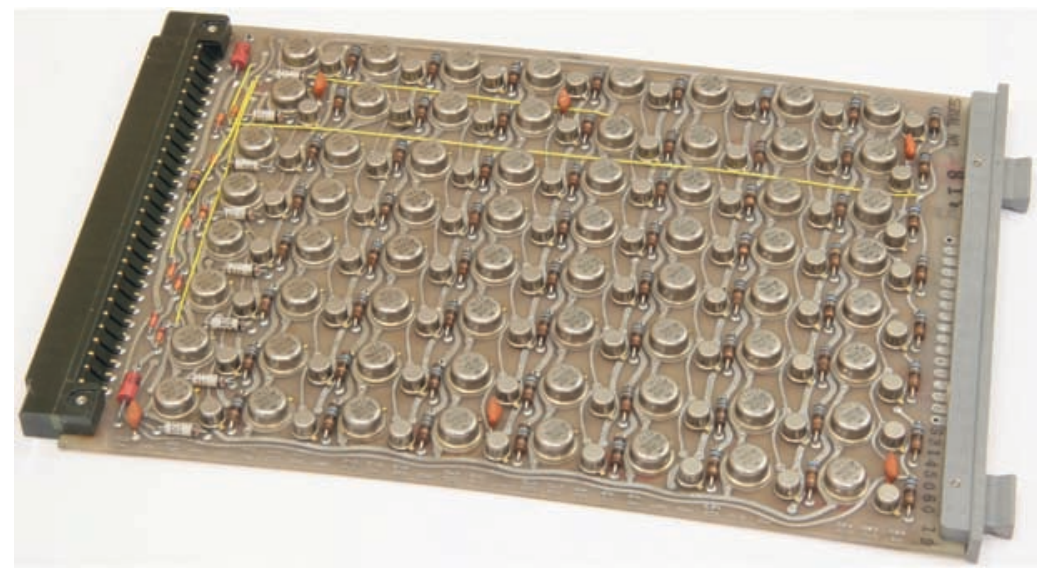

still be grasped by the hand and offered the eye much to take in. Today, it is no longer merely the general optical impression of the exhibits that is remarkable. Having grown steadily over time, the collection now provides a very good and comprehensive overview of the historical development of computer technology and data processing. For example, the visitor with some knowledge of electronics can analyse the precise function of the
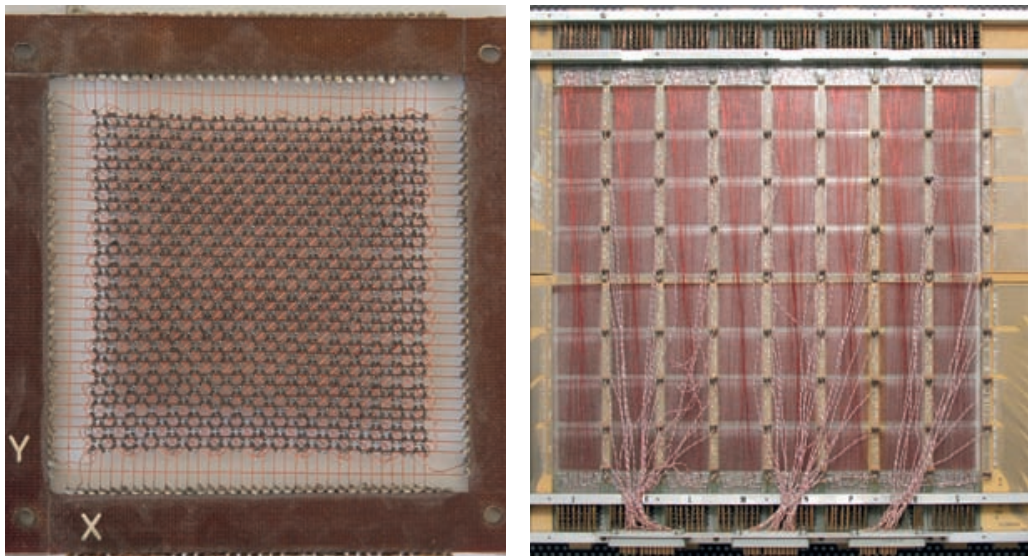


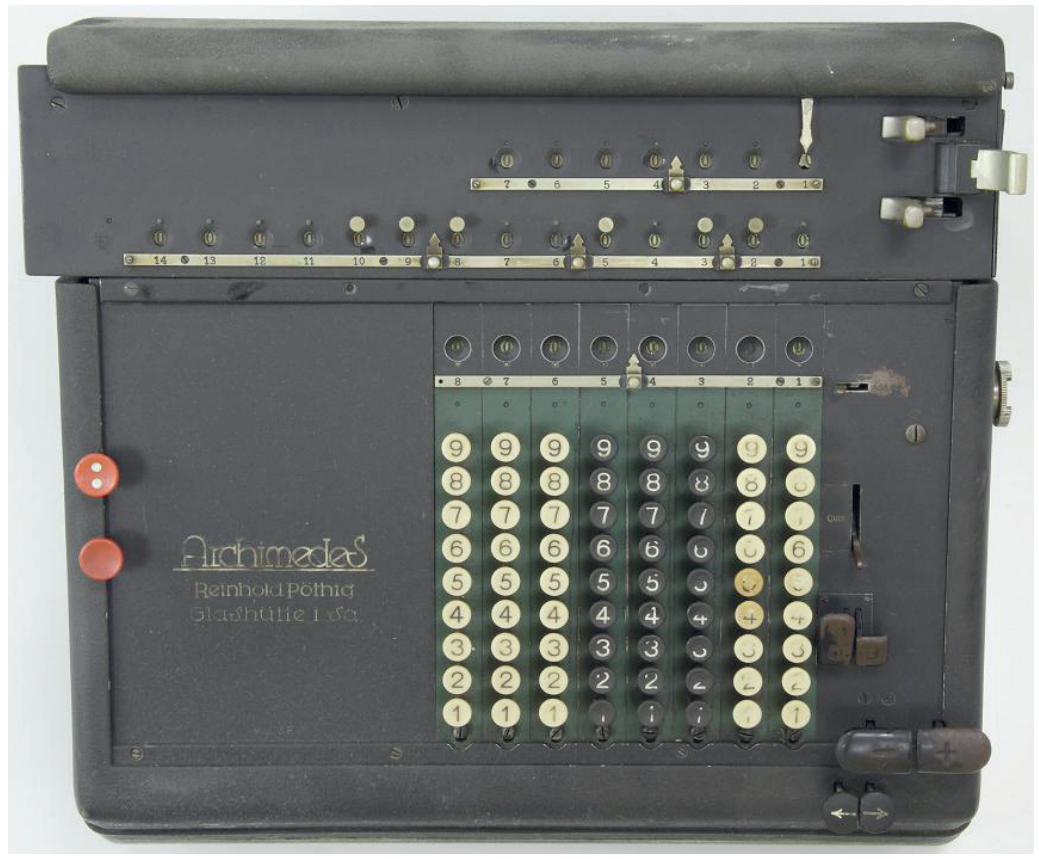

wiring on computer modules dating from the 60s, where the conducting paths are traceable by the naked eye.

The collection contains hundreds of components of computer systems, such as processors and memories, and a similar number of accessories such as memory media and components of input/output peripheric devices. A representative number of calculating devices, including slide rules and adding machines, desk and pocket calculators of all generations, and several complete computer and memory systems, round off the collection.

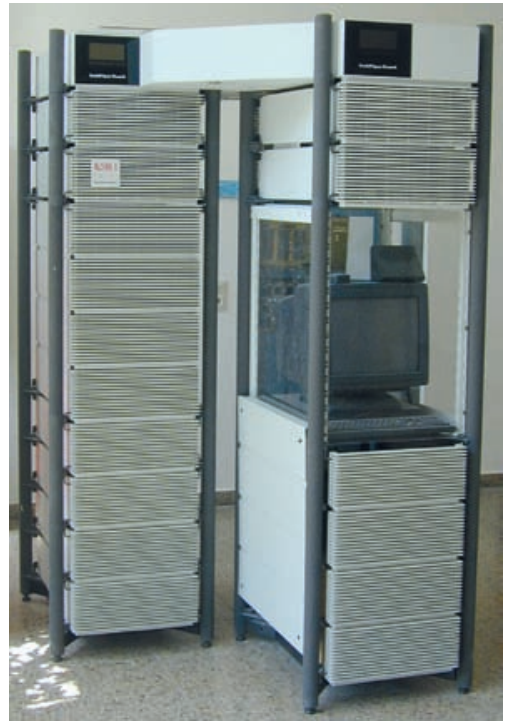

Designed to give users of the data processing centre a vivid overall picture of computing and its historical development, the collection is located in the centre's entrance hall and passages. Much frequented especially by school classes and students of computer science, the collection also attracts smaller groups of visitors from near and far.

Manfred Eyßell
Archimedes-GER. Stepped drum four function electromechanical calculator, 1932
Kendall Square Research 'KSR1'. Parallel computer with 32 processors, 1991 


\section{Collections of Göttingen State and University Library}

Göttingen State and University Library $\bullet$ www.sub.uni-goettingen.de/en

Central Library • Platz der Göttinger Sieben 1 • 37073 Göttingen

Historical Building • Papendiek 14 • 37073 Göttingen

Research using the guard-book catalogue: Dr. Christian Fieseler and Dr. Helmut Rohlfing, Department of Special Collections and Conservation; photographs: Martin Liebetruth

Established: 1734

Number of items: c. 7,700,000

Public exhibition: changing exhibitions

Open: Mon. to Fri. 7:00 - 1:00,

Sat. and Sun. 9:00 - 22:00 (Central Library) and Mon. to Fri. 10:00 - 19:00 (Historical Building)

For opening hours of the divisional libraries, please refer to the SUB Göttingen website

Admission: free

Tours: on request

\section{Contact:}

Dr. Johannes Mangei

Tel.: +49 551 39-5236

hg-info@sub.uni-goettingen.de
With the founding of Göttingen University Library in 1734, the concept of a modern research library was brought into existence for the first time. During the 18th century, the library amassed holdings of national and international significance, the maintenance of which has continued steadily throughout the course of the library's history. As a result, Göttingen State and University Library (Niedersächsische Staats- und Universitätsbibliothek Göttingen, SUB Göttingen) has taken on manifold

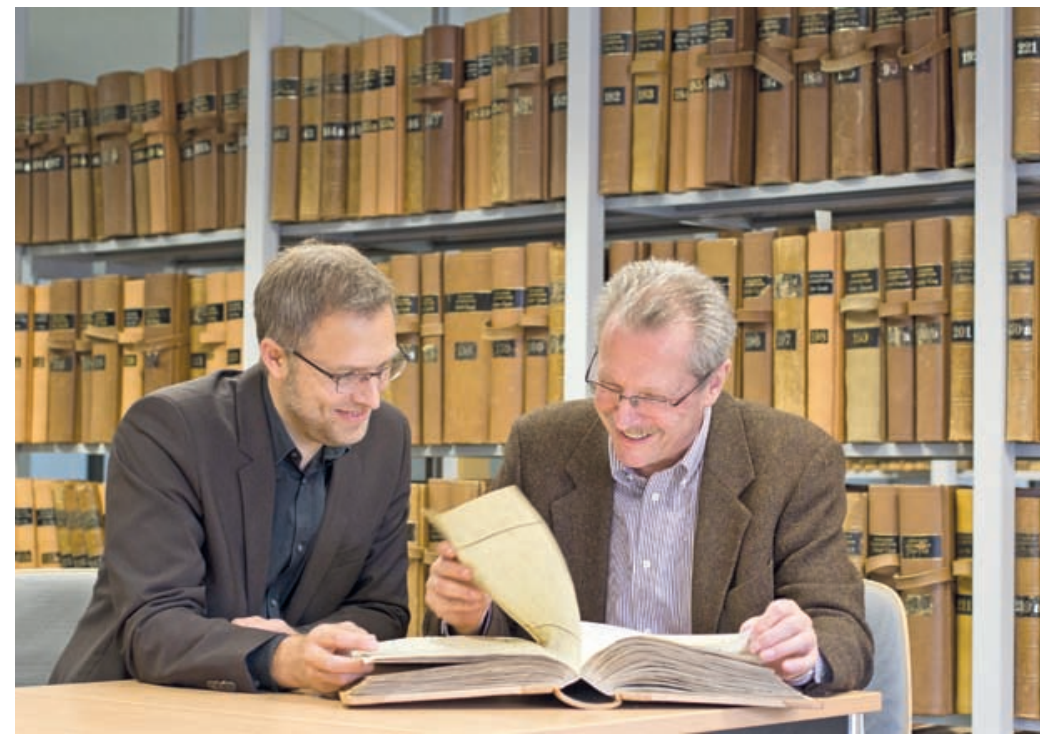

tasks at regional, national and international levels. Today, it constitutes one of Germany's largest libraries with holdings amounting to around 7.7 million items. These include some 5.7 million volumes, 1.6 million microforms, 35,000 licensed electronic journals, 11,000 ongoing print journals and extensive digital holdings. The special collections held at the SUB Göttingen range from manuscripts and a major collection of incunabula to numerous rare publications in all areas of science and scholarship, hand-drawn and printed historical maps, and the scholarly and literary papers of such eminent scholars as Georg Christoph Lichtenberg (1742-1799), Carl Friedrich Gauß (1777-1855), and Jacob (1785-1863) and Wilhelm Grimm (1786-1859). The Gutenberg Bible held by Göttingen State and University Library was declared a UNESCO 'Memory of the World' document in 2002. 


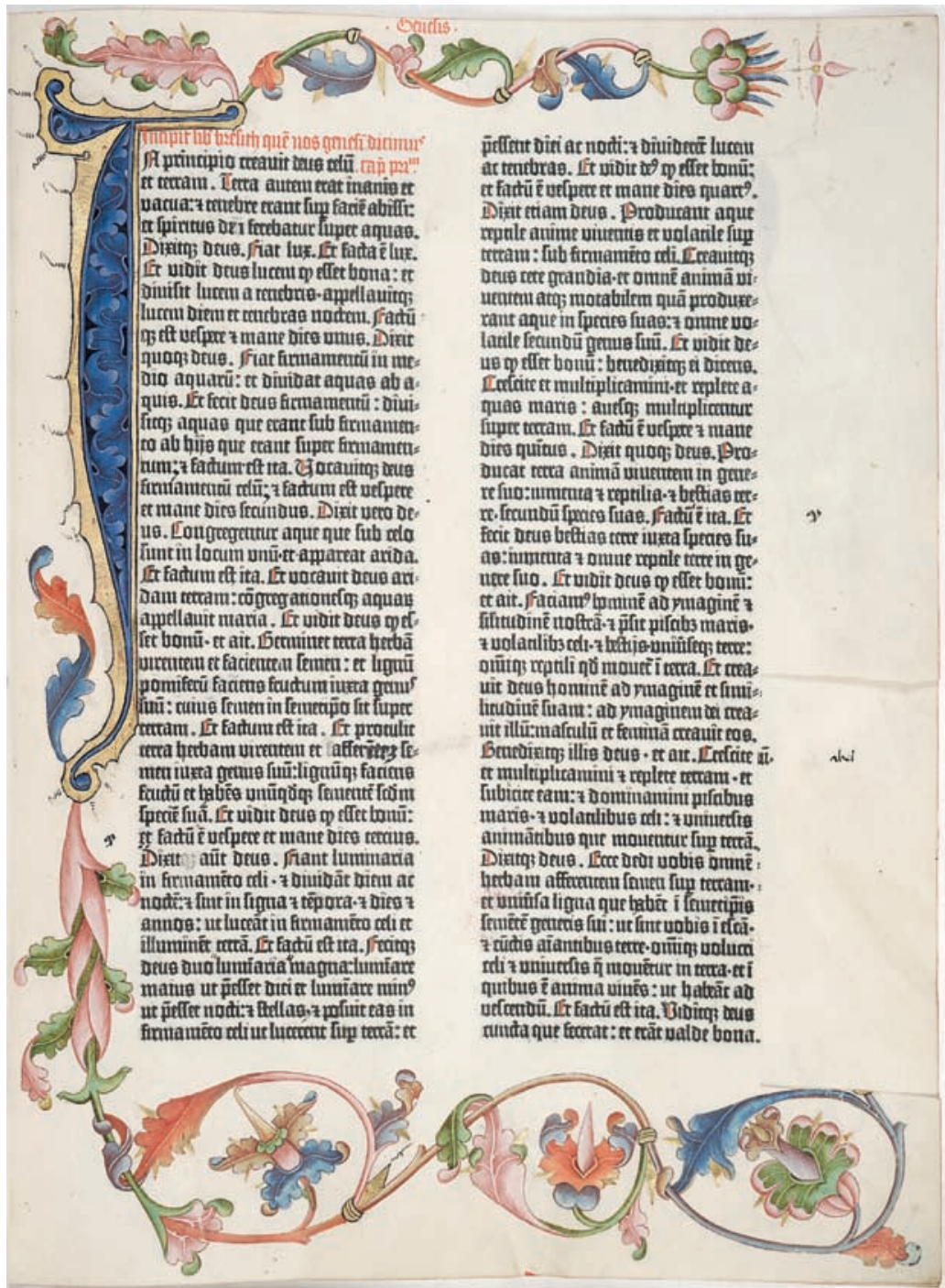

The first book printed with movable type in Europe: Göttingen's 42-line Gutenberg Bible is one of only four complete copies on vellum.

In the context of the German Research Foundation programme for special subject collections, the SUB Göttingen is currently responsible for a number of special collections covering a broad range of subjects. Since 1990, the library has functioned as 'German National Library for the 18th Century' in the framework of the Arbeitsgemeinschaft Sammlung Deutscher Drucke (Working Group Collection of German Printed Books). 


\section{Map Collection}

Göttingen State and University Library

Historical Building • Papendiek 14 • www.sub.uni-goettingen.de/en

In the possession of the Göttingen library since 1754: the Atlas novus coelestis, produced by the publishing house of Homann's heirs, made a significant contribution to popularising the Copernican world view. Photographs: Martin Liebetruth
Since its founding, Göttingen State and University Library (SUB Göttingen) has been investing considerable resources and effort in the collection of maps and atlases. Alongside the purchase of individual items, generous donations and notable bequests laid the foundation for one of the most significant map collections in Europe. The private library of Joachim Hinrich von Bülow, holdings that constituted the original stock of the University Library, already brought the collection 2,000 maps from the 17 th and 18 th centuries. Particularly noteworthy are the famous atlases by Wilhelm (1571-1638) and Johann Blaeu (1596-1673), and by Johann Jansson (1588-1664). Some 3,000 maps from the Nuremberg mappublishing house of Johann Baptist Homann (1664-1724) came into the holdings through Johann Michael Franz (1700-1761), incumbent of the first Chair of Geography at Göttingen University.

The donations made by Baron Georg Thomas von Asch (1729-1807) enriched the collection with unique maps of Siberia, Russia and Asia. Through the 'personal union' of the royal houses of Hanover and Great Britain, the map collection received a large number of maritime charts from the British 'Hydrographical Office', items that in their time were highly confidential and are extremely rare. A further collection of some

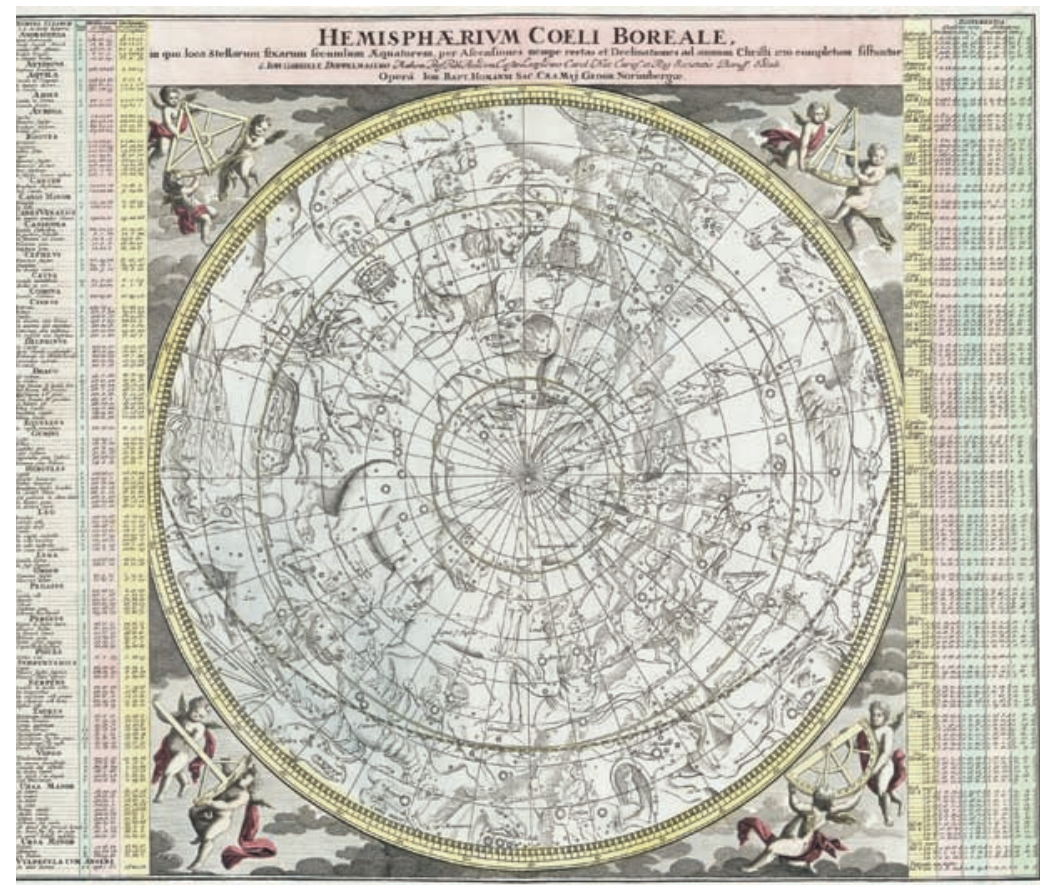




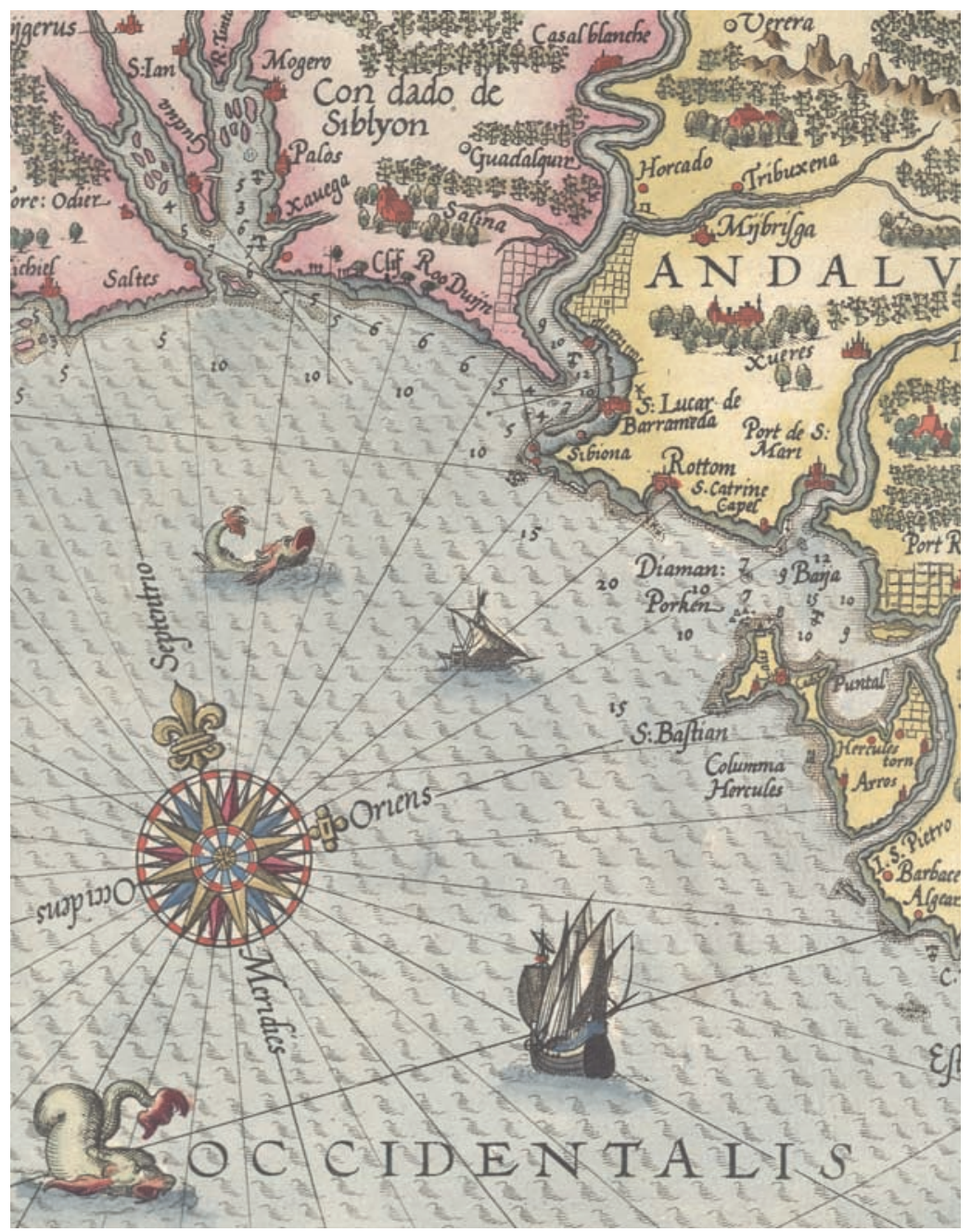

1,500 maps was received through the estate of naturalist and economist Johann Beckmann (1739-1811).

In 1888, a large part of the map collection passed to the University's Geographical Institute (Geographischer Apparat), where the objects remained for approximately a century on long-term loan. Today, however, these historical holdings are back in the SUB Göttingen's map collection and are accessible via the catalogues for research. In addition to the important historical holdings numbering some 65,000 sheets, the collection possesses approximately 320,000 maps and 11,000 atlases dating from the post-1945 period.
Part of a map showing the coastline of the Algarve and Andalusia. The map is included in an atlas entitled Thresoor der Zeevaert, (Treasure of Seafaring), published in 1592 by the Dutch mariner and cartographer, Lucas Janszoon Waghenaer. The atlas contains highly detailed nautical and coastal descriptions, including navigational instructions, and clearly reflects the expansion of the fishing and trading area of the Netherlands during the 16th century. 


\section{Scholarly and Literary Papers}

Göttingen State and University Library

Historical Building • Papendiek 14 • www.sub.uni-goettingen.de/en

The first message communicated by way of telegraph: after the death of Carl Friedrich Gauß, the telegraph alphabet came into the possession of the Göttingen library in 1856, together with his autographs. Photographs: Martin Liebetruth
Göttingen State and University Library holds some 400 complete and partial collections of scholarly and literary papers of eminent persons, the great majority of whom were professors at Göttingen University. The collection thus provides strong evidence of the close historical association between the university and its library. The accumulation of holdings of this kind began at an early stage. Christian Gottlob Heyne (1729-1812), longstanding director of the library, played an active part in the acquisition of the estate of Johann Friedrich Armand von Uffenbach (1687-1769), municipal architect of Frankfurt, which included not only his handwritten papers but also an extensive library and a valuable collection of paintings and prints. To this day, the holdings of scholarly and literary papers have been systematically complemented; over the last twenty years alone, these have grown by almost 100 estates or partial estates. All scientific disciplines are represented as a matter of principle, but the papers of mathematicians and natural scientists make up a particularly substantial portion of the holdings. Taken as a whole, the collections of literary and scholarly papers of distinguished scientists and scholars constitute an important complement to the Göttingen University Archives, where the documentary files of the institutes and the university are preserved and made accessible.

In almost every case, the scientific papers were received by the library as gifts. Frequently, heirs pass such material to the library immediately after

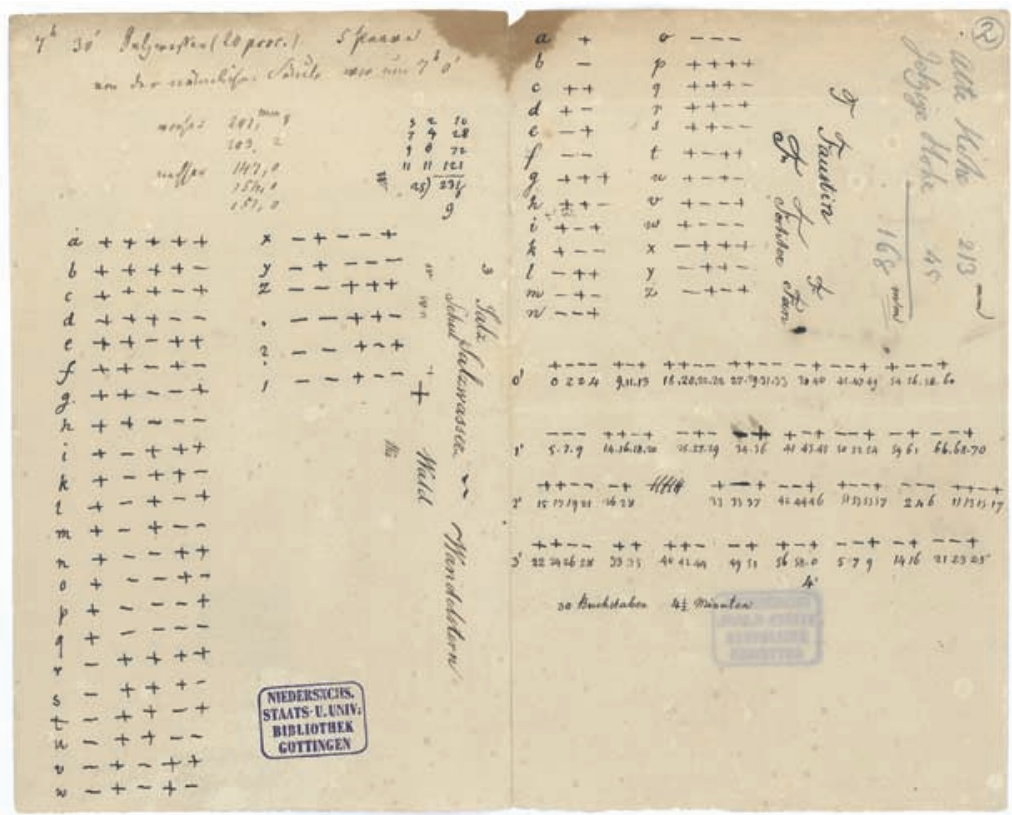



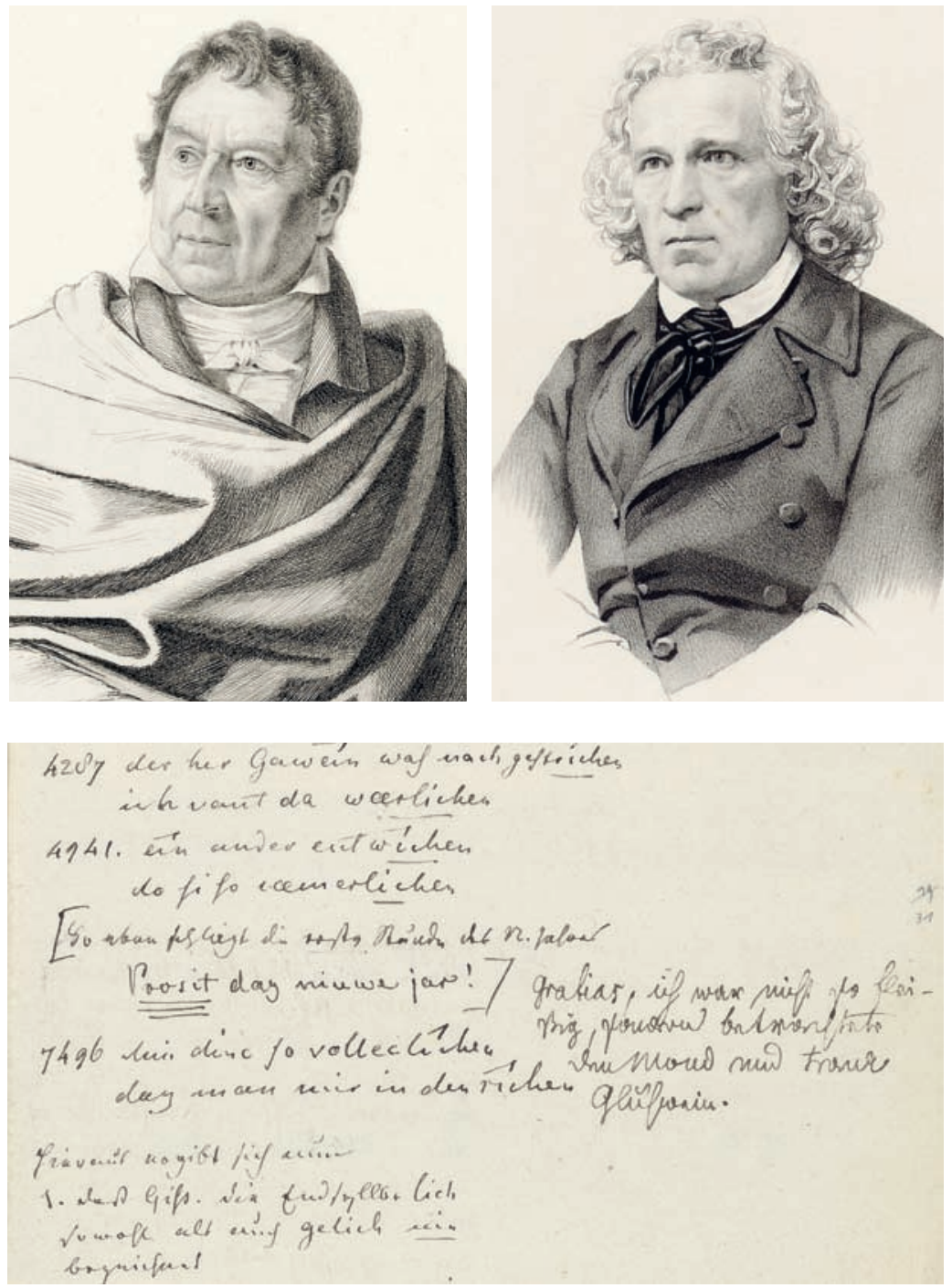

the testator's death, but sometimes the papers are offered decades later. With their assignment, the library takes on the obligation to document and catalogue the papers and make them accessible for research in the context of the history of knowledge. In addition, efforts are made to purchase any individual autograph items that come up for sale to supplement the collections.
Georg Friedrich Benecke (17621844) und Jacob Grimm (17851863)
Adversaria between Georg Friedrich Benecke and Jacob Grimm: this exchange of notes from the period 1819 to 1823 constitutes a special form of correspondence that took place between Georg Friedrich Benecke and Jacob Grimm. For his part in the communications, Benecke used the left-hand column of a sheet of notepaper folded down the middle, while Grimm answered on the same sheet using the right-hand column. The correspondence came into possession of the library with the estate of Wilhelm Conrad Hermann Müller (1812-1890), scholar of German studies.

Helmut Rohlfing 


\section{Collection of 18th Century German Printed Books}

Göttingen State and University Library

Historical Building • Papendiek 14 • www.sub.uni-goettingen.de/en

The Zürcherische[n] AusruffBilder were published between 1748 and 1751 by the Swiss copperplate engraver and publicist David Herrliberger (16971777). The three-part work contains 156 hand-coloured illustrations of Zurich street traders shown wearing attire typical for their profession. The caption consists of the Swiss German 'Ausruf' and a verse in High German describing the wares for sale in each individual case. This work was purchased in 2011 for the Sammlung Deutscher Drucke. Photographs: Martin Liebetruth
During the late 18th century, Göttingen University Library was regarded as one of Europe's leading research libraries, due to its book holdings, modern classification system and acquisition policy. It was rightly seen as constituting a prototype model of a modern research library. In 1989, joining forces with the great libraries in Berlin, Frankfurt, Munich and Wolfenbüttel, the SUB Göttingen entered into a Working Group for the Collection of German Printed Books (Sammlung Deutscher Drucke) with the aim of building up a retrospective, decentralised national library of all books using the German language or published in German-speaking countries in the period 1450 to 1912. In line with its focus area of holdings, the SUB Göttingen is responsible for the period 1701-1800. Continuously adding to its already outstanding bibliographic holdings from this period, the SUB Göttingen thus assumes the role of a national library for the century of the Enlightenment.

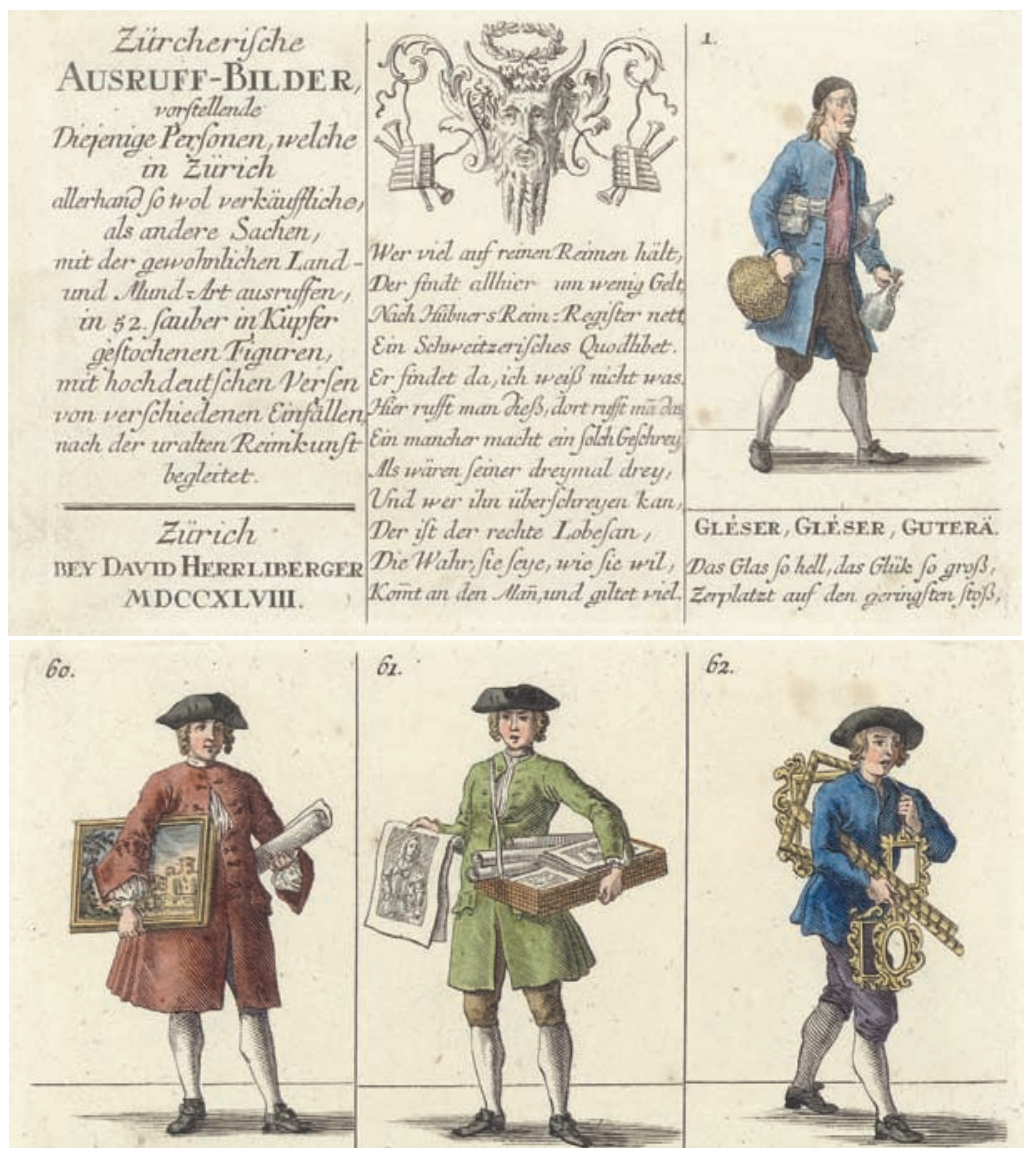




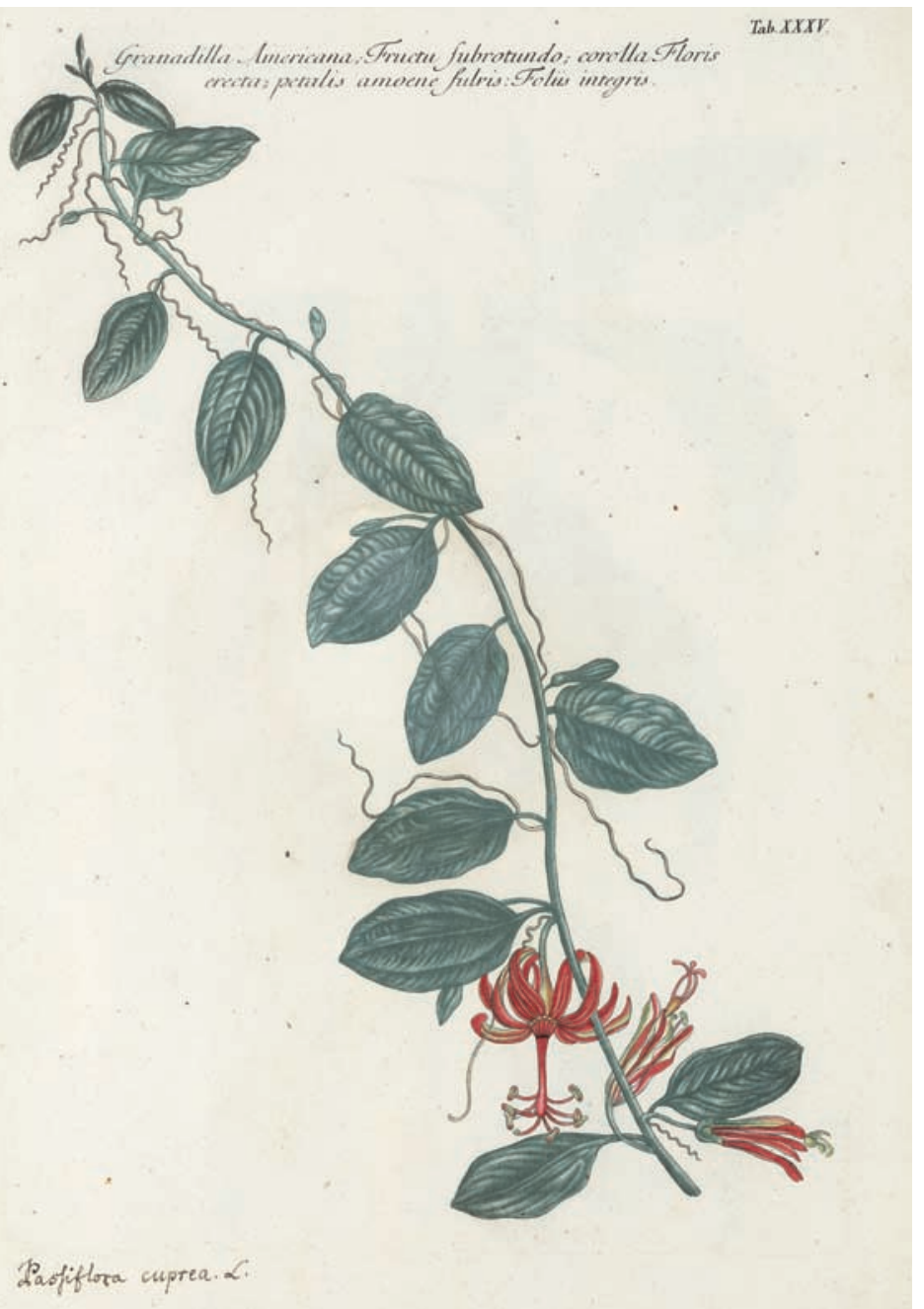

Description of rare plants: the plates in this magnificent early botanical work acquired for the Sammlung Deutscher Drucke are distinctive for their exceptional accuracy in the depiction of all plant details.

In the 25 years of the consortium's existence so far, the Sammlung Deutscher Drucke has acquired some 17,000 books, and on average a further 400 volumes are added every year. Of special note are the printed works that are not present in any other German library, as well as German translations of works written in other languages. At the same time, traditional focus areas of the library, for example in the areas of geography and zoology, are being further expanded, and gaps - in the domains of entertainment literature, cookery books or books for children - filled. With these holdings from the 18th century amounting to a total of 180,000 volumes, a number that will continue to grow through acquisitions in the framework of the Sammlung Deutscher Drucke, the SUB Göttingen offers an outstanding basis for historical research into the early modern era. 


\section{Asch Collection}

Göttingen State and University Library

Historical Building • Papendiek 14 • www.sub.uni-goettingen.de/en

In the course of the 18th century, after the extinction of the valuable fur-bearing animals in eastern Siberia, the chain of Kuril Islands lying between the peninsula of Kamchatka and the Japanese Hokkaido were increasingly sought out by leading Russian fur traders. This map, handdrawn by the Irkutsk merchant Dmitri Sabalin, illustrates the encounter between the Russians and the Japanese. It is one of few early items bearing witness to the island, which at that time was hermetically sealed off to the world. Photograph: Martin Liebetruth
In 1772, a letter arrived in Göttingen from the Russian Baron Georg Thomas von Asch (1729-1807). From 1748 to 1750, Asch had studied medicine at Göttingen University under Albrecht von Haller (1708 -1777). The Baron subsequently rose to high office in Russia, taking up important positions in the area of education. The letter, which conveys his deep gratitude to Göttingen University and its library, was accompanied by a first crate of books and manuscripts as an expression of his appreciation and bond with the institution. This delivery formed the beginning of a correspondence with the library's director Christian Gottlob Heyne (1729-1812), in the course of which the alumnus Asch dispatched to Göttingen rare and precious books and prints, manuscripts, maps, works of art and all manner of research objects. The items stemmed from the Russian physician's extensive network among scientists at work in the Russian Empire and his own work as Surgeon General of the Russian army during the 5th Russian-Turkish war (1768-1774).



The largest portion of these donations consists of approximately 2,000 books. These were originally held as the Bibliotheca Aschiana before being integrated into the general library holdings in 1883/84. The books encompass a broad thematic spectrum covering almost all areas of knowledge in which works were being published at that time. The Bibliotheca Aschiana thus laid the foundation for the SUB Göttingen's highly reputed unique collection of 18th century Slavic literature. Johann 


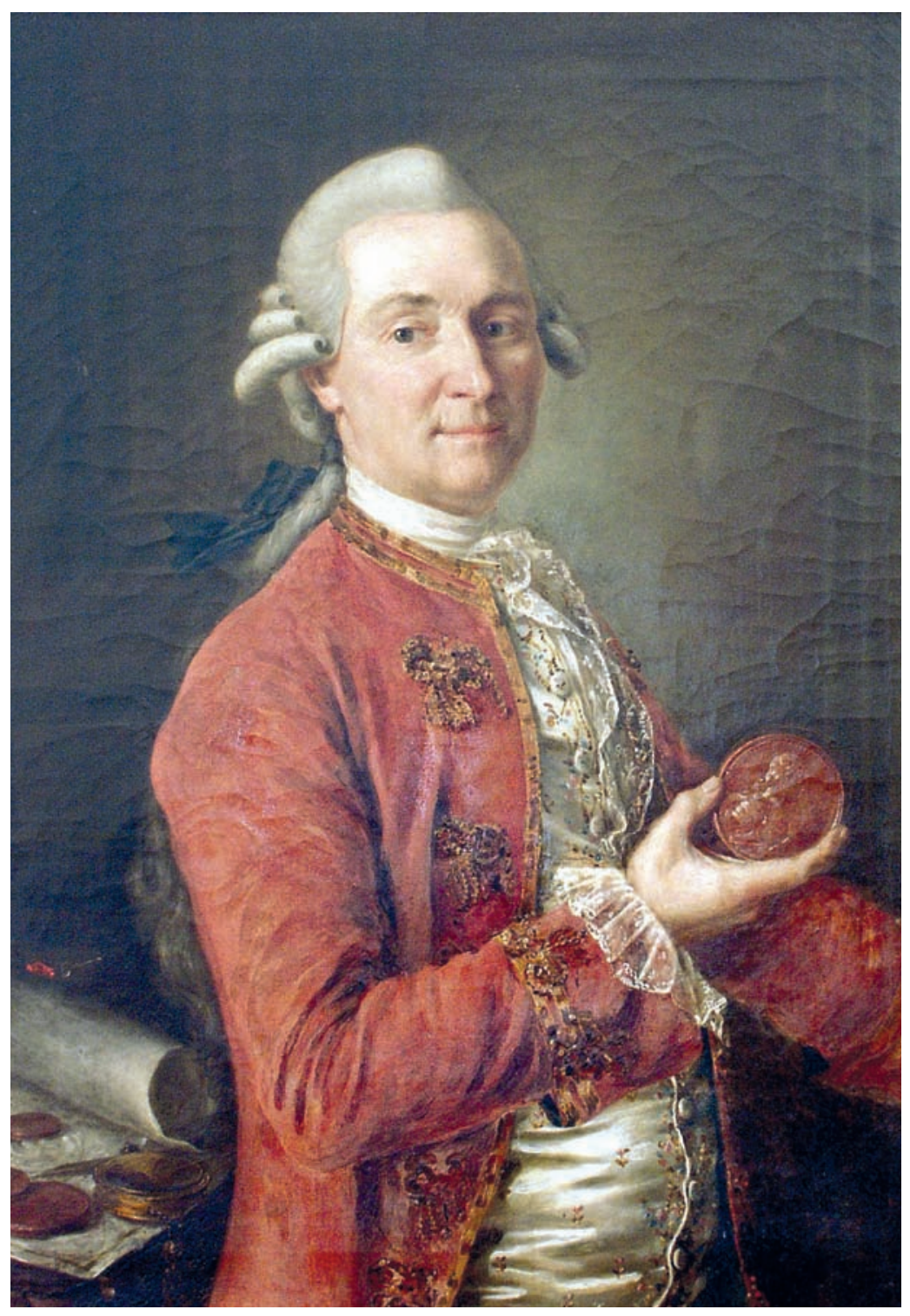

Georg Thomas von Asch (17291807): painting by Kirill Golovačevskij, oil on canvas, Art Collection of Göttingen University. The artist painted this portrait of the 51-year-old Asch in gala attire, a medal in hand, in the year 1780. Among the objects on the table are several further medals, a seal container and some papers, probably maps - all of them objects that Asch bestowed on the University of Göttingen. He also donated the painting itself to his 'alma mater'. Photograph: Harry Haase

Stephan Pütter (1725-1807) honoured Asch during his lifetime with the words: "Quite excellent and unforgettable services to our Library and to the Museum have been rendered by Herr Georg von Asch".

Silke Glitsch 


\section{Göttingen University Archives}

Göttingen University Archives

Papendiek 14 • 37073 Göttingen • www.uni-goettingen.de/universitaetsarchiv

Göttingen University Archives, view into the Paulinerkirche stacks; photographs: Ulrich Hunger

\section{Established: c. 1925}

Number of items: c. 2,500 shelf metres of archived items

Open: Mon. to Fri. 10:00 - 19:00

Tours: by appointment

\section{Contact:}

Dr. Ulrich Hunger

Tel.: +49 551 39-4323, -5309 archiv@sub.uni-goettingen.de hunger@sub.uni-goettingen.de
The University Archives function basically as a state archive for the university. The department takes charge of archival documentation from all university institutions, orders it, and renders it accessible and usable. The material includes all administrative documents that hold lasting importance for the fulfilment of public tasks and historical research.

The files of the Göttingen University Archives are of particular value since they convey a complete record of the university's central offices since its founding in 1737, the holdings having remained unscathed by wartime loss or damage. The intrinsic value of the archived materials is therefore inestimable. Among the extant files are those of the Board of Trustees (1733-1960), University Offices (1733-1930), Rectorate (1930-1995), Faculty of Theology, Faculty of Law, Faculty of Medicine, Faculty of Humanities and Faculty of Mathematics and Natural Sciences. Furthermore, the University Archives preserve the files of the University Court, Church Deputation and the Institute of Higher Education for Social Sciences Wilhelmshaven-Rüstersiel. The archives also hold further university records such as chartularies, official records and accounting ledgers of the university.

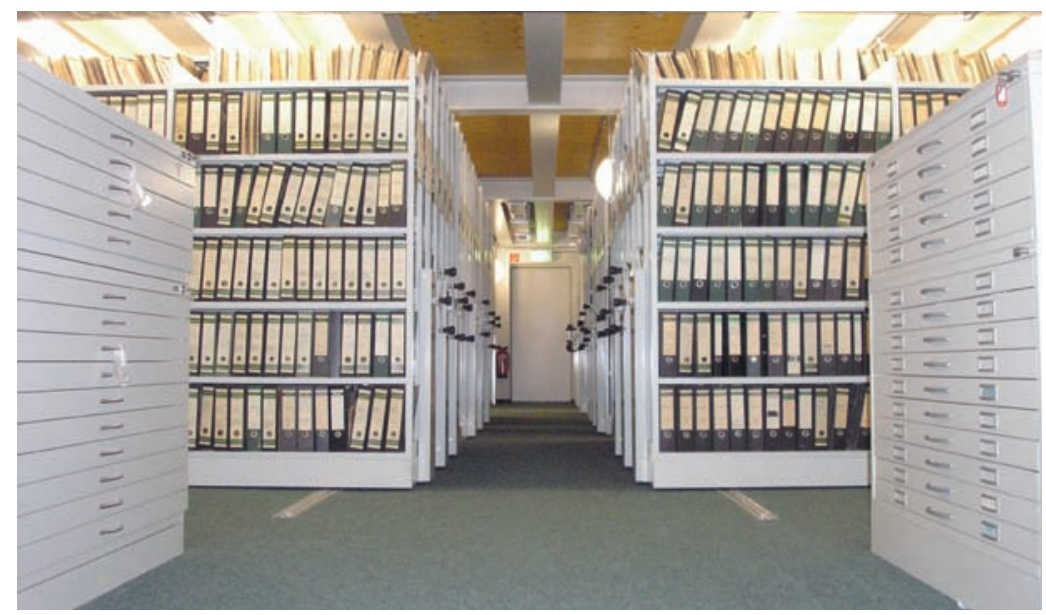

As a working resource, the Göttingen University Archives are extremely highly frequented in comparison to archives of other universities. The files serve as sources providing the basis for research into university history, the history of knowledge and disciplines, biographical research, regional history and genealogy. The majority of users are students and lecturers of Göttingen University, yet external scientists and scholars, authors, publicists, local historians, family researchers and interested citizens create a complex overall spectrum of readers. In addition to performing services 

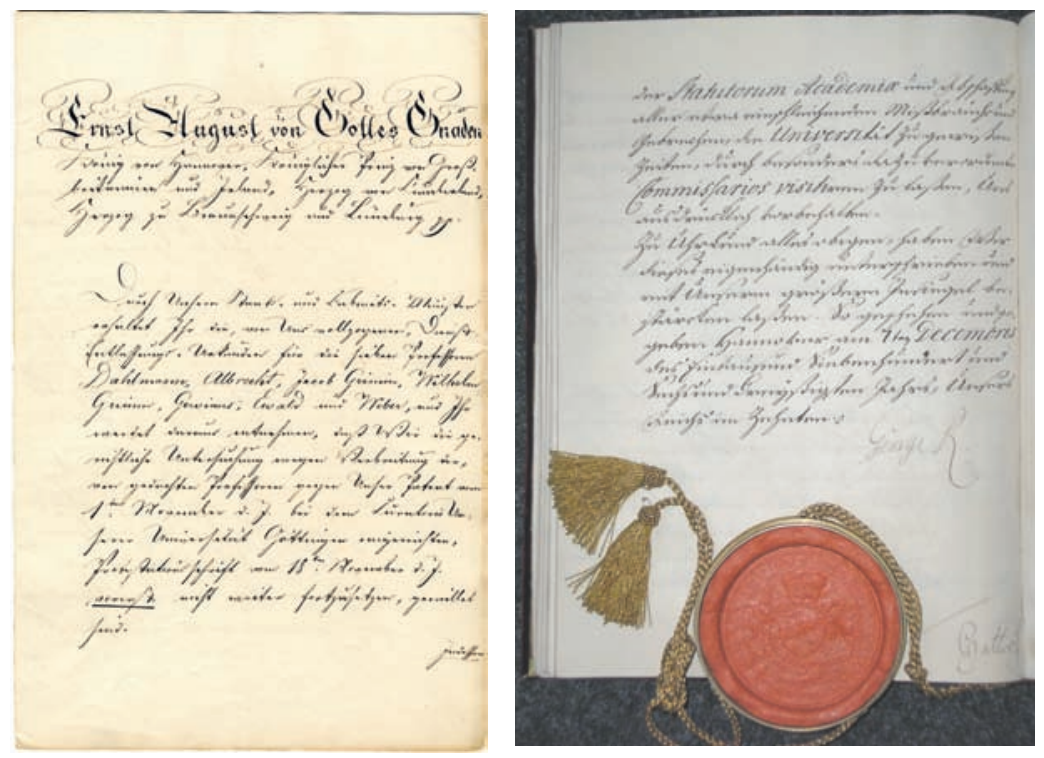

in the context of research and teaching, the Göttingen University Archives also support the work of the academic administrative departments.

As former Registrar's Office of the university, the Archives have existed since 1772; the historical University Archives go back to the year 1925. The first university archivist was Götz von Selle (1893-1956), who as an honorary professor directed the Göttingen University Archives in a part-time capacity. His successor, legal historian Professor Wilhelm Ebel (1908-1980), assumed the tasks of a University Archivist until 1980. It was not until 1986 that a full-time appointment was made to the position of Director of the Archives.

\section{Ulrich Hunger}

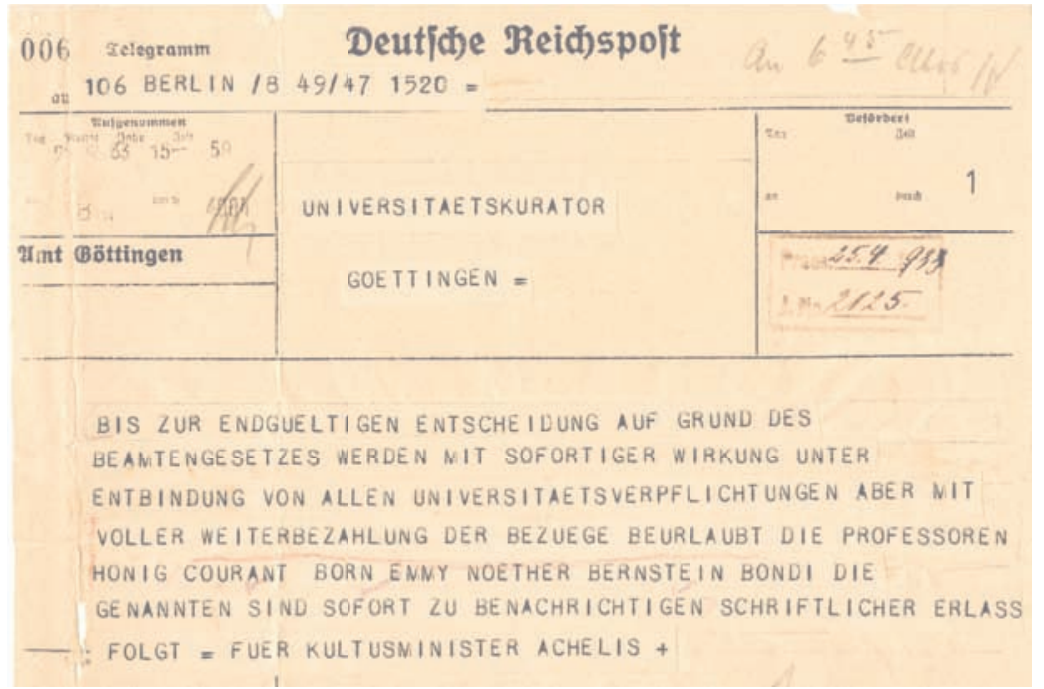

Decree of dismissal for the 'Göttingen Seven' written by Ernst August, King of Hanover, to the Prorector of the University of Göttingen, Professor Friedrich Christian Bergmann, on 12.12 . 1837

Final page of the Königliches Gründungsprivileg (Royal Charter) of the University of Göttingen, dated 07.12.1736, signed "George R.", King of Great Britain and Ireland, simultaneously Kurfürst Georg August von Braunschweig und Lüneburg (Elector Georg August of Brunswick and Lüneburg)

Dismissal of the Jewish professors, 1933. Following the seizure of power by the National Socialists, the state was 'purged' of persons deemed undesirable for racial or political reasons. In Göttingen, the Gesetz zur Wiederherstellung des Berufsbeamtentums (Law for the Restoration of the Professional Civil Service) led as early as 25.4.1933 to the 'suspension', by telegram from the Minister of Culture, of Professors Honig, Courant, Born, Noether, Bernstein and Bondi. 


\section{Bibliographic information}

The Deutsche Nationalbibliothek lists this publication in the Deutsche Nationalbibliografie; detailed bibliographic data is available on the Internet at http://dnb.dnb.de

Supported by:

Sparkasse

Göttingen

Issued by the President of Göttingen University

Georg-August-Universität Göttingen

Public Relations

Wilhelmsplatz 1

D-37073 Göttingen

pressestelle@uni-goettingen.de

This work is protected by German Intellectual Property Right Law. It is also available as an Open Access version through the publisher's homepage and the Göttingen University Catalogue (GUK) at Göttingen State and University Library (http://www.sub.uni-goettingen.de). The license terms of the online version apply.

Editorial staff: PD Dr. Mike Reich, Munich/Göttingen

Dr. Katrin Pietzner, Göttingen

Editorial design: Aron Jungermann, Hanover

Translation: Victoria Viebahn, Göttingen

Additional cover photographs: Stephan Eckardt, Christian Fischer,

Gerhard Hundertmark, all Göttingen

(C) 2015 Göttingen University Press

www.univerlag.uni-goettingen.de

ISBN 978-3-86395-196-2 


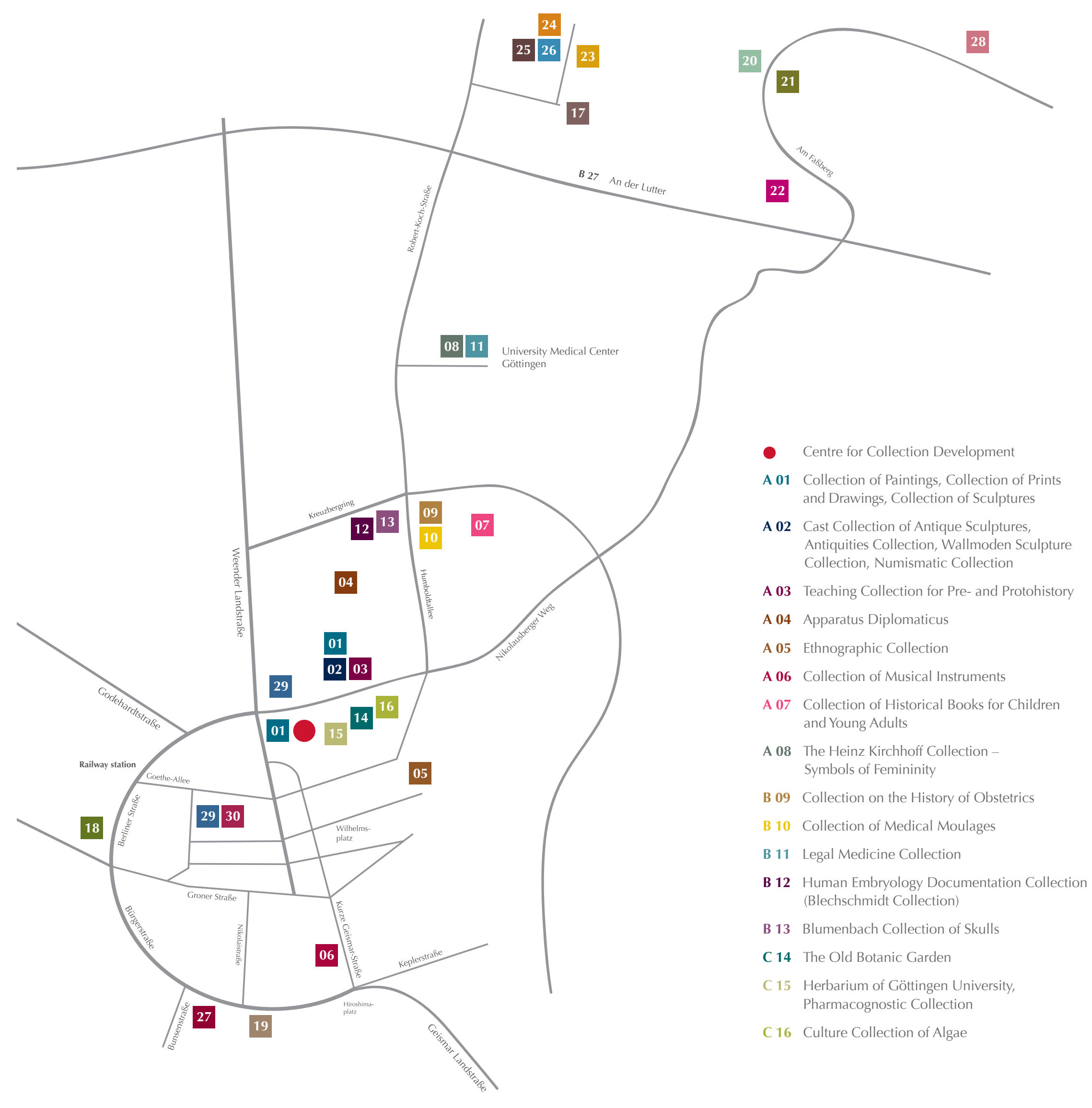

C 17 Palaeobotanical Collection, Palaeozoological Collections, Geological Collections, Geopark, Amber Collections, Geological Collection of the Adolfinum Bückeburg. Mineralogical Collections, Collection of Precious Stones, Collection of Meteorites, Historical Geosciences

C 18 Museum of Zoology, Bird Collection

C 19 Anthropological Collection

C 20 Forest Zoology and Wildlife Biology Collections

C 21 Forest Botanical Garden and Phytogeographical Arboretum

C 22 The Experimental Botanic Garden

C 23 Göttingen Museum of Chemistry

C 24 Collection of Historic Physical Apparatus 'Physicalisches Cabinet', Beckmann Collection

C 25 Collection of Historical Instruments at the Institute of Geophysics

C 26 Collection of Historical Items at the Institute of Astrophysic

C 27 Collection of Mathematical Models and Instruments

C 28 Computing Museum of the GWDC

D 29 Collections of Göttingen State and University Library

D 30 Göttingen University Archives 
